\title{
Intensive Care Medicine in an ageing Population
}

\author{
Lenneke van Lelyveld-Haas
}




\section{Intensive care medicine in an ageing population}

IC-geneeskunde in de oudere patiëntenpopulatie (met een samenvatting in het Nederlands)

\section{Proefschrift}

ter verkrijging van de graad van doctor aan de

$$
\begin{gathered}
\text { Universiteit Utrecht } \\
\text { op gezag van de }
\end{gathered}
$$

rector magnificus, prof.dr. H.R.B.M. Kummeling, ingevolge het besluit van het college voor promoties

$$
\text { in het openbaar te verdedigen op }
$$

donderdag 22 april 2021 des middags te 12.45 uur

Lenneke van Lelyveld-Haas, 2021. All rights reserved. No part of this thesis may be reproduced or transmitted in any form or by any means without prior written permission from the author. The copyright of the papers that have been published or have been accepted for publication has been transferred to the respective journals.

Financial support for publication of this thesis was kindly provided by Diakademie Utrecht, Pfizer, Fisher \& Paykel Healthcare, Hamilton medical, Human protection, Itémedical, Chipsoft and B Braun Medical.

ISBN: 978-94-6423-179-3

Lenneke Elisabeth Maria van Lelyveld-Haas

$$
\text { geboren op } 25 \text { juli } 1978
$$

te Borne

DOI: $10.33540 / 450$

\section{Cover artwork: Kas van Lelyveld}

Lay-out and design: Wendy Schoneveld || www.wenziD.nl

Printed by: $\quad$ ProefschriftMaken I| Proefschriftmaken.nl 
Promotoren

Prof. dr. D. van Dijk

Prof. dr. N.F. de Keizer

Voor mijn ouders 


\section{TABLE OF CONTENT}

\section{PART III Ceneral discussion and summary}

\section{PART I Very old patients admitted to the ICU}

trends, outcomes, costs and triage

Chapter 2 Trends in hospital and intensive care admissions in the Netherlands attributable to the very elderly in an ageing population - Crit Care 2015 from 2008 to 2014 - Intensive Care Med 2017 national observational study - JAGS 2020

Chapter 5 Healthcare-related costs in very elderly intensive care patients Intensive Care Med 2018

Chapter 6 Triage; should we deny ICU admission to the elderly? Crit Care 2020

\section{PART II Very old patients admitted to the ICU for sepsis}

Chapter 7 Outcome of very old patients admitted to the ICU for sepsis: a 115 systematic review - Eur Ger Med 2017

Chapter 8 Frailty is associated with long-term outcome in patients with sepsis who are over 80 years old: results from an observational study in 241 European ICUs - Age and Ageing 2021

Chapter 9 Very old patients admitted to the ICU with sepsis; outcome and discriminative performance of the quick SOFA (qSOFA) and other severity scores for mortality - Acta Anaesth Scand 2019 


\section{CHAPTER 1}

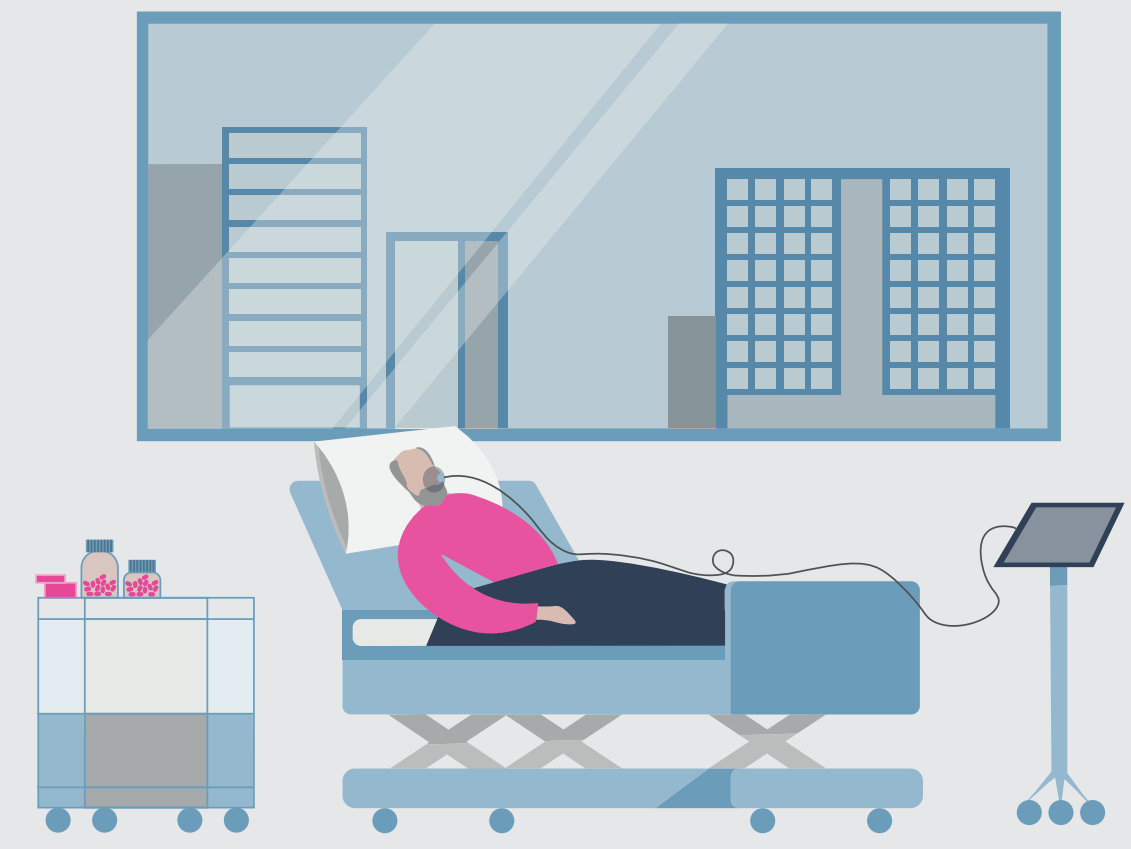

Ceneral introduction and outline of this thesis 


\section{General introduction}

It is estimated that the global number of people aged 80 and older will more than triple between 2015 and 2050.[1, 2] By 2050, people 80 years or older will account for almost $10 \%$ of the population in Europe and North America. In line with the demographic changes observed in many other countries in the Western world, the Dutch population is also ageing.

Although older patients comprise a minority of the population, they are responsible for a substantial proportion of healthcare use, including intensive care unit (ICU) treatment days. Both international and national studies have shown a significant increase of the very elderly admitted to the ICU over the last decades.[3, 4] It is expected that the cohort of very old critically ill patients will grow faster than any other patient group in the ICU. $[5,6]$

Ageing is defined as a persistent decline in the age-specific fitness components due to internal physiological degeneration [Rose 1991] and comprises a complex transition of physiological and cognitive vulnerability, making the individual more prone to diseases and acute medical events. [6, 7] Internationally, there is a lack of clear definitions for 'elderly', 'old' or 'very old' patients and different age thresholds have been used. Being old (the biological or physiological age) is more than just the chronological age, depending on many other factors, including frailty, and definitions might be dynamic since life expectancy is increasing. Although using a fixed age threshold might not be the best way to define the very old population, using a clear and objective definition is important to allow comparisons with previously published studies. The contemporary definition for 'very old intensive care unit patients' (often abbreviated to VIPs or VOPs) considers patients to be 'very old' when they are aged 80 years and over.[3] Patients older than 90 years of age are often called 'the oldest old' or 'the extremely old' patients.

Frailty is a state of vulnerability to poor resolution of homeostasis following stress and is a consequence of cumulative decline in multiple physiological systems over a lifespan.[8] Frailty is common in older ICU patients and higher frailty scores are associated with increased mortality after ICU admission.[9-12]

Obviously, these very old patients often have a shorter life expectancy than younger patients. Despite advanced treatment modalities, a substantial proportion of VOPs will not survive hospitalisation. Moreover, the majority of the patients who do survive, will suffer from a persisting or severe functional and/or cognitive decline after hospital discharge and many will not be discharged home.[11, 13-15] Although survival is conditional for quality of life (QoL), many elderly patients prefer preserving QoL and autonomy above a prolonged survival, they prioritise 'quality' above 'quantity' of life. $[16,17]$ The balance between potential benefits and burden of ICU treatment may therefore be more negative than in younger patients.

According to the first leading principle of medical ethics, the 'non-maleficence' principle (incorporated in Hippocrates' oath as the 'first do no harm'), physicians are obliged not to provide treatment that is not the patient's good, especially if that treatment is burdensome.[18] In addition, ICU is one of the most expensive departments of the hospital, and healthcare costs are soaring with increasing pressure on budgets. Due to the often-disappointing outcomes of VIPs, cost-effectiveness of ICU treatment of VIPs may be questioned.

Sepsis is one of the leading causes of morbidity and mortality in very old patients and appears to be a common reason for very old patients to be admitted to the ICU. Sepsis describes a variable, non-specific acute syndrome caused by an infection. It is not a specific illness, but rather a syndrome which is defined by consensus. The definition of sepsis has undergone three major revisions since 1991. Sepsis was first formally defined as: the presence of infection in conjunction with the systemic inflammatory response syndrome (SIRS).[19] In 2016, sepsis was redefined and the new Sepsis 3.0 definition was introduced, because both sensitivity and specificity of the SIRS criteria to identify sepsis were found to be limited.[20] This most recent sepsis 3.0 definition defines sepsis as life-threatening organ dysfunction caused by overwhelming dysregulated host response to infection.[21, 22] Organ dysfunction is defined as an acute increase of two or more points in the Sequential Organ Failure Assessment (SOFA) score.[23] Septic shock is defined as persisting hypotension requiring vasopressors to maintain a mean arterial pressure (MAP) of $65 \mathrm{mmHg}$ or higher and a serum lactate level greater than $2 \mathrm{mmol} / \mathrm{L}(18 \mathrm{mg} / \mathrm{dL}$ ) despite adequate volume resuscitation. In addition, the quick SOFA (qSOFA) was introduced.[21] Where the SOFA score requires laboratory values that may not be readily available at the bedside, is the qSOFA an easy to use risk stratification tool for non-ICU settings to recognize sepsis at an early stage. It can be obtained without laboratory testing and contains the following 3 components: systolic blood pressure $\leq 100 \mathrm{~mm} \mathrm{Hg}$, respiratory rate $\geq 22$ breaths per minute and altered mentation.

Very elderly are, compared with younger patients, more susceptible to sepsis. They have less physiologic reserve to tolerate the insult from infection, and are more likely to have underlying diseases. As a consequence, they are responsible for the majority of all episodes of sepsis. Incidences of sepsis increased last decades and are still 
increasing and these increases are particularly seen in elderly patients.[24] At present, most sepsis episodes are observed in patients older than 60 years, with a sharp increase of the incidence in people older than 80 years.[25] Therefore, sepsis in patients over 80 years will remain an important medical problem for future decades.

The very old patient requiring ICU treatment is an emerging phenomenon and many intensivists struggle with the question of which of these patients will benefit from ICU admission, and for whom ICU treatment will be inappropriate or even harmful. More information about outcomes and prognostic factors of very elderly admitted to the ICU could aid in these difficult triage decisions. To improve the quality of care for this increasing very elderly ICU population, we wanted to gain more insight into several aspects of intensive care medicine in this ageing population. Therefore, the central research question of this thesis is: "What defines appropriateness of ICU care in very old patients?" To answer this research question the following sub questions concerning ICU treatment of very old critically ill patients in general (Part I) or specifically for sepsis patients (Part II) need to be answered:

1. Is ageing of the general population reflected in ageing of ICU patients?

2. What is the outcome of very old patients admitted to the ICU in the Netherlands? Did outcomes improve over time?

3. What are the healthcare costs of elderly ICU patients? How do these costs compare with costs of younger ICU patients and very old patients not admitted to the ICU? 4. Is it justified to use age for triage for ICU admission?

5. What are the outcomes of very old patients admitted with sepsis? Is sepsis as admissions diagnosis independently associated with worse long-term outcome of a very old patient admitted to the ICU?

6. What is the prognostic value of qSOFA in very elderly admitted to the ICU with sepsis?

To answer these questions, we used the NICE registry [Dutch National Intensive Care Evaluation (NICE) registry].[26, 27] This registry was established in 1996 by intensivists, to facilitate quality-monitoring and quality improvement initiatives and to benchmark the performance of single ICUs to national values and to outcomes of comparable ICUs. Since 2016 all Dutch ICUs are participating. All ICUs are collecting demographic data, physiological data and clinical data of all patients admitted to their ICU. Throughout the years, the content of the reports broadened from only ICU mortality and in-hospital mortality to also long-term survival.

In addition to the NICE registry the Vektis database is another important data source to answer our research questions. Healthcare insurance is compulsory for Dutch citizens and essentially all (99\%) of the Dutch inhabitants have private healthcare insurance.[28] The Vektis database contains reimbursement data on almost all medical treatments paid for by Dutch insurance companies, as well as demographic information, for all registered residents of the Netherlands.[29]

\section{Aim and Outline of this thesis}

The aim of this thesis is to provide information about appropriateness of ICU care in very old patients to guide triage decisions and to inform patients or their surrogate decision-makers and enable them to participate in shared decision-making concerning goals of care.

In Chapter two we investigated the age trends in hospital and ICU admissions in the Netherlands attributable to the very elderly. As in many European countries the Dutch population is ageing and we wanted to explore if this ageing was seen also in the Dutch hospitals and their ICUs. We therefore analysed percentages of hospital and ICU admissions attributable to the very elderly in the period 2005 to 2014.

In Chapter three we explored the trends in mortality of very old ICU patients over time, from 2008 to 2014, in comparison with younger ICU patients, to learn more about the outcomes of the very old patients admitted to Dutch ICUs and to investigate if their outcomes improved over time.

The number of persons aged 90 years and older compose a fast-expanding subgroup of very elderly in our population. Outcome data of patients aged 90 years and older admitted to the ICU are relatively scarce. Nevertheless, many ICU physicians use age as triage criterion and many seem reluctant to admit patients aged 90 years and older to their ICU. An important reason to refuse ICU admission to these patients is the perceived higher mortality risk. However, it is unknown if their outcomes are indeed that worse, compared to the patients aged 80 years and older. In chapter four, we therefore described the outcome of the oldest old ICU population, the ICU patients aged over 90 years old, in the last decade.

The ICU is one of the most expensive departments of the hospital, consuming almost $15 \%$ of the total hospital budget and $1-2 \%$ of the gross domestic product (GDP) in Western countries. In addition, after ICU discharge, survivors continue to consume significant healthcare resources.[30, 31] Since the very elderly are a rapid expanding 
subgroup of ICU patients, they are responsible for a substantial part of these healthcare costs. Because both short- and long-term outcomes of these very elderly are worse than in younger patients, cost-effectiveness of ICU treatment of very old patients is frequently questioned. In chapter five, healthcare-related costs of very old ICU patients are described, in comparison with younger ICU patients (18-65 years old) and a very old control group (not admitted to the ICU).

In chapter six, we discussed the use of age in the decision-making process around ICU admission, both under normal circumstances, as in times of scarcity, like during a pandemic. The ICU triage of critically ill old patients have been put into sharp focus last year, during the COVID-19 pandemic. This pandemic with large numbers of acutely ill patients and high pressure on ICU capacity has quickened discussions about prioritisation of resources, including triage based on age. We discuss whether it could be justified to prioritize the younger patients and withhold ICU admission for very old patients.

Part II focuses on very old patients admitted to the ICU with sepsis.

Chapter seven is a comprehensive systematic review of the literature on outcomes of very old patients admitted to the ICU with sepsis. This review aimed to identify not only short- and long-term mortality rates of these patients worldwide, but also functional outcome and quality of life.

In chapter eight, we investigated both the short- and long-term mortality of VIPs admitted with sepsis and assess the relation of mortality with pre-existing physical and cognitive function. This study is a substudy of the large, prospective, multinational VIP-2 study. We included patients aged $\geq 80$ years admitted to the ICU with sepsis and compared these patients with other patients, aged $\geq 80$ years (and with SOFA score $\geq 2$ ), who are acutely admitted to the ICU for other non-sepsis reasons.

In chapter nine, we analysed the outcome of very old patients admitted to the ICU with sepsis in the Netherlands and defined the discriminative performance of the quick SOFA (qSOFA) and other severity scores for mortality in these patients. Since its introduction in 2016, multiple studies have validated qSOFA for prognostication in different patient categories, but its value in very old patients admitted to the ICU with sepsis was still unknown.

Finally, in chapter ten, the main findings of this thesis are summarized and discussed and recommendations for further research are provided.

\section{References}

1. He, W.; Goodkind D. KP (2016) U.S. Census Bureau, International Population Reports, An Aging World: 2015. Washington, DC

2. Nationaal kompas: vergrijzing. https://www.volksgezondheidenzorg.info/onderwerp/bevolking/cijferscontext/vergrijzing. Accessed 25 Oct 2020

3. Flaatten $\mathrm{H}$, de Lange DW, Artigas A, et al (2017) The status of intensive care medicine research and a

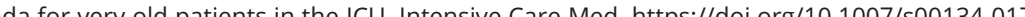
$4718-2$

4. Laake JH, Dybwik K, Flaatten HK, et al (2010) Impact of the post-World War II generation on intensive care needs in Norway. Acta Anaesthesiol Scand 54:479-484. https://doi.org/10.1111/j.1399-6576.2009.02170.x

5. Nguyen Y-L, Angus DC, Boumendil A, Guidet B (2011) The challenge of admitting the very elderly to intensive care. Ann Intensive Care 1:29. https://doi.org/10.1186/2110-5820-1-29

6. Guidet B, Vallet H, Boddaert J, et al (2018) Caring for the critically ill patients over 80: a narrative review. Ann Intensive Care 8:114. https://doi.org/10.1186/s13613-018-0458-7

7. Press RMR (1991). EB of ANYOU (1991) Evolutionary Biology of Aging. Oxford University Press, New York

8. Clegg A, Young J, liffe S, et al (2013) Frailty in elderly people. Lancet (London, England) 381:752-762. https://doi.org/10.1016/S0140-6736(12)62167-9

9. Flaatten H, De Lange DW, Morandi A, et al (2017) The impact of frailty on ICU and 30-day mortality and the level of care in very elderly patients ( $\geq 80$ years). Intensive Care Med 43:1820-1828. https://do org/10.1007/s00134-017-4940-8

10. Guidet B, de Lange DW, Boumendil A, et al (2020) The contribution of frailty, cognition, activity of daily Ife and comorbidities on outcome in acutely admitted patients over 80 years in European ICUs: the VIP study. Intensive Care Med 46:57-69. https://doi.org/10.1007/s00134-019-05853-1

11. Pietilainen L, Hastbacka J, Backlund M, et al (2018) Premorbid functional status as a predictor of 1-year mortality and functional status in intensive care patients aged 80 years or older. Intensive Care Med 44:1221-1229. https://doi.org/10.1007/s00134-018-5273-y

12. Muscedere J, Waters B, Varambally A, et al (2017) The impact of frailty on intensive care unit outcomes: a systematic review and meta-analysis. Intensive Care Med 43:1105-1122. https://doi.org/10.1007/s00134017-4867-0

13. Heyland DK, Garland A, Bagshaw SM, et al (2015) Recovery after critical illness in patients aged 80 years or older: a multi-center prospective observational cohort study. Intensive Care Med 41:1911-1920.

14. Iwashyna T], Ely EW, Smith DM, Langa KM (2010) Long-term Cognitive Impairment and Functional Disability Among Survivors of Severe Sepsis. JAMA 304:1787. https://doi.org/10.1001/jama.2010.1553

15. Pandharipande PP, Girard TD, Jackson JC, et al (2013) Long-term cognitive impairment after critical illness. N Engl J Med 369:1306-1316. https://doi.org/10.1056/NEJMoa1301372

16. Fried TR, Bradley $E H$, Towle $V R$, Allore $H(2002)$ Understanding the treatment preferences of seriously in patients. N Engl J Med 346:1061-1066. https://doi.org/10.1056/NEJMsa012528

17. Philippart F, Vesin A, Bruel C, et al (2013) The ETHICA study (part I): elderly's thoughts about intensive care nit admission for life-sustaining treatments. Intensive Care Med 39:1565-1573. https://doi.org/10.1007/ s00134-013-2976-y 
18. Beauchamp, T.L.; Childress JF (2013) Principles of biomedical ethics, 7th ed. Oxford University Press, Oxford

19. Bone RC, Balk RA, Cerra FB, et al (1992) Definitions for sepsis and organ failure and guidelines for the use of innovative therapies in sepsis. The ACCP/SCCM Consensus Conference Committee. American College of Chest Physicians/Society of Critical Care Medicine. Chest 101:1644-55

20. Kaukonen K-M, Bailey M, Pilcher D, et al (2015) Systemic inflammatory response syndrome criteria in defining severe sepsis. N Engl J Med 372:1629-38. https://doi.org/10.1056/NEJMoa1415236

21. Singer M, Deutschman CS, Seymour CW, et al (2016) The Third International Consensus Definitions for Sepsis and Septic Shock (Sepsis-3). JAMA 315:801-10. https://doi.org/10.1001/jama.2016.0287

22. Seymour CW, Liu VX, Iwashyna TJ, et al (2016) Assessment of Clinical Criteria for Sepsis: For the Third International Consensus Definitions for Sepsis and Septic Shock (Sepsis-3). JAMA 315:762-74. https://doi. org/10.1001/jama.2016.0288

23. Vincent JL, Moreno R, Takala J, et al (1996) The SOFA (Sepsis-related Organ Failure Assessment) score to describe organ dysfunction/failure. On behalf of the Working Group on Sepsis-Related Problems of the
European Society of Intensive Care Medicine. Intensive Care Med 22:707-10

24. Martin GS, Mannino DM, Moss M (2006) The effect of age on the development and outcome of adult sepsis. Crit Care Med 34:15-21

25. Rowe T, Araujo KLB, Van Ness PH, et al (2016) Outcomes of Older Adults With Sepsis at Admission to an Intensive Care Unit. Open forum Infect Dis 3:ofw010. https://doi.org/10.1093/ofid/ofw010

26. Dutch National Intensive Care Evaluation (NICE) registry. http://www.stichting-nice.nl

27. van de Klundert N, Holman R, Dongelmans DA, de Keizer NF (2015) Data Resource Profile: the Dutch National Intensive Care Evaluation (NICE) Registry of Admissions to Adult Intensive Care Units. Int Epidemiol 44:1850-1850h. https://doi.org/10.1093/ije/dyv291 [do]

28. Centraal Bureau voor de Statistiek (CBS). Statline. . http://statline.cbs.nl/Statweb/dome/default.aspx

29. Vektis. http://www.vektis.nl

30. Centraal Bureau voor Statistiek (CBS). Statline. Zorguitgaven: kerncijfers. http://statline.cbs.nl/Statweb/ publication/?VW=T\&DM=SLNL\&PA=83037NED\&D1=a\&D2=a\&HD=160517-1200\&HDR=G1\&STB=T)

31. Lone NI, Seretny M, Wild SH, et al (2013) Surviving intensive care: a systematic review of healthcare resource use after hospital discharge*. Crit Care Med 41:1832-1843. https://doi.org/10.1097/ CCM.0b013e31828a409c [doi] 


\section{PART I}

\section{Very old patients admitted to the ICU}

trends, outcomes, costs and triage 


\section{CHAPTER 2}

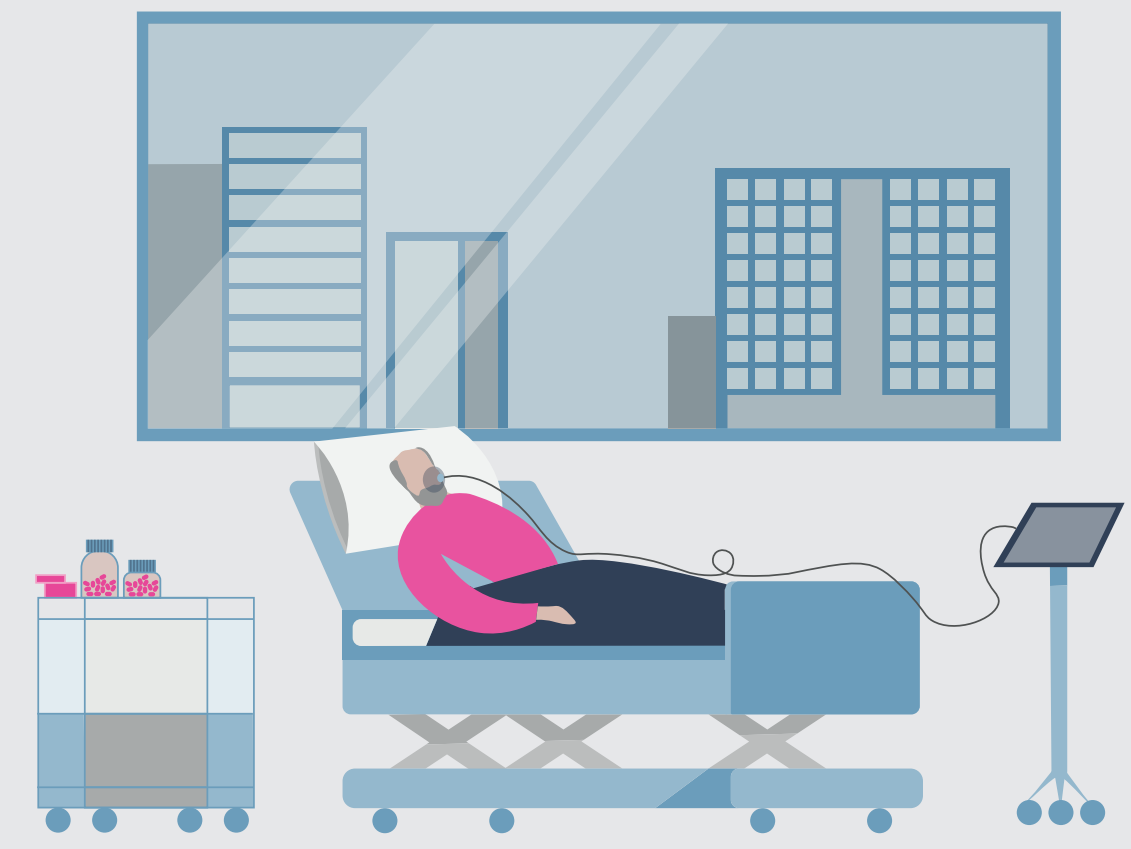

Trends in hospital and intensive care admissions in the Netherlands attributable to the very elderly in an ageing population

Published in: Critical Care 2015 


\section{Abstract}

\section{Introduction}

The Dutch population is ageing and it is unknown how this is affecting trends in the percentage of hospital and intensive care unit (ICU) admissions attributable to patients aged 80 years or older, the very elderly.

\section{Methods}

We present data on the percentage of the very elderly in the general population and the percentage of hospital admissions attributable to the very elderly. We subsequently performed a longitudinal cross-sectional study on ICU admissions from hospitals participating in the National Intensive Care Evaluation registry for the period 2005 to 2014. We modeled the percentage of adult ICU admissions and treatment days attributable to the very elderly separately for ICU admissions following cardiac surgery and other reasons.

\section{Results}

The percentage of Dutch adults aged 80 years and older, increased from $4.5 \%$ in 2005 to $5.4 \%$ in 2014 ( $p$-value $<0.0001$ ) and with this ageing of the population, the percentage of hospital admissions attributable to very elderly increased from $9.0 \%$ in 2005 to 10.6 $\%$ in 2014 ( $p$-value $<0.0001$ ). The percentage of ICU admissions following cardiac surgery attributable to the very elderly increased from $6.7 \%$ in 2005 to $11.0 \%$ in 2014 in nine hospitals ( $p$-value $<0.0001$ ), while the percentage of treatment days attributable to this group rose from $8.6 \%$ in 2005 to $11.7 \%$ in 2014 ( $p$-value $=0.0157$ ). In contrast, the percentage of very elderly patients admitted to the ICU for other reasons than following cardiac surgery remained stable at $13.8 \%$ between 2005 and 2014 in 33 hospitals ( $p$-value $=0.1315$ ). The number of treatment days attributable to the very elderly rose from 11,810 in 2005 to 15,234 in 2014 (p-value = 0.0002), but the percentage of ICU treatment days attributable to this group remained stable at $12.0 \%$ ( $p$-value = $0.1429)$.

\section{Conclusions}

As in many European countries the Dutch population is ageing and the percentage of hospital admissions attributable to the very elderly rose between 2005 and 2014. However, the percentage of ICU admissions and treatment days attributable to very elderly remained stable. The percentage of ICU admissions following cardiac surgery attributable to this group increased between 2005 and 2014.

\section{Introduction}

In the Netherlands, median age is rising [1] corresponding to the demographic changes observed throughout Europe [2]. Life expectancy in the Netherlands was 70 years for men and 79 years for women in 1950. These figures rose to 79 and 83 years in 2013 and are projected to increase to 84 and 87 years by 2055 [2,3]. The percentage of people in the Netherlands aged 80 years or older, the very elderly, increased from $1 \%$ in 1950 to $4 \%$ in 2013 and is expected to rise to $9 \%$ in 2040 and $11 \%$ in 2055 [4]. The observed and projected increases in the percentage of the very elderly are consequences of decreased fertility in recent decades, increased life expectancy and high birth rates in the period 1945 to 1955 [2, 3].

Although older patients comprise a minority of the population, they are responsible for a substantial proportion of hospitalizations and healthcare costs, including intensive care unit (ICU) treatment days [5-7]. An increase in the percentage of elderly patients in the general population may profoundly affect utilization of ICU resources [8-11]. Dutch $[12,12]$ and international researchers $[13,14]$ have predicted that aging may lead to substantial increases in the demand for ICU treatment. Recently conducted studies show that the percentage of ICU admissions attributable to the very elderly is $13 \%$ for Australia and New Zealand [15], 8.9\% for Finland [16], 12.4\% [17] and 18.2\% [18] for France, 19.2\% for Italy [19], 15.5\% for Norway [20] and 11\% for Spain [21]. In Denmark, this percentage increased marginally from $11.7 \%$ in 2005 to $13.8 \%$ in 2011 [22]. However, it is unclear how the results of these studies relate to the situation in the Netherlands.

A study conducted in the Netherlands between 1997 and 2002 showed that $6.9 \%$ of the ICU patients were very elderly [23]. However, it is unclear what percentage of adult ICU admissions in the Netherlands is currently attributable to very elderly patients and whether this percentage has increased in recent years. Multiple factors, including how the healthcare system is organized, ICU admission criteria and ethical choices, may influence decisions on whether very elderly patients are admitted to the ICU [24]. In this study, we describe trends in the percentage of the Dutch population aged 80 years or older and the percentage of hospital and ICU admissions attributable to the very elderly. We also examine trends in the Acute Physiology and Chronic Health Evaluation II (APACHE II) [30] and Simplified Acute Physiology Score II (SAPS II) [31] predicted probabilities of mortality and length of ICU stay for the very elderly and the proportion of very elderly patients with chronic renal, cardiovascular or immunological insufficiency, a malignancy and who were admitted to the ICU for medical reasons. Although some of these trends have previously been compared in general, hospital and ICU populations in Denmark [22], it is unclear whether these results are applicable to other countries, in general, or the Netherlands, in particular. 


\section{Methods}

\section{Data sources}

We used data from Statistics Netherlands, the Dutch national statistical service, on the number and percentage of adults aged 80 years or older in the Dutch population as a whole on the $1^{\text {st }}$ of January [25] of each year from 2005 to 2014. We also used data on the number and percentage of hospital admissions attributable to the very elderly in the period 2005 to 2014 from the Dutch Hospital Data foundation [26]. The Dutch Hospital Data foundation was founded by the Netherlands Association of Hospitals and the Netherlands Federation of University Medical Centers to manage, maintain and monitor collections of hospital data and to provide information on hospital care. We extracted data from the national hospital care basic registration. This is a registry of hospital admissions and includes demographic patient information, primary and secondary diagnoses in terms of International Classification of Diseases codes, operations performed and other information on treatment. All Dutch Hospitals have provided this information since 1963.

In addition, we used data from the Dutch National Intensive Care Evaluation (NICE) registry [27], a voluntary quality registry that contains all consecutive ICU admissions to participating hospitals. The NICE registry was set up in 1996 to enable hospitals to compare and improve the quality of care in Dutch ICUs [28]. The number of hospitals participating rose from six in 1997 to 85 of the 90 Dutch ICUs in 2014 [29]. Participating hospitals deliver demographic, physiological and diagnostic data and the outcomes of all admissions to their ICUs. These data enable the calculation of the APACHE II [30] and SAPS II [31] predicted probability of mortality The NICE registry is registered according to the Dutch Personal Data Protection Act. The medical ethics committee of the Academic Medical Center stated that medical ethics approval for this study was not required under Dutch national law (registration number W15-160).

\section{Definitions and inclusion criteria for data from the NICE registry}

We classified an admission as attributable to the very elderly if the patient was aged at least 80 years on admission to the ICU and as being related to cardiac surgery if the APACHE II or IV reason for admission was related to planned or emergency cardiac surgery, as detailed in supplement I [32]. We present data on admissions following cardiac surgery and admissions for other reasons separately. This is because patients admitted to the ICU following cardiac surgery tend to be younger [33], cardiac surgery is only performed in a limited number of hospitals in the Netherlands and the percentage of cardiac procedures performed on the very elderly in the Netherlands has risen since 2005 [34]. An admission was defined as a medical admission if the patient did not come directly from an operating theatre to the ICU. To describe comorbidities, we defined a patient as having chronic renal insufficiency if he or she has a chronically raised serum creatinine (above $177 \mathrm{umol} / \mathrm{L}$ or $2.0 \mathrm{mg} / \mathrm{dL}$ ) or has received hemodialysis or peritoneal dialysis for a substantial period before the start of the hospital admission. We defined a patient as having chronic cardiovascular insufficiency if he or she has New York Heart Association class IV heart failure. We defined a patient as having a malignancy if he or she had solid tumor metastases or malignant lymphoma, acute leukemia or multiple myeloma. We defined a patient as having immunological insufficiency if he or she used long term immunosuppressive therapy or corticosteroid or chemotherapy or radiotherapy in the last year or had had chemotherapy or radio therapy for Hodgkin or non-Hodgkin lymphoma at any point before ICU admission or had documented cell deficiencies. We calculated the APACHE II [30] and SAPS II predicted probability of mortality [31] using standard methods. We defined the ICU length of stay as the number of fractional days between ICU admission and ICU discharge. We analyzed trends in ICU length of stay by classifying the length of each admission as longer or shorter than the median length of stay over all admissions in all years to all ICUs included in this study. We described the burden of the very elderly on ICUs by examining the number and percentage of admissions and ICU treatment days attributable to them. We obtained the total number of ICU treatment days and the number attributable to the very elderly by summing the length of individual admissions in fractional days in each calendar year in each hospital.

We extracted data from the NICE registry on ICU admissions attributable to patients known to be male or female, aged at least 18 years on admission to the ICU and admitted as a result of medical reasons, planned surgery or emergency surgery between 1 January 2005 and 31 December 2014. We excluded admissions to hospitals with fewer than 10 admissions for other reasons attributable to the very elderly or 10 admissions attributable to younger patients in any calendar year between 2005 and 2014 to increase the stability of estimates of parameters in the logistic models for the percentage of admissions attributable to the very elderly [35]. For the analyses on trends in the predicted probability of mortality and percentage with chronic conditions of very elderly patients admitted to ICUs, we also excluded all admissions not fulfilling the inclusion criteria for both the APACHE II and SAPS II models for predicting the probability of mortality.

\section{Statistical analysis}

We analyzed changes over time in the percentage of very elderly adults in the Statistics Netherlands and hospital admissions attributable to the very elderly in the Dutch Hospital Data using a generalized linear model with a constant and linear term for time 
and a binomial link function. We analyzed changes over time in the absolute number of admissions attributable to the very elderly using generalized linear mixed-effects models with a Poisson link function. We analyzed the proportions of admissions attributable to the very elderly and of the very elderly admitted to an ICU for medical reasons, with each of the chronic conditions and with an ICU length of stay longer than the overall median using generalized linear mixed-effects models with a binomial link function. We analyzed the logarithm of the total number of treatment days attributable to the very elderly, logarithm of the hospital median length of ICU stay and the logit transformed APACHE II and SAPS II predicted probabilities of mortality using linear mixed-effects models. We defined time as the number of whole years since 2005 and included random intercepts and linear terms for time for each hospital in all mixed effects models.

We performed all analyses using version 3.1.0 of the statistical platform R [37] and estimated the parameters for the generalized linear models using the function $\mathrm{glm}$ and for the mixed-effects models using the function glmer in the package Ime4 [38]. We considered p-values smaller than 0.05 as statistically significant and made no corrections for multiple testing. We obtained $95 \%$ confidence intervals using the Wilson score method [39] implemented in the PropCls package [40].

\section{Results}

We present Statistics Netherlands population data on the number and percentage of Dutch adults, who are very elderly, and Dutch Hospital Data on the number and percentage of adult hospital admissions attributable to the very elderly between 2005 and 2014 in Table 1. These data show that the percentage of very elderly adults in the Netherlands increased from 4.5\% (95\% confidence interval (CI) 4.5\% to 4.5\%) in 2005 to $5.4 \%$ (95\% Cl 5.3\% to 5.4\%, p-value < 0.0001$)$ in 2014 and that the percentage of hospital admissions attributable to the very elderly increased from $9.0 \%$ (95\% Cl 9.0\% to $9.1 \%)$ in 2005 to $10.6 \%(95 \% \mathrm{Cl} 10.6 \%$ to $10.6 \%)$ in 2014 (p-value < 0.0001$)$.

We included 83,769 ICU admissions following cardiac surgery to nine hospitals and 286,290 ICU admissions for other reasons to 33 hospitals (Figure 1). The nine hospitals delivering data on admissions following cardiac surgery are a subset of the 33 hospitals delivering data on other admissions. We provide details of the numbers of admissions excluded. Of the nine hospitals supplying admissions following cardiac surgery, 3 (33.3\%) were academic and 6 (66.7\%) were teaching hospitals. Of the 33 hospitals providing data on admissions following other reasons than cardiac surgery, three $(9.1 \%)$ were academic, 17 (51.5\%) were teaching and 13 (39.4\%) were general hospitals.
Table 1. Statistics Netherlands population data and Dutch Hospital Data on the number and percentage of adult hospital admissions attributable to the very elderly for the years 2005 to 2014.

\begin{tabular}{lcccc}
\hline & \multicolumn{2}{c}{$\begin{array}{c}\text { Statistics Netherlands } \\
\text { population data }\end{array}$} & \multicolumn{2}{c}{$\begin{array}{c}\text { Dutch Hospital Data } \\
\text { on hospital admissions }\end{array}$} \\
\hline Year & The very elderly & All adults & The very elderly & All adults \\
2005 & $573,573(4.5 \%)$ & $12,707,935$ & $284,484(9.0 \%)$ & $3,145,476$ \\
2006 & $587,016(4.6 \%)$ & $12,752,453$ & $307,986(9.3 \%)$ & $3,316,256$ \\
2007 & $600,842(4.7 \%)$ & $12,793,540$ & $330,360(9.5 \%)$ & $3,491,052$ \\
2008 & $615,489(4.8 \%)$ & $12,859,287$ & $355,635(9.7 \%)$ & $3,675,625$ \\
2009 & $631,208(4.9 \%)$ & $12,957,546$ & $381,782(9.8 \%)$ & $3,881,713$ \\
2010 & $647,994(5.0 \%)$ & $13,060,511$ & $413,450(10.1 \%)$ & $4,079,607$ \\
2011 & $667,547(5.1 \%)$ & $13,153,716$ & $446,385(10.4 \%)$ & $4,289,547$ \\
2012 & $686,015(5.2 \%)$ & $13,243,578$ & $457,074(10.5 \%)$ & $4,341,407$ \\
2013 & $702,820(5.3 \%)$ & $13,316,082$ & $418,457(10.7 \%)$ & $3,924,802$ \\
2014 & $717,089(5.4 \%)$ & $13,386,487$ & $363,630(10.6 \%)$ & $3,437,061$ \\
\hline
\end{tabular}

The numbers and percentages of ICU admissions, the ICU treatment days and de median length of stay (LOS) for admissions following cardiac surgery and admissions for other reasons attributable to the very elderly in each calendar year between 2005 and 2014 are presented in Table 2 and 3. The number of admissions following cardiac surgery attributable to the very elderly rose from 494 in 2005 to 909 in 2014 ( $p$-value $=0.0004)$, while the percentage of admissions attributable to this group rose from 6.7\% (95\% Cl 6.2\% to $7.3 \%)$ in 2005 to $11.0 \%$ (95\% Cl 10.3\% to $11.6 \%$ ) in 2014 ( $p$-value < 0.0001 ). The number of treatment days attributable to the very elderly rose from 1,143 in 2005 to 1,843 in 2014 ( $p$-value $=0.0403$ ) and the percentage of treatment days attributable to this group rose from $8.6 \%(95 \% \mathrm{Cl} 8.1 \%$ to $9.0 \%$ ) in 2005 to $11.7 \%$ (95\% $\mathrm{Cl} 11.2 \%$ to $12.2 \%)$ in 2014 ( $p$-value $=0.0157$ ). The number of admissions for other reasons than following cardiac surgery attributable to the very elderly rose from 3,033 in 2005 to 4,952 in 2014 ( $p$-value < 0.0001), while the percentage of admissions attributable to this group remained stable at $13.8 \%(95 \% \mathrm{Cl} 13.7 \%$ to $13.9 \%, p$-value $=$ $0.1315)$. The number of treatment days attributable to the very elderly rose from 11,810 in 2005 to 15,234 in 2014 ( $p$-value $=0.0002$ ), but the percentage of treatment days attributable to this group remained stable at $12.0 \%(95 \% \mathrm{Cl} 11.9 \%$ to $12.0 \%, p$-value $=$ 0.1429). The number of other admissions attributable to the very elderly fulfilling both the APACHE II and SAPS II mortality prediction model inclusion criteria and their average predicted probability of mortality are presented in Table 3. The APACHE II predicted probability of mortality remained stable at $0.2950(95 \%$ CI 0.2989 to $0.2919, p$-value $=$ 
0.8563). The SAPS II predicted probability of mortality remained stable at 0.3204 (95\% $\mathrm{Cl} 0.3165$ to 0.3243 , $p$-value $=0.3880$ ). In addition, we present the number and percentage of admissions attributable to the very elderly for medical reasons and several co-morbidities in Table 3. The percentage of admissions, in which the patient was admitted for medical reasons, rose from $44.1 \%(95 \% \mathrm{Cl} 42.1 \%$ to 46.2$)$ to $55.3 \%$ $(53.7 \%$ to $56.8 \%, p$-value $<0.0001)$. The percentage with chronic renal insufficiency rose from $5.0 \%(95 \% \mathrm{Cl} 4.2 \%$ to $6.0 \%)$ to $11.1 \%(95 \% \mathrm{Cl} 10.2 \%$ to $12.1 \%$, $p$-value $<0.0001)$. The percentage with immunological insufficiency rose from $2.8 \%(95 \% \mathrm{Cl} 2.2 \%$ to $3.6 \%)$ to $6.5 \%$ ( $95 \% \mathrm{Cl} 5.8 \%$ to $7.3 \%, p$-value $<0.0001)$. The percentage with a malignancy rose from $3.5 \%$ ( $95 \% \mathrm{Cl} 2.8 \%$ to $4.3 \%$ ) to $5.9 \%(95 \% \mathrm{Cl} 5.2 \%$ to $6.6 \%, p$-value $=0.0062$ ). The percentage with cardio vascular insufficiency remained stable at $7.9 \%(95 \% \mathrm{Cl} 7.6 \%$ to $8.2 \%, p$-value $=0.2456$ ). The median ICU LOS remained stable at 1.61 days (interquartile range 0.85 to $3.68, p$-value $=0.3200$ )

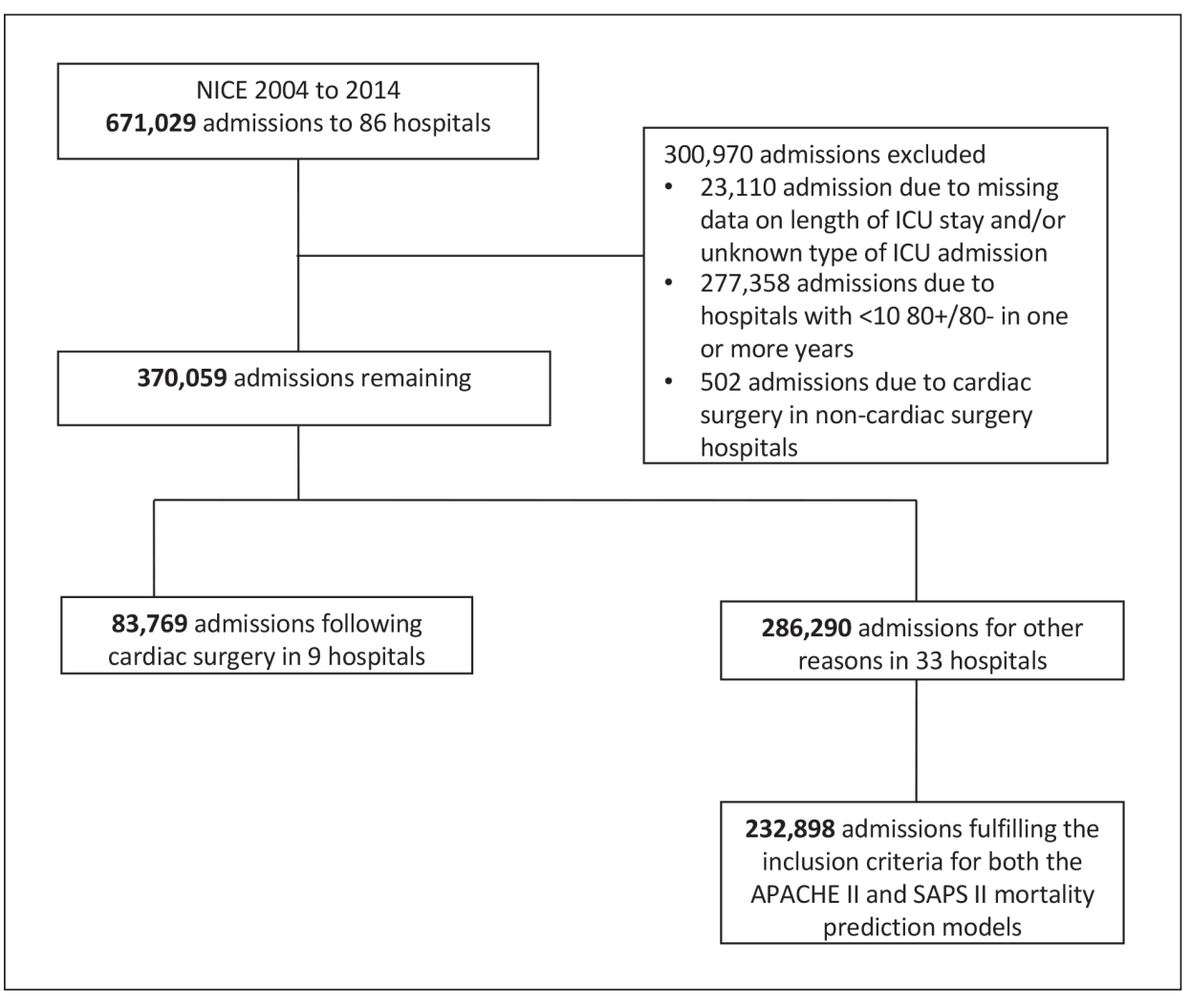

Figure 1. Flow diagram showing the number of intensive care admissions and hospitals included in the analysis.
Table 2. The numbers and percentages of ICU admissions following cardiac surgery and for other reasons attributable to the very elderly in the period 2005 to 2014.

\begin{tabular}{|c|c|c|c|c|c|}
\hline $\begin{array}{l}\text { Reason for ICU } \\
\text { admission }\end{array}$ & Year & $\begin{array}{l}\text { Total } \\
\text { number of } \\
\text { ICU } \\
\text { admissions }\end{array}$ & $\begin{array}{l}\text { Number (and } \\
\text { percentage) of } \\
\text { ICU admission } \\
\text { attributable to } \\
\text { the very elderly }\end{array}$ & $\begin{array}{l}\text { Total } \\
\text { number } \\
\text { of ICU } \\
\text { treatment } \\
\text { days }\end{array}$ & $\begin{array}{l}\text { Number (and } \\
\text { percentage) of } \\
\text { ICU treatment days } \\
\text { attributable to } \\
\text { the very elderly }\end{array}$ \\
\hline \multirow{10}{*}{$\begin{array}{l}\text { Following } \\
\text { cardiac surgery }\end{array}$} & 2005 & 7,364 & 494 (6.7\%) & 13,328 & $1,143(8.6 \%)$ \\
\hline & 2006 & 7,208 & $504(7.0 \%)$ & 13,818 & $1,238(9.0 \%)$ \\
\hline & 2007 & 8,337 & 575 (6.9\%) & 17,336 & 1,598 (9.2\%) \\
\hline & 2008 & 8,444 & $685(8.1 \%)$ & 17,649 & 2,273 (12.9\%) \\
\hline & 2009 & 8,824 & 808 (9.2\%) & 18,451 & $2,301(12.5 \%)$ \\
\hline & 2010 & 9,007 & $924(10.3 \%)$ & 17,635 & 2,249 (12.8\%) \\
\hline & 2011 & 9,114 & 999 (11.0\%) & 17,627 & 2,311 (13.1\%) \\
\hline & 2012 & 8,827 & $936(10.6 \%)$ & 17,243 & $2,140(12.4 \%)$ \\
\hline & 2013 & 8,351 & 885 (10.6\%) & 16,175 & 1,927 (11.9\%) \\
\hline & 2014 & 8,293 & 909 (11.0\%) & 15,725 & $1,843(11.7 \%)$ \\
\hline $\begin{array}{l}\text { Range for } \\
\text { hospitals* }\end{array}$ & & 593 to 1,579 & $\begin{array}{l}71 \text { to } 173 \\
\text { (7.1 to } 14.9 \% \text { ) }\end{array}$ & 732 to 3,034 & $\begin{array}{l}114 \text { to } 375 \\
\text { (5.9 to } 18.6 \% \text { ) }\end{array}$ \\
\hline \multirow[t]{10}{*}{ Other reasons } & 2005 & 22,688 & 3,033 (13.4\%) & 99,492 & 11,810 (11.9\%) \\
\hline & 2006 & 24,506 & 3,172 (12.9\%) & 108,464 & $11,861(10.9 \%)$ \\
\hline & 2007 & 24,266 & $3,270(13.5 \%)$ & 103,742 & $11,826(11.4 \%)$ \\
\hline & 2008 & 24,954 & 3,432 (13.8\%) & 105,367 & $13,027(12.4 \%)$ \\
\hline & 2009 & 28,275 & $4,019(14.2 \%)$ & 113,809 & $13,826(12.1 \%)$ \\
\hline & 2010 & 29,581 & $4,272(14.4 \%)$ & 117,756 & $15,368(13.1 \%)$ \\
\hline & 2011 & 30,482 & $4,280(14.0 \%)$ & 117,037 & $13,942(11.9 \%)$ \\
\hline & 2012 & 32,346 & $4,515(14.0 \%)$ & 121,255 & $14,939(12.3 \%)$ \\
\hline & 2013 & 33,443 & $4,613(13.8 \%)$ & 125,224 & $14,180(11.3 \%)$ \\
\hline & 2014 & 35,749 & 4,952 (13.9\%) & 124,260 & $15,234(12.3 \%)$ \\
\hline $\begin{array}{l}\text { Range for } \\
\text { hospitals* }\end{array}$ & & 329 to 2,349 & $\begin{array}{l}32 \text { to } 350 \\
\text { (4.4 to } 26.4 \%)\end{array}$ & 1,194 to 8,078 & $\begin{array}{l}75 \text { to } 902 \\
\text { (5.2 to } 29.9 \%)\end{array}$ \\
\hline
\end{tabular}

* Data from 2014 


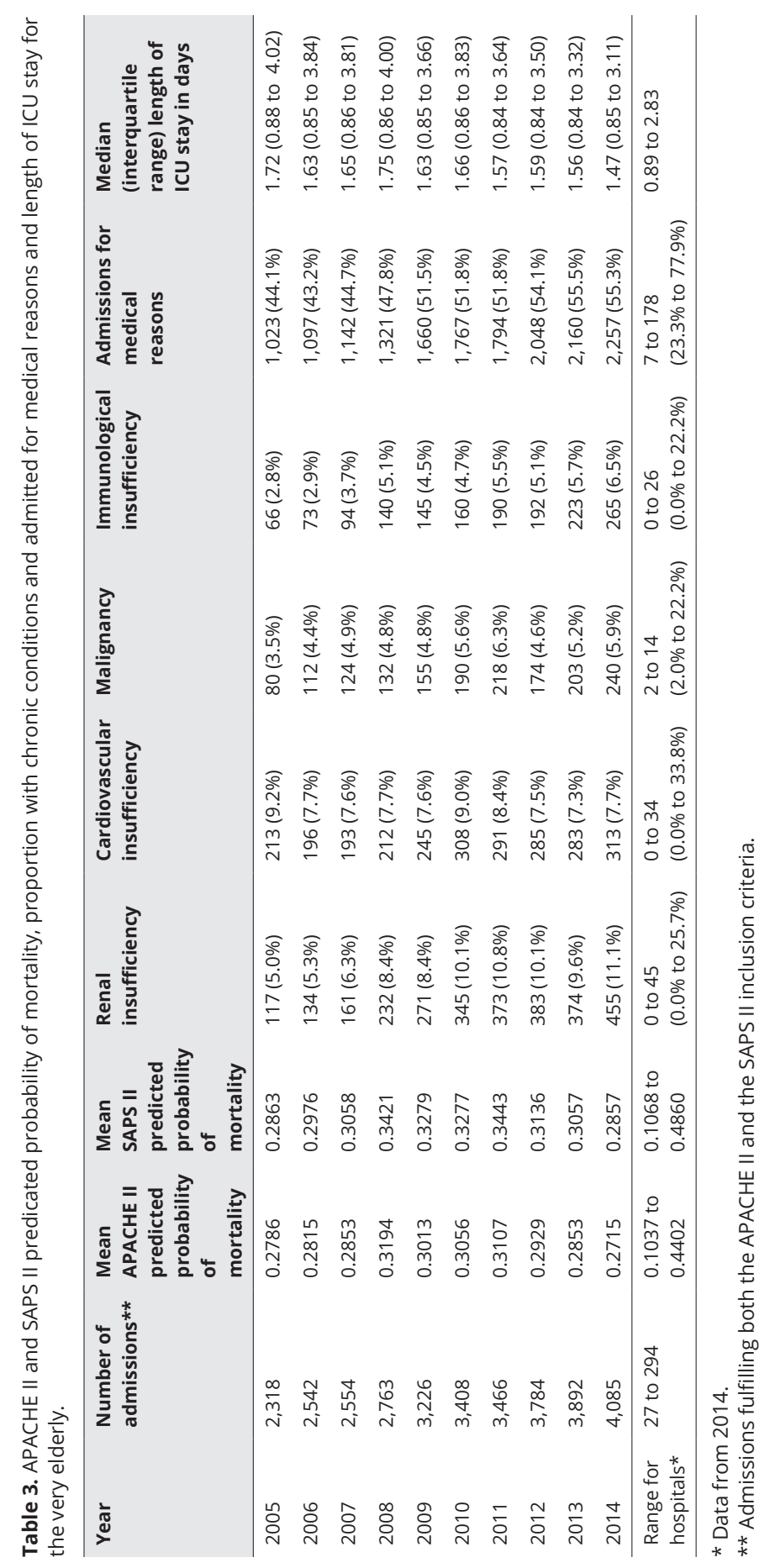

\section{Discussion}

In this study, we have examined changes in the percentage of hospital and ICU admissions in the Netherlands attributable to the very elderly in the period 2005 to 2014 and compared them with changes in the proportion of very elderly in the population as a whole. As the proportion of very elderly in the Dutch population increased, so did the percentage of hospital admissions. However, the percentage of, ICU admissions and treatment days attributable to the very elderly remained stable, except for ICU admissions and treatment days following cardiac surgery, which significantly increased from 2005 to 2014. The severity of illness of very elderly patients, expressed by the APACHEII and SAPS II predicted probability of mortality, remained stable over time. However, the percentage of medical admissions and admissions of patients with chronic renal insufficiency, immunological insufficiency or a malignancy increased.

Our study confirms that the demographic changes occurring in Europe and in other high-income countries are also occurring in the Netherland. These changes have resulted in significant increases in the percentage of adults who are very elderly and percentage of hospital admissions attributable to this group. The percentage of ICU admissions attributable to the very elderly was similar to those reported in studies conducted in Australia and New Zealand [15], Denmark [22], France [17, 18], Italy [19], Norway [20] and Spain [21] and slightly higher than in Finland [16]. However, our finding that, with the exception of admissions following cardiac surgery, the percentage of ICU admissions attributable to the very elderly did not increase between 2004 and 2013 contrasts with previous publications [15, 22]. In Australia and New Zealand, the ICU admission rates of very old patients increased by $5.6 \%$ per year between 2000 and 2005 and in Denmark the percentage the percentage of ICU patients who were very elderly rose from $11.7 \%$ in 2005 to $13.8 \%$ in 2011. In our study, we only observed an increase in this percentage for cardiac surgery admissions from 6.7\% in 2005 to $11.0 \%$ in 2014. Previously, researchers ascribed observed increases to demographic changes and the introduction of new technologies and pharmaceuticals [8, 15, 41, 42]. In Denmark, the percentage of ICU admissions attributable to the very elderly increased while there was a decrease in absolute number of ICU admissions and no change in the percentage of very elderly in de general population during the study period. This suggests that the increase of ICU admissions is primarily due to a change in admission policy in Denmark with regard to age. In contrast, in our study there was a significant increase in the percentage of very elderly adults in the general population (from $4.5 \%$ in 2005 to 5,4\% in 2014) and this percentage was higher than in Denmark (4.1\% in both 2005 and 2011). In addition, the proportion of ICU admissions attributable to the very 
elderly admitted to the ICU in the Netherlands in 2005 was similar to percentage in Denmark in 2011. Finally, our study cohort included more admissions with a longer observation period than compared to the study performed in Denmark.

Our finding that the percentage of Dutch ICU admissions attributable to the very elderly did not increase, except for cardiac surgery patients, could be explained by more strict ICU admission policies due to changing opinions about treatment of the very elderly or experiences of poorer outcomes for the very elderly following ICU admission. Proactive treatment restrictions set on the wards on hospital admission in consultation with patients and relatives such as do not resuscitate orders and no ICU admission policies could have influenced our findings. Whether this policy is justified remains questionable since researchers have shown that elderly patients have more ICU rejections than younger patients [43]. They also showed that elderly patients have a higher mortality when admitted, but that the mortality benefit of ICU admission appears greater for elderly patients than for younger patients. Although limited healthcare resources may have negatively influenced decisions to admit very elderly patients to ICUs, this is not likely since the absolute number of ICU admissions has increased for both younger and very elderly patients.

In contrast, we demonstrated that the increase in the percentages of admissions following cardiac surgery attributable to the very elderly is larger than the increase in the percentage of hospital admissions attributable to the very elderly. This may be due to improvements in techniques in cardiac surgery and general medical care and changed ethical reasoning around cardiac surgery in elderly patients. This finding is consistent with an earlier Dutch report, which mentioned increases in the mean age of patients undergoing cardiothoracic surgery and in the proportion of patients aged 76 years and older between 1995 and 2011 [34].

Decrease in absolute number of hospital admissions after 2012 are most probably due to excluding day case admissions from the hospital admissions. Since 2013 health insurance companies forced hospitals to register day case admissions as outpatient cases for financial payout. These changes were partly implemented by hospitals in 2013 and complete implementation was only reached in 2014

The strengths of our study include the combination of data from the three registries (Statistics Netherlands, Dutch Hospital data and the NICE registry), the long study period and the large number of admissions included. We included hospitals which provided data to the NICE registry for the whole period from 2005 to 2014 to investigate longterm trends. Since hospitals voluntarily participate in the NICE registry, it is reasonable to assume that missing data caused by a hospital not choosing to participate are nonignorable [36]. Therefore, we decided to focus on hospitals which provided data to the NICE registry for the whole period from 2005 to 2014 to investigate long-term trends and exclude a bias caused by differences in patient populations between participating hospitals.

However, our study also has some limitations. Firstly, the changes in the percentage of admissions attributable to the very elderly in individual hospitals may be substantially different from the group trends. Secondly, we modeled the NICE data using mixedeffects logistic models, but the Statistics Netherlands data and Dutch Hospital Data using ordinary logistic models. This is because we assumed that the Statistics Netherlands data and Dutch Hospital Data had total population coverage, whereas we obtained NICE data from a selection of hospitals covering only part of the population of ICU admissions in the Netherlands. Thirdly, the data presented in this paper reflect the first ICU admissions within any hospital stay. Hence, the total ICU admissions of the very elderly including re-admissions may be higher than suggested by our results if the very elderly have significantly more ICU readmissions within single hospital admissions. However, this is not likely because the very elderly are more likely to have no-return or do-not-resuscitate orders than younger patients. Fourthly, the burden of the very elderly could only be expressed by the number of treatment days as the NICE registry does not currently contain data on nursing workload or end-of-life decisions. Fifthly, we used the older APACHE II and SAPS II models to calculate the predicted probability of mortality as data for the APACHE IV model was only available in the NICE registry from 2008. Sixthly, at the point of data extraction, registration of hospital admissions at the Dutch Hospital Data registry was not complete for 2014. However, admissions of almost $96 \%$ of the hospitals had already been registered for this year. In addition, the absolute number of hospital admissions has decreased since 2012 due to a change in the way health insurance companies reimbursed day case admissions. These changes were partly implemented in 2013 and completely implemented in 2014.

Our results are of importance for the Netherlands, but possibly also for other European countries with comparable healthcare systems. In the past, Dutch researchers predicted that, as the population ages, the pressure on healthcare facilities, including ICUs, would continue to increase. They expected that, between 2006 and 2021, ICU treatment days for the very elderly would increase by $32 \%$ [12]. We did find a significant rise of treatment days for the very elderly. However, the percentage of ICU treatment days attributable to this group remained stable meaning that the increase in ICU admissions and treatment days are equally distributed over younger and very elderly patients. This finding does not support statements made by researchers suggesting that the increasing percentage of very elderly in the population in combination with developments in healthcare technology would fuel ICU admissions of the very elderly. Based on our results, we question whether these massive increases will occur. Our 
models have not been constructed to predict demand for health care resources, but could still be useful when modelling future ICU capacity requirements in the Netherlands and in countries with similar patterns of population aging.

However, to make rational decisions about the admission of very elderly to the ICU, it is important to have data on short- and long-term outcomes, including quality of life after discharge of the hospital. Intensive care specialists need to know whether the very elderly benefit from ICU admission as much as younger patients, whether they have an acceptable quality of life after ICU treatment and which patient characteristics predict good outcomes. Future research should examine these topics to enable optimal allocation of ICU resources and guide ethical decisions whether the very elderly should be offered ICU care.

\section{Conclusion}

Although the Dutch population is ageing and both the absolute number and percentage of hospital admissions attributable to the very elderly increased between 2005 and 2014, we did not see an increase in the percentage of general ICU admissions and treatment days attributable to the very elderly non cardiac surgery patients in this period. In contrast, we have shown that the percentage of ICU admissions and treatment days following cardiac surgery attributable to the very elderly increased between 2005 and 2014

\section{References}

1. Silvia Andueza Robustillo, Veronica Corsini, Monica Marcu, Katya Vasileva, DG ESTAT: EU Employment and Social Situation, Quarterly Review. Special Supplement on Demographic Trends. European Commission. March 2013.

2. CBS-Bevolking-Cijfers [http://www.cbs.nl/nl-NL/menu/themas/bevolking/cijfers/default.htm] (Statistics Netherlands, the Dutch national statistical service, population)

3. Nationaal Kompas-Bevolking-vergrijzing [http://www.nationaalkompas.nl/bevolking/vergrijzing/]

4. CBS-Statline-Bevolking [http://statline.cbs.nl/StatWeb/dome/?TH=3600\&LA=nl] (Statistics Netherlands, the Dutch national statistical service, population)

5. Boumendil A, Guidet B: Elderly patients and intensive care medicine. Intensive Care Med 2006, 32(7):965967.

6. Song X, MacKnight C, Latta R, Mitnitski AB, Rockwood K: Frailty and survival of rural and urban seniors: results from the Canadian Study of Health and Aging. Aging Clin Exp Res 2007, 19(2):145-153.

7. Mitnitski AB, Mogilner AJ, MacKnight $C$, Rockwood $K$ : The accumulation of deficits with age and possible invariants of aging. ScientificWorldJournal 2002, 2:1816-1822.

8. Angus DC, Barnato AE, Linde-Zwirble WT, Weissfeld LA, Watson RS, Rickert T, Rubenfeld GD, Robert Wood Johnson Foundation ICU End-Of-Life Peer Group: Use of intensive care at the end of life in the United States: an epidemiologic study. Crit Care Med 2004, 32(3):638-643.

9. Chalfin DB: Outcome assessment in elderly patients with critical illness and respiratory failure. Clin Chest Med 1993, 14(3):583-589.

10. Groeger JS, Guntupalli KK, Strosberg M, Halpern N, Raphaely RC, Cerra F, Kaye W: Descriplive analysis of critical care units in the United States: patient characteristics and intensive care unit utilization. Crit Car

11. Jakob SM, Rothen HU: Intensive care 1980-1995: change in patient characteristics, nursing workload and outcome. Intensive Care Med 1997, 23(11):1165-1170.

12. Hansen J, van der Velden LFJ, Hingstman L: Behoefteraming Intensive Care voor Volwassenen 2006-2016. Nivel 2008.

13. Adhikari NK, Fowler RA, Bhagwanjee S, Rubenfeld GD: Critical care and the global burden of critical illness in adults. Lancet 2010, 376(9749):1339-1346.

14. Adhikari NK, Rubenfeld GD: Worldwide demand for critical care. Curr Opin Crit Care 2011, 17(6):620-625.

15. Bagshaw SM, Webb SA, Delaney A, George C, Pilcher D, Hart GK, Bellomo R: Very old patients admitted to intensive care in Australia and New Zealand: a multi-centre cohort analysis. Crit Care 2009, 13(2):R45.

16. Reinikainen $\mathrm{M}$, Uusaro $\mathrm{A}$, Niskanen $\mathrm{M}$, Ruokonen E: Intensive care of the elderly in Finland. Acta Anaesthesiol Scand 2007, 51(5):522-529.

17. Roch A, Wiramus S, Pauly V, Forel JM, Guervilly C, Gainnier M, Papazian L: Long-term outcome in medica patients aged 80 or over following admission to an intensive care unit. Crit Care 2011, 15(1):R36.

18. Tabah A, Philippart F, Timsit JF, Willems V, Francais A, Leplege A, Carlet J, Bruel C, Misset B, GarrousteOrgeas M: Quality of life in patients aged 80 or over after ICU discharge. Crit Care 2010, 14(1):R2.

19. Pavoni V, Gianesello L, Paparella L, Buoninsegni LT, Mori E, Gori G: Outcome and quality of life of elderly critically ill patients: an Italian prospective observational study. Arch Gerontol Geriatr 2012, 54(2):e193-8. 
20. Andersen FH, Kvale R: Do elderly intensive care unit patients receive less intensive care treatment and have higher mortality? Acta Anaesthesiol Scand 2012, 56(10):1298-1305.

21. Puchades R, Gonzalez B, Contreras M, Gullon A, de Miguel R, Martin D, Gutierrez C, Navarro R: Cardiovascular profile in critically ill elderly medical patients: Prevalence, mortality and length of stay. Eur J Intern Med 2015, 26(1):49-55.

22. Nielsson MS, Christiansen CF, Johansen MB, Rasmussen BS, Tonnesen E, Norgaard M: Mortality in elderly ICU patients: a cohort study. Acta Anaesthesiol Scand 2014, 58(1):19-26.

23. de Rooij SE, Govers AC, Korevaar JC, Giesbers AW, Levi M, de Jonge E: Cognitive, functional, and quality of-life outcomes of patients aged 80 and older who survived at least 1 year after planned or unplanned surgery or medical intensive care treatment. J Am Geriatr Soc 2008, 56(5):816-822.

24. Boumendil A, Angus DC, Guitonneau AL, Menn AM, Ginsburg C, Takun K, Davido A, Masmoudi R, Doumenc B, Pateron D, Garrouste-Orgeas M, Somme D, Simon T, Aegerter P, Guidet B, ICE-CUB study
group: Variability of intensive care admission decisions for the very elderly. PLoS One 2012, 7(4):e34387.

25. CBS Data. CBS Statline Tabel: Bevolking. [http://statline.cbs.n//Statweb] (Statistics Netherlands, the Dutch national statistical service, population)]. 26. 'Dutch Hospital Data': National Hospital Care Basic Registration; "Landelijke Basisregistratie

27. Koetsier A, Peek N, de Jonge E, Dongelmans D, van Berkel G, de Keizer N: Reliability of in-hospital mortality as a quality indicator in clinical quality registries. A case study in an intensive care quality register. Methods Inf Med 2013, 52(5):432-440.

28. de Keizer NF, de Jonge E: National IC Evaluation (NICE): A Dutch Quality Control System. ICU Managemen 2005, 5(3):62-64.

29. Stichting Nationale Intensive Care Evaluatie: FocusIC jaarboek 2013. juni 2014

30. Knaus WA, Draper EA, Wagner DP, Zimmerman JE: APACHE II: a severity of disease classification system. Crit Care Med 1985, 13(10):818-829.

31. Le Gall JR, Lemeshow S, Saulnier F: A new Simplified Acute Physiology Score (SAPS II) based on a European/ North American multicenter study. JAMA 1993, 270(24):2957-2963.

32. Zimmerman JE, Kramer AA, McNair DS, Malila FM: Acute Physiology and Chronic Health Evaluation (APACHE) IV. hospital mortality assessment for today's critically ill patients. Crit Care Med 2006, 34(5):1297-1310.

33. de Jonge E, Bosman RJ, van der Voort PH, Korsten HH, Scheffer GJ, de Keizer NF: Intensive care medicine in the Netherlands, 1997-2001. I. Patient population and treatment outcome. Ned Tijdschr Geneeskd

34. Nederlandse vereniging van thoraxchirurgie, van Herwerden L, Noyez L, Takkenberg $H$, Versteegh M, Wijgergangs L: Hartchirurgie, De Nederlandse Dataregistratie Hartchirurgie, Resultaten van Mamenwerking tussen 16 nederlandse hartchirurgische centra. November 2012, 2.2:22-23.

35. Peduzzi P, Concato J, Kemper E, Holford TR, Feinstein AR: A simulation study of the number of events per variable in logistic regression analysis. J Clin Epidemiol 1996, 49(12):1373-1379.

36. Little RJA, Rubin DB: Statistical analysis with missing data. Second ed. Hoboken, New Jersey: John Wiley and Sons, Inc.; 2002

37. R Core Team. A language and environment for statistial computing.[http://www.R-project.org/]

38. [http://CRAN.R-project.org/package=Ime4]
39. Ralph Scherer (2014). PropCls: Various confidence interval methods for proportions. R package version 0.2-5. [http://CRAN.R-project.org/package=PropCls]

40. Newcombe RG: Improved confidence intervals for the difference between binomial proportions based on paired data. Stat Med 1998, 17(22):2635-2650.

41. Blot S, Cankurtaran M, Petrovic M, Vandijck D, Lizy C, Decruyenaere J, Danneels C, Vandewoude K, Piette A, Vershraegen G, Van Den Noortgate N, Peleman R, vogelaers D. Epidemiology and outcome of nosocomial blodstream inction in elderly, old, and very old patients. Crit Care Med 2009, 37(5):1634-1641

42. Nguyen $Y L$, Angus DC, Boumendil A, Guidet B: The challenge of admitting the very elderly to intensive care. Ann Intensive Care 2011, 1(1):29-5820-1-29.

43. Sprung CL, Artigas A, Kesecioglu J, Pezzi A, Wiis J, Pirracchio R, Baras M, Edbrooke DL, Pesenti A, Bakker J, Hargreaves C, Gurman G, Cohen SL, Lippert A, Payen D, Corbella D, lapichino G: The Eldicus prospective, observational study of triage decision making in European intensive care units. Part II: intensive care benefit for the elderly. Crit Care Med 2012, 40(1):132-138.

44. Minne L, Eslami S, de Keizer N, de Jonge E, de Rooij SE, Abu-Hanna A: Effect of changes over time in the performance of a customized SAPS-II model on the quality of care assessment. Intensive Care Med 2012, 
Additional file 1. APACHE II and APACHE IV reasons for intensive care unit admission related to cardiac surgery, Reasons for intensive care unit admission

APACHE II Heart valve surgery - surgical

Chronic cardiovascular disease - surgica

APACHE IV Aortic and mitral valve replacement

Aortic valve replacement, isolated

Atrial septal defect repair

Coronary artery bypass grafting alone

Coronary artery bypass grafting redo

Coronary artery bypass grafting redo with other operation

Coronary artery bypass grafting redo with valve repair/replacement

Coronary artery bypass grafting with aortic valve replacement

Coronary artery bypass grafting with double valve repair/replacement

Coronary artery bypass grafting with mitral valve repair

Coronary artery bypass grafting with mitral valve replacement

Coronary artery bypass grafting with other operation

Coronary artery bypass grafting with pulmonic or tricuspid valve repair or replacement only

Coronary artery bypass grafting, minimally invasive, mid-CABG

Mitral valve repair

Mitral valve replacement

Tricuspid valve surgery

ventricular septal defect repair 


\section{CHAPTER 3}

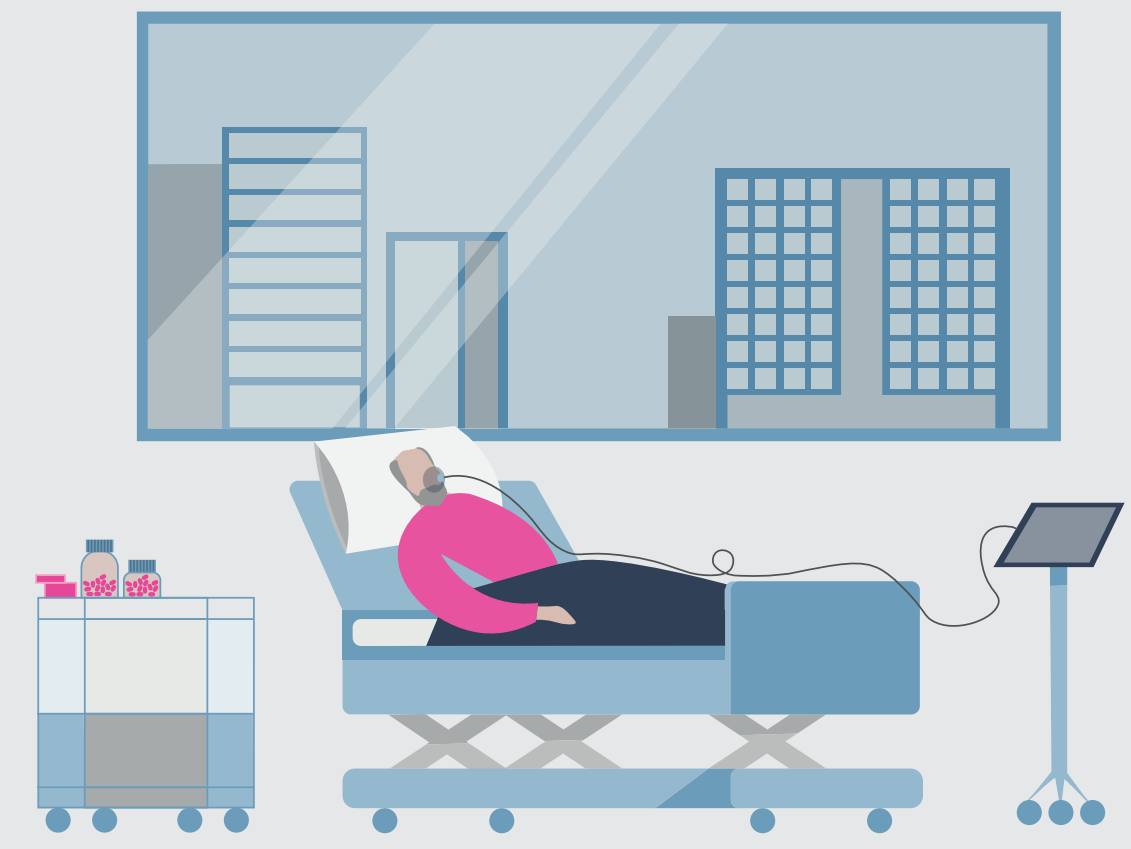

Trends in short-term and 1-year mortality in very elderly intensive care patients in the Netherlands: a retrospective study from 2008 to 2014

Published in: Intensive Care Medicine 2018 


\section{Abstract}

\section{Purpose}

To describe the trends in short-term and long-term mortality in very elderly intensive care unit (ICU) patients between 2008 and 2014.

\section{Methods}

A retrospective cohort study was conducted using data from the National Intensive Care Evaluation Foundation from 31 Dutch ICUs. Generalized linear mixed-effects models were used to determine the change in adjusted short-term mortality (ICU/ hospital deaths) and long-term mortality (3, 6, and 12 months after ICU admission) over the period 2008-2014 in very elderly patients and in patients less than 80 years old admitted to the ICU.

\section{Results}

A total of 216,196 patients admitted to 31 ICUs in the period from 2008 to 2014 were included in the study, including $28,284(13.1 \%$ ) very elderly patients (80 years or older). Follow-up data for determination of 3-, 6-, and 12-month mortality were available for 210,005 (97.1\%), 202,551 (93.7\%), and 176,847 (81.8\%) ICU admissions, respectively. The crude ICU and in-hospital mortality decreased from $17.6 \%$ to $13.0 \%$ and from $30.7 \%$ to $21.0 \%$ respectively. The annual risk-adjusted ICU and in-hospital mortality of very elderly patients (adjusted for APACHE III score, comorbidities, and admission type) decreased significantly during the study period [adjusted odds ratio 0.97 (0.95-0.99) and 0.92 (0.91-0.93), respectively]. Additionally, the annual risk-adjusted 3-, 6-, and 12-month mortality decreased significantly from 2008 to 2014 [adjusted odds ratio 0.96 (0.95-0.97), 0.96 (0.94-0.97), and 0.97 (0.95-0.98), respectively]. A similar significant annual decrease in risk-adjusted short-term and long-term mortality was observed in patients aged less than 80 years.

\section{Conclusions}

Both short-term and long-term risk-adjusted mortality decreased significantly during the study period in both very elderly ICU patients and patients aged less than 80 years in the Netherlands. This study clearly shows that in our setting very elderly patients benefit almost as much as their younger counterparts from improvement in quality of care over time.

\section{Introduction}

Many studies in developed countries have shown a progressive decline in in-hospita mortality for patients admitted to hospitals over the last few decades, including elderly patients [1 -8]. The same trend has been shown in multicenter studies for patients admitted to intensive care units (ICUs) with a total reduction of in-hospital mortality of 6\% in the USA from 1988 to 2012 [9], 4\% in Australia New Zealand from 1993 to 2003 [10], and an annual decrease of 2.4\% in England from 2000 to 2006 [11]. However these studies did not specifically report about the trends in in-hospital mortality of the very elderly patients admitted to the ICU.

Studies on trends in short-term mortality over time in specifically very elderly patients admitted to the ICU are limited. A recent single-center study in France comparing two cohorts of patients aged 80 years or older admitted to the same ICU (1992-1995 vs. 2001-2004) showed a decrease in ICU mortality over time, while interestingly an increase of mortality was observed in the same time in patients aged less than 80 years [12]. A multicenter study in Australia and New Zealand showed no change in in-hospital mortality over time in patients aged 80 years or older from 2000 to 2005 [13].

To our knowledge there are no studies available reporting on both trends in short-term as well as long-term mortality over time in very elderly patients admitted to the ICU. It is unknown whether a potential annual decrease in short-term mortality over time would also translate into an improved long-term outcome in this group of patients. In addition, it is questionable whether a significant improvement in outcome can still be observed in very elderly ICU patients in a more recent time period. Furthermore, these data are relevant for discussions about justification of ICU treatment of very elderly patients considering the increased utilization of ICU resources.

The aim of this study was to evaluate the trends in ICU, in-hospital, and long-term mortality of very elderly patients admitted to the ICU.

\section{Methods}

\section{Data sources}

We retrospectively used data from the Dutch National Intensive Care Evaluation (NICE) registry, a quality registry that prospectively collects all consecutive ICU admissions to participating hospitals. The number of hospitals participating rose from 6 in 1997 to 86 of the 90 Dutch ICUs in 2014. Participating hospitals deliver among others demographic, physiological and diagnostic data and the ICU and in-hospital mortality of all patients admitted to their ICUs [14,15]. 
We used a deterministic linkage algorithm based on the hospital to which the patient was admitted, gender, date of birth, ICU admission and discharge date to link ICU admissions in the NICE registry to the national claims database for health insurance companies (Vektis). [16,17] For the analyses on long-term mortality, we extracted date of death from the Vektis database. Since health care insurance is compulsory for all inhabitants of the Netherlands, the Vektis database provides nearly complete coverage of medical care provided in the country.

The NICE registry is registered according to the Dutch Personal Data Protection Act. The medical ethics committee of the Academic Medical Centre stated that medical ethics approval for this study was not required under Dutch national law (registration number W15-160).

\section{Definitions and inclusion criteria for data from the NICE registry}

We classified a patient as very elderly if the patient was 80 years or older at the time of admission to the ICU. We defined a patient as having chronic renal insufficiency if he or she had a chronically raised serum creatinine (above $177 \mathrm{umol} / \mathrm{L}$ or $2.0 \mathrm{mg} / \mathrm{dL}$ ) or had received haemodialysis or peritoneal dialysis for a substantial period before the start of the hospital admission. We defined a patient as having chronic cardiovascular insufficiency if he or she had New York Heart Association class IV heart failure. We defined a patient as having a malignancy if he or she had solid tumour metastases or malignant lymphoma, acute leukaemia or multiple myeloma. We defined a patient as having immunological insufficiency if he or she used long-term immunosuppressive therapy, or corticosteroid therapy, chemotherapy, radiotherapy in the last year, or had had chemotherapy or radiotherapy for Hodgkin's or nonHodgkin's lymphoma at any point before ICU admission, or had documented cell deficiencies. We calculated the Acute Physiology and Chronic Health Evaluation (APACHE) III score using standard methods [18].

We included only hospitals that provided data of their admissions during the whole study period between 1 January 2008 and 31 December 2014, as APACHE III variables were not available before 2008 and long-term outcomes were not yet available for patients admitted after 31 December 2014 at the time of analysis. Furthermore, we only included ICU admissions with a known gender, admission type (medical, planned surgery or emergency surgery) and aged at least 18 years on ICU admission. We excluded readmissions and all admissions to hospitals with fewer than 10 ICU deaths and 10 ICU survivors attributable to the very elderly or fewer than 10 ICU deaths and 10 ICU survivors attributable to younger patients in any calendar year between 2008 and 2014 to increase the stability of estimates of parameters in the mixed-effects logistic models $[19,20]$.
When analyzing the fixed long-term mortality outcomes, we also excluded all patients whose NICE records could not be matched with a Vektis record. In addition, there was a changeover in administrative systems at Vektis that came into effect on 1 January 2012. As a result of this changeover, we could not determine whether a patient was still alive: 3 months after ICU admission if the patient was admitted to an ICU between 1 October and 31 December 2011; 6 months after ICU admission if the patient was admitted to an ICU between 1 July and 31 December 2011; and 12 months after ICU admission if the patient was admitted to an ICU between 1 January and 31 December 2011. We excluded these patients from the relevant fixed long-term mortality analyses.

\section{Outcomes}

We examined the trends in ICU mortality; post-ICU mortality (mortality during hospitalization after ICU discharge); in-hospital mortality (total of ICU and post-ICU mortality); and mortality 3, 6, and 12 months after ICU admission. The first three outcomes are hospital based using data from the NICE registry. The long-term outcomes are defined using data from the NICE registry and the Vektis database. We also examined the trends in short-term and long-term mortality in four different subgroups of patients: 1) medical; 2) emergency surgery; 3) planned surgery; 4) cardiac surgery patients. The emergency and planned surgery subgroup consist of cardiac and noncardiac patients.

\section{Statistical analysis}

Case-mix characteristics of the ICU patients aged at least 80 and less than 80 years were compared using a Mann-Whitney test in which a $p$-value $<0.05$ is considered significant.

First, we examined the observed mortality in each year of the study period to check for differences between mortality across years. Second, we analysed the probability that a patient died during hospitalization (ICU and post-ICU) or within the 3, 6 or 12 months after ICU admission using mixed-effects logistic regression models with a random intercept per hospital to account for the clustering of patients within hospitals. With these mixed-effects logistic regression models the odds ratios of the covariate year of ICU admission was calculated for patients aged at least 80 and less than 80 years while correcting for gender, admission type, chronic renal insufficiency, chronic cardiovascular insufficiency, malignancy, immunological insufficiency, and the APACHE III score without the age points to determine whether there is a significant difference in proportions of patients who died over time. The APACHE III score without the age points was included in the mixed-effects logistic regression model as restricted cubic spline.

We performed all analyses using version 3.1.0 of the statistical platform $R$ and estimated the parameters for the generalized linear models using the function $\mathrm{glm}$ and for the 
mixed-effects models using the function gImer in the package Ime4. [21, 22] We considered $p$-values smaller than 0.05 as statistically significant and made no corrections for multiple testing.

\section{Results}

During the study period of 7 years, a total of 538,197 patients were admitted to 86 ICUs. After excluding hospitals and patients who did not meet the inclusion criteria, a total of 216,196 patients admitted to 31 ICUs could be used for final analysis (Figure 1). Follow-up data for determining 3,6 , and 12 months mortality after ICU admission were available for respectively 210,005 (97.1\%), 202,551 (93.7\%) and 176,847 (81.8\%) ICU admissions. About $13.1 \%$ of the 216,196 patients were aged at least 80 years $(n=28,284)$. Demographic and baseline characteristics are summarized in table 1. The percentages of diabetes, chronic renal failure, chronic respiratory insufficiency, cardiovascular insufficiency were higher in very elderly patients while immunological insufficiency and malignancy were lower. The median APACHE III score without age points, ICU and hospital length of stay were significantly higher in very elderly patients compared to patients aged less than 80 years (see Table 1).

\section{Short-term mortality}

The crude ICU, post-ICU, and in-hospital mortality decreased from 2008 to 2014 in both very elderly patients (aged at least 80 years) as well as in patients aged less than 80 years (Figure 2). In patients aged at least 80 years the absolute decrease of crude ICU and in-hospital mortality were respectively $4.6 \%$ (from $17.6 \%$ to $13.0 \%$, relative decrease of $26.1 \%$ ) and $9.7 \%$ (from $30.7 \%$ to $21.0 \%$, relative decrease of $31.6 \%$ ). In patients aged less than 80 years the absolute decrease of crude ICU and in-hospital mortality were respectively $2.6 \%$ (from $10.4 \%$ to $7.8 \%$, relative decrease of $25.0 \%$ ) and $4.9 \%$ (from $15.8 \%$ to $10.9 \%$, relative decrease of $31.0 \%$ ). The annual risk-adjusted ICU, post-ICU, and in-hospital mortality (adjusted for APACHE III score without age points, comorbidities, and admission type) significantly decreased during the study period in both very elderly patients and in patients aged less than 80 years (Figure 3). Adjusted odds ratio for ICU, post-ICU and in-hospital mortality were respectively $0.97,0.91$ and 0.92 for very elderly patients and respectively $0.96,0.92$ and 0.94 for patients aged less than 80 years. The extent of decrease of risk-adjusted ICU, post-ICU and in-hospital mortality over time in patients aged less than 80 years and very elderly were comparable (p-value> 0.05)

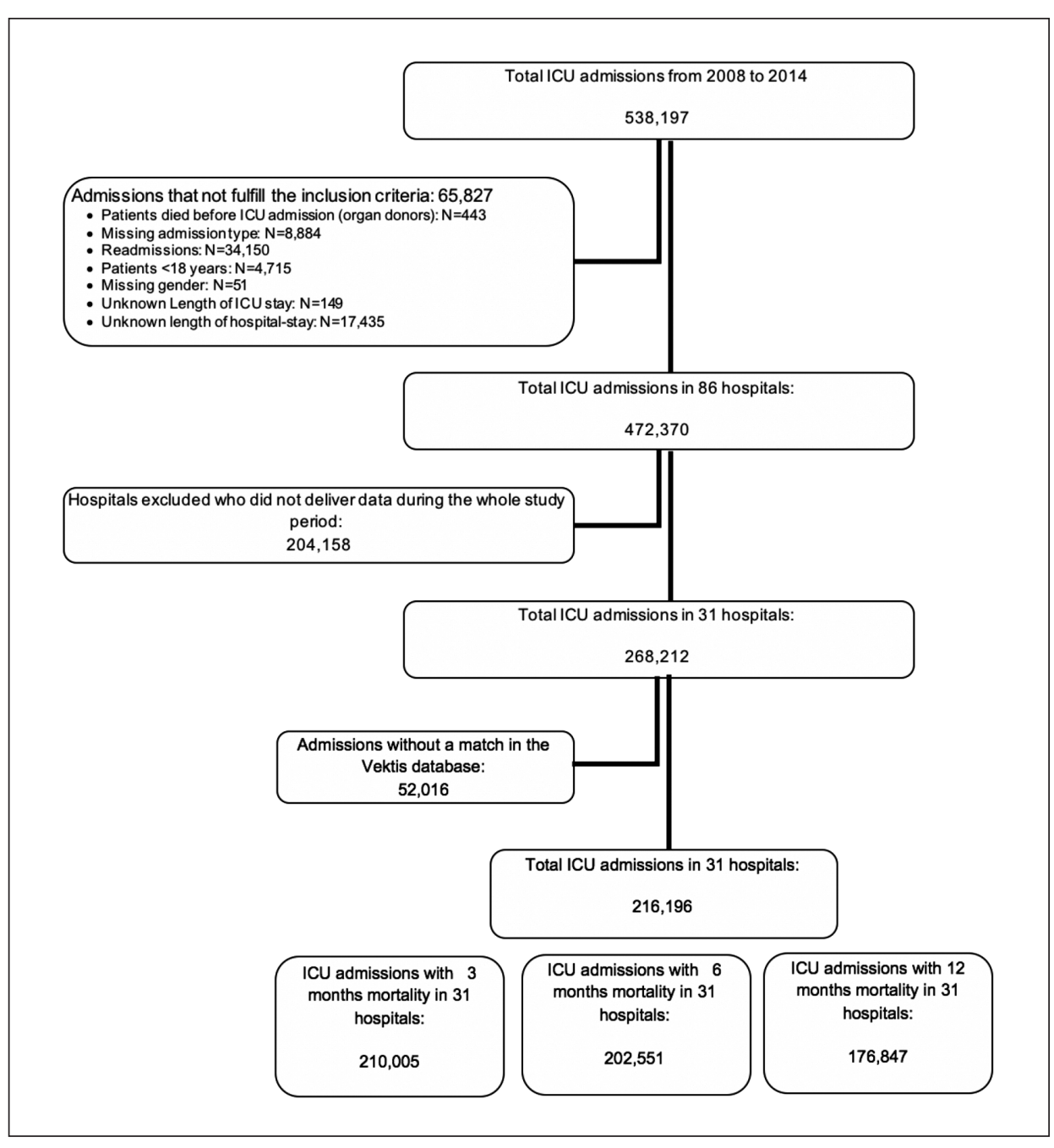

Figure 1. Flow chart

\section{Long-term mortality}

The crude 3,6, and 12 months mortality significantly decreased over time in the very elderly patients and patients aged less than 80 years (Figure 4). In very elderly patients the crude 3 months mortality decreased $6.9 \%$ (from $37.0 \%$ to $30.1 \%$, relative decrease of $18.6 \%$ ), the crude 6 months mortality decreased $7.6 \%$ (from $41.6 \%$ to $34.0 \%$, relative decrease 18.3\%), and the crude 12 months mortality decreased $5.9 \%$ (from $46.0 \%$ to $40.1 \%$, relative decrease $12.8 \%$ ). The risk-adjusted 3,6 , and 12 months mortality showed 
also a significant decrease in very elderly patients from 2008 to 2014 (adjusted odds ratios were respectively $0.96,0.96$, and 0.97 ) (Figure 3 ). A similar significant decrease in risk-adjusted long-term mortality was observed in patients aged less than 80 years (adjusted odds ratios of respectively $0.95,0.96$, and 0.96 ).

\section{Short-term and long-term mortality among subgroups}

Figure 5 shows odds ratios for ICU, post-ICU and in-hospital mortality and the 3,6, and 12 months mortality in the four different subgroups of patients based on type of ICU admission (medical, emergency surgery, planned surgery, and cardiac surgery) in both very elderly patients and patients aged less than 80 years. The risk-adjusted ICU, postICU, in-hospital mortality and long-term mortality significantly decreased over time in both the very elderly patients and patients aged less than 80 years in all subgroups, with exception of the ICU mortality in very elderly patients admitted for medical or emergency surgery reasons and 3-month mortality in very elderly patients admitted for medical reasons.

Table 1. Patient characteristics

\begin{tabular}{|c|c|c|}
\hline & $\begin{array}{c}<80 \text { years } \\
\mathrm{N}(\%)\end{array}$ & $\begin{array}{c}>=80 \text { years } \\
N(\%)\end{array}$ \\
\hline Total & 187.912 & 28.284 \\
\hline Male & $11.5537(61.5)$ & $14.614(51.7)^{\star}$ \\
\hline Diabetes & $30.280(16.1)$ & $5.210(18.4)^{\star}$ \\
\hline Chronic renal failure & $9.175(4.9)$ & $2.327(8.2)^{\star}$ \\
\hline Chronic respiratory failure & $27.589(14.7)$ & $4.840(17.1)^{\star}$ \\
\hline Cardiac insufficiency & $11.026(5.9)$ & $2.450(8.7)^{\star}$ \\
\hline Immunodeficiency & $12.069(6.4)$ & $1.142(4.0)^{\star}$ \\
\hline Malignancy & $11.061(5.9)$ & $1.169(4.1)^{\star}$ \\
\hline Medical admission & $83.644(44.5)$ & $13.293(47.0)^{*}$ \\
\hline Emergency surgery admission & $22.161(11.8)$ & $4.798(17.0)^{\star}$ \\
\hline Planned surgery admission & $43.610(23.2)$ & $5.460(19.3)^{\star}$ \\
\hline \multirow[t]{2}{*}{ Cardiac surgery admission } & $38.497(20.5)$ & $4.733(16.7)^{\star}$ \\
\hline & Median (Q1-Q3) & Median (Q1-Q3) \\
\hline APACHE III score, without age points & $41(27-61)$ & $48(34-68)^{*}$ \\
\hline APACHE III score, with age points & $52(37-73)$ & $68(53-88)^{*}$ \\
\hline ICU length of stay (days) & $1.1(0.8-3.2)$ & $1.3(0.8-3.2)^{*}$ \\
\hline Hospital length of stay (days) & $9(5-18)$ & $11(6-19)^{*}$ \\
\hline
\end{tabular}

* Significant difference based on a p-value less than 0.05 .

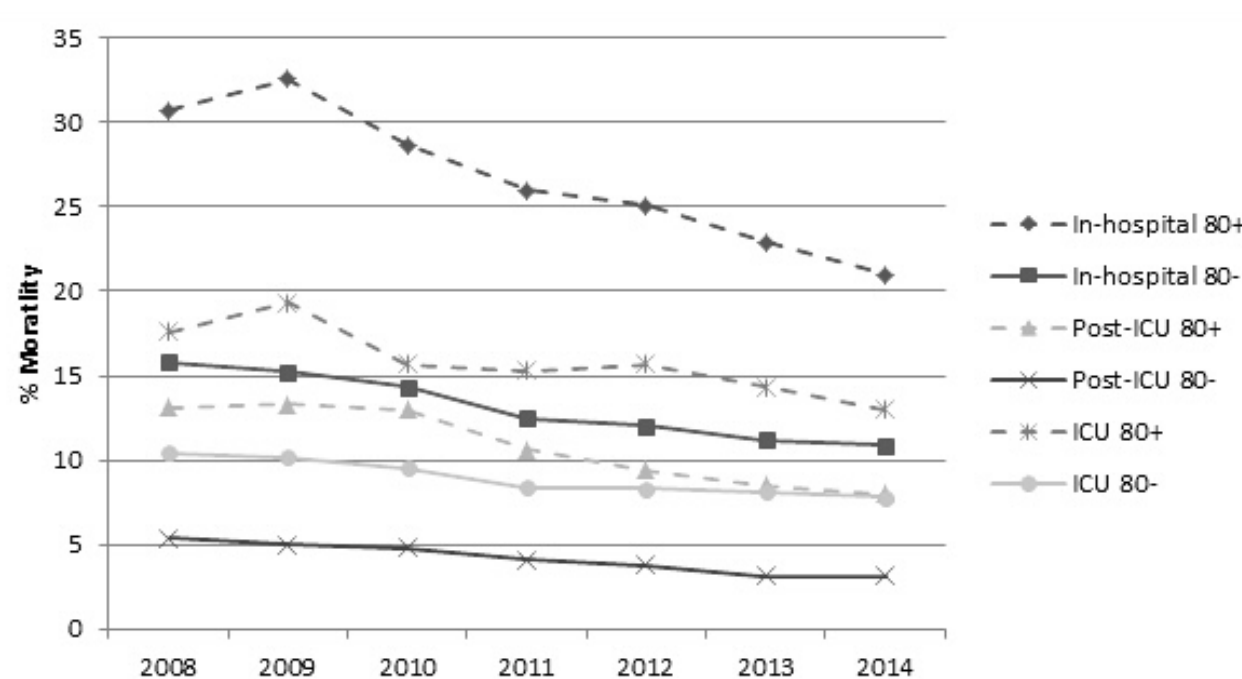

Figure 2. ICU, post-ICU and in-hospital mortality from 2008 to 2014.

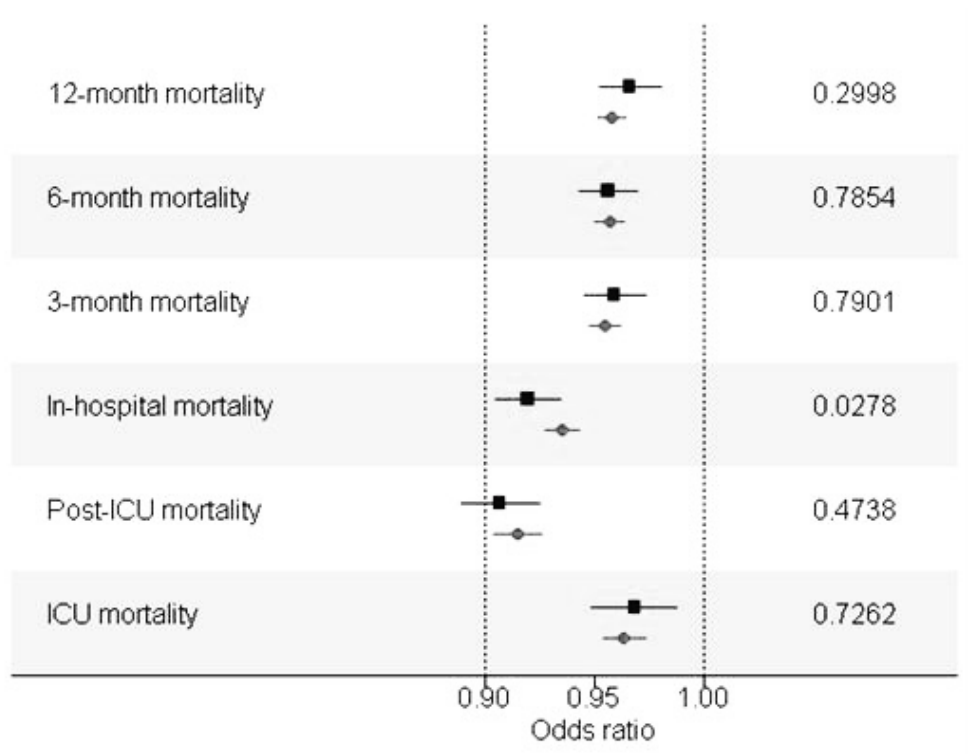

Figure 3. Odds ratios of the mortality per year for the very elderly (squares and lines) and patients $<80$ years (dots and lines). The p-values express whether the odds ratio is different for the very elderly and younger patients. 


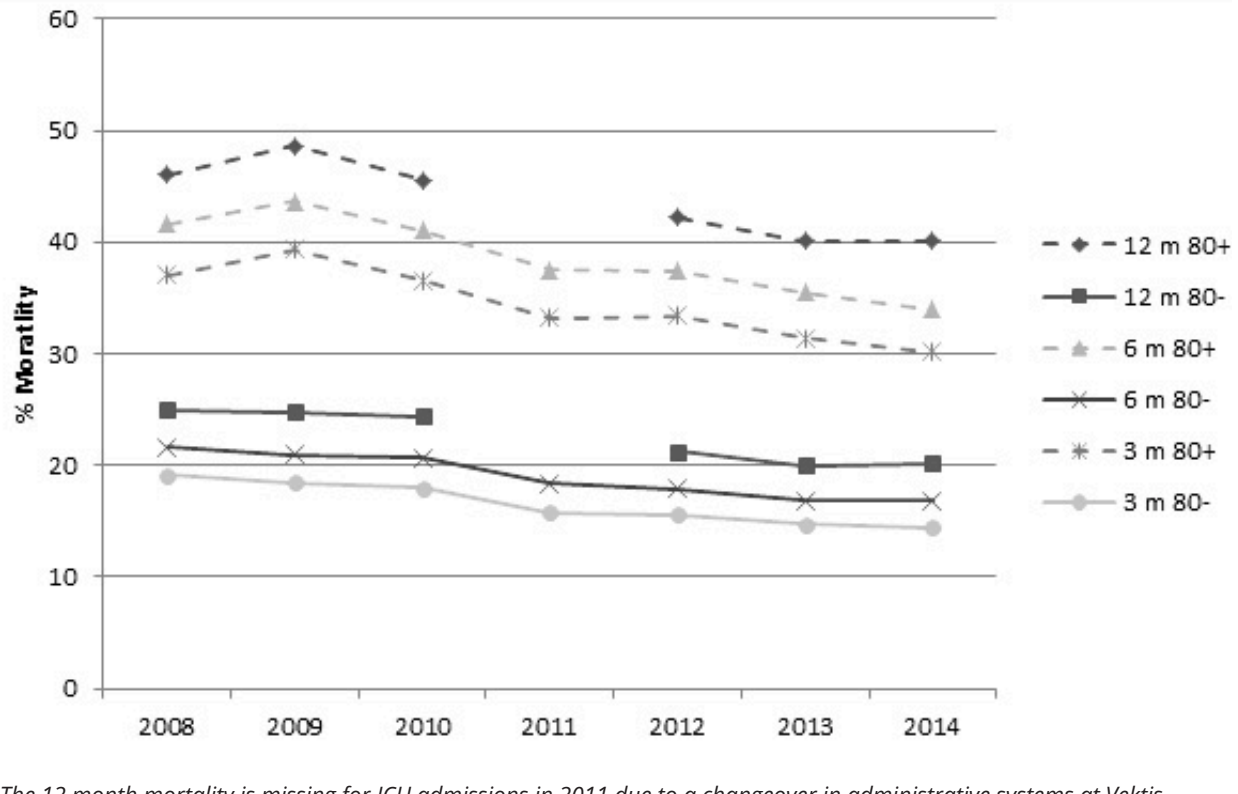

The 12 month mortality is missing for ICU admissions in 2011 due to a changeover in administrative systems at vektis.

Figure 4. Long-term mortality (3, 6, 12 months after ICU admission) from 2008 to 2014.

\section{Discussion}

This large retrospective study shows that both unadjusted and risk-adjusted ICU, postICU, and in-hospital mortality have significantly decreased between 2008 and 2014 in very elderly patients. The risk adjusted long-term mortality $(3,6$, and 12 months after ICU admission) also significantly decreased over time in very elderly patients. Similar results are shown for patients younger than 80 years. The decrease in risk-adjusted ICU mortality over time could not be explained as a result of mortality shift from the ICU to the wards due to early discharge of patients from the ICU over time since the risk-adjusted post-ICU and in-hospital mortality also decreased in both patients aged at least 80 and less than 80 years during the same study period. As the risk-adjusted long-term mortality (3, 6, and 12 months after ICU admission) also significantly declined from 2008 to 2014, the significant decrease in in-hospital mortality over time seems not to be associated with early hospital discharge of patients to acute or palliative care facilities shifting the mortality outside the hospitals. The mortality reduction in very elderly patients could also not be explained by better triage, since SAPS II/APACHE ॥ predicted mortality did not change and the comorbidity scores even increased from 2005 to 2014 in a study we published earlier [23]. Our study has shown that very elderly
12 month cardiac surgery

12 month planned surgery

12 month planned surgery

12 month medical

6 month cardiac surgery

6 month planned surgery

6 month emergency surgery

6 month medical

3 month cardiac surgery

3 month planned surgery

3 month emergency surgery

3 month medical

Hospital cardiac surgery

Hospital planned surgery

Hospital emergency surgery

Hospital medical

Post-ICU cardiac surgery

Post-ICU planned surgery

Post-tCU emergency surgery

Post-ICU medical

ICU cardiac surgery

ICU planned surgery

ICU emergency surgery

ICU medical

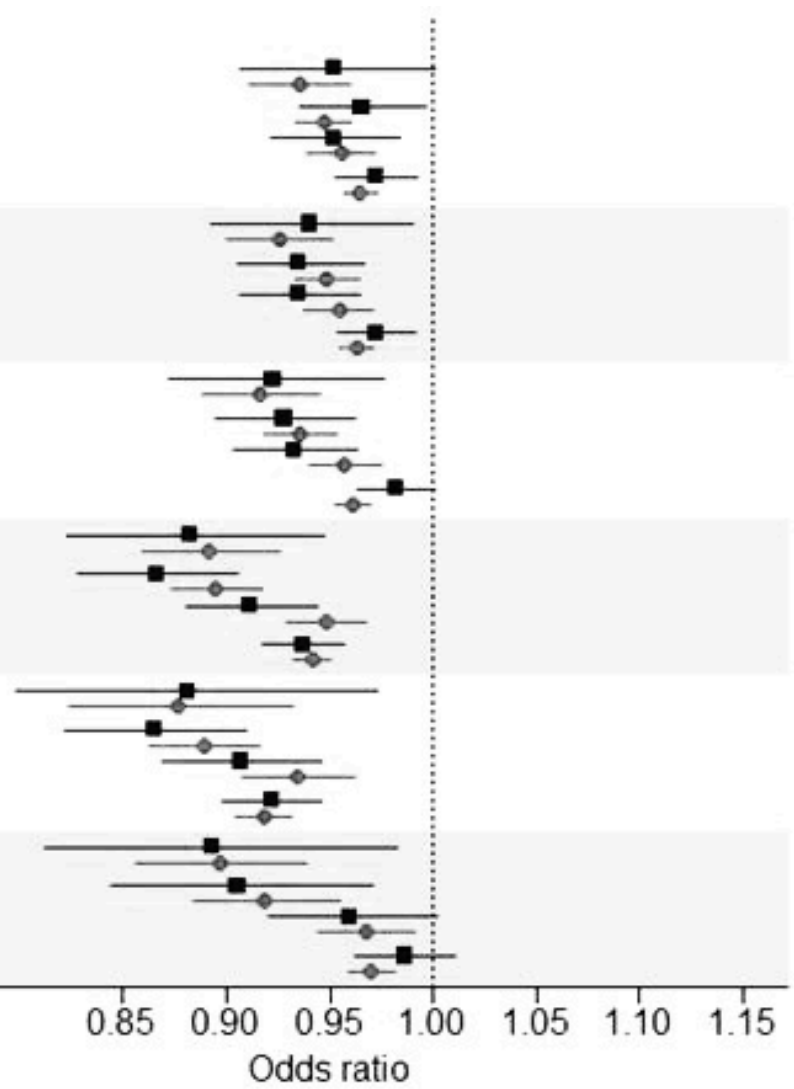

Figure 5. Odds ratios of the mortality per year in different admission subgroups for the very elderly (squares and lines) and patients $<80$ years (dots and lines).

patients benefit equally from improvement in quality of care over time. However, we must also emphasize that the short-term and long-term mortality in very elderly ICU patients still remains to be about two times higher when compared to younger patients. To what extent this excess mortality is modifiable with advance care planning is unknown. In addition, future research should focus on adequate triage tools in order to better select very elderly ICU patients who might benefit from ICU treatment. This is especially important given limited healthcare resources.

In a single-center retrospective cohort study in France, comparing ICU admission between 1992-1995 and 2001-2004, Lerolle et al. suggested that the ICU survival of patients improved in patients aged at least 80 years over time owing to more intensive treatment of patients despite higher severity of illness scores in the second period [12]. These findings were limited to only one center and no valid long-term data were available because a lot of patients were lost to follow up. Another study in Australia 
and New Zealand showed no change in in-hospital mortality from 2000 to 2005 in patients aged 80 years or older [13]. This study did not report about long-term mortality. Our study showed a significant and substantial annual decrease in risk-adjusted ICU, post-ICU, and in-hospital mortality over time with a subsequent annual reduction in long-term-mortality in both patients aged at least 80 and less than 80 years in 31 Dutch hospitals. Several studies reported relative undertreatment and higher refusal rate for intensive care treatment in very elderly compared to younger patients [23-26], while in a study of Wehler et al. no differences could be found in ICU treatment between very elderly and younger patients [27]. Although we have no data on intensity of treatment, we believe that there is no justification for undertreatment in very elderly patients once they have been accepted for ICU treatment since very elderly patients equally benefitted in risk-adjusted short-term and long-term mortality reduction.

The crude ICU and in-hospital mortality of patients aged at least 80 years were 1.5 to 2 times higher compared with patients aged less than 80 years. These results are comparable with results of the study from Australia and New Zealand [13]. Other studies have reported much higher ICU and in-hospital mortality rates in very elderly patients, with ICU mortality rates up to $20-35 \%$ [12, 28-32]. The mean long-term mortality rates $(3,6,12$ months) of very elderly patients were two times higher compared to patients aged less than 80 years. In our study the mean ICU and 12 month mortality of very elderly ICU patients were respectively $15.6 \%$ and $43.5 \%$ vs $26.5 \%$ and $52.2 \%$ in the study of Docherty et al [30]. However, the mortality after ICU discharge was comparable ( $25.7 \%$ vs $28.0 \%$ in our study). The mean 12 -month mortality of our medical admissions was $55.5 \%$, which was slightly lower than the $58.0 \%$ reported by Nielsson et al. However, the mean 12-month mortality for surgical admissions was substantially lower in our study (32.7\% vs $44.2 \%$ reported by Nielsson) [33],

De Rooij et al. evaluated the short-term and long-term outcome of 578 very elderly medical, emergency surgery and planned surgery patients (80 years or older) admitted to the mixed medical/surgical ICU of a single university hospital in the Netherlands between 1997-2002 [29]. In contrast to our study, Rooij et al. did not evaluate the change in mortality over time in these subgroups of patients. We showed a significant decrease of risk-adjusted short-term and long-term mortality over time in different admission subgroups (Figure 5), with exception of the ICU mortality in very elderly patients admitted for medical or emergency surgery reasons and 3-month mortality in very elderly patients admitted for medical reasons. The reduction of ICU mortality over time in very elderly patients (Figure 3) appears to be predominantly determined by significant decrease of mortality in planned surgery and cardiac surgery patients, probably owing to improvement in surgical techniques and better perioperative care over time. However, in contrast to ICU mortality, the in-hospital mortality and long-term mortality (6- and 12-months) in very elderly patients admitted for medical reasons significantly decreased. A possible explanation for this finding could be an increased application of treatment restrictions in the ICU or just improved care on the wards over time.

Our study had several limitations. First, selection bias in admission criteria of very elderly patients to the ICU might have occurred over time, resulting in selection of patients with a better functional status. Data about functional status are unfortunately not included in the NICE database. Second, we could only include the 31 of the 86 ICUs that provided data of their admissions during the whole study period (see Figure 1). The majority of the excluded patients had a slightly lower severity of illness (i.e., lower APACHE III score) and therefore probably had a lower short-term and long-term mortality than the included patients. Furthermore, as a result of a changeover in administrative systems at Vektis associated with a change in the remuneration system for hospitals in the Netherlands that came into effect on 1 January 2012, the long-term follow up data for determining 3-, 6-, and 12-month mortality were available for respectively $97.1 \%, 93.7 \%$, and $81.8 \%$ of the patients. The majority of the excluded patients had a slightly lower severity of illness (i.e. lower APACHE III score) and therefore probably had a lower short-term and long-term mortality than the included patients. Third, the NICE database contains no information about withholding or withdrawing treatment. However, we would expect that death from withholding treatment has more likely occurred in very elderly patients. Finally, since this study is performed in only one country, generalizability of our findings to other countries might be limited.

\section{Conclusions}

This study clearly shows that both in very elderly patients and in patients aged less than 80 years admitted to Dutch ICUs the crude and risk-adjusted short-term and long-term mortality significantly decreased from 2008 to 2014. The significant annual decrease in risk-adjusted mortality was also shown in different groups of patients (medical, emergency surgery, planned surgery, and cardiac surgery) in both very elderly and younger age group. Only the ICU mortality in very elderly patients admitted for medical or emergency surgery reasons and the 3-month mortality in very elderly patients admitted for medical reasons did not significantly decrease over time. Very elderly patients admitted to the ICU seem to have benefitted almost equally from improvement in quality of care over time compared to patients aged less than 80 years. 


\section{References}

1. Andrews RM, Russo CA, Pancholi M (2007) Trends in hospital risk-adjusted mortality for select diagnoses and procedures. 1994-2004. Healthcare Cost and Utilization Project (HCUP) Statistical Brief\#38 . Agency for Healthcare Research and Quality.

2. Hines A, Stranges E, Andrews R (2010) Trends in hospital risk-adjusted mortality for select diagnoses by patient subgroups: 2000-2007. Healthcare Cost and Utilization Project (HCUP) Statistical Brief\#98 Agency for Healthcare Research and Quality.

3. Korabathina R, Weintraub AR, Price LL, Kapur NK, Kimmelstiel CD, lafrati MD, Ali Tahir SM (2013) Twenty-year analysis of trends in the incidence and in-hospital mortality for lower-extremity arterial thromboembolism. Circulation 128(2):115-21

4. Insam C, Paccaud F, Marques-Vidal P. BMC Public Health (2013) Trends in hospital discharges, management and in-hospital mortality from acute myocardial infarction in Switzerland between 1998 and 2008. BMC Public Health 13:270. doi: 10.1186/1471-2458-13-270.

5. Slobbe LC, Arah OA, de Bruin A, Westert GP (2008) Mortality in Dutch hospitals: trends in time, place and cause of death after admission for myocardial infarction and stroke. An observational study. BMC Health

6. Kirksey M, Chiu YL, Ma Y, Della Valle AG, Poultsides L, Gerner P, Memtsoudis SG (2012) Trends in inhospital major morbidity and mortality after total joint arthroplasty: United States 1998-2008. Anesth Analg. 115(2):321-327.

7. Ruhnke GW, Coca Perraillon M, Cutler DM (2013) Mortality reduction among pneumonia patients still substantial despite the impact of coding changes. Am J Med.126(3):266-269.

8. Finks JF, Osborne NH, Birkmeyer JD (2011) Trends in hospital volume and operative mortality for high-risk surgery. N Engl J Med. 364:2128-2837

9. Zimmerman JE, Kramer AA, Knaus WA (2013) Changes in hospital mortality for United States intensive care unit admissions from 1988 to 2012 . Crit Care. 17(2):R81.

10. Moran JL, Bristow P, Solomon PJ, George C, Hart GK (2008) Mortality and length-of-stay outcomes, 1993 2003, in the binational Australian and New Zealand intensive care adult patient database. Australian and 61

11. Hutchings A, Durand MA, Grieve R, Harrison D, Rowan K, Green J, Carins J, Black N (2009) Evaluation of modernization of adult critical care services in England: time series and cost effectiveness analysis. BM]

12. Lerolle $\mathrm{N}$, Trinquart L, Bornstain C, et al (2010) Increased intensity of treatment and decreased mortality in elderly patients in an intensive care unit over a decade. Crit Core Med 3811): 59-64. doi:101097/ CCM.0b013e3181b088ec [doi]

13. Bagshaw SM, Webb SA, Delaney A, George C, Pilcher D, Hart GK, Bellomo R (2009) Very old patients R45. doi:10.1186/cc7768 [doi].

14. Dutch National Intensive Care Evaluation (NICE) Foundation (2012); Available at: http://www.stichtingnice.nl. Accessed 07/24,

15. van de Klundert N, Holman R, Dongelmans DA, de Keizer NF (2015) Data Resource Profile: the Dutch National Intensive Care Evaluation (NICE) Registry of Admissi 3/ije/dyv291 [doi].
16. Vektis (2012); Available at: http://www.vektis.nl. Accessed July 24, 2017.

17. Roos LL, Wajda A (1991) Record linkage strategies. Part I: Estimating information and evaluating approaches. Methods Inf Med 30(2): 117-23. doi:91020117 [pii].

18. Knaus WA, Wagner DP, Draper EA, et al (1991) The APACHE III prognostic system. Risk prediction of hospital mortality for critically ill hospitalized adults. Chest 100(6): 1619-36.

19. Peduzzi P, Concato J, Kemper E, Holford TR, Feinstein AR (1996) A simulation study of the number of events [pii].

20. Moineddin R, Matheson Fl, Glazier RH (2007) A simulation study of sample size for multilevel logistic regression models. BMC Med Res Methodol 7: 34. doi:1471-2288-7-34 [pii].

21. R Core Team (2015) R: A language and environment for statistical computing. R Foundation for Statistical Computing, Vienna, Austria; Available at: https://www.R-project.org/.

22. Bates D, Mächler M, Bolker B, Walker S (2015) Fitting Linear Mixed-Effects Models Using Ime4. Journal of Statistical Software 67(1): 1-48.

23. Haas LE, Karakus A, Holman R, Cihangir S, Reidinga AC, de Keizer NF (2015) Trends in hospital and intensive care admissions in the Netherlands attributable to the very elderly in an ageing population. Crit Care. 30;19:353. doi: 10.1186/s13054-015-1061-z.

24. Castillo-Lorente E, Rivera-Fernandez R, Vazquez-Mata G (1997) Limitation of therapeutic activity in elderly critically ill patients. Project for the Epidemiological Analysis of Critical Care Patients. Crit Care Med 25(10)

25. Boumendil A, Aegerter P, Guidet B, CUB-Rea Network (2005) Treatment intensity and outcome of patients aged 80 and older in intensive care units: a multicenter matched-cohort study. J Am Geriatr Soc 53(1): 88-93. doi:]GS53016 [pii].

26. Sprung CL, Artigas A, Kesecioglu J, et al (2012) The Eldicus prospective, observational study of triage Med 40(1): 132-8, doi:10.1097/CCM.0b013e318232d6bo [doi]

27. Wehler M, Strauss R, Mueller A, Reulbach U, Martus P, Hahn EG (2000) Therapeutic activity in elderly medical intensive care patients. Crit Care 4 (Suppl 1): P226.

28. Roch A, Wiramus S, Pauly V, Forel JM, Guervilly C, Gainnier M, Papazian L (2011) Long-term outcome . 84 [do

29. de Rooij SE, Govers A, Korevaar JC, Abu-Hanna A, Levi M, de Jonge E (2006) Short-term and long-term mortality in very elderly patients admitted to an intensive care unit. Intensive Care Med 32(7): 1039-44. doi:10.1007/s00134-006-0171-0 [doi].

30. Docherty AB, Anderson NH, Walsh TS, Lone NI (2016) Equity of Access to Critical Care Among Elderly Patients in Scotland: A National Cohort Study. Crit Care Med 44(1): 3-13. doi:10.1097/CCM.0000000000001377 doi].

31. Somme D, Maillet JM, Gisselbrecht M, Novara A, Ract C, Fagon JY (2003) Critically ill old and the oldestdoi:10.1007/s00134-003-1929-2 [doi].

32. Heyland D1, Cook D, Bagshaw SM, Garland A, Stelfox HT, Mehta S, Dodek P, Kutsogiannis J, Burns K Muscedere J, Turgeon AF, Fowler R, Jiang X, Day AG (2015) The Very Elderly Admitted to ICU: A Quality

33. Nielsson MS, Christiansen CF, Johansen MB, Rasmussen BS, Tønnesen E, Nørgaard M (2014) Mortality in 2013 Oct 13. 


\section{Supplement}

Table S1. ICU-, post-ICU, in-hospital, 3-month, 6-month, and 1-year mortality of all admissions.

\begin{tabular}{|c|c|c|c|c|c|c|c|}
\hline \multirow{4}{*}{ ICU mortality } & \multirow[b]{3}{*}{ Year } & \multicolumn{3}{|c|}{ Patients $<80$ years } & \multicolumn{3}{|c|}{ Patients $\geq 80$ years } \\
\hline & & \multicolumn{3}{|c|}{ Mortality } & \multirow[b]{2}{*}{ Total } & \multicolumn{2}{|c|}{ Mortality } \\
\hline & & Total & $\mathbf{N}$ & $\%$ & & $\mathbf{N}$ & $\%$ \\
\hline & 2008 & 20935 & 2174 & 10.4 & 3210 & 564 & 17.6 \\
\hline & 2009 & 22661 & 2304 & 10.2 & 3452 & 666 & 19.3 \\
\hline & 2010 & 23276 & 2218 & 9.5 & 3720 & 584 & 15.7 \\
\hline & 2011 & 25339 & 2126 & 8.4 & 3834 & 588 & 15.3 \\
\hline & 2012 & 32018 & 2645 & 8.3 & 4586 & 718 & 15.7 \\
\hline & 2013 & 32907 & 2661 & 8.1 & 4855 & 696 & 14.3 \\
\hline & 2014 & 30776 & 2398 & 7.8 & 4627 & 603 & 13.0 \\
\hline \multirow[t]{7}{*}{ Post-ICU mortality } & 2008 & 20935 & 1134 & 5.4 & 3210 & 421 & 13.1 \\
\hline & 2009 & 22661 & 1133 & 5.0 & 3452 & 459 & 13.3 \\
\hline & 2010 & 23276 & 1121 & 4.8 & 3720 & 483 & 13.0 \\
\hline & 2011 & 25339 & 1031 & 4.1 & 3834 & 408 & 10.6 \\
\hline & 2012 & 32018 & 1203 & 3.8 & 4586 & 431 & 9.4 \\
\hline & 2013 & 32907 & 1034 & 3.1 & 4855 & 415 & 8.5 \\
\hline & 2014 & 30776 & 946 & 3.1 & 4627 & 369 & 8.0 \\
\hline \multirow[t]{7}{*}{ In-hospital mortality } & 2008 & 20935 & 3308 & 15.8 & 3210 & 985 & 30.7 \\
\hline & 2009 & 22661 & 3437 & 15.2 & 3452 & 1125 & 32.6 \\
\hline & 2010 & 23276 & 3339 & 14.3 & 3720 & 1067 & 28.7 \\
\hline & 2011 & 25339 & 3157 & 12.5 & 3834 & 996 & 26.0 \\
\hline & 2012 & 32018 & 3848 & 12.0 & 4586 & 1149 & 25.1 \\
\hline & 2013 & 32907 & 3695 & 11.2 & 4855 & 1111 & 22.9 \\
\hline & 2014 & 30776 & 3344 & 10.9 & 4627 & 972 & 21.0 \\
\hline \multirow[t]{7}{*}{ 3-month mortality } & 2008 & 20935 & 3995 & 19.1 & 3210 & 1187 & 37.0 \\
\hline & 2009 & 22661 & 4198 & 18.5 & 3452 & 1357 & 39.3 \\
\hline & 2010 & 23276 & 4180 & 18.0 & 3720 & 1361 & 36.6 \\
\hline & 2011 & 19955 & 3160 & 15.8 & 3027 & 1006 & 33.2 \\
\hline & 2012 & 32018 & 5007 & 15.6 & 4586 & 1531 & 33.4 \\
\hline & 2013 & 32907 & 4847 & 14.7 & 4855 & 1525 & 31.4 \\
\hline & 2014 & 30776 & 4423 & 14.4 & 4627 & 1392 & 30.1 \\
\hline \multirow[t]{7}{*}{ 6-month mortality } & 2008 & 20935 & 4519 & 21.6 & 3210 & 1336 & 41.6 \\
\hline & 2009 & 22661 & 4740 & 20.9 & 3452 & 1506 & 43.6 \\
\hline & 2010 & 23276 & 4816 & 20.7 & 3720 & 1530 & 41.1 \\
\hline & 2011 & 13525 & 2485 & 18.4 & 2003 & 751 & 37.5 \\
\hline & 2012 & 32018 & 5736 & 17.9 & 4586 & 1713 & 37.4 \\
\hline & 2013 & 32907 & 5523 & 16.8 & 4855 & 1725 & 35.5 \\
\hline & 2014 & 30776 & 5164 & 16.8 & 4627 & 1574 & 34.0 \\
\hline \multirow[t]{6}{*}{ 1-year mortality } & 2008 & 20935 & 5237 & 25.0 & 3210 & 1476 & 46.0 \\
\hline & 2009 & 22661 & 5626 & 24.8 & 3452 & 1679 & 48.6 \\
\hline & 2010 & 23207 & 5653 & 24.4 & 3707 & 1692 & 45.6 \\
\hline & 2012 & 32018 & 6773 & 21.2 & 4586 & 1935 & 42.2 \\
\hline & 2013 & 32324 & 6451 & 20.0 & 4763 & 1910 & 40.1 \\
\hline & 2014 & 22635 & 4572 & 20.2 & 3349 & 1342 & 40.1 \\
\hline
\end{tabular}

Table S2. ICU, post-ICU, in-hospital, 3-month, 6-month and 1-year mortality of medical admissions.

\begin{tabular}{|c|c|c|c|c|c|c|c|}
\hline & \multirow[b]{3}{*}{ Year } & \multicolumn{3}{|c|}{ Patients $<80$ years } & \multicolumn{3}{|c|}{ Patients $\geq 80$ years } \\
\hline & & \multicolumn{3}{|c|}{ Mortality } & & \multicolumn{2}{|c|}{ Mortality } \\
\hline & & Total & $\mathbf{N}$ & $\%$ & Total & $\mathbf{N}$ & $\%$ \\
\hline \multirow[t]{7}{*}{ ICU mortality } & 2008 & 9332 & 1599 & 17.1 & 1406 & 362 & 25.7 \\
\hline & 2009 & 10327 & 1746 & 16.9 & 1639 & 420 & 25.6 \\
\hline & 2010 & 11036 & 1682 & 15.2 & 1763 & 392 & 22.2 \\
\hline & 2011 & 10551 & 1602 & 15.2 & 1689 & 413 & 24.5 \\
\hline & 2012 & 13504 & 2071 & 15.3 & 2156 & 521 & 24.2 \\
\hline & 2013 & 14639 & 2109 & 14.4 & 2329 & 517 & 22.2 \\
\hline & 2014 & 14364 & 1916 & 13.3 & 2329 & 449 & 19.3 \\
\hline \multirow[t]{7}{*}{ Post-ICU mortality } & 2008 & 9332 & 737 & 7.9 & 1406 & 215 & 15.3 \\
\hline & 2009 & 10327 & 725 & 7.0 & 1639 & 255 & 15.6 \\
\hline & 2010 & 11036 & 716 & 6.5 & 1763 & 276 & 15.7 \\
\hline & 2011 & 10551 & 637 & 6.0 & 1689 & 241 & 14.3 \\
\hline & 2012 & 13504 & 823 & 6.1 & 2156 & 266 & 12.3 \\
\hline & 2013 & 14639 & 698 & 4.8 & 2329 & 268 & 11.5 \\
\hline & 2014 & 14364 & 671 & 4.7 & 2329 & 248 & 10.6 \\
\hline \multirow[t]{7}{*}{ In-hospital mortality } & 2008 & 9332 & 2336 & 25.0 & 1406 & 577 & 41.0 \\
\hline & 2009 & 10327 & 2471 & 23.9 & 1639 & 675 & 41.2 \\
\hline & 2010 & 11036 & 2398 & 21.7 & 1763 & 668 & 37.9 \\
\hline & 2011 & 10551 & 2239 & 21.2 & 1689 & 654 & 38.7 \\
\hline & 2012 & 13504 & 2894 & 21.4 & 2156 & 787 & 36.5 \\
\hline & 2013 & 14639 & 2807 & 19.2 & 2329 & 785 & 33.7 \\
\hline & 2014 & 14364 & 2587 & 18.0 & 2329 & 697 & 29.9 \\
\hline \multirow[t]{7}{*}{ 3-month mortality } & 2008 & 9332 & 2742 & 29.4 & 1406 & 661 & 47.0 \\
\hline & 2009 & 10327 & 2955 & 28.6 & 1639 & 814 & 49.7 \\
\hline & 2010 & 11036 & 2926 & 26.5 & 1763 & 820 & 46.5 \\
\hline & 2011 & 8380 & 190 & 26.1 & 1339 & 643 & 48.0 \\
\hline & 2012 & 13504 & 3649 & 27.0 & 2156 & 1008 & 46.8 \\
\hline & 2013 & 14639 & 3588 & 24.5 & 2329 & 1048 & 45.0 \\
\hline & 2014 & 14364 & 3319 & 23.1 & 2329 & 965 & 41.4 \\
\hline \multirow[t]{7}{*}{ 6-month mortality } & 2008 & 9332 & 3007 & 32.2 & 1406 & 729 & 51.8 \\
\hline & 2009 & 10327 & 3218 & 31.2 & 1639 & 891 & 54.4 \\
\hline & 2010 & 11036 & 3256 & 29.5 & 1763 & 918 & 52.1 \\
\hline & 2011 & 5714 & 1660 & 29.1 & 903 & 481 & 53.3 \\
\hline & 2012 & 13504 & 4022 & 29.8 & 2156 & 1098 & 50.9 \\
\hline & 2013 & 14639 & 3952 & 27.0 & 2329 & 1150 & 49.4 \\
\hline & 2014 & 14364 & 3734 & 26.0 & 2329 & 1064 & 45.7 \\
\hline \multirow[t]{6}{*}{ 1-year mortality } & 2008 & 9332 & 3314 & 35.5 & 1406 & 789 & 56.1 \\
\hline & 2009 & 10327 & 3597 & 34.8 & 1639 & 980 & 59.8 \\
\hline & 2010 & 11003 & 3621 & 32.9 & 1758 & 1003 & 57.1 \\
\hline & 2012 & 13504 & 4486 & 33.2 & 2156 & 1203 & 55.8 \\
\hline & 2013 & 14467 & 4388 & 30.3 & 2295 & 1240 & 54.0 \\
\hline & 2014 & 10507 & 3136 & 29.8 & 1676 & 856 & 51.1 \\
\hline
\end{tabular}


Table S3. ICU-, post-ICU, in-hospital, 3-month, 6-months and 1-year mortality of surgical admissions (both planned and emergency surgery).

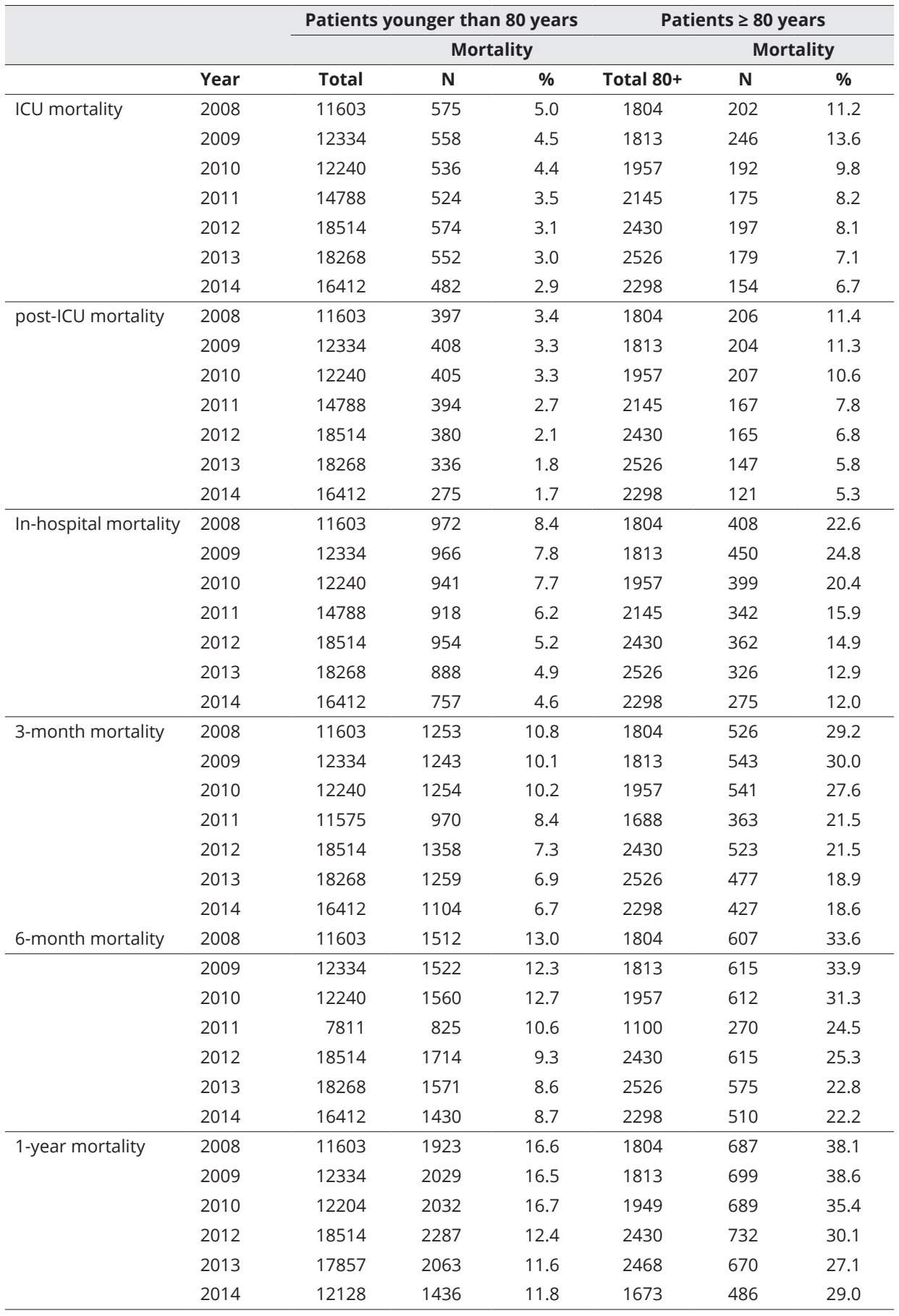

Table 54. Patients characteristics of excluded patients.

\begin{tabular}{|c|c|c|c|c|c|c|}
\hline & \multicolumn{2}{|c|}{$\begin{array}{l}\text { Excluded due to } \\
\text { patients' data inclusion } \\
\text { criteria }\end{array}$} & \multicolumn{2}{|c|}{$\begin{array}{l}\text { Excluded due to } \\
\text { admitted to a hospital } \\
\text { with less than } 10 \\
\text { admissions* }\end{array}$} & \multicolumn{2}{|c|}{$\begin{array}{l}\text { Excluded due to no } \\
\text { match in Vektis } \\
\text { database }\end{array}$} \\
\hline & $80-$ & $80+$ & $80-$ & $80+$ & 80- & $80+$ \\
\hline Total & 57,543 & 8,284 & 173,419 & 30,739 & 24,315 & 2,836 \\
\hline $\begin{array}{l}\text { Male } \\
(\%)\end{array}$ & 39.7 & 46.8 & 40.7 & 51.3 & 34.6 & 49.4 \\
\hline $\begin{array}{l}\text { Diabetes } \\
(\%)\end{array}$ & 11.5 & 14.0 & 16.2 & 18.5 & 14.3 & 16.9 \\
\hline $\begin{array}{l}\text { Chronic renal failure } \\
(\%)\end{array}$ & 5.7 & 7.7 & 5.1 & 9.5 & 3.4 & 5.5 \\
\hline $\begin{array}{l}\text { Chronic respiratory } \\
\text { failure (\%) }\end{array}$ & 13.8 & 17.6 & 17.7 & 20.3 & 11.3 & 15.2 \\
\hline $\begin{array}{l}\text { Cardiac insufficiency } \\
(\%)\end{array}$ & 4.6 & 7.3 & 6.5 & 10.7 & 10.5 & 11.4 \\
\hline $\begin{array}{l}\text { Immunodeficiency } \\
(\%)\end{array}$ & 6.9 & 4.0 & 8.6 & 5.2 & 4.0 & 3.1 \\
\hline $\begin{array}{l}\text { Malignancy } \\
(\%)\end{array}$ & 5.1 & 3.9 & 6.7 & 5.3 & 3.6 & 3.6 \\
\hline $\begin{array}{l}\text { Medical admission } \\
(\%)\end{array}$ & 66.2 & 63.9 & 42.5 & 43.6 & 30.0 & 33.7 \\
\hline $\begin{array}{l}\text { Emergency surgery } \\
\text { admission (\%) }\end{array}$ & 17.4 & 20.4 & 13.2 & 20.5 & 11.2 & 15.0 \\
\hline $\begin{array}{l}\text { Planned surgery } \\
\text { admission (\%) }\end{array}$ & 11.4 & 11.4 & 29.7 & 27.8 & 17.0 & 12.4 \\
\hline $\begin{array}{l}\text { Cardiac surgery } \\
\text { admission (\%) }\end{array}$ & 5.0 & 4.2 & 14.7 & 8.2 & 41.8 & 38.9 \\
\hline $\begin{array}{l}\text { APACHE III score, } \\
\text { without age points }\end{array}$ & $33(19-63)$ & $84(48-120)$ & $35(24-53)$ & $43(30-61)$ & $35(24-52)$ & $42(30-59)$ \\
\hline ICU length of stay & $0.9(0.3-3.2)$ & $1.0(0.2-3.1)$ & $1.0(0.8-2.7)$ & $1.1(0.8-2.8)$ & $0.9(0.7-1.9)$ & $1.0(0.7-2.0)$ \\
\hline Hospital length of stay & $23(10-46)$ & $21(11-36)$ & $9(5-16)$ & $10(6-18)$ & $8(5-14)$ & $9(6-17)$ \\
\hline
\end{tabular}

* fewer than 10 ICU deaths and 10 ICU survivors attributable to the very elderly or fewer than 10 ICU death and 10 ICU survivors attributable to younger patients in any calendar year between 2008 and 2014. 
Table 55. Patients characteristics of patients that were lost to follow-up.

\begin{tabular}{|c|c|c|c|c|c|c|}
\hline & \multicolumn{2}{|c|}{$\begin{array}{l}\text { Excluded for } 3 \\
\text { months long-term } \\
\text { outcome }\end{array}$} & \multicolumn{2}{|c|}{$\begin{array}{l}\text { Excluded for } 6 \\
\text { months long-term } \\
\text { outcome }\end{array}$} & \multicolumn{2}{|c|}{$\begin{array}{l}\text { Excluded for } 12 \\
\text { months } \\
\text { long- term outcome }\end{array}$} \\
\hline & $80-$ & $80+$ & 80- & $80+$ & 80- & $80+$ \\
\hline Total & 5384 & 807 & 11814 & 1831 & 34132 & 5217 \\
\hline $\begin{array}{l}\text { Male } \\
(\%)\end{array}$ & 38.6 & 48.0 & 37.5 & 48.4 & 38.4 & 48.1 \\
\hline $\begin{array}{l}\text { Diabetes } \\
(\%)\end{array}$ & 16.7 & 18.7 & 16.2 & 20.3 & 16.1 & 19.9 \\
\hline $\begin{array}{l}\text { Chronic renal failure } \\
\text { (\%) }\end{array}$ & 4.5 & 8.3 & 4.4 & 8.2 & 4.5 & 8.6 \\
\hline $\begin{array}{l}\text { Chronic respiratory failure } \\
(\%)\end{array}$ & 14.4 & 15.5 & 14.3 & 16.4 & 14.8 & 17.5 \\
\hline $\begin{array}{l}\text { Cardiac insufficiency } \\
(\%)\end{array}$ & 6.3 & 8.1 & 5.6 & 8.8 & 5.3 & 8.5 \\
\hline $\begin{array}{l}\text { Immunodeficiency } \\
(\%)\end{array}$ & 6.4 & 3.7 & 6.2 & 4.9 & 6.6 & 4.3 \\
\hline $\begin{array}{l}\text { Malignancy } \\
(\%)\end{array}$ & 6.4 & 5.0 & 6.3 & 4.0 & 6.0 & 3.8 \\
\hline $\begin{array}{l}\text { Medical admission } \\
\text { (\%) }\end{array}$ & 40.3 & 43.4 & 40.9 & 42.9 & 42.8 & 45.6 \\
\hline $\begin{array}{l}\text { Emergency surgery } \\
\text { admission (\%) }\end{array}$ & 12.8 & 18.7 & 12.3 & 17.6 & 11.3 & 15.8 \\
\hline $\begin{array}{l}\text { Planned surgery admission } \\
\text { (\%) }\end{array}$ & 23.4 & 20.1 & 23.5 & 19.6 & 22.9 & 19.0 \\
\hline $\begin{array}{l}\text { Cardiac surgery admission } \\
(\%)\end{array}$ & 23.5 & 17.8 & 23.3 & 19.9 & 23.1 & 19.6 \\
\hline \multicolumn{7}{|l|}{ APACHE III score } \\
\hline with age points & $50(36-70)$ & $67(53-88)$ & $50(36-70)$ & $67(53-87)$ & $50(36-70)$ & $66(53-85)$ \\
\hline without age points & 39 (27-59) & $48(34-69)$ & $39(27-59)$ & $47(34-67)$ & 39 (27-59) & $47(33-65)$ \\
\hline ICU length of stay & $1.0(0.8-3.0)$ & $1.2(0.8-3.4)$ & $1.0(0.8-3.0)$ & $1.2(0.8-3.1)$ & $1.1(0.8-3.0)$ & $1.2(0.8-3.1)$ \\
\hline Hospital length of stay & $9(6-17)$ & $11(6-19)$ & $9(5-17)$ & $11(6-19)$ & $9(5-17)$ & $10(6-19)$ \\
\hline
\end{tabular}

Table 56. Number of excluded patients per inclusion criteria per year.

\begin{tabular}{|c|c|c|c|c|c|c|c|}
\hline & 2008 & 2009 & 2010 & 2011 & 2012 & 2013 & 2014 \\
\hline $\begin{array}{l}\text { Excluded due to patients' } \\
\text { data inclusion criteria }\end{array}$ & $\begin{array}{l}7,375 \\
(13.2 \%)\end{array}$ & $\begin{array}{l}9,265 \\
(13.1 \%)\end{array}$ & $\begin{array}{l}9,516 \\
(12.6 \%)\end{array}$ & $\begin{array}{l}9,678 \\
(12.3 \%)\end{array}$ & $\begin{array}{l}9,687 \\
(11.7 \%)\end{array}$ & $\begin{array}{l}9,716 \\
(11.4 \%)\end{array}$ & $\begin{array}{l}10,590 \\
(11.7 \%)\end{array}$ \\
\hline $\begin{array}{l}\text { Excluded due to admitted } \\
\text { to a hospital with }<10 \\
\text { admissions }\end{array}$ & $\begin{array}{l}16,229 \\
(33.6 \%)\end{array}$ & $\begin{array}{l}25,631 \\
(41.8 \%)\end{array}$ & $\begin{array}{l}28,009 \\
(42.5 \%)\end{array}$ & $\begin{array}{l}30,548 \\
(44.4 \%)\end{array}$ & $\begin{array}{l}32,263 \\
(44.3 \%)\end{array}$ & $\begin{array}{l}34,133 \\
(45.4 \%)\end{array}$ & $\begin{array}{l}37,345 \\
(46.6 \%)\end{array}$ \\
\hline $\begin{array}{l}\text { Excluded due to no match } \\
\text { with Vektis }\end{array}$ & $\begin{array}{l}7,942 \\
(24.8 \%)\end{array}$ & $\begin{array}{l}9,589 \\
(26.9 \%)\end{array}$ & $\begin{array}{l}10,825 \\
(28.6 \%)\end{array}$ & $\begin{array}{l}9,143 \\
(23.9 \%)\end{array}$ & $\begin{array}{l}3,896 \\
(9.6 \%)\end{array}$ & $\begin{array}{l}3,275 \\
(8.0 \%)\end{array}$ & $\begin{array}{l}7,346 \\
(17.2 \%)\end{array}$ \\
\hline $\begin{array}{l}\text { Excluded for } 3 \text { months } \\
\text { long-term outcome }\end{array}$ & 0 & 0 & 0 & $\begin{array}{l}6,191 \\
(21.2 \%)\end{array}$ & 0 & 0 & 0 \\
\hline $\begin{array}{l}\text { Excluded for } 6 \text { months } \\
\text { long-term outcome }\end{array}$ & 0 & 0 & 0 & $\begin{array}{l}13,645 \\
(47.8 \%)\end{array}$ & 0 & 0 & 0 \\
\hline $\begin{array}{l}\text { Excluded for } 12 \text { months } \\
\text { long-term outcome }\end{array}$ & 0 & 0 & $\begin{array}{l}82 \\
(0.3 \%)\end{array}$ & $\begin{array}{l}29,173 \\
(100 \%)\end{array}$ & 0 & $\begin{array}{l}675 \\
(1.8 \%)\end{array}$ & $\begin{array}{l}9,419 \\
(26.6 \%)\end{array}$ \\
\hline
\end{tabular}




\section{CHAPTER 4}

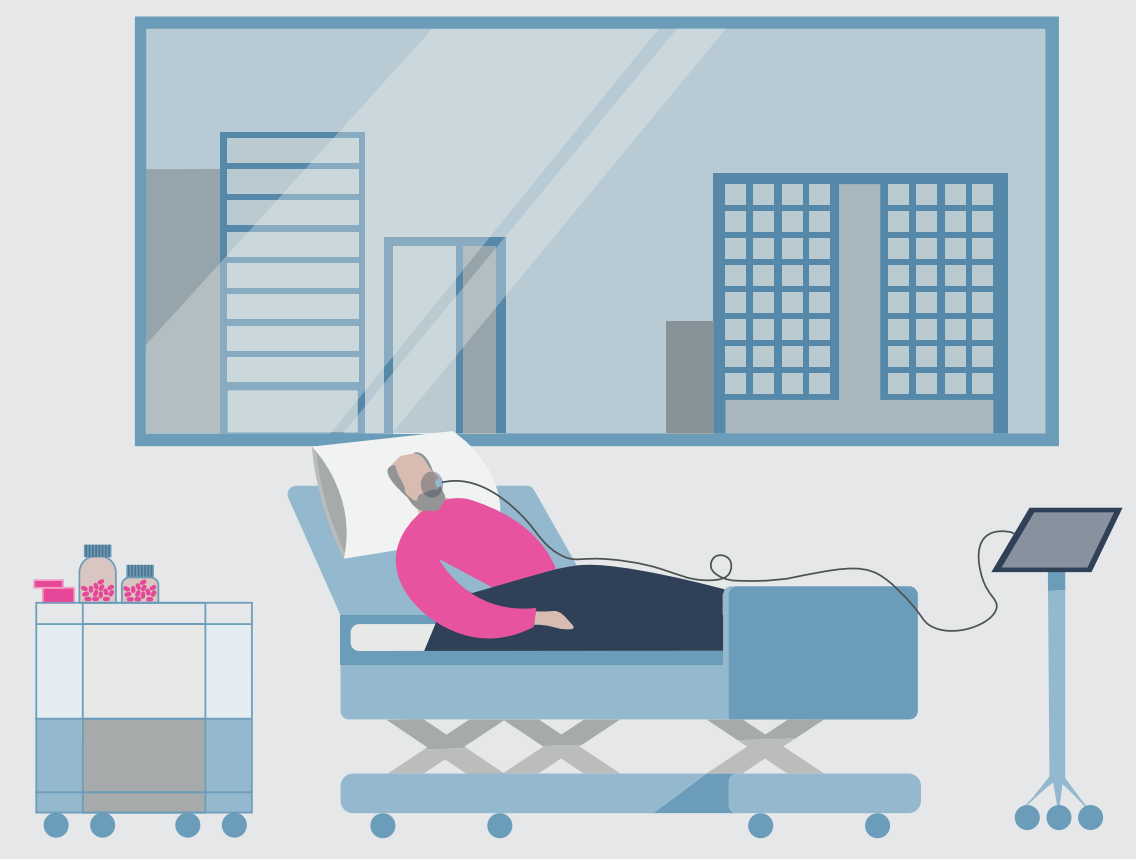

Outcomes of intensive care patients over 90 years old, a 11-year national observational study

Published in: Journal of the American Geriatrics Society 2020 


\section{Abstract}

\section{Background}

Many intensive care unit (ICU) physicians are reluctant to admit patients aged 90 years and older, although evidence to support these decisions is scarce. Despite the body of evidence on outcomes of patients aged 80 years and older is growing, this does not count for patients aged 90 years and older.

The aim of this study is to compare the short- and long-term mortality of ICU patients aged 90 years and older in the Netherlands to ICU patients aged 80 to 90 years, i.e. octogenarians.

\section{Design}

Multicenter, national cohort study over a 11-year period (2008-2018), using data of the National Intensive Care Evaluation (NICE) registry and the Dutch insurance claims registry.

\section{Setting}

All 82 ICUs in the Netherlands.

\section{Participants}

All patients aged 80 years and older at the time of ICU admission.

\section{Measurements and Main Results}

A total of 104,754 patients 80 years and older, of whom 9,495 (9\%) aged 90 years and older, were admitted to Dutch ICUs during the study period. ICU mortality of the patients aged 90 years and older was lower $(13.8 \%$ vs. $16.1 \% ; p<0.001)$ and hospital mortality was similar ( $26.1 \%$ vs. $25.7 \%$; $p=0.41$ ) compared to octogenarians. After 3 months mortality was higher for the patients aged 90 years and older (43.1\% vs. $33.7 \%$; $p<0.001)$ and after one-year mortality was $55.0 \%$ vs. $42.7 \%, p<0.001$.

\section{Conclusions}

In the Netherlands, mortality rates of patients aged 90 years and older admitted to the ICU are not as disappointing as often assumed. They have a lower ICU mortality and a similar hospital mortality compared to octogenarians. Nevertheless, their longer-term mortality is higher compared to octogenarians. However, almost 3 out of 4 leave the hospital alive and almost half of the patients aged 90 years and older are still alive 1 year after their ICU admission.

\section{Introduction}

Worldwide, the number of persons aged 90 years and older rose from less than 7 million in 1995 to more than 12 million in 2010 and is expected to exceed 76 million in 2050.[1] In the Netherlands, their proportion might triple in the upcoming decade. [2] As a consequence, patients aged 90 years and older compose an expanding subgroup in the hospitals and on the intensive care units (ICUs) (Supplementary Figure S1a and S1b).[2-4].

In the last decade, multiple studies were published about older ICU patients (defined as $\geq 80$ years; often called very elderly ICU patients, abbreviated as VIPs).[5] It has been demonstrated that these patients are responsible for a substantial proportion of hospital and ICU admission days, that their mortality risk is high and when they survive, they more often suffer from functional decline and long-term sequelae.[6-9] However despite the body of evidence on outcomes of patients aged 80 years and older is growing, this does not count for patients aged 90 years and older. Outcome data of patients aged 90 years and older admitted to the ICU are relatively scarce. In the future, intensivists will probably be confronted more often with the question whether admission of these patients to the ICU is beneficial.

Although age is an important prognostic factor, other factors like frailty and illness severity are more important.[10-12] However, many ICU physicians use age as a triage criterion and many seem reluctant to admit patients aged 90 years and older.[13] More insight into the outcomes of these patients is needed to support decisions about ICU treatment of patients aged 90 years and older.

Therefore, the aim of this study is to compare the short- and long-term mortality of ICU patients aged 90 years and older in the Netherlands with ICU patients aged 80 to 90 years.

\section{Methods}

\section{Study design, setting and participants}

We performed a retrospective cohort study, including all patients from the Dutch quality registry database for ICUs (the Dutch National Intensive Care Evaluation (NICE) registry), aged 80 years and older at the time of ICU admission, from January 1, 2008 to December 31, 2018. We compared the outcomes of the patients aged 90 years and older with the patients aged 80 to 90 years old (i.e. octogenarians). Additionally, we analyzed differences in outcomes based on sex. 


\section{Data sources}

Data were extracted from two different sources: 1) the national ICU quality registry and 2) the Dutch insurance claims database.

The Dutch National Intensive Care Evaluation (NICE) registry is a national quality registry in which currently all 82 Dutch ICUs participate.[14] Participating hospitals prospectively collect and upload, among others, demographic, physiological and clinical data of all admitted patients, including variables required to quantify the severity of illness (acute physiology score (APS) and acute physiology and chronic health evaluation based on APACHE IV model and the ICU and in-hospital mortality of all patients admitted to their ICUs.[15] The number of comorbidities was calculated based on the presence of one or more of following conditions at ICU admission, i.e. chronic renal insufficiency, chronic dialysis, neoplasm, hematological malignancy, aids, cirrhosis. cardiovascular insufficiency, respiratory insufficiency, immunological insufficiency, diabetes, and chronic obstructive pulmonary disease.[14]

Long term mortality, that is, 3-months and 12-months mortality, was derived from the Dutch insurance claims database (the Vektis database).[16] The Vektis databases contain reimbursement data on all medical treatments paid for by Dutch insurance companies, as well as demographic information, such as gender, date of birth, and date of death, for all registered residents of the Netherlands. Health insurance is obligatory for all Dutch citizens (coverage over 99\%). All ICU patients with an ICU admission in 2017 were followed up for 12 months to calculate 3-month and 12-month mortality.

\section{Variables}

The primary outcome of this study was the short-term mortality after ICU admission (i.e. ICU and hospital mortality). Secondary outcomes were the long-term mortality rates, that is, 3-month and 1-year mortality and the length of stay (LOS).

\section{Quantitative variables and statistical analysis}

Categorical variables are presented as percentages, and continuous variables are presented as mean and SD or as median and interquartile range (IQR) depending on the data distribution.

Baseline patient characteristics and outcomes were compared between the two patient groups (ICU patients aged $80-90$ years vs. $\geq 90$ years). We used chi-square tests for comparisons of categorical variables and independent t-test or Mann-Whitney $\mathrm{U}$ test to assess differences for continuous variables. The crude overall long-term (1-year) survival was estimated using Kaplan-Meier method. A p-value of less than 0.05 was considered to indicate statistical significance.

All statistical analyses were performed using IBM SPSS statistics, version 25 and R Statistical Environment, version 3.6.3.

\section{Ethics}

The NICE registry and Vektis are registered according to the Dutch Personal Data Protection Act. The need for ethical approval for this study was waived by the Medical Ethics Committee of the Academic Medical Center and stored under number 20_043.

\section{Results}

A total of 104,754 patients aged 80 years and older admitted to Dutch ICUs during the study period were included, including 9,495 patients aged 90 years and older (9\%) Patient characteristics are shown in Table 1 and Supplementary Table S1.

The patients aged 90 years and older admitted to the ICU had a significantly lower ICU mortality $(13.8 \%$ vs. $16.1 \%, p<0.001)$ and a similar hospital mortality $(26.1 \%$ vs. $25.7 \%, p=$ 0.41) compared to the octogenarians admitted to the ICU (Figure 1). After 3 months, mortality was higher for the ICU patients aged 90 years and older compared with the octogenarians admitted to the ICU ( $43.1 \%$ vs. $33.7 \%$; $p<0.001)$. Mortality after one year was $55.0 \%$ vs. $42.7 \%, p<0.001$ (Table 1, Figure 2 , and supplementary Table S3 and Figure S4 and S5). ICU- and hospital mortality rates were higher for the male patients compared to female patients, in both age groups in our cohort (Supplementary Table S2 and Figure S6).
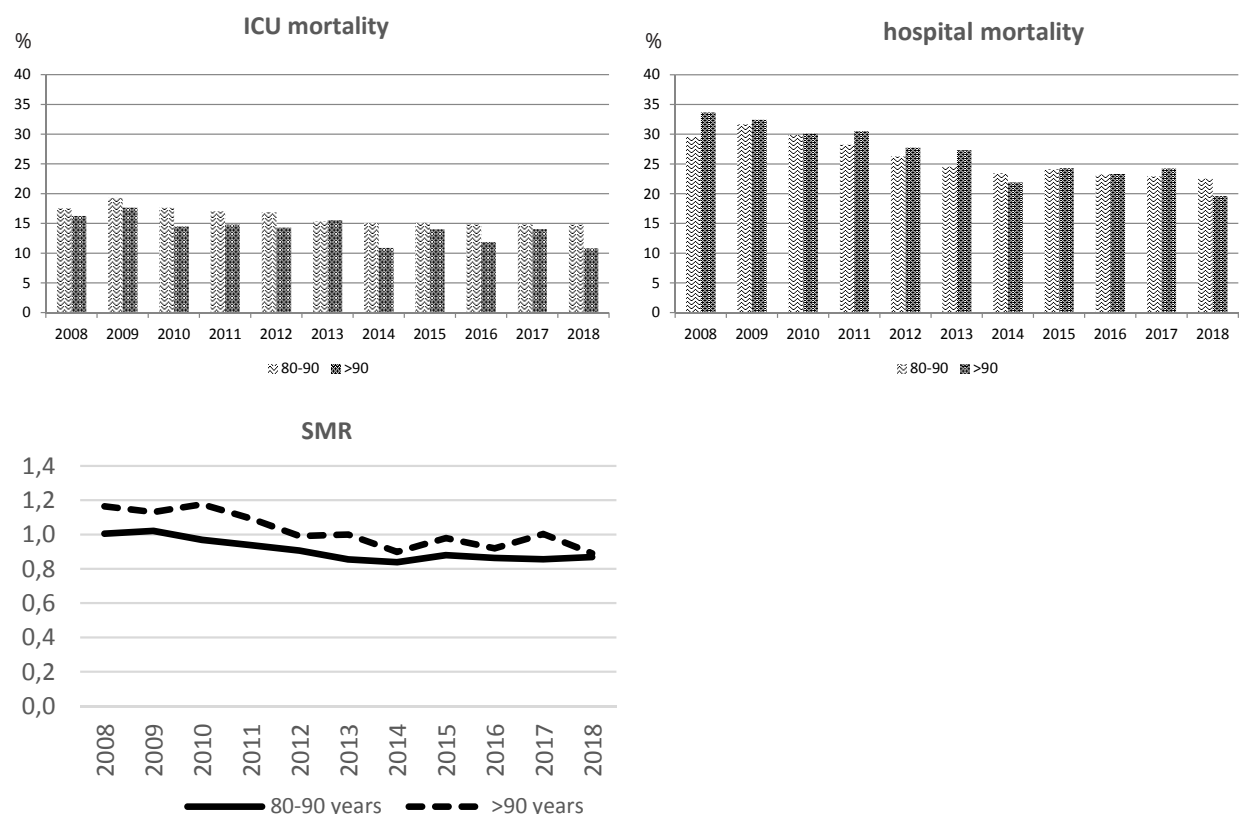

Figure 1. ICU- and hospital mortality and Standardized Mortality Ratio (SMR) of patients aged 90 years and older in comparison to patients aged 80 to 90 years, admitted to Dutch ICUs in the period 2008-2018. 
The LOS of the patients aged 90 years and older was significantly shorter than the LOS of the octogenarians, both in the ICU as in the hospital (LOS in the ICU was $0.90(0.56$ 1.89) days for the ICU patients 90 years and older, compared with $1.2(0.74-3.0)$ days for the octogenarians $(p<0.001)$; LOS in the hospital was 9.0 (5.0-15.0) days for the patients aged 90 years and older and 11.0 (5.4-19.0) days for the octogenarians $(p<0.001)$, Supplementary Table S1).

Table 1. Case-mix and outcomes of patients aged $\geq 90$ years vs patients aged 80 to 90 years admitted to Dutch ICUs, 2008 to 2018 [NICE data].

\begin{tabular}{|c|c|c|c|}
\hline & $80-90$ years & $\geq 90$ years & p-value \\
\hline Number (N) & 95259 & 9495 & \\
\hline Male (\%) & $52.2 \%$ & $36.9 \%$ & $<0.001$ \\
\hline Type of admission (\%) & & & $<0.001$ \\
\hline Medical & $55.6 \%$ & $45.0 \%$ & \\
\hline Elective surgery & $18.0 \%$ & $27.2 \%$ & \\
\hline Emergency surgery & $23.2 \%$ & $23.7 \%$ & \\
\hline \multicolumn{4}{|l|}{ Subgroups $(\%)$} \\
\hline Trauma & $6.0 \%$ & $17.8 \%$ & $<0.001$ \\
\hline OHCA & $2.9 \%$ & $2.9 \%$ & 0.026 \\
\hline Sepsis & $6.3 \%$ & $6.3 \%$ & $<0.001$ \\
\hline First admission (\%) & $93.5 \%$ & $96.9 \%$ & $<0.001$ \\
\hline \multicolumn{4}{|l|}{ Severity of illness (median (IQR)) } \\
\hline APACHE IV & $65(49-86)$ & $65(50-83)$ & NS \\
\hline APACHE IV APS & $45(30-65)$ & $41(26-59)$ & $<0,001$ \\
\hline Severity of illness (\%) & & & $<0.001$ \\
\hline Low mortality risk & $63.9 \%$ & $68.6 \%$ & \\
\hline Intermediate risk & $24.1 \%$ & $22.0 \%$ & \\
\hline High mortality risk & $12.0 \%$ & $9.4 \%$ & \\
\hline Number of comorbidities (\%) & & & $<0.001$ \\
\hline 0 & $54.4 \%$ & $66.1 \%$ & \\
\hline 1 & $28.9 \%$ & $24.3 \%$ & \\
\hline$\geq 2$ & $16.7 \%$ & $9.5 \%$ & \\
\hline Mechanical ventilation (N/\%) & $36.6 \%$ & $23.8 \%$ & $<0.001$ \\
\hline LOS-ICU (days; median (IQR)) & $1.2(0.74-3.0)$ & $0.90(0.56-1.89)$ & $<0.001$ \\
\hline LOS-Hospital (days; median (IQR)) & $11.0(5.4-19.0)$ & $9.0(5.0-15.0)$ & $<0.001$ \\
\hline ICU Mortality (\%) & $16.1 \%$ & $13.8 \%$ & $<0.001$ \\
\hline Hospital Mortality (\%) & $25.7 \%$ & $26.1 \%$ & 0.209 \\
\hline 3-months Mortality $(\%)^{\star \star}$ & $33.7 \%$ & $43.1 \%$ & $<0.001$ \\
\hline 1-year mortality $(\%)^{\star *}$ & $42.7 \%$ & $55.0 \%$ & $<0.001$ \\
\hline
\end{tabular}

** ICU patients admitted in 2017 were followed up for 12 months.
The patients aged 90 years and older admitted to the ICU had a greater proportion patients in the low mortality risk group, a smaller proportion on mechanical ventilation, a greater proportion admitted after elective surgery and smaller proportion admitted because of a medical reason, compared with octogenarians. The severity of disease as expressed by the APACHE IV score was comparable between the two age groups (65 (50-83) vs. 65 (49-86), NS) (Supplementary Figure S2a). However, since the APACHE IV score includes age, with more points with increasing age, we also compared the APACHE IV APS Score (Supplementary Figure S2b).

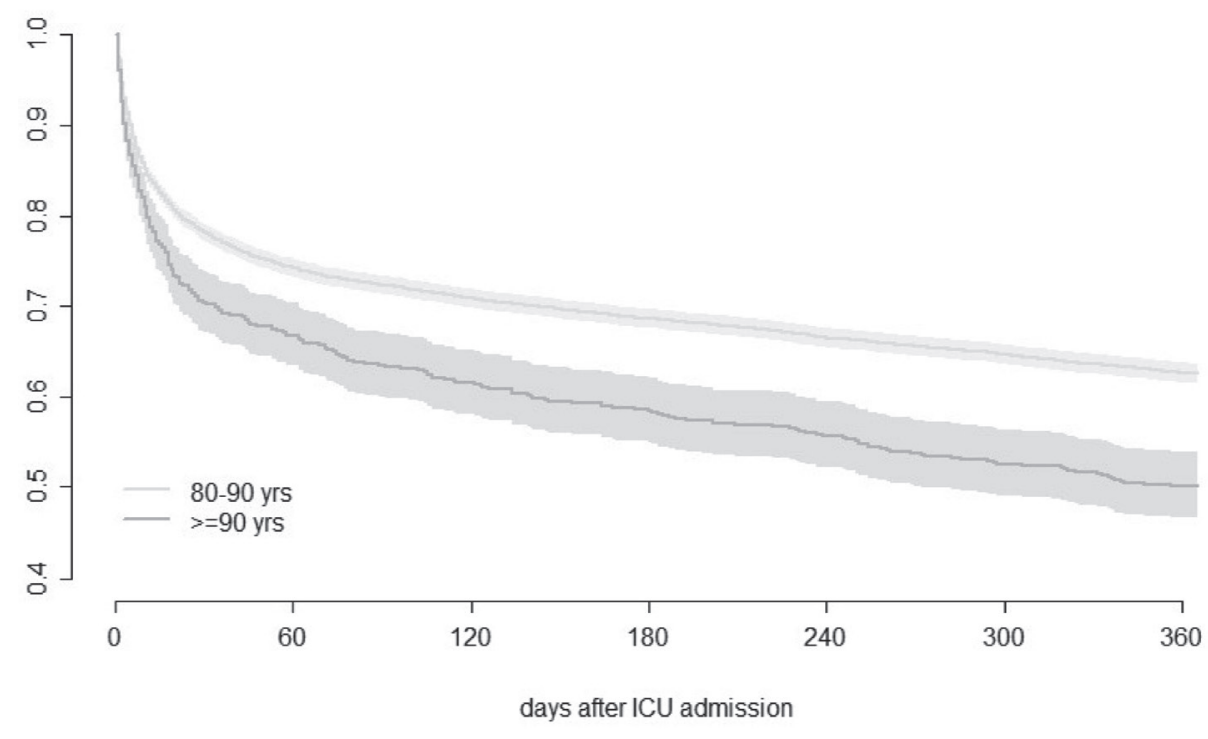

Figure 2. Kaplan-Meier curve of patients aged 90 years and older compared to patients aged 80 to 90 years, admitted to Dutch ICUs in the period 2008-2018.

\section{Discussion}

In this cohort study, we compared the short- and long-term mortality of ICU patients aged 90 years and older to ICU patients aged 80 to 90 years.

Although long-term mortality was higher for patients aged 90 years and older admitted to the ICU, our study showed a significantly lower ICU mortality and similar hospital mortality, compared to octogenarians admitted to the ICU. This is a surprising finding and we have three possible explanations. First, it could be the result of more strict triage. Because ICU physicians can be more reluctant to admit patients aged 90 years and older, the patients aged 90 years and older who were admitted to the ICU, are 
likely to be the 'better' (e.g. fitter patients, less frail, with fewer comorbidities, with lower severity of illness, activities of daily living independent etc.). Unfortunately, we were not able to include cognitive and functional status or frailty scores in our study. Specific factors related to older adults, such as frailty, are far more predictive of mortality than age per se.[10-12] Frailty is one of the most important prognostic factors in older adults and should be taken into account when evaluating outcomes in this population. The patients aged 90 years and older admitted to the ICU indeed had fewer comorbidities and seemed to be less ill, as demonstrated by the comparable APACHE IV and lower APACHE IV APS scores. Second, it might be a result of some natural selection, the "survival of the fittest", with people who survive life beyond the age of 90 years representing a selection of stronger persons.[17] Third, the lower ICU mortality of the patients aged 90 years and older could be due to earlier ICU discharge, with subsequent dying on the general ward, because we see that the in-hospital mortality was similar in both age groups. A fourth explanation could be the larger proportion of women within the nonagenarians, because both ICU and hospital survival were higher for the female patients compared with male patients (Table S2 and Figure S6).

Mortality of the patients aged 80 years and older is comparable with previous studies. $[4,10,11,18,19]$ However, studies on patients aged 90 years and older admitted to the ICU are scarce, and comparison is difficult, because of differences in case mix and time period. Reported ICU and hospital mortality rates of patients aged 90 years and older admitted to the ICU range between $9.5 \%$ and $35.7 \%$ and $27.1 \%$ and $50.0 \%$ respectively (Supplementary Table S4 and Fig. S3).[3,4,20-25] The hospital and long-term mortality of the patients aged 90 years and older is more than twice as high as that of younger patients admitted to Dutch ICUs in the last decade (ICU- and hospital mortality $10.3 \%$ and $12.9 \%, 3$-month and 1 -year mortality $17.7 \%$ and $23.9 \%$ ).[26]

The strength of our study is that it includes a very large multicenter cohort of patients aged 90 years and older admitted to ICUs in the last decade. To the best of our knowledge, it is the largest cohort of patients aged 90 years and older admitted to ICUs thus far. Other studies including ICU patients aged 90 years and older were single center studies and/or substantially older, whereas outcomes may have improved last years due to medical progress.

Our study has limitations as well. First, we only studied the patients who were admitted to the ICU and unfortunately, we were not able to compare these patients with the patients who were refused to be admitted to the ICU. Second, as mentioned previously, frailty is unfortunately not registered in the NICE database. Including frailty is important in outcome studies concerning older ICU patients, since it is one of the key drivers of poor outcome and more predictive of mortality than age. Although we were not able to include frailty scores, we included comorbidities which contribute to and correlate with frailty.[10-12] Third, we have no information about decisions to limit life support. It has been demonstrated that older patients receive lower treatment intensity than younger patients, also after adjustment for severity of illness.[27] In addition, life support is more often withdrawn in the older ICU patients. Fourth, we have no information about functional recovery, quality of life $(\mathrm{Q} o \mathrm{~L})$ or to return home. These outcomes might be even more important than survival information.

An important reason to refuse ICU admission of patients aged 90 years and older is the perceived higher risk of mortality. However, our data suggest that short-term outcome of these patients is not that worse, especially if compared to octogenarians. Long-term mortality rates are higher, but this could partly also be explained by a shorter average life expectancy of this population (less than 4 years for someone of 90 years old compared to more than 8 years for someone of 80 years old).[28] Patients aged 90 years and older might also benefit from ICU admission and these patients should also have the possibility to be admitted to ICUs. It is not fair and viable to refuse ICU admission to patients simply because they are aged 90 years and older. However, old patients have in common that their life expectancy is limited and the risk of functional decline higher. The balance between potential benefits and burden of treatment is often more negative than in younger patients. The patients do not always prefer life-extending treatment over care focused on preserving functional capacity or relieving pain and discomfort. Therefore, ICU admission should always be preceded by a careful triage process in which benefit and harm are carefully weighed and should be proceeded only after an open discussion with the patient and relatives about risk factors, expected outcomes, treatment goals, personal values and patients' preferences. $[29,30]$ Involvement of a geriatrician could help in this triage process.

In conclusion, in the Netherlands, mortality rates of patients aged 90 years and older admitted to the ICU are not as disappointing as often assumed. They have a lower ICU mortality and a similar hospital mortality compared to octogenarians. Nevertheless, their longer-term mortality is higher compared to octogenarians. However, almost 3 out of 4 of the patients aged 90 years and older admitted to Dutch ICUs survived the hospital and almost one-half of the patients are still alive 1 year after ICU admission. 


\section{References}

1. population un esa. population.un.org; esa.un.org. Accessed November 9, 2019,

2. CBS Statline. https://opendata.cbs.nl/statline/\#/CBS/nl. Accessed April 29, 2019,

3. Le Borgne P, Maestraggi Q, Couraud $S$, et al. Critically ill elderly patients (>/=90 years): Clinica characteristics, outcome and financial implications. PLoS One. 2018;13(6):e0198360. doi:10.1371/journal. pone. 0198360

4. Bagshaw SM, Webb SA, Delaney A, et al. Very old patients admitted to intensive care in Australia and New Zealand: a multi-centre cohort analysis. Crit Care. 2009;13(2):R45. doi:10.1186/cc7768 [doi]

5. Flaatten $\mathrm{H}$, de Lange DW, Artigas A, et al. The status of intensive care medicine research and a future agenda for very old patients in the ICU. Intensive Care Med. February 2017. doi:10.1007/s00134-017. 4718-z

6. Chin-Yee N, D'Egidio G, Thavorn K, Heyland D, Kyeremanteng K. Cost analysis of the very elderly admitted to intensive care units. Crit Care. 2017;21(1):109-017-1689-y. doi:10.1186/s13054-017-1689-y [doi]

7. Sacanella E, Perez-Castejon JM, Nicolas JM, et al. Functional status and quality of life 12 months after discharge from a medical ICU in healthy elderly patients: a prospective observational study. Crit Care. ai:10.1186/cc10121

8. Tabah A, Philippart F, Timsit JF, et al. Quality of life in patients aged 80 or over after ICU discharge. Crit Care. 2010;14(1):R2. doi:10.1186/cc8231 [doi]

9. Villa P, Pintado MC, Luján J, et al. Functional Status and Quality of Life in Elderly Intensive Care Unit Survivors. J Am Geriatr Soc. 2016;64(3). doi:10.1111/jgs.14031

10. Flaatten $\mathrm{H}$, De Lange DW, Morandi A, et al. The impact of frailty on ICU and 30-day mortality and the level of care in very elderly patients ( $\geq 80$ years). Intensive Care Med. 2017;43(12):1820-1828. doi:10.1007/

11. Guidet B, de Lange DW, Boumendil A, et al. The contribution of frailty, cognition, activity of daily life and comorbidities on outcome in acutely admitted patients over 80 years in European ICUs: the VIP2 study. Comorbidities on outcome in acutely admitted patients over 80 years
Intensive Care Med. 2020;46(1):57-69. doi:10.1007/s00134-019-05853-1

12. Pietiläinen L, Hästbacka J, Bäcklund M, Parviainen I, Pettilä V, Reinikainen M. Premorbid functional status as a predictor of 1 -year mortality and functional status in intensive care patients aged 80 years or older. Intensive Care Med. 2018;44(8):1221-1229. doi:10.1007/s00134-018-5273-y

13. Docherty AB, Anderson NH, Walsh TS, Lone NI. Equity of Access to Critical Care Among Elderly Patients in Scotland: A National Cohort Study. Crit Care Med. 2016;44(1):3-13. doi:10.1097/CCM.0000000000001377 [doi]

14. van de Klundert N, Holman R, Dongelmans DA, de Keizer NF. Data Resource Profile: the Dutch National Intensive Care Evaluation (NICE) Registry of Admissions to Adult Intensive Care Units. Int J Epidemiol. 2015;44(6):1850-1850h. doi:10.1093/ije/dyv291 [doi]

15. Zimmerman JE, Kramer AA, McNair DS, Malila FM. Acute Physiology and Chronic Health Evaluation (APACHE) IV. hospital mortality assessment for today's critically ili patients. Crit Care Med. 2006;34(5):12971310. doi:10.1097/01.CCM.0000215112.84523.Fo [doi]

16. Vektis. http://www.vektis.nl.

17. C. D. The origin of species. In: Fifth Edit. United Kingdom: John Murray; 1869.
18. Nielsson MS, Christiansen CF, Johansen MB, Rasmussen BS, Tonnesen E, Norgaard M. Mortality in elderly ICU patients: a cohort study. Acta Anaesthesiol Scand. 2014;58(1):19-26. doi:10.1111/aas.12211 [doi]

19. Karakus A, Haas LEM, Brinkman S, de Lange DW, de Keizer NF. Trends in short-term and 1-year mortality in very elderly intensive care patients in the Netherlands. a retrospective study from 2008 to 2014 Intensive Care Med. 2017;43(10):1476-1484. doi:10.1007/s00134-017-4879-9

20. Becker S, Muller J, de Heer G, Braune S, Fuhrmann V, Kluge S. Clinical characteristics and outcome of very elderly patients $>=90$ years in intensive care: a retrospective observational study. Ann Intensive Care.

21. Demoule A, Cracco $C$ L Lefort $Y$, Ray $P$, Derenne J-P. Similowski T. Patients aged 90 years or older in the intensive care unit. / Gerontol A Biol Sci Med Sci. 2005;60(1):129-132. doi:10.1093/gerona/60.1.129

22. Oeyen $S$, Vermassen J, Piers R, Benoit D, Annemans $L$, Decruyenaere J. Critically ill octogenarians and nonagenarians: evaluation of long-term outcomes, posthosp 2017:83(6):598-609. doi:10.23736/503759393.16.11434-8

23. Ouchi K, Jambaulikar GD, Hohmann S, et al. Prognosis After Emergency Department Intubation to Inform Shared Decision-Making. J Am Geriatr Soc. 2018;66(7):1377-1381. doi:10.1111/jgs.15361

24. Rellos K, Falagas ME, Vardakas KZ, Sermaides G, Michalopoulos A. Outcome of critically ill oldest-old patients (aged 90 and older) admitted to the intensive care unit. J Am Geriatr Soc. 2006;54(1):110-114. doi:10.1111/j.1532-5415.2005.00544.x

25. Sim YS, Jung H, Shin TR, Kim DG, Park SM. Mortality and outcomes in very elderly patients 90 years of age or older admitted to the ICU. Respir Care. 2015;60(3):347-355. doi:10.4187/respcare.03155

26. Haas LEM, Kerckhoffs MC, Bakhshi-Raiez F, Emmelot-Vonk MH, De Lange DW. The admission of very old patients to our intensive care units: a review. Netherlands J Crit Care. 2020

27. Boumendil A, Aegerter P, Guidet B, Network C-R. Treatment intensity and outcome of patients aged 80 and older in intensive care units: a multicenter matched cohort study. J Am Geriatr Soc. 2005:53(1):88-93. doi:JGS53016 [pii]

28. Volksgezondheid https://www.volksgezondheidenzorg.info/onderwerp/levensverwachting/cijfers-context/ huidige-situatie\#node-resterende-levensverwachting.

29. Philippart F, Vesin A, Bruel C, et al. The ETHICA study (part I): elderly's thoughts about intensive care unit dist 013-2976-y

30. De Jonge E, Mooijaart SP. Framework to decide on withholding intensive care in older patients. Netherlands Crit Care. 2019;27:150-4. 


\section{Supplement}

Table S1. Additional information about the length of stay (LOS) of patients aged 90 years and older in comparison to patients aged 80 to 90 years admitted to Dutch ICUs in the period 2008 to 2018 [NICE data].

\begin{tabular}{lll}
\hline & $\begin{array}{l}\mathbf{8 0 - 9 0} \text { years } \\
(\mathbf{N}=95,259)\end{array}$ & $\begin{array}{l}\mathbf{2 9 0} \text { years } \\
(\mathbf{N}=9,495)\end{array}$ \\
\hline LOS-ICU & & \\
$\%<3$ days & $74.7 \%$ & $86.8 \%$ \\
$\% 3$-7 days & $15.5 \%$ & $10.4 \%$ \\
$\%>7$ days & $9.8 \%$ & $2.8 \%$ \\
\hline LOS-Hospital & & \\
$\%<7$ days & $30.4 \%$ & $36.4 \%$ \\
$\% 7-14$ days & $30.1 \%$ & $33.9 \%$ \\
$\%>14$ days & $39.5 \%$ & $29.7 \%$ \\
\hline
\end{tabular}

Table S2. Outcomes of male and female patients aged 90 years and older in comparison to male and female patients aged 80 to 90 years admitted to Dutch ICUs in the period 2008 to 2018 [NICE data].

\begin{tabular}{lllllll}
\hline & \multicolumn{3}{l}{$\mathbf{8 0 - 9 0}$ years } & \multicolumn{3}{l}{$\mathbf{2 9 0}$ years } \\
\cline { 2 - 7 } & Male & Female & $\mathbf{p}$ & Male & Female & $\mathbf{p}$ \\
\hline ICU Mortality (\%) & $16.9 \%$ & $15.2 \%$ & $<0.001$ & $17.0 \%$ & $11.9 \%$ & $<0.001$ \\
Hospital Mortality (\%) & $27.2 \%$ & $24.1 \%$ & $<0.001$ & $31.5 \%$ & $23.0 \%$ & $<0.001$ \\
3-months Mortality (\%) & $35.1 \%$ & $32.1 \%$ & 0.003 & $46.5 \%$ & $40.9 \%$ & 0.069 \\
1-year mortality (\%)* & $44.8 \%$ & $40.1 \%$ & $<0.001$ & $57.7 \%$ & $53.2 \%$ & 0.122 \\
\hline
\end{tabular}

* ICU patients admitted in 2017 were followed up for 12 months.
Table S3. Outcomes of the subgroups of patients aged 90 years and older in comparison to patients aged 80 to 90 years admitted to Dutch ICUs in the period 2008 to 2018 [NICE data].

\begin{tabular}{lcc}
\hline & $\begin{array}{c}\mathbf{8 0 - 9 0} \text { years } \\
(\mathbf{N = 9 5 , 2 5 9 )}\end{array}$ & $\begin{array}{c}\mathbf{2 9 0} \text { years } \\
\mathbf{( N = 9 , 4 9 5 )}\end{array}$ \\
\hline ICU Mortality (\%) & & \\
Trauma & $8.2 \%$ & $6.5 \%$ \\
OHCA & $60.6 \%$ & $63.6 \%$ \\
Sepsis & $27.9 \%$ & $30.6 \%$ \\
Medical & $21.6 \%$ & $20.2 \%$ \\
Elective surgery & $16.5 \%$ & $12.0 \%$ \\
Emergency surgery & $3.4 \%$ & $4.3 \%$ \\
\hline Hospital Mortality (\%) & & \\
Trauma & $16.9 \%$ & $18.0 \%$ \\
OHCA & $68.8 \%$ & $72.5 \%$ \\
Sepsis & $39.3 \%$ & $45.5 \%$ \\
Medical & $33.1 \%$ & $33.8 \%$ \\
Elective surgery & $8.9 \%$ & $13.8 \%$ \\
Emergency surgery & $27.4 \%$ & $25.1 \%$ \\
\hline 3-months Mortality (\%)* & & \\
Trauma & $31.0 \%$ & $42.5 \%$ \\
OHCA & $66.8 \%$ & $76.0 \%$ \\
Sepsis & $44.0 \%$ & $56.1 \%$ \\
Medical & $40.1 \%$ & $46.6 \%$ \\
Elective surgery & $13.2 \%$ & $31.0 \%$ \\
Emergency surgery & $36.3 \%$ & $46.5 \%$ \\
\hline 1-year mortality (\%)* & & \\
Trauma & $39.6 \%$ & $53.9 \%$ \\
OHCA & $86.1 \%$ & $100.0 \%$ \\
Sepsis & $51.9 \%$ & $68.4 \%$ \\
Medical & $48.5 \%$ & $58.4 \%$ \\
Elective surgery & $25.3 \%$ & $45.3 \%$ \\
Emergency surgery & $43.4 \%$ & $56.1 \%$ \\
\hline
\end{tabular}

* ICU patients admitted in 2017 were followed up for 12 months. 


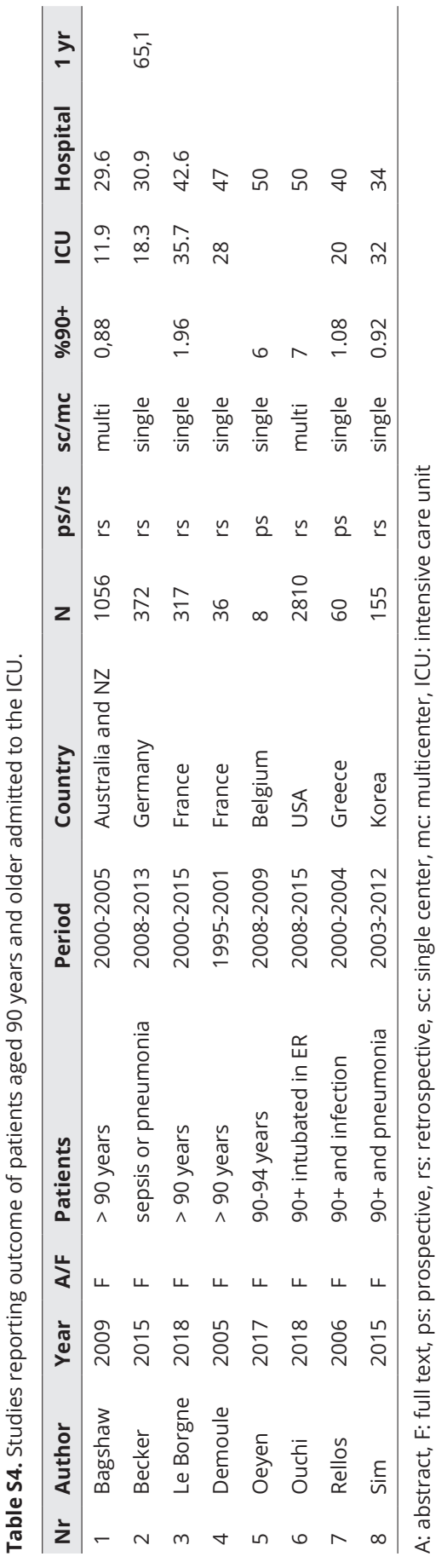

A. $\%$

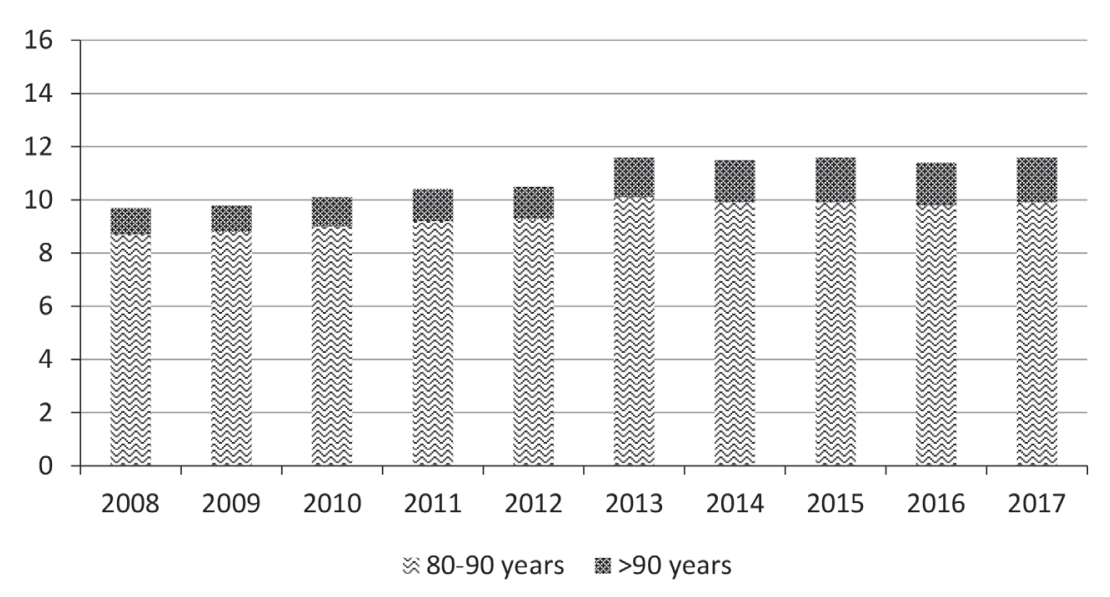

B. $\%$

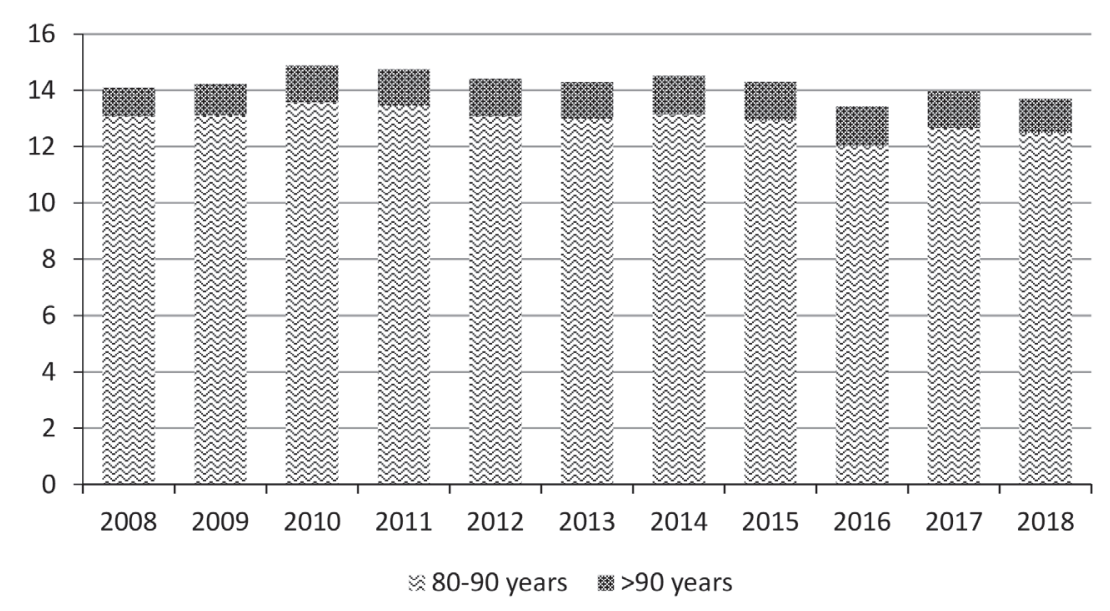

Agure S1. Trends in demographics of the Dutch hospltal and ICU populations,

A. Proportions of patients aged 80 to 90 years and patients aged 90 years and older admitted to Dutch hospitals in the perted age categories during this period (resp. 14\% for octogenarians and 63\% for patients aged 90 years and older) (CBS Statline).

B. Proportions of patients aged 80 to 90 years and patients aged 90 years and older admitted to Dutch ICUs in the period 2008-2018 (NICE registry). 
APACHE IV severity of illnes score

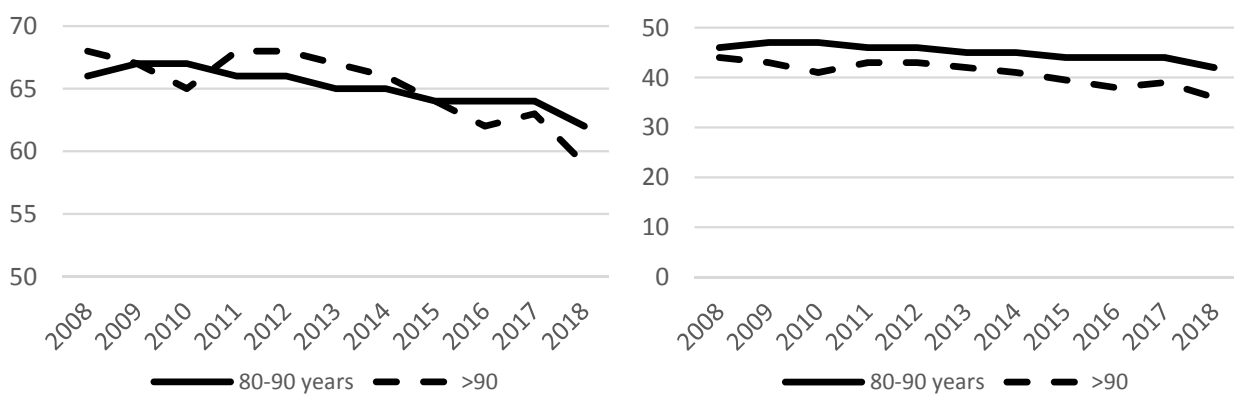

Figure S2. Disease severity as expressed by the APACHE IV and APACHE IV APS score of patients aged 90 years and older in comparison to patients aged 80 to 90 years, admitted to Dutch ICUs in the period 2008-2018.

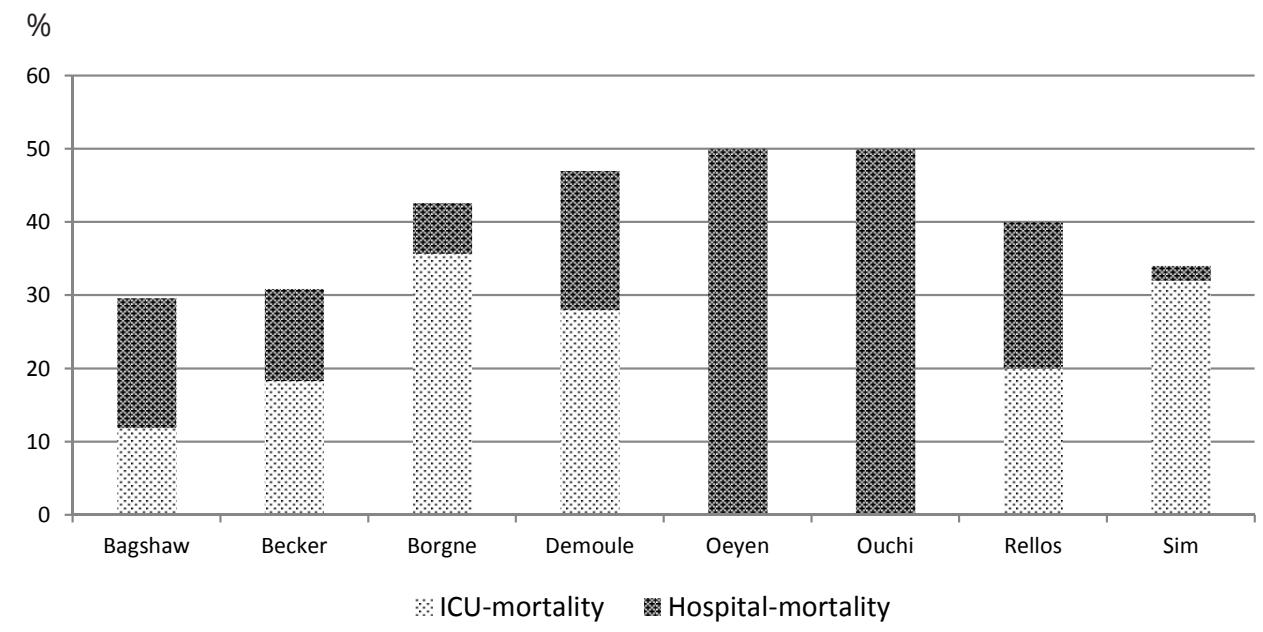

Figure S3. ICU- and hospital mortality in other studies including ICU patients aged 90 years and older.

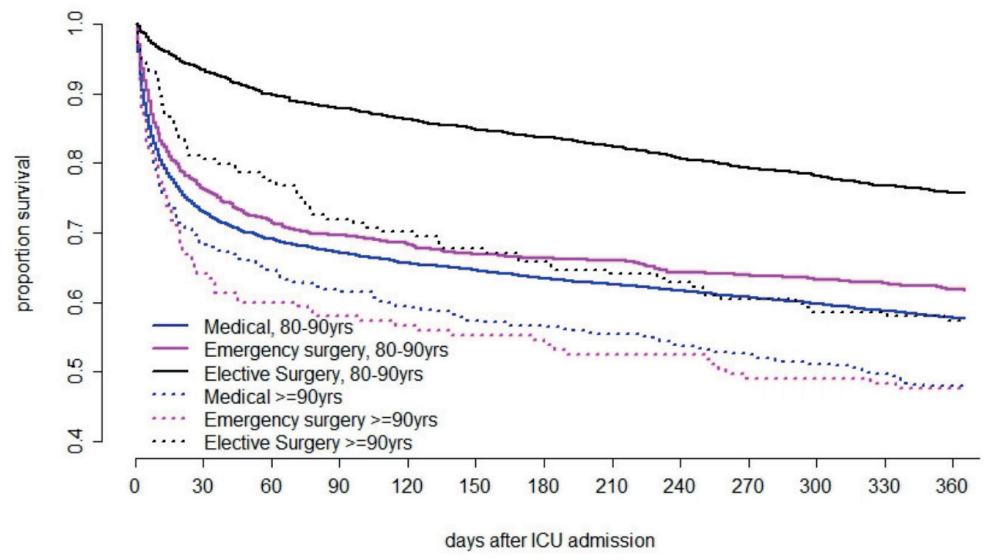

Figure S4. Kaplan-Meier curve per admission category

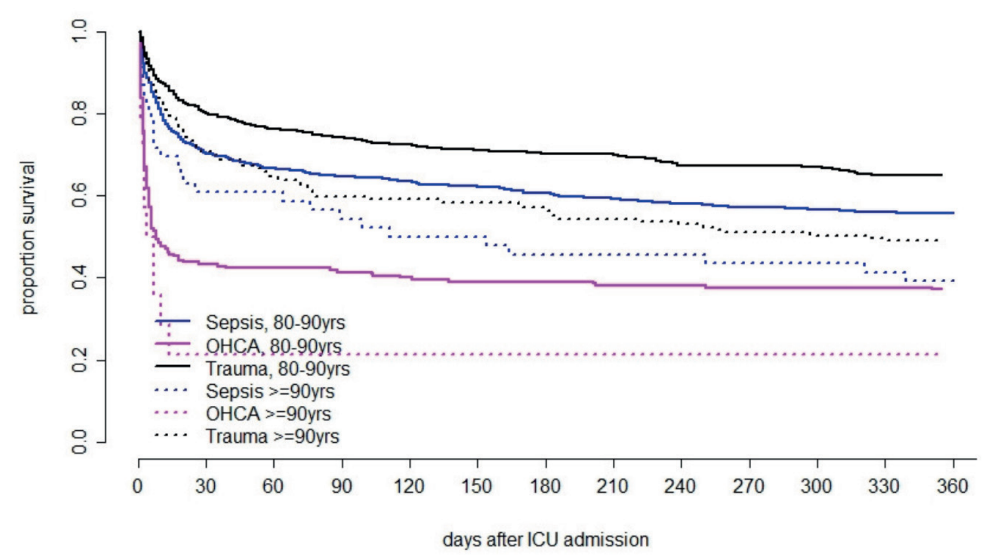

Figure 55. Kaplan-Meier curve per admission diagnosis.

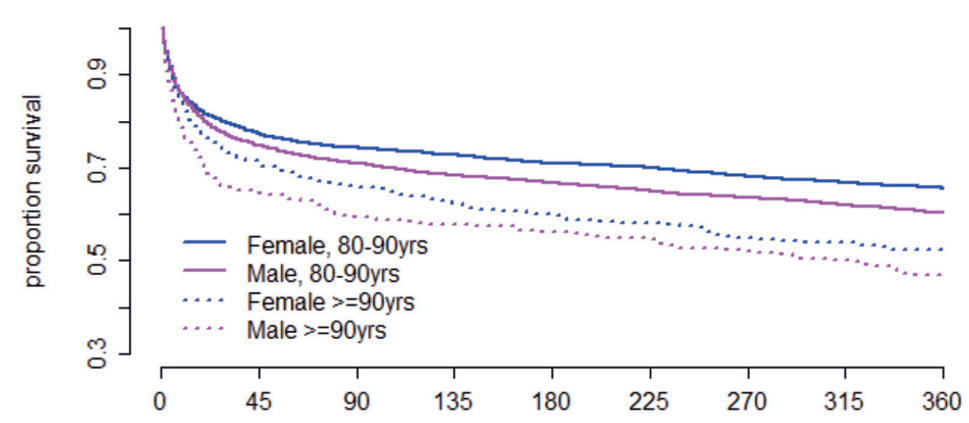

Figure S6. Kaplan-Meier curves by gender. 


\section{CHAPTER 5}

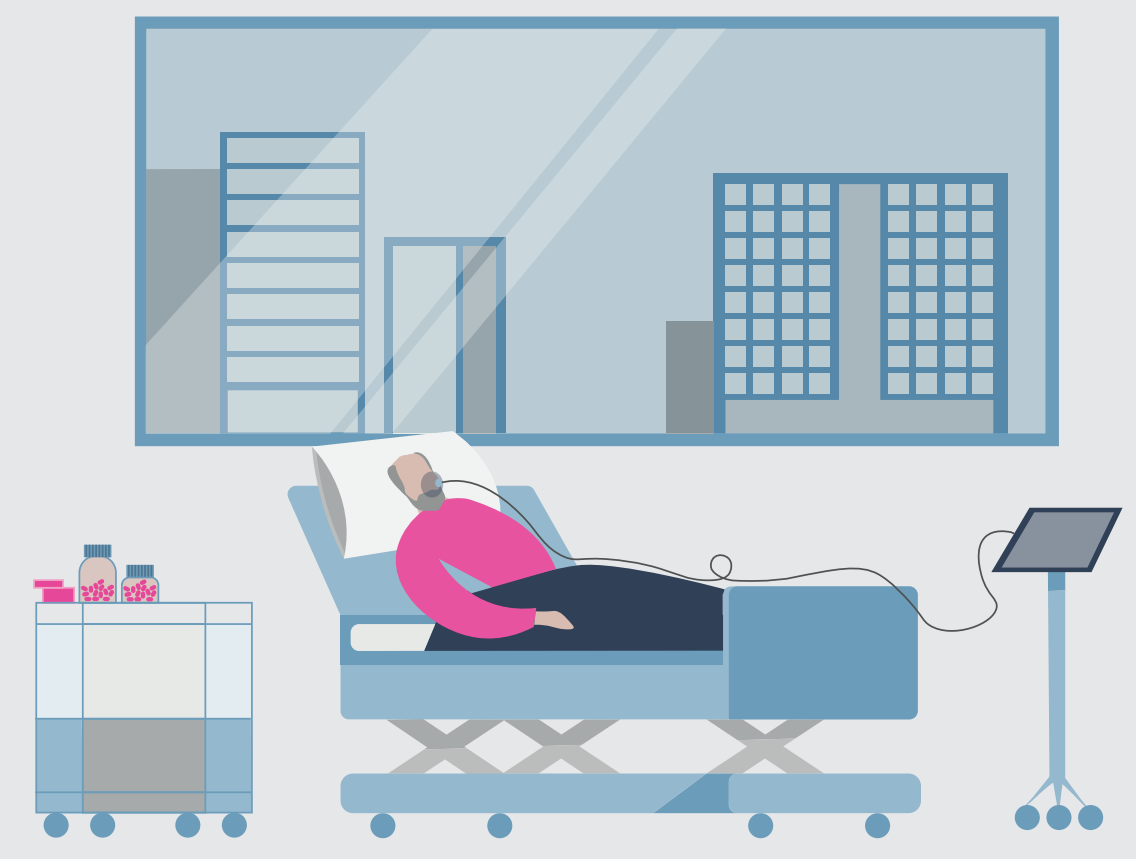

Healthcare-related costs in very elderly intensive care patients

Published in: Intensive Care Medicine 2018 


\section{Abstract}

\section{Introduction}

The long-term outcome of "very old intensive care unit patients" (VOPs; $\geq 80$ years) is often disappointing. Little is known about the healthcare costs of these VOPs in comparison to younger ICU patients and very elderly in the general population not admitted to the ICU.

\section{Methods}

Data from a national health insurance claims database and a national quality registry for ICUs were combined. Costs of VOPs admitted to the ICU in 2013 were compared with costs of younger ICU patients (two groups, respectively 18-65 and 65-80 years old) and a matched control group of very elderly subjects who were not admitted to the ICU. We compared median costs and median costs per day alive, in the year before ICU admission (2012), the year of ICU admission (2013) and the year after ICU admission (2014).

\section{Results}

9272 VOPs were included and compared to three equally sized study groups. Median costs for VOPs in 2012, 2013 and $2014(€ 5,944, € 35,653$ and $€ 12,565)$ are higher compared to the ICU 18-65 population ( $€ 3,022$, $€ 30,223$ and $€ 5,052$, all $p<0.001)$ and the very elderly control population ( $€ 3,590, € 4,238$ and $€ 4,723$, all $p<0.001$ ). Compared to the ICU 65-80 population, costs of VOPs are higher in the year before and after ICU admission $(€ 4,323$ and $€ 6,750$, both $p<0.001)$, but not in the year of ICU admission $(€ 34,448, p=0.9495)$. The median healthcare costs per day alive in the year before, the year of, and the year after ICU admission are all higher for VOPs than for the other groups $(p<0.001)$

\section{Conclusions}

VOPs required more health care resources in the year before, the year of and the year after ICU admission compared to younger ICU patients and the very elderly control population, except compared to the ICU 65-80 population in the year of ICU admission. Health care costs per day alive, however, are substantially higher for VOPs than for all other study groups in all three studied years.

\section{Introduction}

The intensive care unit (ICU) is one of the most expensive departments of a hospital consuming almost $15 \%$ of hospital budget and $1-2 \%$ of the gross domestic product (GDP) in Western countries [1-4]. After discharge, ICU survivors continue to consume significant healthcare resources [5]

"Very old intensive care unit patients" (VOPs; $\geq 80$ years old) are responsible for a substantial proportion of ICU admissions, and due to ageing of the general population, they are a rapidly expanding subgroup of ICU patients in most Western countries [6-9] Since both short- and long-term outcome of VOPs are worse than in younger patients $[7,10-15]$, the cost-effectiveness of ICU treatment in VOPs has been questioned. Although several studies about the outcome of ICU treatment of VOPs have been published in the last decade, little is known about the healthcare costs of VOPs in the period surrounding the ICU admission and how these costs compare to those of younger ICU patients or of very elderly not admitted to the ICU. Information about health care utilization among VOPs before, during and after ICU treatment in relation to outcome is relevant to ethical and political discussions and decision making in times of increasing healthcare costs.

The aim of this study is to describe the healthcare costs of VOPs in the year before, the year of, and the year after their ICU admission and compare them to younger ICU patients, and to a population-based control group of very elderly not treated in the ICU.

\section{Methods}

\section{Study design}

This is a retrospective cohort study, combining clinical data of the Dutch national quality registry for ICUs [16], with data from the Dutch insurance claims database [17].

\section{Data sources}

Dutch National Intensive Care Evaluation registry

The Dutch National Intensive Care Evaluation (NICE) registry [16] is a national quality registry in which currently all Dutch ICUs participate [18]. These ICUs collec demographic, physiologic, and clinical data of all admitted patients, including variables required to quantify the severity of illness (acute physiology score (APS) and acute physiology and chronic health evaluation (APACHE) III score [19]). APACHE III score is a covariate in the APACHE IV mortality prediction model [19]. 
Vektis insurance claims database

Health insurance is obligatory for all Dutch citizens. The Vektis databases [17] contain reimbursement data of essentially all (99\%) Dutch inhabitants on all medical treatments paid for by Dutch insurance companies, as well as demographic information for all registered inhabitants of the Netherlands, such as date of birth, gender and a proxy for date of death (health insurance unregister date) and socioeconomic status (SES). The SES is derived from the zip code of the person and the SES score for that zip code, as determined by the Netherlands Institute for Social Research [20]. The SES score is based on the mean income of a zip code area where a person lives, the fraction of people with a low income, the fraction of people with low education and the fraction of unemployed people. The SES score is ranked and the national mean is 0 (range -6.65; 3.02). A lower score indicates a lower SES and a higher score indicates a higher SES. Vektis also collects claims for pharmaceutical care. This information was used to determine chronic conditions (see Supplement Table S1).

\section{Patient selection}

For this study, all patients from the NICE registry aged $\geq 18$ years during the year of ICU admission, admitted to an ICU in 2013 and discharged from the hospital before January 1st 2014, were included. From the Vektis database, an ICU-subset and a control group were extracted. The ICU-subset included all patients who had a claim for one or more ICU days in the year 2013 and were 18 years or older during the year of ICU admission. Based on this Vektis ICU-subset, a population-based control group was created from all registered inhabitants of the Netherlands in the Vektis database. The control population, who had no claims for ICU care during the year 2013, was weighted on the combination of the variables age (in years), gender, and quartiles of SES. Only ICU patients with no missing items for gender, age and SES were used in the weighting process.

\section{Linking and matching processes}

To link cost data of the Vektis database to clinical data of the NICE database, records were linked anonymously using a deterministic linkage algorithm [21] and linked in three steps [22]. First, records were linked if gender, date of birth, hospital of admission, and both the date of ICU admission date and ICU discharge date were identical in both datasets. Records which could not be linked during the first step, proceeded to the second step. In the second step records were linked if gender, date of birth, hospital of admission and ICU admission date were identical. Records which could not be linked during the second step, proceeded to the third step. In the third step records were linked if, besides gender, date of birth and hospital of admission, the ICU discharge date was identical in both databases. Records which were not linked after the third step were excluded.

After linking the NICE database and the Vektis database, we created our four study populations; the VOPs, the ICU $18-65$, the ICU $65-80$ patients, and a very elderly population control group. All ICU patients $\geq 80$ years were included in the VOP population. This VOP population was matched 1:1 with very elderly control persons in the combined database based upon equal age, gender and quartile of SES. The VOP population was also matched 1:1 with ICU patients aged 18-65 years and ICU patients aged 65-80 years in the combined database. Matching for these two populations was done based upon equal gender and quartile of SES.

\section{Primary outcome}

Total healthcare costs were only available as a total sum in Euros per person per calendar year. The total healthcare costs are based on all reimbursement data available from health insurance companies and also include costs for long-term facilities and nursing homes. The primary outcome of this study is the median healthcare costs. We analysed costs of three years: (1) the year before ICU admission, defined as January 1st 2012 until December 31st 2012, (2) the year of ICU admission, defined as January 1st 2013 until December 31st 2013, and (3) the year after ICU admission, defined as January 1st 2014 until December 31st 2014. For the readability, we will use the term median healthcare costs in the year before, during and after ICU admission. We will also report the mean healthcare costs, as from a societal perspective, the mean costs enable to calculate a total burden for society.

\section{Secondary outcome}

The secondary outcome of this study is the median healthcare costs per day alive during the year before, the year of and the year after ICU admission. Costs per day alive are the total healthcare costs per patients per year divided by the number of days alive. The healthcare costs per day live are calculated for the total population, and for subgroups based on mortality, comorbidities, APACHE IV predicted mortality (i.e. lowrisk (predicted mortality $\geq 0 \%-30 \%$ ), medium-risk (predicted mortality $\geq 30 \%-70 \%$ ) and high risk (predicted mortality $\geq 70 \%$ ) [19]), gender, SES and admission category. Subgroup analyses were performed for survivors and non-survivors and we analyzed the patients who survived the 3-years study period separately to identify drivers for increased costs.

\section{Statistical analysis}

Descriptive statistics were used to characterize the demographic data. Mean and standard deviation (SD) were used for normally distributed data, median and inter- 
quartile ranges (IQR) for non-normally distributed data, numbers and proportions were used to present categorical data. The non-parametric Kruskal-Wallis test was used to test the differences in median healthcare costs and in median healthcare costs per day alive between the study groups.

General linear modelling was used to estimate the cohort effect on the healthcare costs during the year before, the year of and the year after ICU admission. The healthcare costs per patient were skewed to the right and therefore, the natural logarithm of the healthcare costs was used. Because of multiple comparisons a more stringent $p$-value of $<0.001$ was considered to indicate a statistically significant difference. All statistical analyses were performed in SAS software (version 7.1; SAS Institute Inc, Cary, NC).

\section{Results}

The NICE database contains 75690 ICU admissions in 2013, of which 10425 admissions of VOPs (13.8\%). When linked with the Vektis database, 71018 ICU (94\%) admissions of 65731 individual ICU patients remained, including 9749 admissions of 9272 individual VOPs. After 1:1 matching, all four study groups consisted of 9068 unique individuals, as we excluded 204 (2\%) patients that could not be matched. Figure 1 gives an overview of the data linkage and matching process.

The patient characteristics are shown in Table 1. The median APACHE III and APS (APACHE III score based on physiological disturbance, without reason for admission, age and comorbidities) scores of VOPs were higher than the scores of the younger ICU populations (all $\mathrm{p}<0.001$ ).

Hospital mortality rates of the VOPs, the ICU $18-65$ and the ICU $65-80$ population were $24.2 \%, 8.5 \%$ and $14.9 \%$ respectively ( $p<0.001$ ). Of the VOPs $35 \%$ died in 2013 and another $10 \%$ died in 2014 , versus $11 \%$ and $5 \%$ of the ICU $18-65,21 \%$ and $7 \%$ of the ICU 65-80 population and $8 \%$ in 2013 as well as in 2014 for the very elderly control population $(\mathrm{p}<0.001)$.

Median and mean healthcare costs are shown in Figure 2. Median costs per patient for VOPs in the year before, during and after ICU admission (€5,944, €35,653 and $€ 12,565)$ are higher than for the ICU $18-65$ population ( $€ 3,022$, $€ 30,223$ and $€ 5,052$, all $p<0.001)$ and the very elderly control population costs ( $€ 3,590, € 4,238$ and $€ 4,723$, all $\mathrm{p}<0.001$ ). Compared to the ICU 65-80 population, costs of VOPs are higher in the year before $(€ 5,944$ vs. $€ 4,323 p<0.001$ ) and the year after ICU admission ( $€ 12,565$ vs. $€ 6,750$, $p<0.001$ ), but comparable in the year of ICU admission ( $€ 35,653$ vs. $€ 34,448, p=0.95$ ). The median healthcare costs per day alive during the year before, the year of, and the

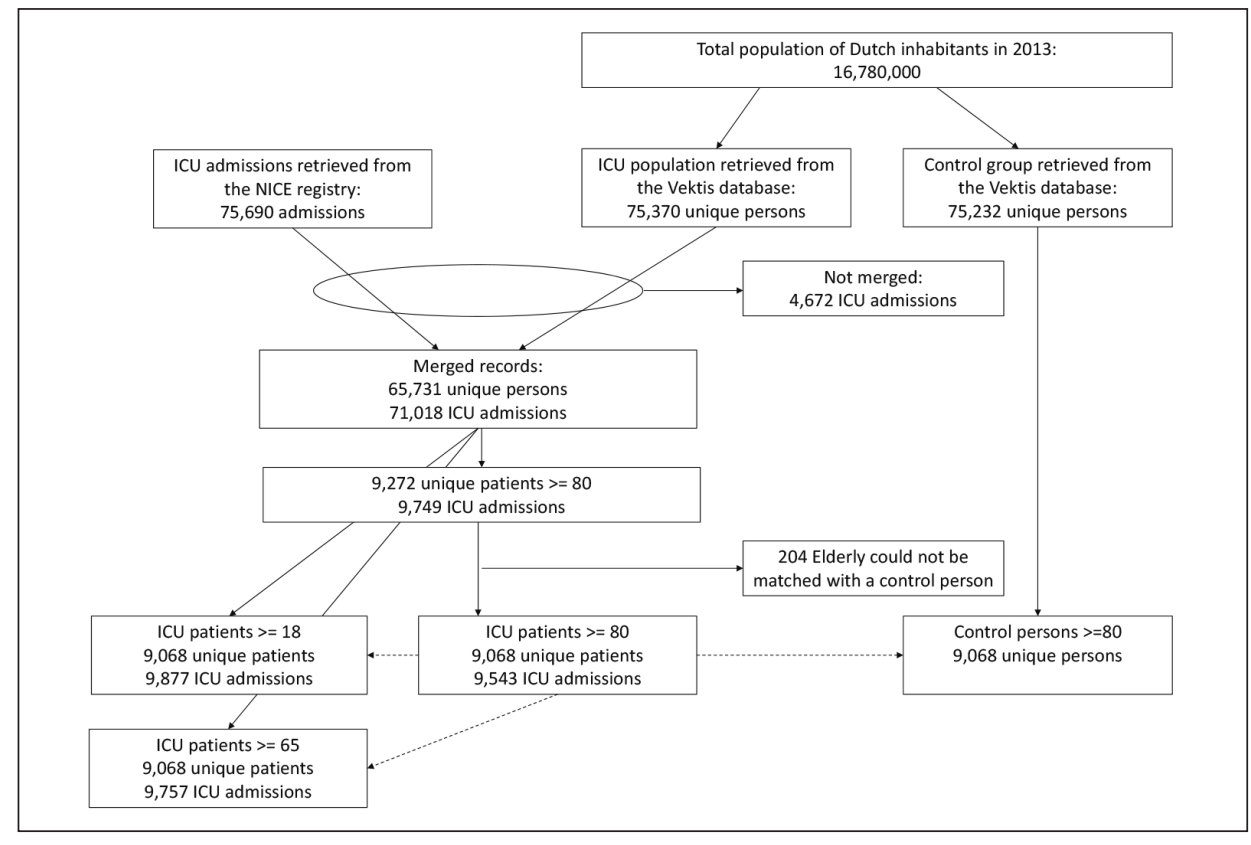

Figure 1. Overview of the data linkage process.

year after ICU admission are higher for VOPs than for all the other study groups $(p<0.001)$ (Figure 3).

Subgroup analyses are presented in detail in the Supplement (Figure S1-S7). VOPs have more chronic conditions in the year prior to admission and healthcare costs increase with increasing number of chronic conditions. During the year of ICU admission, healthcare costs are significantly higher for patients in the higher risk group based on APACHE IV mortality prediction, for female patients, patients with a lower SES and patients admitted because of emergency surgery. 
Table 1. Characteristics of the 4 populations during the year of ICU admission

\begin{tabular}{|c|c|c|c|c|}
\hline $\begin{array}{l}\text { Socio-demographic } \\
\text { characteristics }\end{array}$ & $\begin{array}{l}\text { VOPs } \\
(\mathrm{n}=9068)\end{array}$ & $\begin{array}{l}\text { ICU } 18-65 \\
(n=9068)\end{array}$ & $\begin{array}{l}\text { ICU 65-80 } \\
(\mathrm{n}=9068)\end{array}$ & $\begin{array}{l}\text { Control 80+ } \\
(n=9068)\end{array}$ \\
\hline Male $^{+}$ & $4709(52 \%)$ & 4709 (52\%) & 4709 (52\%) & 4709 (52\%) \\
\hline Age $^{\ddagger}$ & $83(81 ; 86)$ & $54(44 ; 60)$ & $72(68 ; 76)$ & $83(81 ; 86)$ \\
\hline $\mathrm{SES}^{\ddagger}$ & $0.13(-0.61 ; 0.75)$ & $0.15(-0.60 ; 0.76)$ & $0.15(-0.60 ; 0.75)$ & $0.14(-0.61 ; 0.76)$ \\
\hline Died during $2013^{\dagger}$ & $3191(35 \%)$ & $1029(11 \%)$ & $1903(21 \%)$ & $748(8 \%)$ \\
\hline Died during $2014^{+}$ & $933(10 \%)$ & $443(5 \%)$ & $666(7 \%)$ & $701(8 \%)$ \\
\hline \multicolumn{5}{|c|}{ Characteristics of the first ICU admission } \\
\hline \multicolumn{5}{|c|}{ Admission type $^{\dagger}$} \\
\hline - Medical & $4338(48 \%)$ & 4484 (49\%) & $3658(40 \%)$ & \\
\hline - Planned surgery & 3219 (35\%) & $3383(37 \%)$ & $4348(48 \%)$ & \\
\hline - Emergency surgery & $1466(16 \%)$ & $1157(13 \%)$ & $1030(11 \%)$ & \\
\hline - Missing & $45(0.5 \%)$ & $44(0.5 \%)$ & $32(0.4 \%)$ & \\
\hline \multicolumn{5}{|l|}{ Acute diagnosist } \\
\hline$\cdot \mathrm{CPR}$ & $493(5 \%)$ & $421(5 \%)$ & $461(5 \%)$ & \\
\hline - Burns & $8(0.1 \%)$ & $16(0.2 \%)$ & $2(0.02 \%)$ & \\
\hline - Cardiac dysrhythmia & $1340(15 \%)$ & $543(6 \%)$ & $913(10 \%)$ & \\
\hline • Gl bleeding & $264(3 \%)$ & $154(2 \%)$ & $177(2 \%)$ & \\
\hline - CVA & $396(4 \%)$ & $330(4 \%)$ & $334(4 \%)$ & \\
\hline - Intracranial mass effect & $149(2 \%)$ & $427(5 \%)$ & $258(3 \%)$ & \\
\hline - Sepsis & $1055(12 \%)$ & $638(7 \%)$ & $827(9 \%)$ & \\
\hline - OHCA & $321(4 \%)$ & $296(3 \%)$ & $275(3 \%)$ & \\
\hline - SAH & $26(0.3 \%)$ & $185(2 \%)$ & $76(0.8 \%)$ & \\
\hline - Trauma & $667(7 \%)$ & $537(6 \%)$ & $288(3 \%)$ & \\
\hline $\begin{array}{l}\text { Mechanical ventilation during } \\
\text { the first } 24 \text { hrs of ICU } \\
\text { admissiont }\end{array}$ & $4142(46 \%)$ & $4256(47 \%)$ & $5046(56 \%)^{*}$ & \\
\hline Length of ICU stay $¥[1][2]$ & $1.12(0.79 ; 2.89)$ & $0.99(0.76 ; 2.55)$ & $1.07(0.81 ; 2.90)$ & \\
\hline Length of hospital stay $¥[1]$ & $10(6 ; 16.57)$ & $8(4 ; 14)$ & $9(6 ; 16)$ & \\
\hline APACHE III score $\ddagger[3]$ & $65(52 ; 84)$ & $41(29 ; 61)$ & $57(44 ; 75)$ & \\
\hline APS $\neq[3]$ & $45(32 ; 63)$ & $35(24 ; 54)$ & $41(29 ; 58)$ & \\
\hline
\end{tabular}

† Number and percentage (\%); ¥ Median and IQR

Number and percentage (\%); ₹ Median and IQR
* Median and IQR. Only calculated for ICU admissions which met the APACHE IV inclusion criteria $(80+n=8481$,

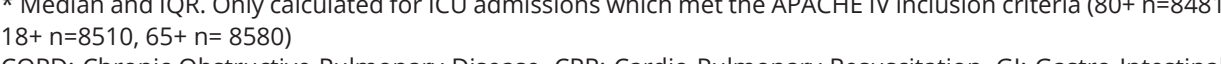
COPD: Chronic Obstructive Pulmonary Disease, CPR: Cardio Pulmonary Resuscitation, Gl: Gastro Intestin CVA: Cerebrovascular Accident, OHCA: Out of Hospital Cardiac Arrest, SAH: Subarachnoid Haemorrhage *not significant

[1] Length of ICU stay and length of hospital stay significantly different ( $p<0.001)$

[2] Average costs of one day in the ICU in the Netherlands are about $€ 2500$

[3] APACHE III and APS scores significantly different between groups $(p<0.001)$
A. Median
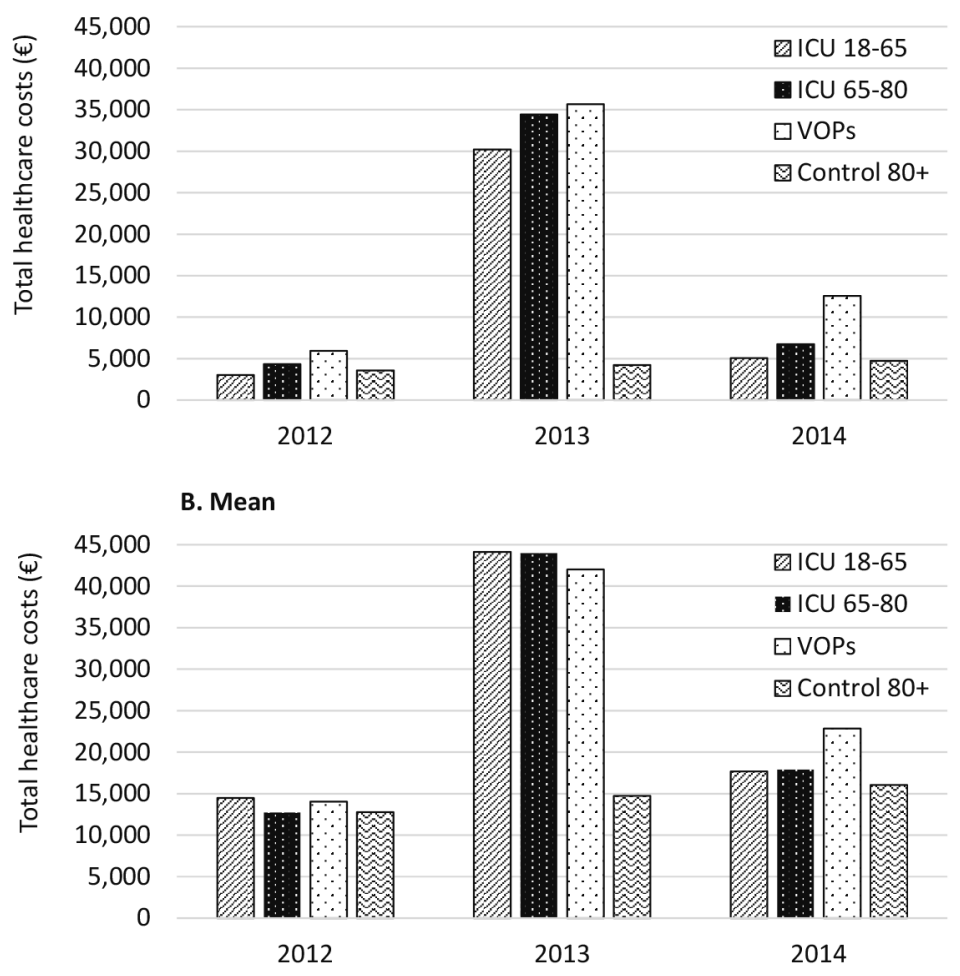

Figure 2. Median (A) and mean (B) total healthcare costs for the four study groups.

\section{Discussion}

In this study, we evaluated healthcare costs of VOPs in comparison with two groups of younger ICU patients and a very elderly population control group, in the year before during and after ICU admission. VOPs required more health care resources during all three study years compared to the other study groups, with one exception: during the year of ICU admission costs of VOPs are similar to the costs of ICU 65-80 patients. However, health care costs per day alive are substantially higher for VOPs than for the other study groups in all studied years. Costs per day alive of VOPs are, compared to the ICU 18-65 patients, respectively 2, 1.5 and 3 times higher in the year before, the year of and the year after ICU admission, while remaining life expectancy is significantly lower. 


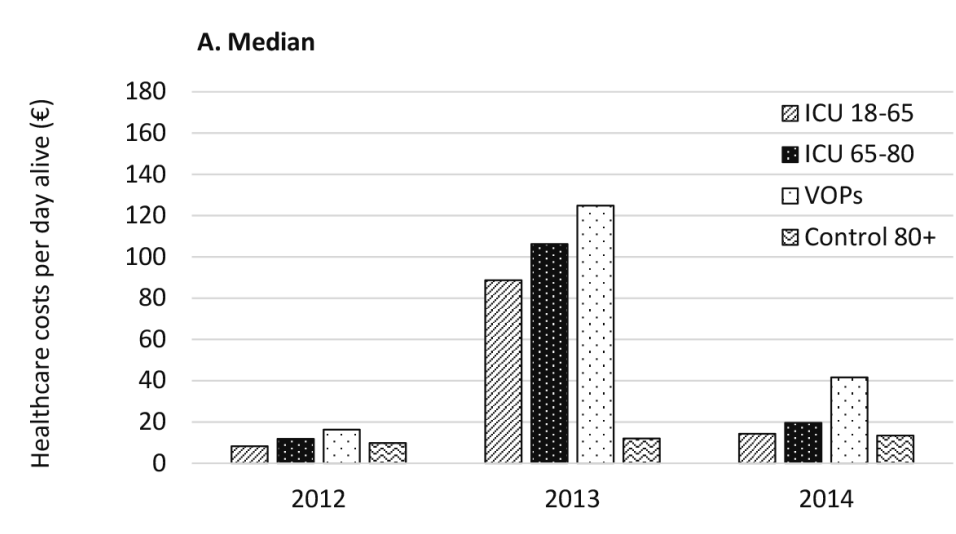

B. Mean

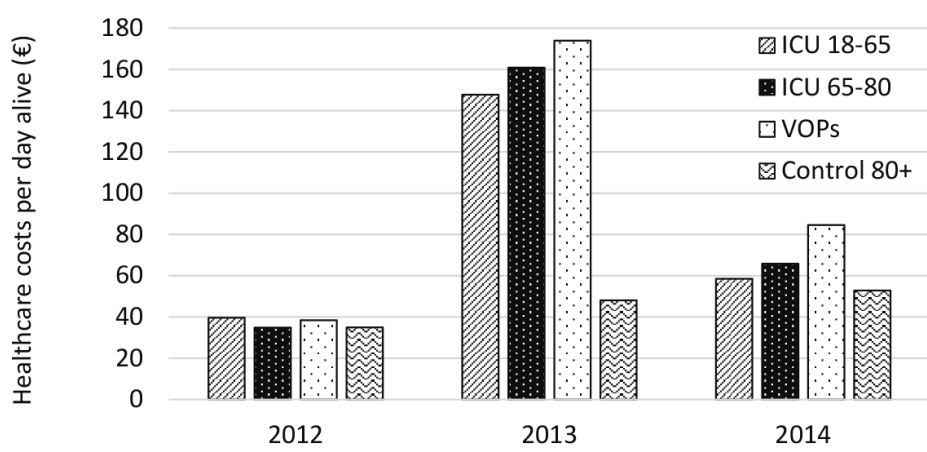

Figure 3. Median (A) and mean (B) healthcare costs per day alive for the four study groups.

Comparing our results to earlier studies is complicated for several reasons, including the different methods of cost calculation that are used and the various types of costs that are reported. Obviously, the absolute healthcare-related costs also depend on other factors, including country, region and health care system, and as a consequence, previous studies report a wide range of healthcare costs for older ICU patients. Our results are in contrast with a study in the United States, which showed that daily and total hospital costs were lower in older patients [23], but comparable with the results of a Canadian study on costs of ICU treatment in VOPs. The average costs in this study were $\$ 31,679$ per ICU admission, $\$ 48,744$ per ICU survivor, and $\$ 61,783$ per one-year survivor. These studies showed that the costs of ICU care of elderly patients are substantial, but only used direct ICU-associated costs and did not look beyond hospital discharge. Knowing that many of the healthcare-related or societal costs are made outside the hospital, we also included costs in the year before and after ICU admission. In all age groups, costs were significantly higher in the year after ICU admission compared to the year before ICU admission, but this difference was most explicit in VOPs. It is known that ICU survivors, from all ages, suffer long-term physical, cognitive and/or psychiatric disabilities, defined as the post intensive care syndrome (PICS) [25] with increased healthcare costs. However, after discharge the VOPs are more likely to be readmitted and are more dependent of long-term care facilities, nursing homes or rehabilitation centres compared to younger people [26-28].

In times of scarce health care resources, it is frequently questioned what the society should accept to pay for a gained life year ('Value of the Statistical Life Year' (VOSL)). These numbers will differ between persons and countries. In addition, in interpreting our results it is important to realize that for many very elderly, preserving quality of life (QoL) is more important than prolonging their life and many of them prefer a lesser intensity of care, without undergoing invasive procedures $[29,30]$. This reinforces the importance of early goals of care discussions. Unfortunately, we were not able to analyse functional outcome and QoL as this was not included in our datasets. If QoL data had been available, we could have calculated costs per 'quality adjusted life year' (QALY). It is important to keep in mind, however, that QALYs are often based on surveys that incorporate physical functioning which is often lower in the elderly. Also, life expectancy in very elderly persons is generally low. Simply calculating QALYs may not do justice to these nuances and carry the risk of unjustly suggesting that only limited resources should be allocated to these patients. In the Netherlands, a maximum of 80,000 Euros per QALY was once suggested in cost utility analyses, but never enforced, because of several shortcomings and ethical objections [31]. Provided that QoL is good, the costs of VOPs that we found in our study would have been within these limits, although it might be unrealistic to assume that all VOPs have a good QoL after ICU discharge. HRQoL studies suggest that some older ICU survivors may accommodate to a degree of physical disability and still report good emotional and social well-being $[34,35]$, but it is also important to realize that these HRQoL studies are subject to survivorship and proxy-response bias [36].

To our knowledge no studies exist in which healthcare-related costs of older versus younger ICU patients in the years around ICU admission are compared. Another strength of our study is that we used total healthcare costs, inpatient as well as outpatient costs of care and preceding and following ICU admission, rather than ICU costs only. This is important since many of these patients have extended hospitalizations and a prolonged recovery period. We used both total healthcare costs as costs per day alive. The linkage between the national health insurance claims database and the national clinical ICU registry, covering almost the entire country, provides valuable insight in the healthcare utilization of VOPs in comparison with younger ICU patients and a general population control group. 
The study has limitations as well. One of the limitations is that the total costs per patient, based on all reimbursement data available from health insurance companies, were only available as a total sum in Euros per person per calendar year. We translated these costs into median and mean healthcare costs per patient per year and per patient per day alive. A limitation of the first, costs per patient per year, is mainly that it depends on the number of days alive, since follow up periods in these groups might differ. However, a limitation of the second, costs per patient per day alive, is that if mortality is high, costs per day will likely be higher, since costs (including the high ICU costs) are spread out over fewer days alive. We believe that by reporting both outcome measures we provide good insight. A second limitation is that our study illustrates that substantial healthcare costs are made in ICU patients of all ages, both in the year of their ICU admission and the year thereafter, but does not provide an answer to the important question whether these costs are justified. A third limitation is that we did not adjust costs for severity of illness. The VOPs were more severely ill as both the median APACHE III and APS scores in the VOPs were significantly higher at ICU admission. The APACHE III score is dependent on age and more points are appointed for the older patients. However, the acute physiology score (points based only physiological parameters) was also higher in VOPs. This suggests more severe derangement at admission. This could, at least partially, be explained by a lower fraction of VOPs being admitted after elective surgery. Both severity of illness and type of admission will contribute to higher costs and mortality in VOPs. Another limitation is that we have no insights in the exact composition of the healthcare costs and that we only included the total amount of healthcare cost reimbursed by health insurance companies. The total healthcare costs do not include services paid for out of pocket or reimbursements via voluntary additional insurance, but we think this has not (or barely) affected our results, since our cost data included the most important parts of healthcare costs. Since the point of view of was the healthcare perspective and not the societal perspective, we did not include factors like loss of a job and other societal losses. These limitations notwithstanding, we believe our results provide valuable insight in the healthcare utilization of VOPs in comparison to younger ICU patients and a very elderly control population.

In conclusion, we showed that VOPs required more health care resources in the year before, during and after ICU admission compared to the ICU 18-65 population and a very elderly control group. Compared to the ICU 65-80 population, VOPs required more health care resources in the year before and after ICU admission, but not in the year of ICU admission. However, costs corrected per day alive are substantially higher for VOPs in all three study years and compared to both other ICU populations and the very elderly control population. Our study illustrates that substantial healthcare costs are made in ICU patients of all ages, both in the year of their ICU admission and the year thereafter. Our study does not provide an answer to the difficult question whether these costs can always be justified. Because ICU resources are often limited, as well as the number of life years that can be gained in good health in VOPs, there is a need for studies that evaluate cost per QALY in VOPs admitted to the ICU. 


\section{Supplement}

\section{Subgroups analyses}

Median and mean total healthcare costs for the studygroups and the costs per patient and per patient per day alive for the different mortality groups are shown in Figure S1 and S2. Additional subgroup analyses have been performed for patients who survived the whole 3-years study period. Among this group of survivors, we first divided the elderly ICU group, the younger ICU group and the matched control group into groups based upon their number of chronic conditions (0, 1, 2 or more) (Figure S3). Second, we looked at severity of illness based upon the APACHE IV predicted mortality (Figure S4). Furthermore, we analyzed the differences in costs between subgroups, based on gender (Figure S5) and SES (Figure S6). Finally, we grouped the three ICU populations by type of ICU admission (Figure S7), based on the definitions of the NICE registry [16] VOPs have more chronic conditions in the year prior to admission compared to the ICU 18-65 population, the ICU 65-80 population and the control population $(p<0.0001)$ (Table SI). Healthcare costs increase with increasing number of chronic conditions and this is seen for all four study groups and in all three study years ( $p<0.0001)$ (Figure S3). Stratifying the healthcare costs by chronic conditions showed great deviations and demonstrated that more chronic conditions means higher costs. These increased costs with more chronic conditions were seen in all three study years; before, during and after ICU admission and for all four studies populations, indicating that chronic conditions largely contribute to the healthcare costs.

During the year before ICU admission, survivors of the high mortality risk group have lower healthcare costs compared to survivors of the low mortality risk group ( $p<0.0001$ ). During the year of ICU admission, healthcare costs are significantly higher for higher Apache IV risks groups $(p<0.0001)$. During the year after ICU admission survivors of the median mortality risk group have the highest healthcare cost $(p<0.0001)$ (Figure S4).

Female patients are more expensive than male patients in all three years of the study period $(p<0.0001)$ within the ICU $65-80$ population and the VOPs. In the ICU 18-65 population, female patients are significantly more expensive in the year before $(p<0.0001)$ and the year after ICU admission $(p<0.0001)$, but during the year of ICU admission the difference between men and women of this study population is not significant $(p<0.42)$ (Figure $S 5)$.

Patients with a higher SES had significantly less healthcare costs compared to people with a lower SES, in all four study populations, during the year before and the year after admission $(p<0.0001)$ (Figure 56$)$.

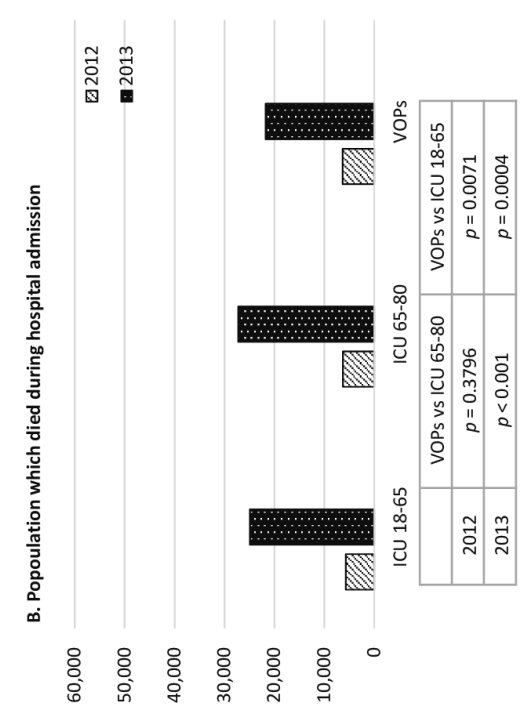

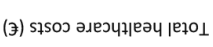

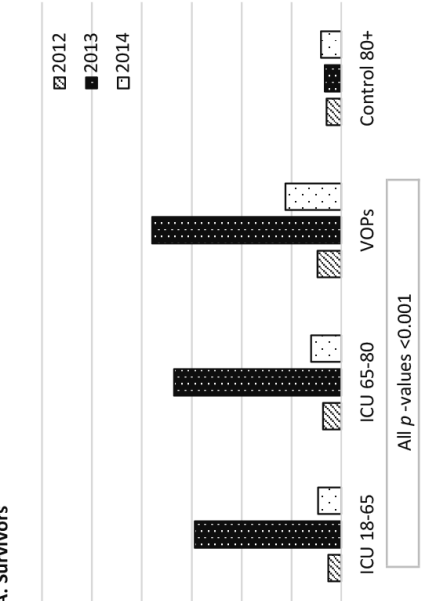

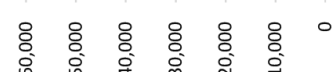

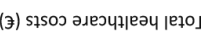

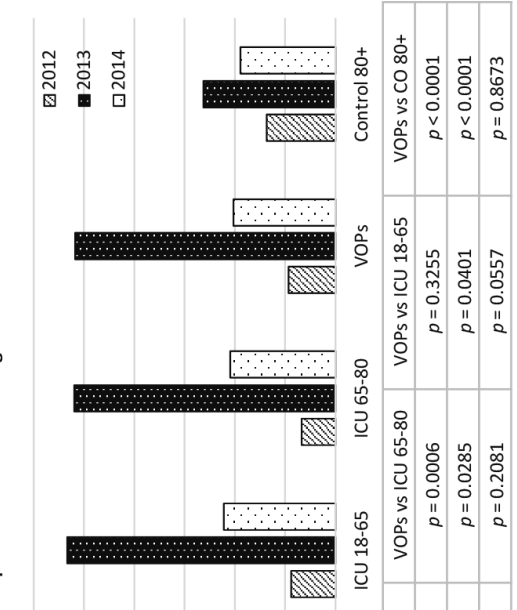

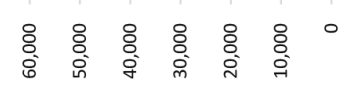

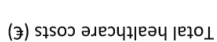

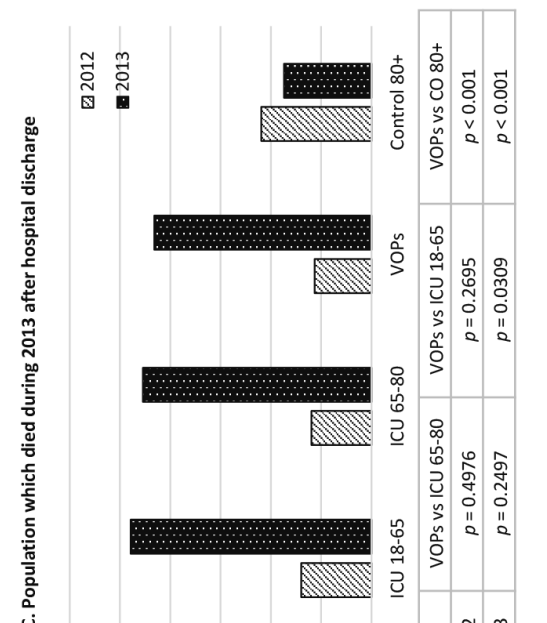

ะ ะ ะ ะ ะ

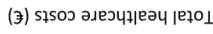



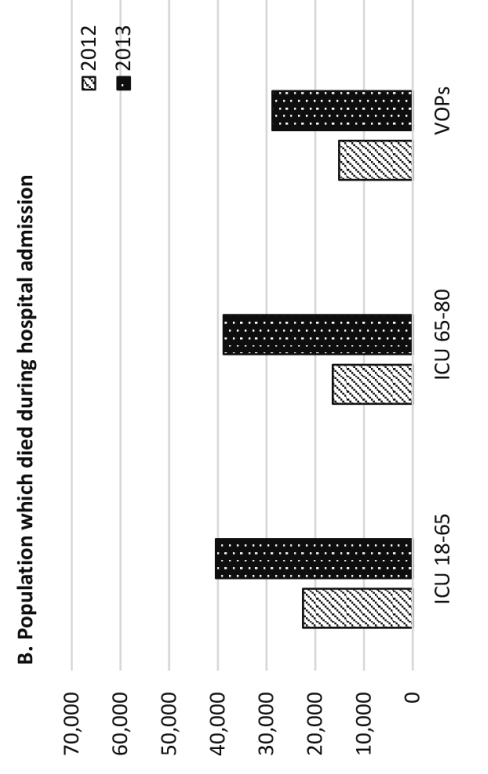

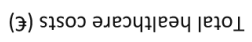

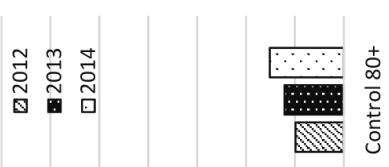
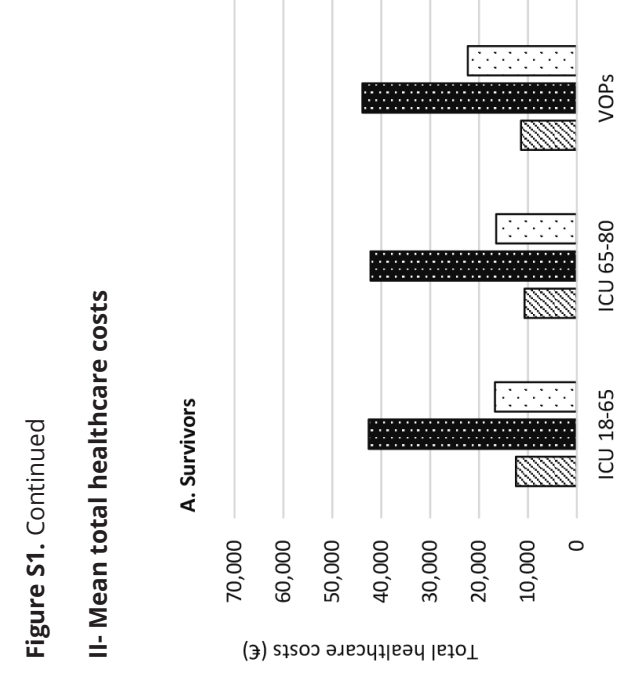

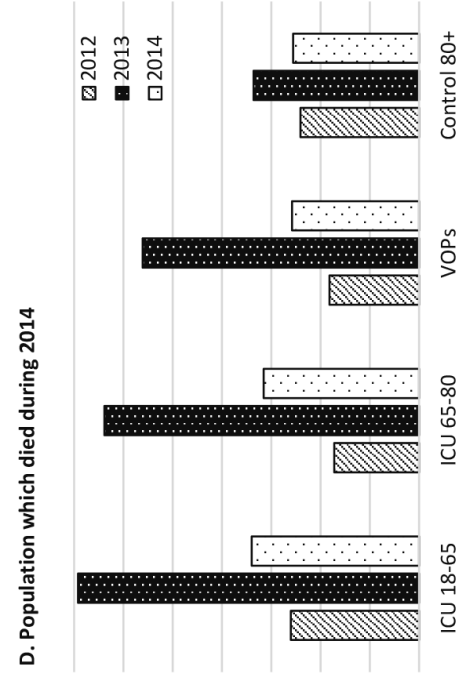

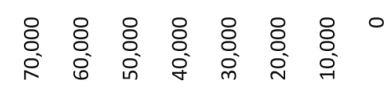

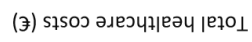

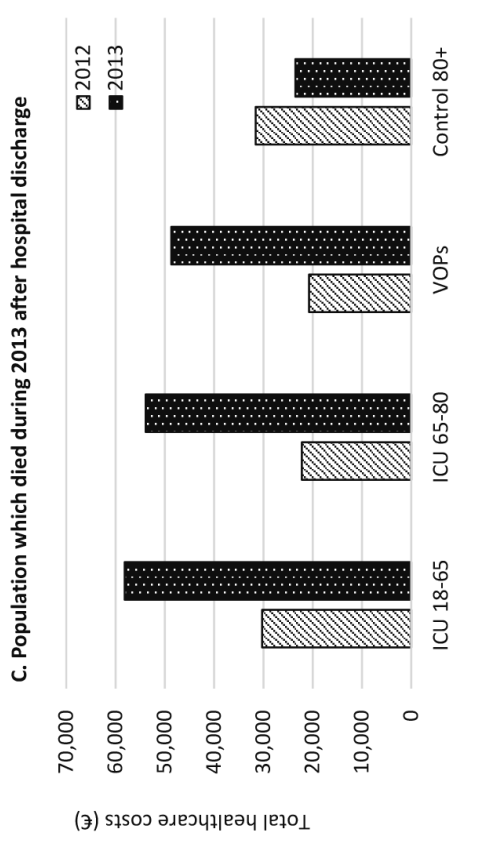

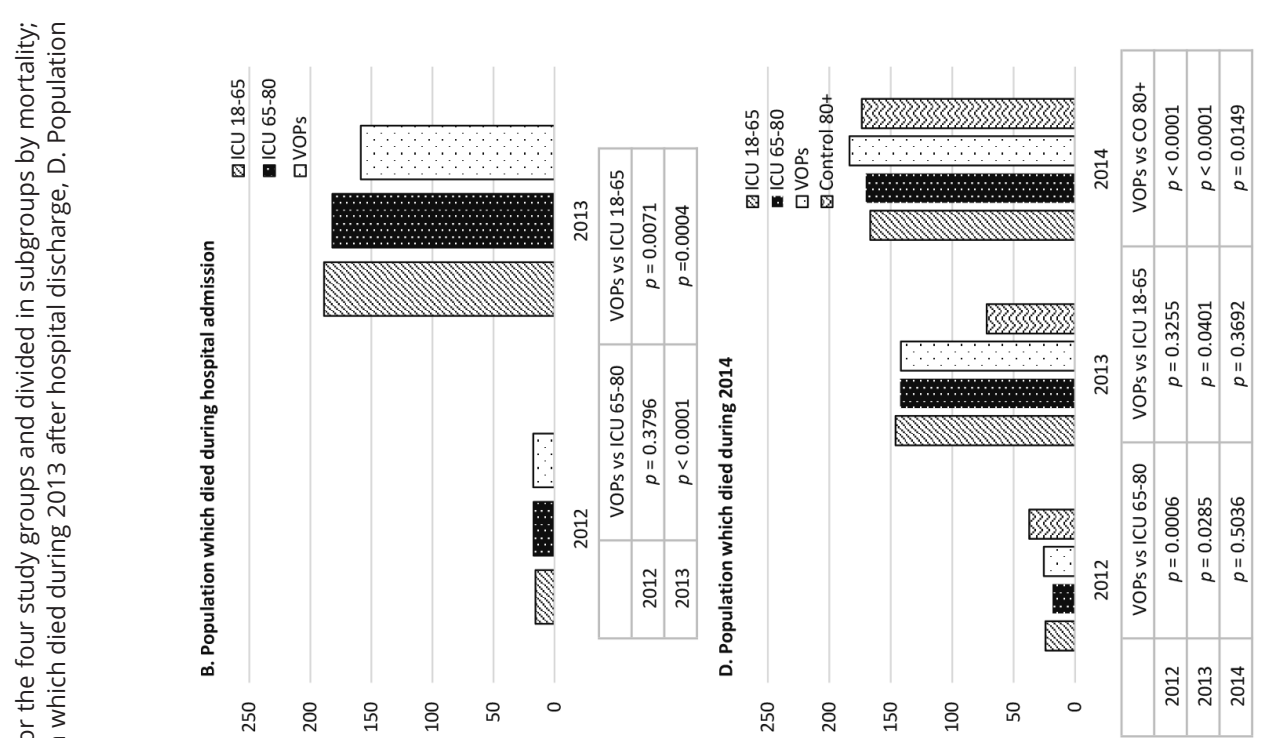

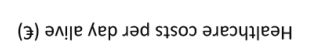

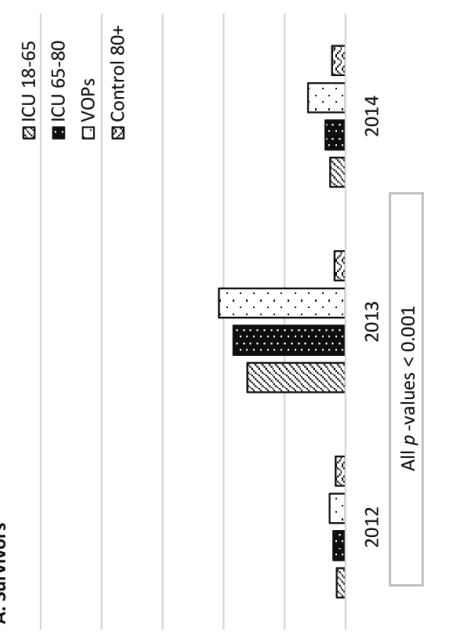

品 욱 总 号

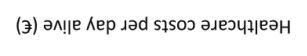

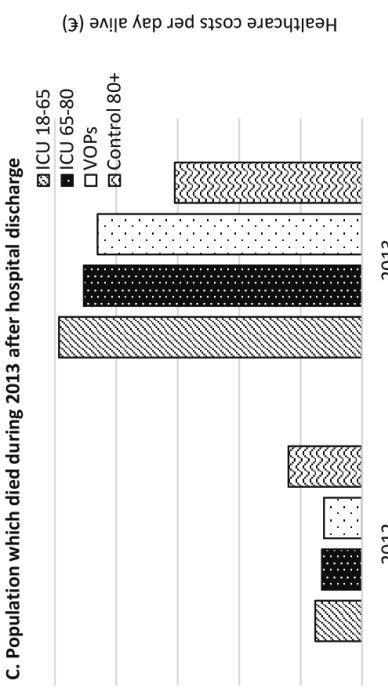

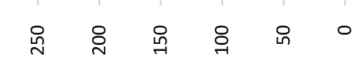

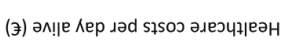




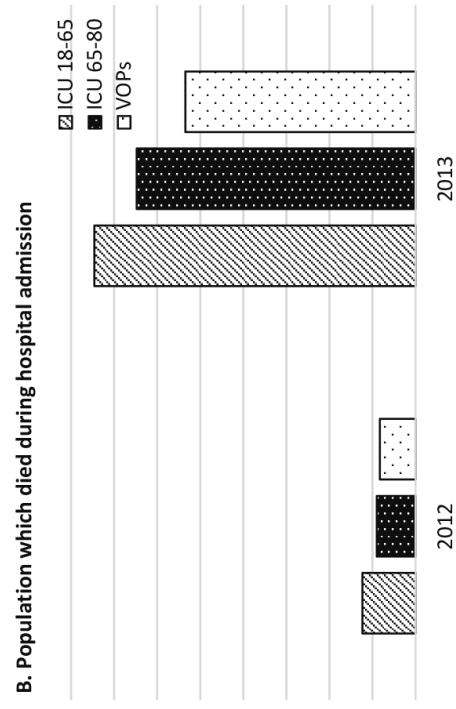

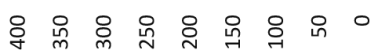

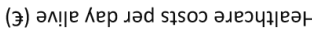
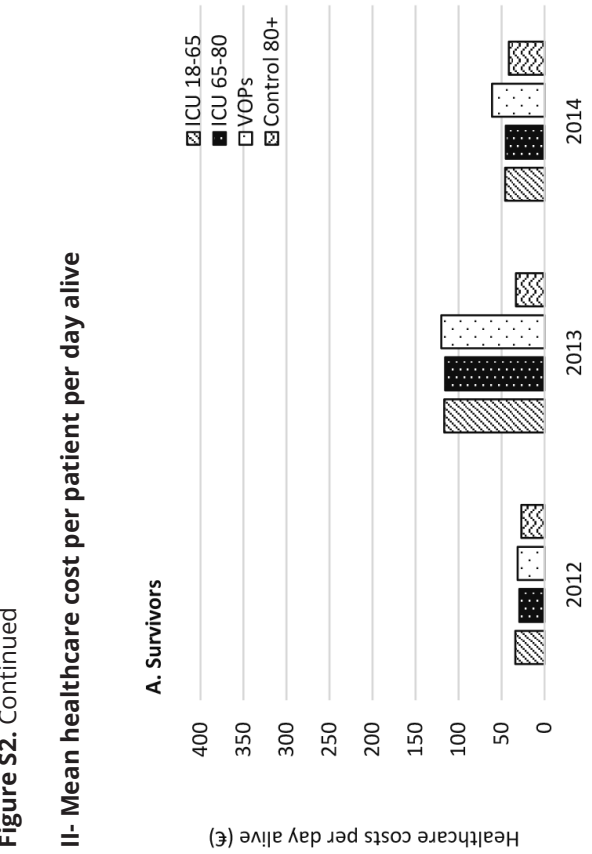

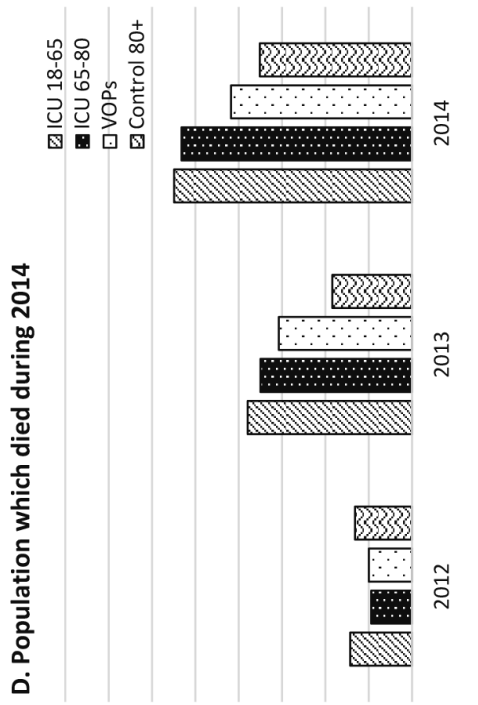

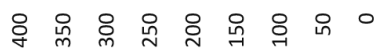

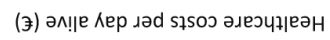

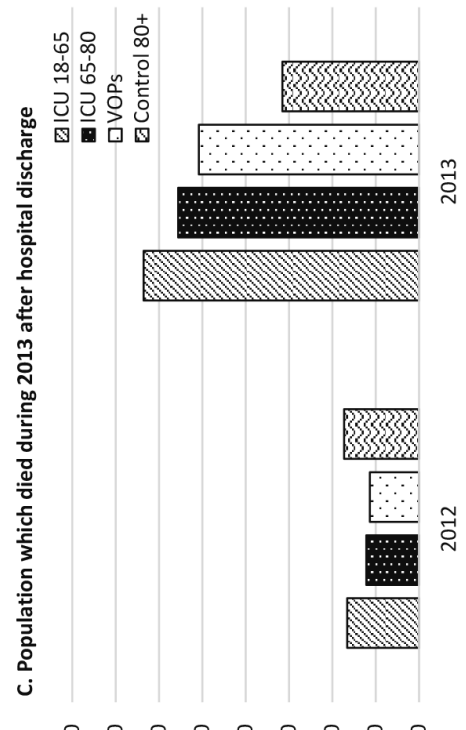

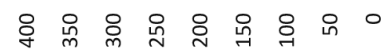

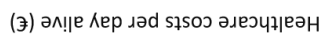

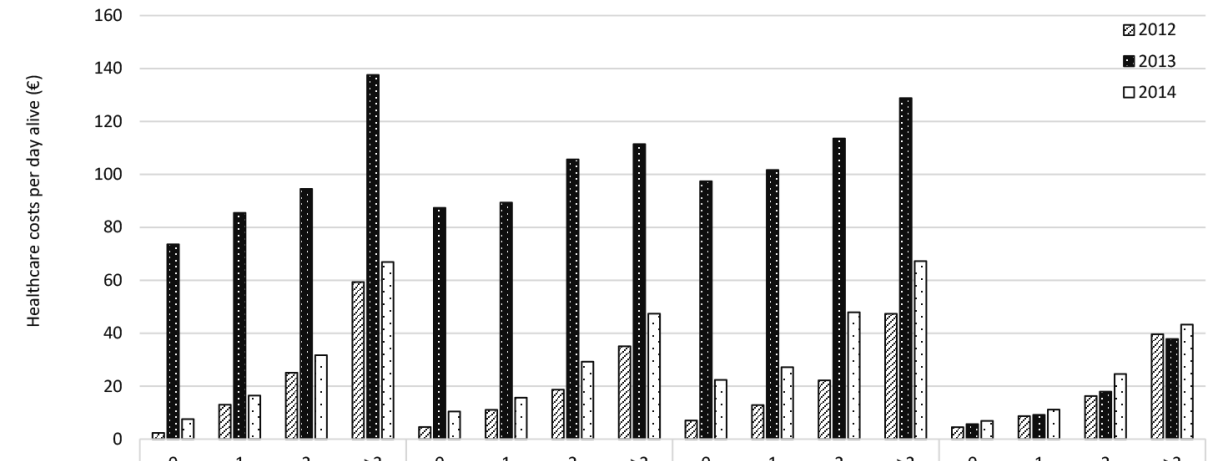

Figure S3. Median healthcare costs per day alive of survivors, stratified by number of chronic conditions.

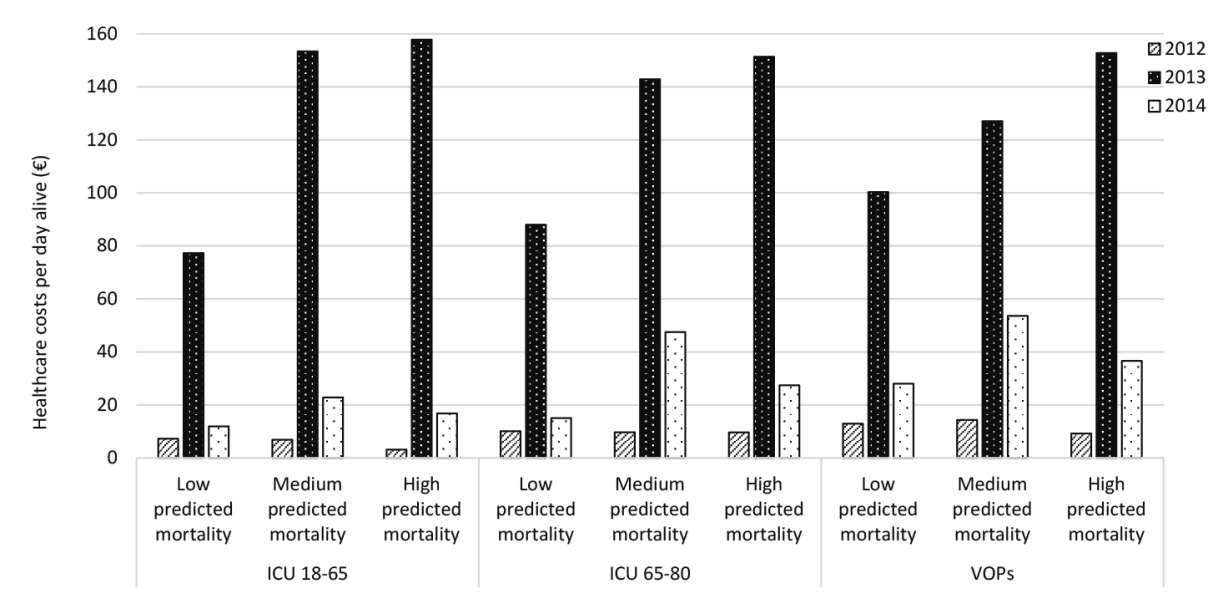

Figure S4. Median healthcare costs per day alive of survivors, stratified by APACHE IV mortality risk-group.

Survivors with a medical admission were most expensive in the year before and after ICU admission, compared to survivors of the elective and emergency surgery groups in these years (all $\mathrm{p}<0.0001$ ). During the year of ICU admission, patients admitted because of emergency surgery were the most expensive, for all three ICU populations $(p<0.0001$, Figure S7). For emergency patients, healthcare costs during the year of ICU admission were higher for the VOP population than for the ICU 18-65 population ( $p$-value for interaction $p=0.0004$ ), but the differences between VOPs and the ICU 65-80 population was not significant ( $p$-value for interaction $p=0.9942$ ). 


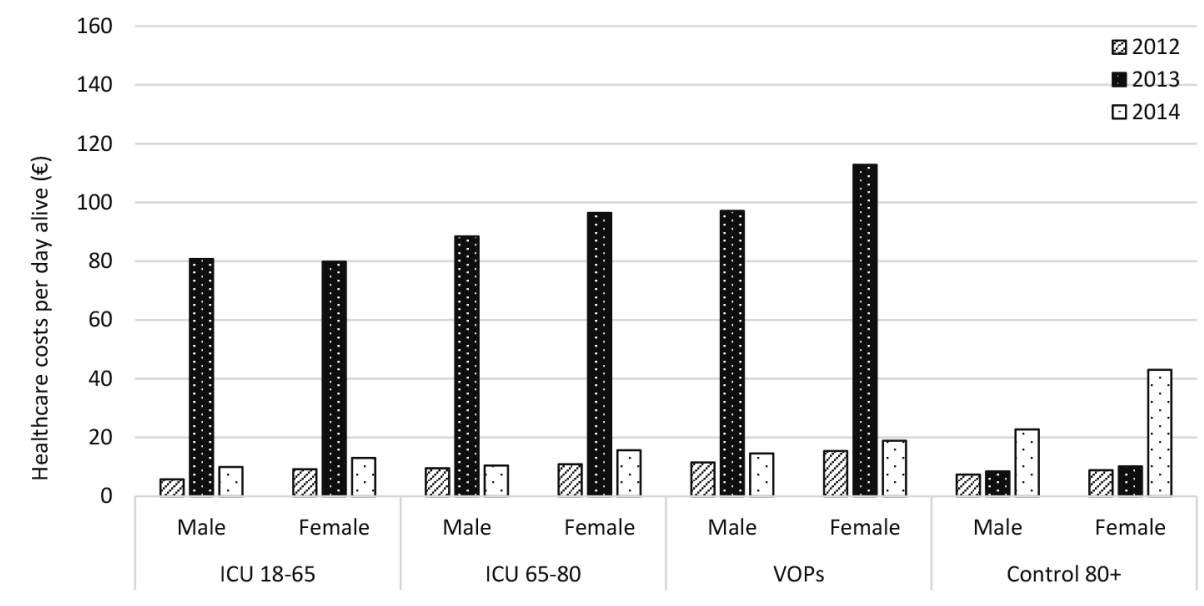

Figure 55. Median healthcare costs per day alive of survivors, stratified by gender.

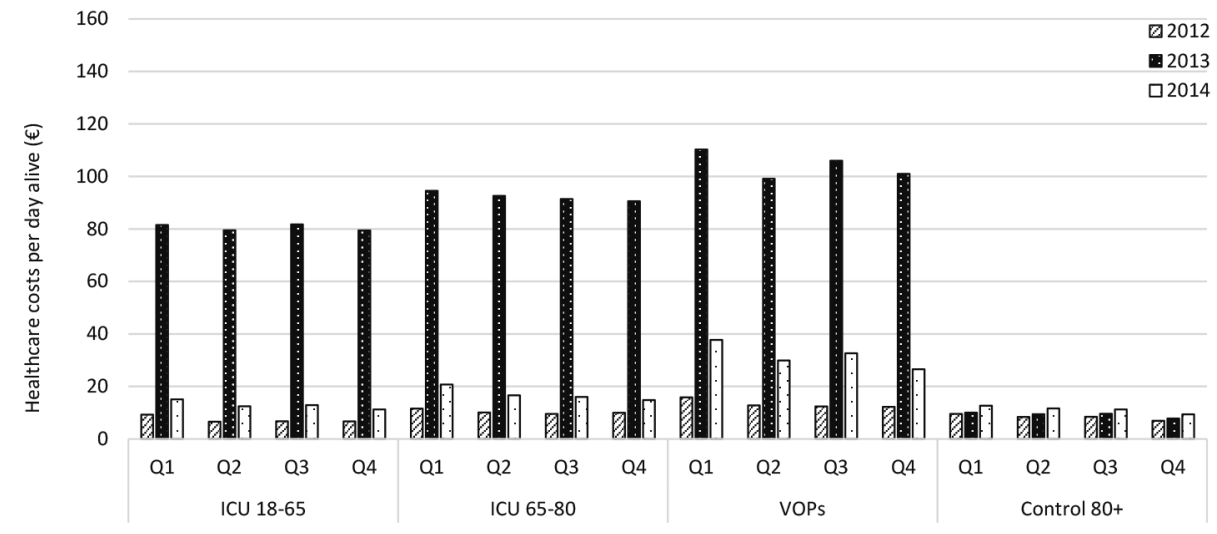

Figure S6. Median healthcare costs per day alive of survivors, stratified by socioeconomic status quartile.

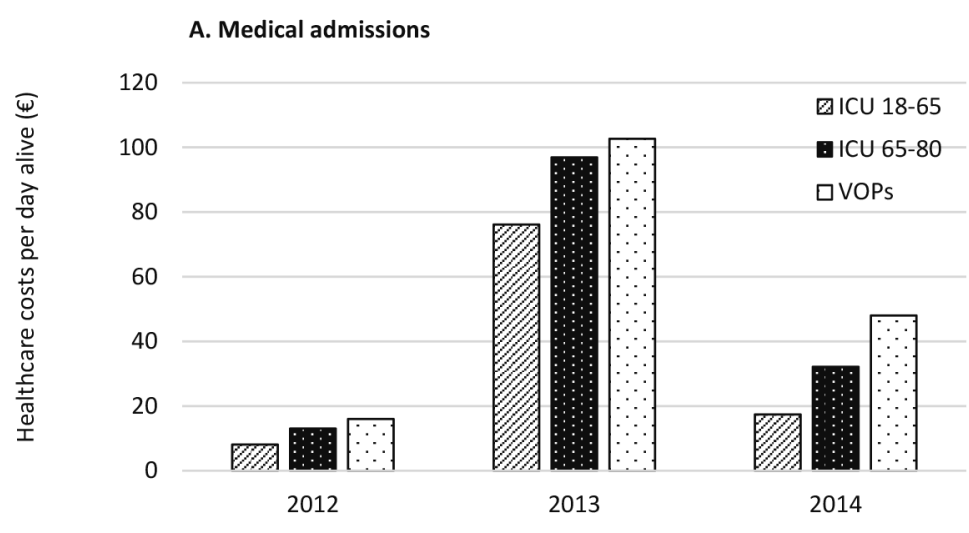

B. Elective surgery admissions

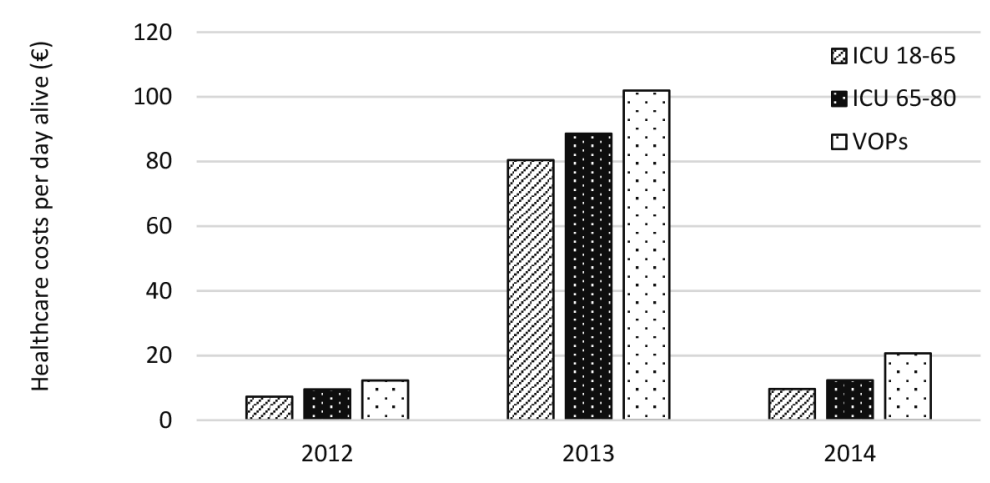

C. Emergency surgery admissions

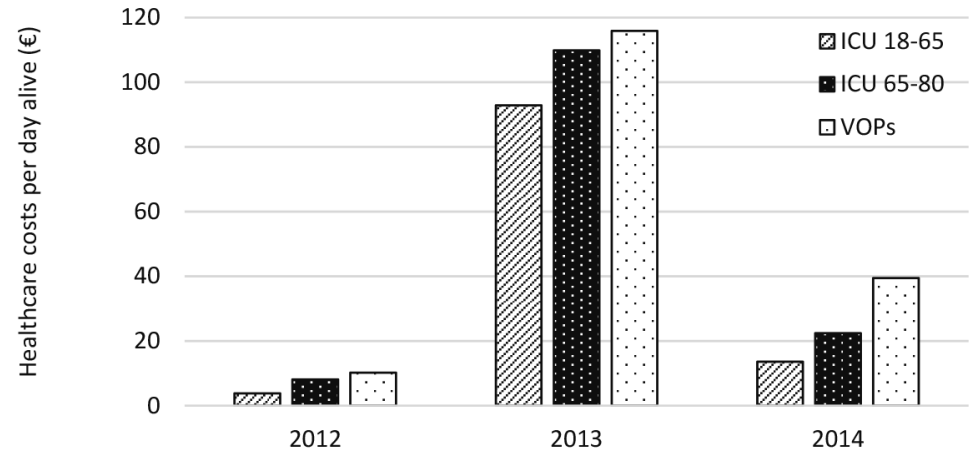

Figure S7. Median healthcare costs per day alive of survivors in relation to admission category*. A: medical admissions; B: elective admissions; C: emergency admissions

Definitions of the three admission types according the NICE registry.

CU admissions which are not directly transferred from the operation room or the recovery

department to the ICU
$B$ Planned surgical: surgery planned on a date and time convenient for both patient and doctor or early C Emergency surgery: immediate surgery where resuscitation, stabilization and physiological support occurs preceding or simultaneous with the surgery 
Table SI. Overview of the number of chronic conditions* of the studied populations during the year before ICU admission.

\begin{tabular}{lllll}
\hline & $\begin{array}{l}\text { ICU 18-65 } \\
\text { (n=9068) }\end{array}$ & $\begin{array}{l}\text { ICU 65-80 } \\
(\mathbf{n = 9 0 6 8 )}\end{array}$ & $\begin{array}{l}\text { VOPs } \\
\text { (n=9068) }\end{array}$ & $\begin{array}{l}\text { CO 80+ } \\
(\mathbf{n}=9068)\end{array}$ \\
\hline No chronic condition & $4949(55 \%)$ & $3145(35 \%)$ & $2775(31 \%)$ & $3770(42 \%)$ \\
One or more chronic conditions & $4119(45 \%)$ & $5923(65 \%)$ & $6393(71 \%)$ & $5298(58 \%)$ \\
Two or more chronic conditions & $1336(15 \%)$ & $2279(25 \%)$ & $2497(28 \%)$ & $1691(19 \%)$ \\
\hline
\end{tabular}

*Vektis also collects claims for pharmaceutical care, stored in 'The Pharmacy Information System'. This information system contains information on provided drugs, including the Anatomical Therapeutic Chemical (ATC) code, the quantity that was supplied and the date the drug was supplied [37].

To determine chronic conditions, pharmaceutical cost groups (PCGs) were used as a proxy. PCGs are based on the idea that a patient with a certain chronic condition can be identified by claims known to be prescribed for that chronic condition [38, 39]. An insured person is included into a specific PCG if more than a certain amoun prescribed during a calendar year. The PCG a e.g. Over 180 defna dally $\mathrm{PCG}$ if more than a cet combined in order to reach the minimum defined daily doses. A person can be included in multiple PCGs. The definition of pharmaceutical cost groups is maintained by the 'Zorginstituut Nederland' (National Institute for Health Care) and classification is routinely performed by Vektis [40]

\section{References}

1. Centraal Bureau voor de Statistiek (CBS). Statline. http://statline.cbs.nl/Statweb/dome/default.aspx.

2. Halpern NA, Goldman DA, Tan KS, Pastores SM (2016) Trends in Critical Care Beds and Use Among Population Groups and Medicare and Medicaid Beneficiaries in the United States: 2000-2010. Crit Care Med 44:1490-1499. doi: 10.1097/CCM.0000000000001722 [doi]

3. Rhodes A, Ferdinande P, Flaatten $\mathrm{H}$, et al (2012) The variability of critical care bed numbers in Europe intensive Care Med 38:1647-1653. doi: 10.1007/500134012-2627-8 [dol]

4. https://www.zorgcijfersdatabank.nl.

5. Lone NI, Seretny M, Wild SH, et al (2013) Surviving intensive care: a systematic review of healthcare resource use after hospital discharge*. Crit Care Med 41:1832-1843. doi: 10.1097/CCM.0b013e31828a409c [doi]

6. Bagshaw SM, Webb SA, Delaney A, et al (2009) Very old patients admitted to intensive care in Australia and New Zealand: a multi-centre cohort analysis. Crit Care 13:R45. doi: 10.1186/cc7768 [doi]

7. Nielsson MS, Christiansen CF, Johansen MB, et al (2014) Mortality in elderly ICU patients: a cohort study. Acta Anaesthesiol Scand 58:19-26. doi: 10.1111/aas.12211 [doi]

8. Haas LEM, Karakus A, Holman R, et al (2015) Trends in hospital and intensive care admissions in the Netherlands attributable to the very elderly in an ageing population. Crit Care 19:353. doi: 10.1186/ s13054-015-1061-z

9. Flaatten $\mathrm{H}$, de Lange DW, Artigas $\mathrm{A}$, et al (2017) The status of intensive care medicine research and future agenda for very old patients in the ICU. Intensive Care Med. doi: 10.1007/s00134-017-4718-z

10. Vosylius S, Sipylaite J, Ivaskevicius J (2005) Determinants of outcome in elderly patients admitted to the intensive care unit. Age Ageing 34:157-162. doi: 34/2/157 [pii]

11. Garrouste-Orgeas M, Timsit JF, Montuclard L, et al (2006) Decision-making process, outcome, and 1-year 34-006-0169-7 [doi]

12. Fuchs L, Chronaki CE, Park S, et al (2012) ICU admission characteristics and mortality rates among elderly and very elderly patients. Intensive Care Med 38:1654-1661. doi: 10.1007/s00134-012-2629-6 [doi]

13. Docherty AB, Anderson NH, Walsh TS, Lone NI (2016) Equity of Access to Critical Care Among Elderly Patients in Scotland: A National Cohort Study. Crit Care Med 44:3-13. doi: 10.1097/CCM.0000000000001377 [doi]

14. Flaatten H, De Lange DW, Morandi A, et al (2017) The impact of frailty on ICU and 30-day mortality and the level of care in very elderly patients ( $>/=80$ years). Intensive Care Med 43:1820-1828. doi: 10.1007/ 500134-017-4940-8 [doi]

15. Karakus A, Haas LEM, Brinkman S, et al (2017) Trends in short-term and 1-year mortality in very elderly intensive care patients in the Netherlands: a retrospective study from 2008 to 2014. Intensive Care Med 43:1476-1484. doi: 10.1007/s00134-017-4879-9 [doi]

16. Dutch National Intensive Care Evaluation (NICE) registry. http://www.stichting-nice.nl.

17. Vektis. http://www.vektis.n.

18. van de Klundert N, Holman R, Dongelmans DA, de Keizer NF (2015) Data Resource Profile: the Dutch National Intensive Care Evaluation (NICE) Registry of Admissions to Adult Intensive Care Units. Int
Epidemiol 44:1850-1850h. doi: 10.1093/ije/dyv291 [doi] 
19. Zimmerman JE, Kramer AA, McNair DS, Malila FM (2006) Acute Physiology and Chronic Health Evaluation (APACHE) IV: hospital mortality assessment for today's critically ill patients. Crit Care Med 34:1297-1310. doi: 10.1097/01.CCM.0000215112.84523.FO [doi]

20. Knol FA Van hoog naar laag: van laag naar hoog., ISBN 90-57. Elsevier, Den Haag

21. Roos LL, Wajda A (1991) Record linkage strategies. Part I: Estimating information and evaluating approaches. Methods Inf Med 30:117-123. doi: 91020117 [pii]

22. van Beusekom I, Bakhshi-Raiez F, de Keizer NF, et al (2017) Healthcare costs of ICU survivors are higher before and after ICU admission compared to a population based control group: A descriptive study 351. doi: S0883-9441(17)31009-2 [pii]

23. Chelluri L, Mendelsohn AB, Belle SH, et al (2003) Hospital costs in patients receiving prolonged mechanical ventilation: does age have an impact? Crit Care Med 31:1746-1751. doi: 10.1097/01. CCM.0000063478.91096.7D [doi]

24. Chin-Yee N, D'Egidio G, Thavorn K, et al (2017) Cost analysis of the very elderly admitted to intensive care units. Crit Care 21:109-017-1689-y. doi: 10.1186/s13054-017-1689-y [doi]

25. Needham DM, Davidson J, Cohen H, et al (2012) Improving long-term outcomes after discharge from CCM 0 b 013 e318232 375 [doi]

26. Rady MY, Johnson DJ (2004) Hospital discharge to care facility: a patient-centered outcome for the evaluation of intensive care for octogenarians. Chest 126:1583-1591. doi: S0012-3692(15)31375-1 [pii]

27. Feng $Y$, Amoateng-Adjepong $Y$, Kaufman $D$, et al (2009) Age, duration of mechanical ventilation, and outcomes of patients who are critically ill. Chest 136:759-764. doi: 50012-3692(09)60544-4 [pii]

28. Conti $M$, Friolet $R$, Eckert $P$, Merlani $P$ (2011) Home return 6 months after an intensive care unit admission for elderly patients. Acta Anaesthesiol Scand 55:387-393. doi: 10.1111/j.1399-6576.2011.02397.x [doi]

29. Philippart F, Vesin A, Bruel C, et al (2013) The ETHICA study (part I): elderly's thoughts about intensive care unit admission for life-sustaining treatments. Intensive Care Med 39:1565-1573. doi: 10.1007/s00134013-2976-y

30. Heyland DK, Barwich D, Pichora D, et al (2013) Failure to engage hospitalized elderly patients and their families in advance care planning. JAMA Intern Med 173:778-787. doi: 10.1001/jamainternmed.2013.180

31. Raad voor Volksgezondheid en Zorg. Zicht op zinnige en duurzame zorg. 2006, publicatienummer 06/07. ISBN-10: 90-5732-172-6.

32. Heyland DK, Garland A, Bagshaw SM, et al (2015) Recovery after critical illness in patients aged 80 years or older: a multi-center prospective observational cohort study. Intensive Care Med 41:1911-1920. do 1007/s00134-015-4028-2

33. Kaarlola A, Tallgren $M$, Pettila $\vee$ (2006) Long-term survival, quality of life, and quality-adjusted life-years among critically
CCM.0000227656.31911.2E

34. Andersen $\mathrm{FH}$, Flaatten $\mathrm{H}$, Klepstad $\mathrm{P}$, et al (2015) Long-term survival and quality of life after intensive care for patients 80 years of age or older. Ann Intensive Care 5:53-015-0053-0. Epub 2015 Jun 3. doi: 10.1186/ s13613-015-0053-0 [doi]

35. Tabah A, Philippart F, Timsit JF, et al (2010) Quality of life in patients aged 80 or over after ICU discharge. Crit Care 14:R2. doi: 10.1186/cc8231 [doi]
36. Baldwin MR (2015) Measuring and predicting long-term outcomes in older survivors of critical illness. Minerva Anestesiol 81:650-661.

37. WHO Collaborating Centre for Drug Statistics Methodology. Available at: https://www.whocc.no/ Accessed 10.6.2018

38. Lamers LM. Pharmacy costs groups: a risk-adjuster for capitation payments based on the use of prescribed drugs. Med Care. 1999;37:824-30.

39. Lamers LM, van Vliet RC. The Pharmacy-based Cost Group model: validating and adjusting the classification of medications for chronic conditions to the Dutch situation. Health Policy. 2004:68:113-21.

40. National Health Care Institute. Available at: https://english.zorginstituutnederland.nl. Accessed 08.11.2016 


\section{CHAPTER 6}

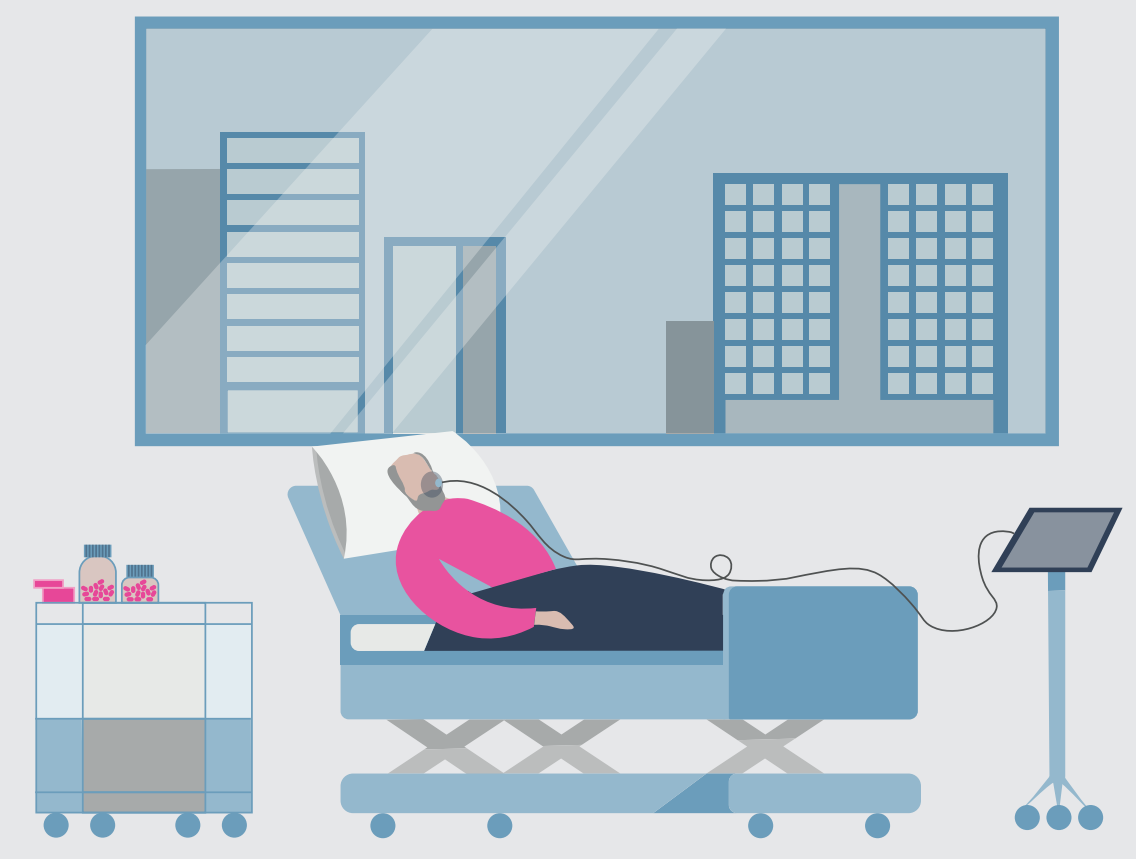

Should we deny ICU admission to the elderly?

Ethical considerations in times of COVID-19

Published in: Critical Care 2020. 


\section{Introduction}

The SARS-CoV-2 (COVID-19) pandemic leads to severe shortages of intensive care unit (ICU) facilities in many countries. Although most people appear to be asymptomatic, some reports suggest that $5 \%$ to $25 \%$ of infected people require hospitalization and 2-4\% require mechanical ventilation.[1] This strains many ICUs beyond their maximum capacity. National critical care societies have adopted protocols to increase their beds up to $200 \%$ or more. However, although a lot of effort can be done to increase the ICU capacity, demand may still outpace the supply. As a consequence, a scenario can arise in which not every patient who needs ICU treatment can be admitted, and difficult decisions about allocation of ICU beds need to be made.[2-4] In this article we discuss the use of age as a criterion for ICU treatment in times of scarce ICU capacity by contrasting it with deciding under normal conditions.

\section{Deciding about ICU treatment under normal conditions}

Medical treatment has to be justified by serving the wellbeing of the patient and it should be aligned with the wishes of the patient. The burden of an ICU treatment has to be carefully balanced against the estimated chance of recovery. This chance of recovery is affected by age, and many other factors like the admission diagnosis, severity of organ failure, comorbidities, frailty and pre-admission performance status. [5] Sometimes, ICU admission might be more appropriate for a fit 90-year-old patient than for a vulnerable 65-year-old patient.

Elderly patients (defined as 70 years and older) have a higher risk of death and of functional decline than younger patients. However, the majority of them survives and in addition, several studies have demonstrated that elderly ICU survivors might accept their disabilities and accommodate to a degree of physical disability quite well, consider their quality of life to be good or satisfactory and report good emotional and social well-being after hospital discharge.[6]

The carefully balancing of pros and cons of ICU treatment should be done before ICU admission (as Advance Care Planning) but also during a (prolonged-) ICU admission.

What is common to all decisions on starting, continuing or foregoing life support, is that they should be justified by the autonomous wish of the patient and the benefit of treatment for that unique patient. Age may play a role in these decisions in several ways. It is proxy for the medical condition of the patient, and advanced age is clearly a factor that should be weighed together with other risk factors for a poor outcome of ICU treatment. Elderly patients themselves may also have the feeling that they have lived life to its full and that therefore life-sustaining treatments should not be applied in their own case. There is, however, no valid reason to limit ICU-admissions to those under a specific age.

\section{Outcomes of elderly ICU patients with COVID-19}

Elderly patients admitted to the ICU with COVID-19 are at increased risk of death.[7,8] Although we need more robust data about short-and long-term outcomes of elderly patients admitted to the ICU because of COVID-19, the mortality rates reported up to now are $40 \%$ to $80 \% .[7,9]$ These numbers will even become higher, since at the time of reporting a substantial portion of the patients was still in the ICU and the follow-up was short.

\section{Using age as a selection criterion in time of scarcity}

In circumstances of a pandemic, not only the autonomy of the patient and proportionality of treatment, but also shortage of resources may play a role in decisions about ICU treatment. Emanuel and colleagues proposed to use an utilitarian framework. [10] This strategy aims to maximize the benefits for the largest number of people and prioritize care based on the (estimated) greatest advantage of ICU treatment, the so called "incremental probability of survival". According to this approach, for instance parents of young children should be prioritized, then parents of teenagers, middle aged people, then elderly. Chances of survival rates after ICU admission decrease with increasing age, making age an important factor in this utilitarian approach.

The use of age as a selection criterion in case of scarcity can also be justified by pointing at the 'fair innings' that a patient has had, meaning that older patients have already had their opportunity to reach a certain 'mature' age, which has given them a fair equality of opportunity. The idea is that everyone should have an equal opportunity to lead a life of a certain duration. While there is no hard and fast rule for what is an unfulfilled life age for a person, most policies distributing lifesaving resources look to those under 18 as gaining priority while those in their 80 s and beyond, who have had a chance to experience life and flourish as human being receive lower priority. We submit that this strategy does not amount to age discrimination as all people are treated alike: when they become older their claim on life-sustaining treatment decreases.

\section{Conclusion}

In this article, we discussed two ways of using age in the triage of ICU admission. Under normal circumstances, age should be weighed as a risk factor for poor outcome. Together with other risk factors, it may lead to the shared decision to forego ICU treatment. It cannot be justified to withhold ICU admission for all patients above a certain age. In times of scarcity, however, we believe it is justified to prioritize the younger patients, in order to maximize the benefits for the largest number of people, and because of the 'fair innings' that an elderly patient has already had. 


\section{References}

1. Guan W-J, Ni Z-Y, Hu Y, Liang W-H, Ou C-Q, He J-X, et al. Clinical Characteristics of Coronavirus Disease 2019 in China. N Engl J Med. 2020 Apr;382(18):1708-20.

2. Phua J, Weng L, Ling L, Egi M, Lim C-M, Divatia JV, et al. Intensive care management of coronavirus disease 2019 (COVID-19): challenges and recommendations. Lancet Respir Med. 2020 May;8(5):506-17.

3. Rosenbaum L. Facing Covid-19 in Italy - Ethics, Logistics, and Therapeutics on the Epidemic's Front Line. N Engl J Med. 2020 Mar;

4. Christian MD, Sprung CL, King MA, Dichter JR, Kissoon N, Devereaux A V, et al. Triage: care of the critically ill and injured during pandemics and disasters: CHEST consensus statement. Chest. 2014 Oct:146r4 Suppl):e615-74S.

5. Guidet B, de Lange DW, Boumendil A, Leaver S, Watson X, Boulanger C, et al. The contribution of frailty, cognition, activity of daily life and comorbidities on outcome in acutely admitted patients over 80 years in European ICUs: the VIP2 study. Intensive Care Med. 2020 Jan;46(1):57-69.

6. Kaarlola A, Tallgren M, Pettila V. Long-term survival, quality of life, and quality-adjusted life-years among critically ill elderly patients. Crit Care Med. 2006 Aug;34(8):2120-6.

7. Grasselli G, Zangrillo A, Zanella A, Antonelli M, Cabrini L, Castelli A, et al. Baseline Characteristics and Outcomes of 1591 Patients Infected With SARS-CoV-2 Admitted to ICUs of the Lombardy Region, Italy. JAMA. 2020 Apr;

8. Yang X, Yu Y, Xu J, Shu H, Xia J, Liu H, et al. Clinical course and outcomes of critically ill patients with SARSCoV-2 pneumonia in Wuhan, China: a single-centered, retrospective, observational study. Lancet Respir Med. 2020 May;8(5):475-81.

9. ICNARC report on COVID-19 in critical care. 08 May 2020. ICNARC Case Mix Programme Database. https:// www.icnarc.org/Our-Audit/Audits/Cmp/Reports.

10. Emanuel EJ, Persad G, Upshur R, Thome B, Parker M, Glickman A, et al. Fair Allocation of Scarce Medical Resources in the Time of Covid-19. N Engl J Med. 2020 Mar. 
PART II

\author{
Very old \\ patients \\ admitted to \\ the ICU for \\ sepsis
}




\section{CHAPTER 7}

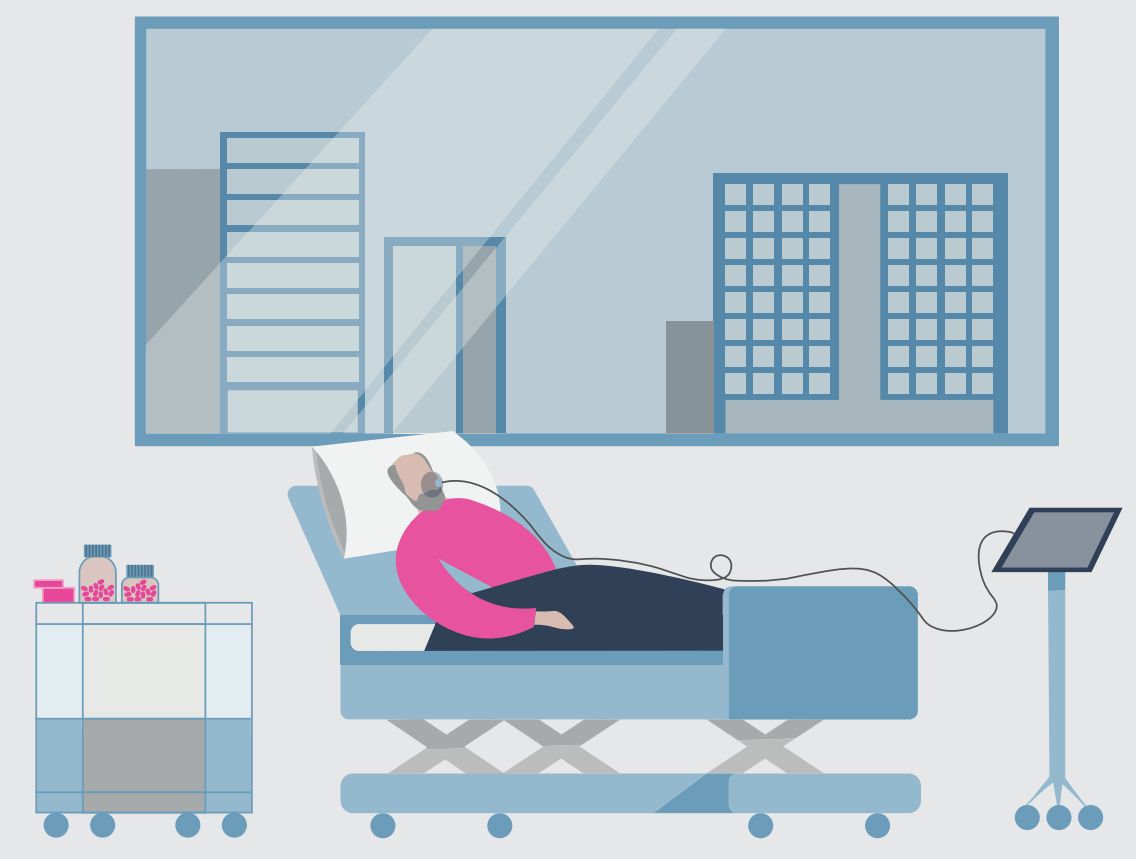

Outcome of very old patients admitted to the ICU for sepsis: a systematic review

Published in: European Geriatric Medicine 2017 


\section{Abstract}

\section{Background}

Due to ageing of the general population an increasing number of very old patients ( $>80$ years old) is admitted to the hospital and to the intensive care unit (ICU). Sepsis is one of the most frequent reasons for admission. However, it is questioned whether admission of these very old intensive care patients (abbreviated to VOPs) is always indicated, as survival is generally poor. To enhance decision making, more information about chances of VOPs is of the utmost importance for the physicians, the patients and relatives and policy-makers.

\section{Methods}

A systematic search was performed in MEDLINE and Embase up to 2017 to identify studies that described the outcome (either ICU-, hospital- mortality and/or any other short- or longterm outcome measure; e.g. 30-day mortality or one year mortality and also functional outcome and quality of life of VOPs admitted for sepsis.

\section{Results}

We identified 4,562 potentially relevant publications, 18 studies could be included. In total, 4,256 patients aged 80 years and older were incorporated in this systematic review. The median ICU mortality was 43\% [range 30-79\%], the median hospital mortality $47 \%$ [31-84\%] and the median 1-year mortality 68\% [53-83\%]

\section{Conclusions}

Although relatively few studies are performed in VOPs admitted with sepsis, mortality rates seem to be high. Future studies are needed to identify factors that can predict survival and quality of life after discharge of VOPs in order to identify subgroups that benefit most from ICU treatment.

\section{Introduction}

The proportion of people aged 80 years or older is the fastest growing segment of the European population and it is estimated to increase from $4.7 \%$ in 2010 to $11.0 \%$ in 2050 [1-3]. Although older patients comprise a minority of the population, they are responsible for a substantial proportion of hospitalizations and health care costs, including intensive care unit (ICU) treatment days [4-6]. The "very old intensive care patients" (abbreviated to VOPs; more than 80 years old) are probably the fastest expanding subgroup of all ICU patients [7].

Infection is one of the most frequent reasons for ICU admission of elderly people, with increasing incidences over the last decades [8]. Despite the fact that increasing age appears to confer a higher risk of death from severe infection there is some evidence to suggest that many older patients respond well to therapy [9-13].

The ageing population increases pressure on healthcare facilities, including the ICU, and has led to debate on the rationing of resources and stricter admission selection. Intensivists are frequently confronted with the question whether admission of elderly VOP to the ICU is appropriate, because of their relatively high risk of mortality and shorter life expectancy [14-17]. Despite sophisticated diagnostic and advanced treatment modalities, an ICU treatment may result in prolonged suffering instead of survival beyond hospital discharge with acceptable quality of life [18-24]. In addition, for many VOPs, preserving quality of life is more important than prolonging their survival $[25,26]$. This combination of the questionable benefit coupled with the altered patient preferences requires thoughtful decision-making concerning ICU admission of VOPs.

To aid treatment decisions and to guide prognostic discussion, healthcare providers need to be informed about the outcome of VOPs.

In this study, we performed a systematic review to provide an overview of outcomes of VOPs admitted for sepsis.

\section{Methods}

\section{Search strategy}

A systematic search was conducted to identify studies evaluating outcome of very elderly patients (defined as $\geq 80$ years of age) admitted to an ICU due to an infection. On 10th April 2017, a MEDLINE and Embase search was performed using synonyms of "sepsis" or "infection" and "intensive care" and "elderly". The full search details can be found in Appendix 1. Due to the great developments in ICU care in the last decade, 
only studies executed since 2005 were included. The search was limited to studies written in English, French, German and Dutch.

\section{Study selection}

First, one author screened the titles of the retrieved records to determine which warranted further examination. All potentially eligible studies were subsequently assessed by two authors based on abstracts and full texts. Disagreements were discussed with a third reviewer.

We included studies that addressed the outcome of very elderly patients, defined as aged 80 years and older, admitted to the ICU due to an infection. Studies that included or focused exclusively on patients admitted to the ICU for other reasons, but who subsequently developed an infection while in the ICU, were excluded. Every study with an outcome measurement, being either ICU mortality, hospital mortality or any other short- or long-term outcome measure (e.g. 30 day mortality or one year mortality) was included.

In case of insufficient data in the original publication, the corresponding authors were contacted in an attempt to acquire additional information that would allow the study to be included, such as specific outcome data for the $\geq 80$ years subgroup.

Finally, references of included publications were cross-referenced to retrieve any additional, relevant citations.

\section{Data extraction}

The following data were independently extracted by two authors (LH and LvD): study design (prospective or retrospective), journal and year of publication, country and time period in which the study was performed, number of patients studied, diagnoses at ICU admission, type of hospital and patient demographics (age, sex and disease severity expressed as APACHE, SAPS or SOFA score if reported), survival (ICU, hospital and long-term survival), functional outcome data and quality of life.

\section{Quality assessment}

The methodological quality of the included studies was assessed by New Castle Ottawa Scale, adapted to this particular analysis (Appendix 2a). The quality assessment was independently performed by the first two authors. Differences were discussed until a consensus was reached. When necessary, disagreements were resolved through discussion with the last author.

\section{Results}

\section{Study characteristics}

A total of 4,562 potentially relevant articles were identified by the search strategy of which 315 were duplicates. After exclusion of another 4,228 articles for various reasons (Figure 1), a total of 19 publications covering 17 different patient cohorts remained [27-45]. Cross-referencing yielded eight additional publications [46-53]. Seven studies were not published as full articles and were excluded [27, 29, 30, 41-44]. Eventually 18 studies are included in this review [28, 31, 33-37, 39, 40, 45-53].

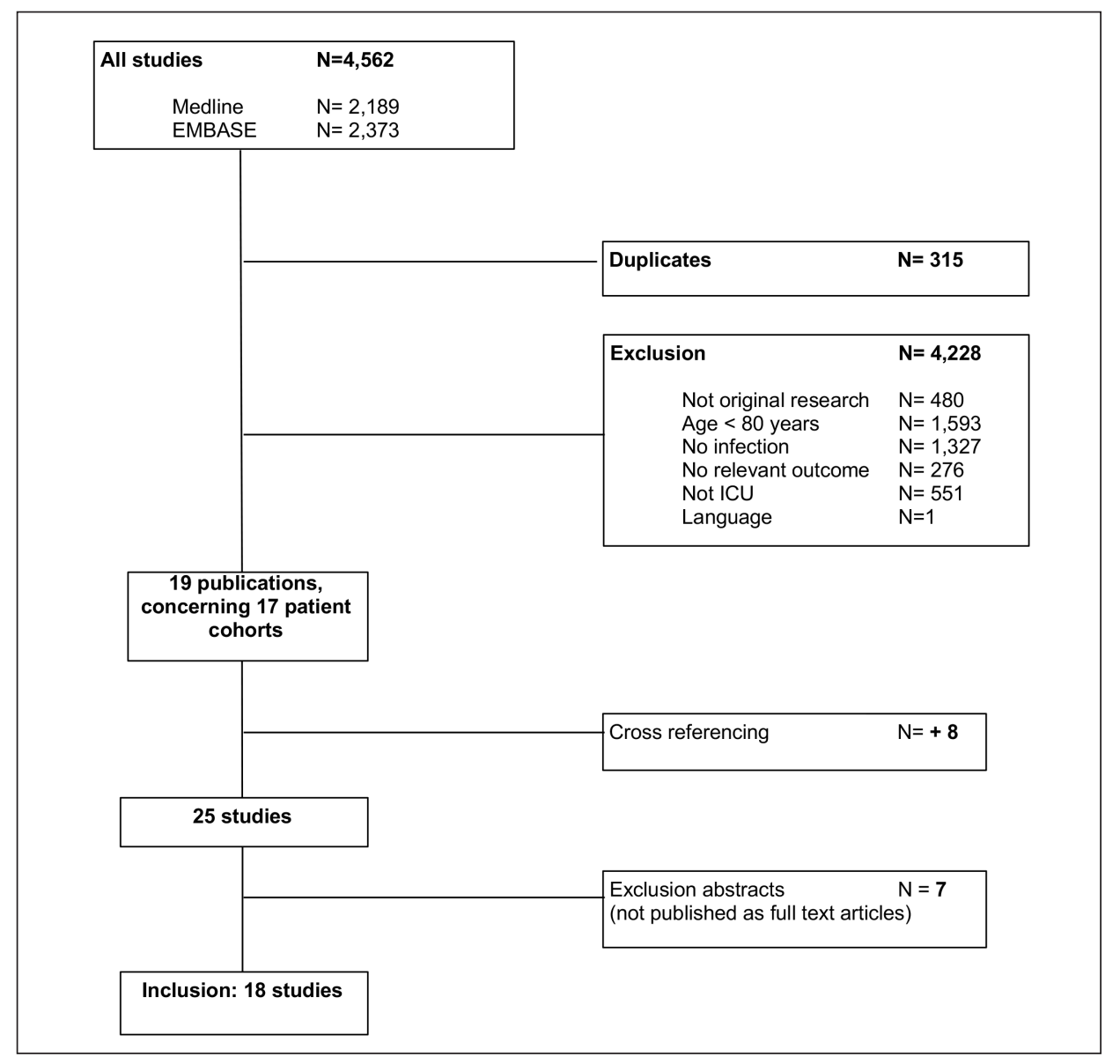

Figure 1. Search strategy and study selection 
As a result of the heterogeneity in inclusion criteria and studied outcome parameters of the different studies, a formal meta-analysis was not possible. Therefore, descriptive data are presented.

The characteristics of the included studies are summarized in Table 1. The 18 studies involved a total of 4,256 patients aged 80 years and older worldwide (number of patients included ranged from 15 to 1,735). Most studies were conducted in Europe $(n=7,39 \%)[28,45-47,50,51,53]$, six studies $(33 \%)$ in Asia [33, 35-37, 39, 49] and two studies $(11 \%)$ in North America [34, 48]. The other three included patients in respectively Australia [40], South America [52] and worldwide [31]. Twelve studies (67\%) were conducted retrospectively $[28,33,35,36,39,40,45,47,49,50,52,53]$. Thirteen studies (72\%) used an age-cut off of 80 years [33, 34, 36, 37, 40, 45, 47-50, 52, 53]; two studies $(11 \%)$ included patients aged 85 years and older $[31,35]$ and three studies $(17 \%)$ used the age-cut off of 90 years $[28,39,46]$. Eight studies (44\%) included patients with sepsis $[33,34,37,45,47,50-52]$, of which two studies (11\%) exclusively included patients with a septic shock $[45,51]$. Five studies $(28 \%)$ included patients with pneumonia [35, 39, $40,48,53]$, of which two (11\%) only included patients with pneumonia requiring invasive mechanical ventilation $[35,53]$. Two studies $(11 \%)$ included patients with pneumonia and/or sepsis $[28,49]$. The three other studies (17\%) included VOPs admitted with various types of infections $[31,36,46]$.

The study from Dreiher and colleagues [33] is the only full text study that exclusively included very elderly with an infection; the other 17 studies concerned studies in which the very elderly with an infection represented a subgroup of the study population, either because the study also included younger patients with an infection [31, 35-37, $40,48]$, or because the study also included very elderly without an infection [28, 34, $39,45-47,50-52]$, or both [49, 53].

\section{Quality assessment}

An overview of the quality assessment is shown in Figure 2; details of the assessment can be found in Appendix II. All studies scored a low risk of bias for outcome not present at start of study, assessment of outcome and adequacy of follow up. One study scored a high risk of bias [31] and four an intermediate risk of bias [35, 36, 45, 51, 53] for representativeness of exposed cohort. The study of Dimopoulos et al. included ICU patients with an infection using a 1-day point-prevalence study design, and therefore may not have exclusively included patients admitted to the ICU with an infection, but probably also some with ICU acquired infections [31]. Docherty, Izhakian and Hifumi focused exclusively on VOPs with pneumonia requiring mechanical ventilation [35, 36, 53] and Tabah and Voga addressed only patients with a septic shock [45, 51].

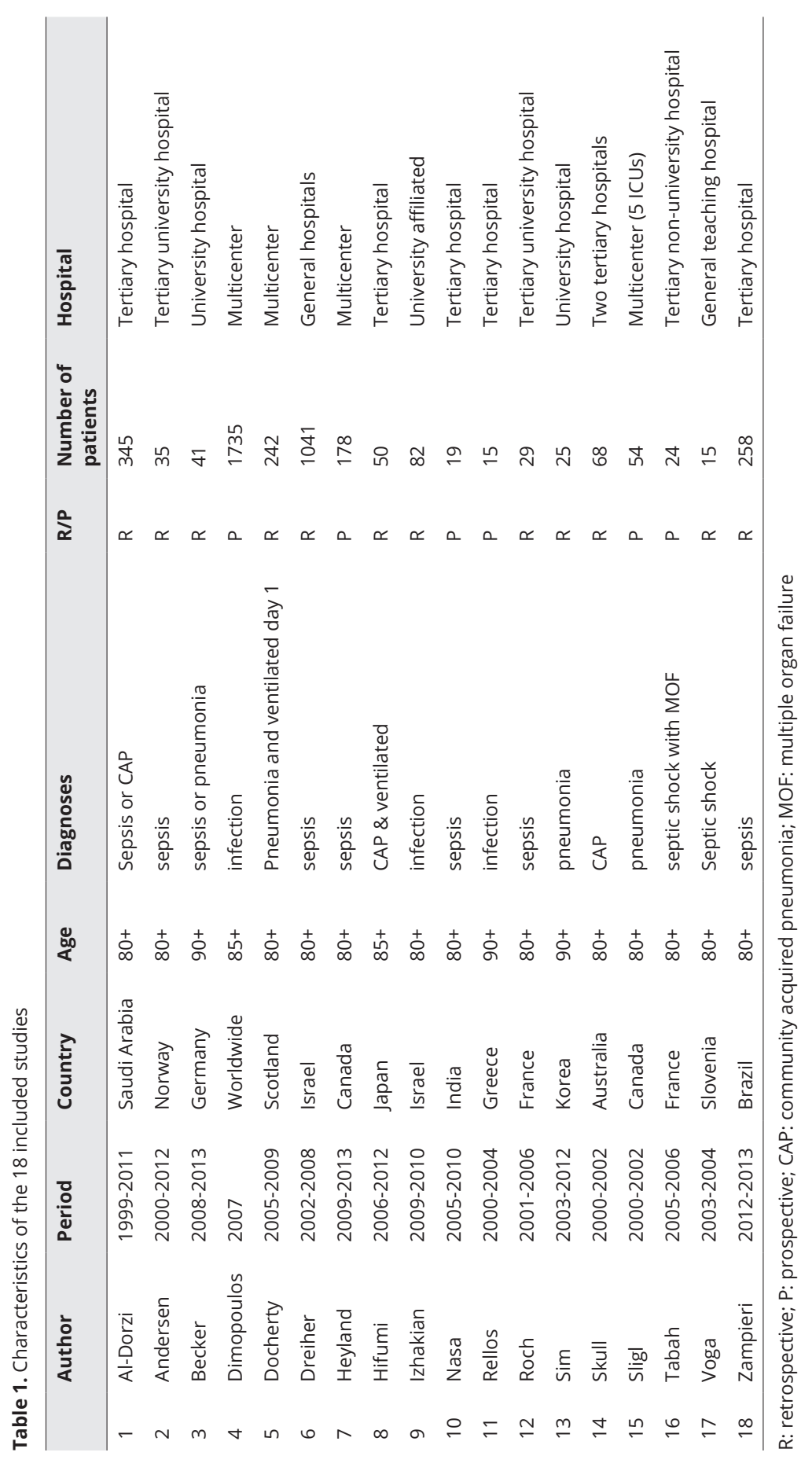


Quality assessment: Selection Quality assessment: Outcome
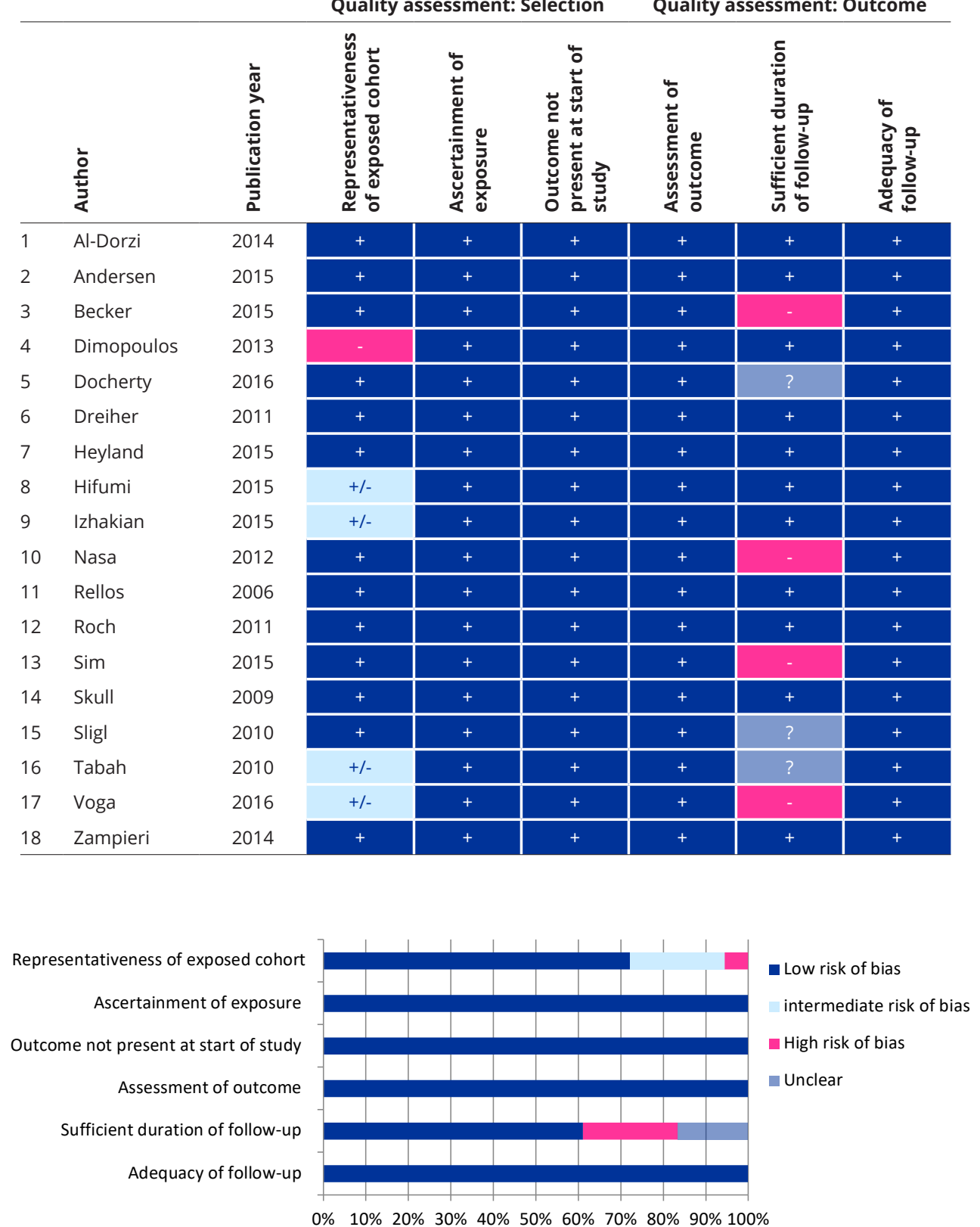

$0 \% 10 \% 20 \%$ 30\% $40 \%$ 50\% $60 \%$ 70\% $80 \%$ 90\% $100 \%$

Figure 2. Quality assessment, New Castle - Ottawa Quality Assessment Scale
Seven studies do not report hospital mortality: four studies report exclusively ICUmortality [28, 37, 39, 45], one report ICU- and 1-year mortality [53]; another only reports 30-days and 1-year mortality [48] and another reports only 1-year mortality [51].

\section{Short-term outcome}

ICU-mortality was reported in 9 studies including a total number of 2632 patients, with a median of $43 \%$ (range $30-79 \%$, mean $50 \%$, Figure 3a) $[28,31,34,37,39,45,49,50,53$ ] Hospital mortality was reported in 11 studies including a total number of 3836 patients with a median mortality rate of $47 \%$ (range $31-84 \%$, mean $51 \%$, Figure 3b) [31, 33-36, 40, $46,47,49,50,52]$. Two studies reported 30 -days mortality of resp. $51 \%$ and $30 \%[48,50]$.

A.

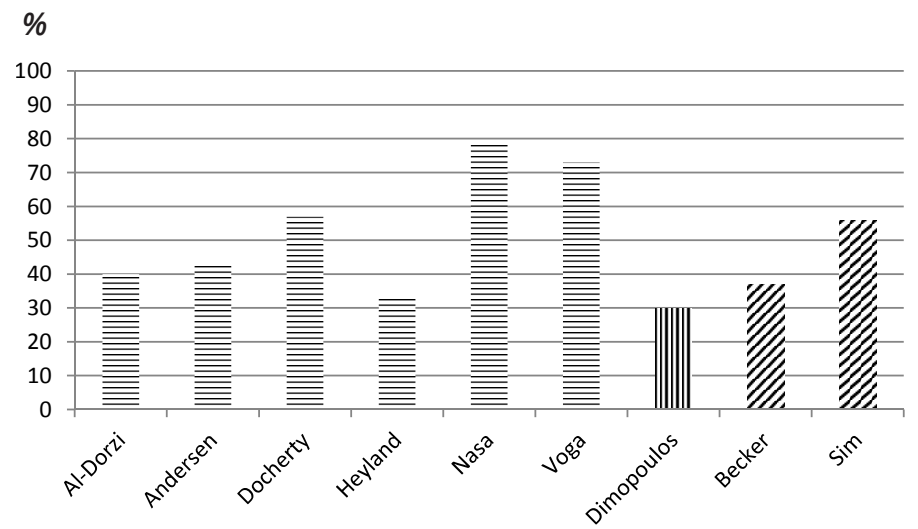

Horizontal stripes: patients aged 80 years and older, vertical stripes: patients aged 85 years and older, diagonal stripes: patients aged

Figure 3A. ICU-mortality

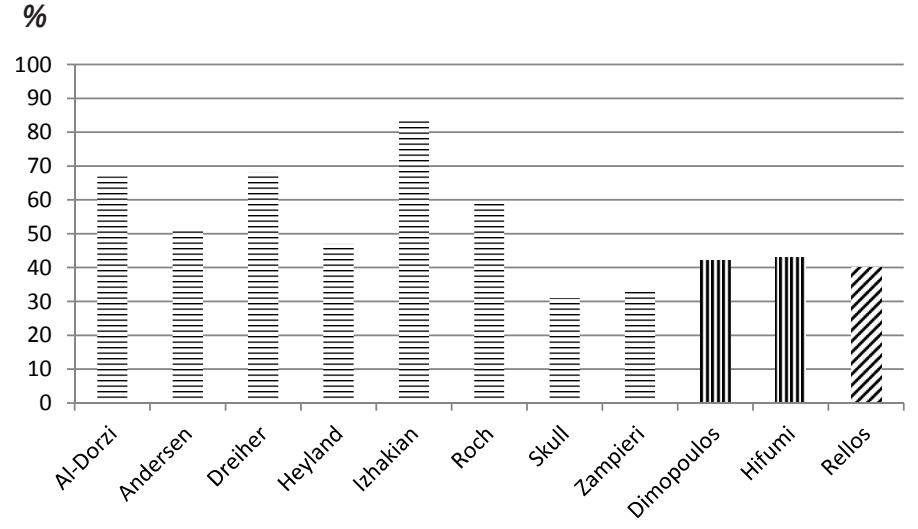

Horizontal stripes: patients aged 80 years and older, vertical stripes: patients aged 85 years and older, diagonal stripes: patients aged years and older.

Figure 3B. Hospital mortality 


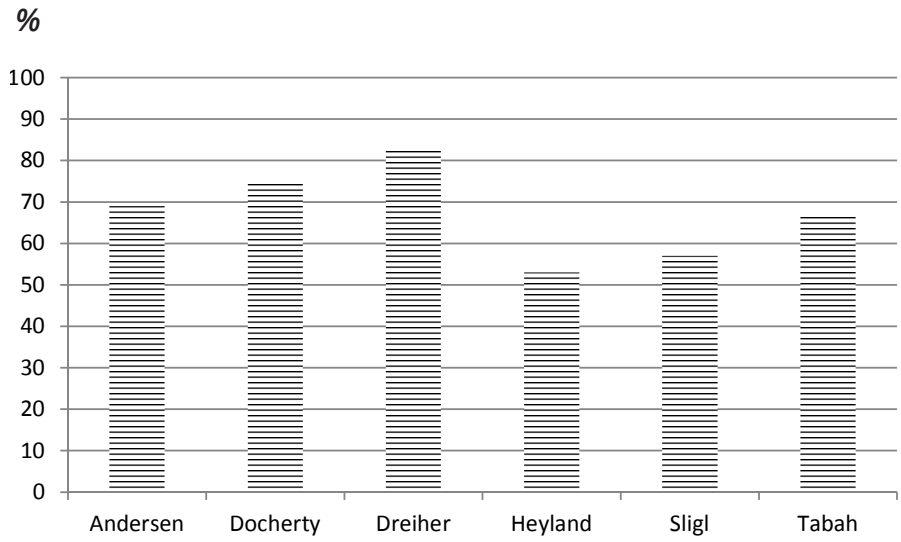

Patients aged 80 years and older.

Figure 3C. 1-year mortality

\section{Long-term outcomes}

Six studies with a total number of 1574 patients reported the one-year mortality of VOPs with sepsis, ranging from $53 \%$ to $83 \%$, with a median mortality after one year of $68 \%$, Figure 3C) $[33,34,48,50,51,53]$.

Andersen has sent us mortality data of the VOPs admitted for sepsis after 90 and 180 days (both 60\%) and after two and five years (both 79\%) [50]. The study of Dreiher and colleagues also report mortality rates after two and five years, respectively $85 \%$ and $92 \%$. Additionally, they reported mortality after 8 -years, which was $94 \%$ (while the life expectancy in Israel in that time period, 2002-2008, was 79,45-80,95 years) [33].

\section{Functional outcome and quality of life}

Data about functional outcome of the VOPs were reported in three studies [47, 50,51], but these data concern the total group and unfortunately no information was available about functional outcome of the subgroup VOPs admitted for sepsis. One study reported that almost 10\% of long-term ICU survivors was bedridden and one third experiencing severe functional limitations [47]. In contrast, Tabah et al. reported that one year after ICU discharge, 80\% of the patients still alive were independent in their basic activities of daily living [51]. Two studies reported on health-related quality of life (HRQOL) in survivors and found this to be equal [50] or even slightly better [51] than in an age-matched sample of the general population.

\section{Comparison of outcome of VOPs admitted for sepsis with other patient}

Comparison with younger patients (See appendix C.1)

Results regarding comparisons of outcome of the very elderly and younger patients are contradictory. Two studies reported similar outcomes irrespective of age [35, 40], while other studies showed significantly higher mortality rates for the very elderly [31, $37,39,48-50]$, with age per se as an independent risk factor for mortality [39, 48-50]. Sligl showed that, compared with patients younger than 60 years of age, the crude hazard ratios (HR) for short-term (30-day) and long-term (1-year) mortality of VOPs admitted for pneumonia was respectively 3.03 and 4.18 . In multivariable analysis, age was independently associated with mortality at 30 days and 1-year (adjusted HR respectively 1.24 and 1.39 per 10 -yr increase) [48].

Comparison with patients with another reason for admission than infection

Outcome of VOPs admitted for sepsis showed to be worse [28, 34, 39, 50, 52] or equivalent $[46,47,51]$ compared to the outcome of VOPs admitted for other reasons (See appendix C.2)

\section{Discussion}

In this systematic review, we present an overview of the outcomes of various studies looking at VOPs with sepsis. We showed that mortality rates are high, with a median ICU-mortality of $43 \%$, a median hospital mortality of $47 \%$ and a 1 -year mortality of $68 \%$. Although VOPs compose a significant proportion of the ICU population, literature about their outcome is, unfortunately, relatively scarce. The proportion of people aged 80 years or older is the fastest growing segment of the European population and they are responsible for a substantial proportion of hospitalizations, including ICU admissions [3-6]. Increasing age is associated with increasing rate of infection on admission to the ICU and pneumonia and sepsis are leading causes of morbidity and mortality in very elderly, with incidences that are still increasing [54-60].

Being old entails that the life expectancy is considerably shortened. It is, therefore, logical to balance the harm of ICU care against the potential life years saved. For this, we need to know what the average prognosis is of VOPs. While the prognosis of VOPs has been the subject of several recent studies [20,21,61-63], these studies included patients admitted because of heterogeneous reasons, including elective and emergency surgery. Elective surgery patients represent a quite different patient category than emergency admissions due to an infection. Current data suggest that planned surgical patients aged 80 years and older may benefit from ICU care [62-65], but for VOPs who 
are admitted for medical reasons, the benefits of an ICU hospitalization are less clear. Therefore, the main strength of this paper is that it focuses exclusively on the outcome of VOPs with an infection. However, we could not prevent that the included studied differed in included populations and endpoints.

We found that the mortality of VOPs admitted with an infection was higher than mortality of the total cohort VOPs in several studies [28, 34, 39, 45, 50, 52] and, as expected, it seems to be that VOPs have a much higher short- and long-term mortality than younger patients who are admitted for the same infectious reason (see Appendix III) $[31,36,37,40,45,46,48,53]$. Of course, these results are difficult to translate to individual patients. The mortality rates are averages with quite wide ranges due to heterogeneity of included patients.

For the majority of very elderly, preserving quality of life is more important than prolonging survival. Unfortunately, only a minority of the included studies reported on HRQoL or functional outcomes and none of these reported these data for the subgroup VOPs admitted with an infection. Somewhat counter-intuitive, most survivors suffered from severe functional disability [47], but $\mathrm{HRQ}$ oL was not decreased compared to the general population [50,51]. One possible explanation is that, while self-sufficiency is an objective outcome, HRQoL assessments concerns the individual's perception of their position in life in the context of the culture and value systems in which they live and in relation to their goals, expectations and concerns [66, 67]. As a consequence, HRQoL may have a different meaning for older individuals than it does for younger ones.

This review has some limitations. First, we were not able to include some of the studies we identified, as they used age only as a factor in regression analyses, but did not report absolute mortality rates. In these cases, we contacted the authors in an attempt to obtain additional data, but were not always successful. Second, while the number of patients who were admitted to the ICUs is known, the size of the pool from which these patients were derived is unknown. There is evidence to suggest that age is a restrictive factor for ICU admission [19, 53, 68-71] and thus, the very elderly included in this review could therefore represent the fitter part, resulting in better outcome data. Unfortunately, few data were presented on patient characteristics, such as comorbidity, performance status and frailty, or disease-related factors such as the severity of illness, all of which are known to affect outcome.[47,52, 72-77] On the other hand, it has been demonstrated that very elderly receive less aggressive treatment on the ICU, which could have led to a higher mortality compared to younger patients [62, 78-81].

Overall, it is disappointing that only a few good studies could be found, while there is so much debate about this subject these days. Information about the outcome of this population is of utmost importance in the rationing of resources, necessary due to the ageing of the population with increasing pressures on healthcare. Further large multicenter studies on the longer-term outcomes of elderly ICU patients are warranted, with more detailed assessments of functional outcome and quality of life. Understanding the factors associated with good outcome of VOPs with infections is of great importance and could aid individual decision making with regard to admission or withdrawal and limitation of therapy. When patient groups with poor prognosis are characterized, courageous ethical decisions are required in order to prevent unnecessary suffering of the patients and their families.

\section{Conclusion}

In conclusion, literature about the outcome of VOPs admitted for sepsis is scarce. Reported mortalities are high; almost half of the patients died in the hospital and after one year more than two thirds of the patients have died. VOPs who survived experience significant disability, although HRQoL is often maintained.

Future research is required to better quantify outcomes of this subgroup, including important issues as post-discharge survival and health-related quality of life, because expected benefits of these VOPs are expected to be less, while costs are considerable. 


\section{References}

1 Population Division, Department of Economic and Social Affairs (DESA), United Nations. World population ageing: 1950-2050. 2002. Report No.: 207 2 Lutz W, Sanderson W, Scherbov S. The coming acceleration of global population ageing. Nature. $2008 \mathrm{Feb}$

3 Population structure by major age groups, EU-28, 2015-80 [Internet]. Available from: http://ec.europa. eu/eurostat/statistics-explained/index.php/File:Population_structure_by_major_age_groups,_EU28,_2015\%E2\%80\%9380_(\%C2\%B9)_(\%25_of_total_population)_YB16.png.

4 Boumendil A, Guidet B. Elderly patients and intensive care medicine. Intensive Care Med. 2006 Jul;32(7):965-7.

5 Song X, MacKnight C, Latta R, Mitnitski AB, Rockwood K. Frailty and survival of rural and urban seniors: Results from the canadian study of health and aging. Aging Clin Exp Res. 2007 Apr;19(2):145-53.

6 Carson SS. The epidemiology of critical illness in the elderly. Crit Care Clin. 2003 Oct; 19(4):605,17, v.

7 Flaatten H, de Lange DW, Artigas A, Bin D, Moreno R, Christensen S, et al. The status of intensive care medicine research and a future agenda for very old patients in the ICU. Intensive Care Med. $2017 \mathrm{Feb} 25$.

8 Health care cost and utilization project [Internet]. Available from: http://hcup-us.ahrq.gov/faststats/Nati cluded2=18expansionlnfoState-hide\&datablestate=hide\&definitionsState=hide\&exportState=hide.

9 Kaplan V, Angus DC, Griffin MF, Clermont G, Scott Watson R, Linde-Zwirble WT. Hospitalized communityacquired pneumonia in the elderly: Age- and sex-related patterns of care and outcome in the united states. Am J Respir Crit Care Med. 2002 Mar 15;165(6):766-72.

10 Luna CM, Palma I, Niederman MS, Membriani E, Giovini V, Wiemken TL, et al. The impact of age and pneumonia. Ann Am Thorac Soc 2016 Sep:13(9):1519-26.

11 Janssens JP, Krause KH. Pneumonia in the very old. Lancet Infect Dis. 2004 Feb;4(2):112-24.

12 Nasa P, Juneja D, Singh O. Severe sepsis and septic shock in the elderly: An overview. World J Crit Care Med. 2012 Feb 4;1(1):23-30.

13 Winters BD, Eberlein M, Leung J, Needham DM, Pronovost PJ, Sevransky JE. Long-term mortality and quality of life in sepsis: A systematic review. Cit Care Med. 2010 May:38(5):1276-83.

14 Nguyen $\mathrm{YL}$, Angus DC, Boumendil A, Guidet B. The challenge of admitting the very elderly to intensive care. Ann Intensive Care. 2011 Aug 1;1(1):29,5820-1-29.

15 Laake JH, Dybwik K, Flaatten HK, Fonneland IL, Kvale R, Strand K. Impact of the post-world war I generation on intensive care needs in norway. Acta Anaesthesiol Scand. 2010 Apr;54(4):479-84.

16 Flaatten H. The impact of age in intensive care. Acta Anaesthesiol Scand. 2014 Jan;58(1):3-4.

17 Esteban A, Anzueto A, Frutos-Vivar F, Alia I, Ely EW, Brochard L, et al. Outcome of older patients receiving mechanical ventilation. Intensive Care Med. 2004 Apr;30(4):639-46.

18 Vosylius S, Sipylaite J, Ivaskevicius J. Determinants of outcome in elderly patients admitted to the intensive care unit. Age Ageing. 2005 Mar;34(2):157-62.

19 Garrouste-Orgeas M, Timsit JF, Montuclard L, Colvez A, Gattolliat O, Philippart F, et al. Decision-making process, outcome, and 1-year quality of life of octogenarians referred for intensive care unit admission.
20 Boumendil A, Latouche A, Guidet B, ICE-CUB Study Group. On the benefit of intensive care for very old patients. Arch Intern Med. 2011 Jun 27;171(12):1116-7.

21 Fuchs L, Chronaki CE, Park S, Novack V, Baumfeld Y, Scott D, et al. ICU admission characteristics and mortality rates among elderly and very elderly patients. Intensive Care Med. 2012 Oct;38(10):1654-61.

22 Chelluri L, Im KA, Belle SH, Schulz R, Rotondi AJ, Donahoe MP, et al. Long-term mortality and quality of life after prolonged mechanical ventilation. Crit Care Med. 2004 Jan;32(1):61-9.

23 Ely EW, Wheeler AP, Thompson BT, Ancukiewicz M, Steinberg KP, Bernard GR. Recovery rate and prognosis in older persons who develop acute lung injury and the acute respiratory distress syndrome. Ann Intern Med. 2002 Jan 1;136(1):25-36.

24 Jandziol AK, Ridley SA. Validation of outcome prediction in elderly patients. Anaesthesia. 2000 Feb;55(2):107-12.

25 Philippart F, Vesin A, Bruel C, Kpodji A, Durand-Gasselin B, Garcon P, et al. The ETHICA study (part I): (1)

26 Heyland DK, Barwich D, Pichora D, Dodek P, Lamontagne F, You JJ, et al. Failure to engage hospitalized elderly patients and their families in advance care planning. JAMA Intern Med. 2013 May 13;173(9):77887.

27 Anumakonda V, Garud C. Community acquired pneumonia (CAP) in octogenarians admitted to a critical care unit at a district general hospital (DGH): Dilemma of an intensivist. Intensive Care Med. 2011 ;37:S121

28 Becker S, Muller J, de Heer G, Braune S, Fuhrmann V, Kluge S. Clinical characteristics and outcome of very elderly patients $>/=90$ years in intensive care: A retrospective observational study. Ann Intensive Care. 2015 Dec;5(1):53,015-0097-1. Epub 2015 Dec 21.

29 Boon K, Sentjens R, Sleeswijk M. A high post ICU mortality in elderly patients admitted to the ICU with abdominal sepsis. Intensive Care Med. 2011 /;37:S217.

30 Bramall J, Hogan B, Agarwal B, Walecka A. Outcomes for very elderly patients admitted to intensive community acquired pneumonia: A single centre experience. Intensive Care Med. 2012

31 Dimopoulos G, Koulenti D, Blot S, Sakr Y, Anzueto A, Spies C, et al. Critically ill elderly adults with Dec;61(12):2065-71.

32 Dreiher J, Einav S, Codish S, Singer P, Talmor D, Almog Y, et al. Long-term survival of octogenarian following intensive care admission with sepsis: A multicenter study. Eur J Intern Med. 2011 /;22:S27.

33 Dreiher J, Almog Y, Sprung CL, Codish S, Klein M, Einav S, et al. Temporal trends in patient characteristics and survival of intensive care admissions with sepsis: A multicenter analysis*. Crit Care Med. 2012 Mar;40(3):855-60.

34 Heyland D, Cook D, Bagshaw SM, Garland A, Stelfox HT, Mehta S, et al. The very elderly admitted to ICU: A quality finish? Crit Care Med. 2015 Jul;43(7):1352-60.

35 Hifumi T, Jinbo I, Okada I, Kiriu N, Kato H, Koido Y, et al. The impact of age on outcomes of elderly ED patients ventilated due to community acquired pneumonia. Am J Emerg Med. 2015 Feb;33(2):277-81.

36 Izhakian S, Buchs AE. Characterization of patients who were mechanically ventilated in general medicine wards. Isr Med Assoc J. 2015 Aug; 17(8):496-9.

37 Nasa P, Juneja D, Singh O, Dang R, Arora V. Severe sepsis and its impact on outcome in elderly and very elderly patients admitted in intensive care unit. J Intensive Care Med. 2012 May-Jun;27(3):179-83. 
38 Juneja D, Singh O, Javeri Y, Garg N. Severe sepsis and its impact on outcome in old and very old patients admitted to the intensive care unit. Crit Care. 2010 2010/09;14:S15.

39 Sim YS, Jung H, Shin TR, Kim DG, Park SM. Mortality and outcomes in very elderly patients 90 years of age or older admitted to the ICU. Respir Care. 2015 Mar;60(3):347-55.

40 Skull SA, Andrews RM, Byrnes GB, Campbell DA, Kelly HA, Brown GV, et al. Hospitalized communityacquired pneumonia in the elderly: An australian case-cohort study. Epidemiol Infect. 2009 Feb;137(2):194 202.

41 Stuart E, Ure D. Outcomefromsepsisrelatedtoageinascottish intensivecare unit. Intensive Care Med. 2011 l;37:S146.

42 Touqir Z, Shaheen S, Upadhyay S, Marak CP, Kumar G, Guddati AK. Outcomes of severe sepsis in very elderly (age >80 years) patients with metastatic cancer. J Clin Oncol. 2013 2013/05;31(15).

43 Vijhani P, Patarroyo G, Duggal A, Guzman J. Outcomes of elderly patients admitted to a medical icu with severe sepsis and septic shock. Chest. 2014 /;146(4).

44 Knafelj R, Fister M. Octagenerians in medical ICU-adding days to life or life to days? . Critical Care. 2016;20(SUPPL. 2).

45 Voga G, Gabrscek-Pareznik L. Early hemodynamic assessment and treatment of elderly patients in the medical ICU. Wien Klin Wochenschr. 2016 Dec;128(Suppl 7):505-11.

46 Rellos K, Falagas ME, Vardakas KZ, Sermaides G, Michalopoulos A. Outcome of critically ill oldest-old patients (aged 90 and older) admitted to the intensive care unit. J Am Geriatr Soc. 2006 Jan;54(1):110-4.

47 Roch A, Wiramus S, Pauly V, Forel JM, Guervilly C, Gainnier M, et al. Long-term outcome in medical patients aged 80 or over following admission to an intensive care unit. Crit Care. 2011;15(1):R36.

48 Sligl WI, Eurich DT, Marrie TJ, Majumdar SR. Age still matters: Prognosticating short- and long-term mortality for critically ill patients with pneumonia. Crit Care Med. 2010 Nov;38(11):2126-32.

49 Al-Dorzi HM, Tamim HM, Mundekkadan S, Sohail MR, Arabi YM. Characteristics, management and outcomes of critically ill patients who are 80 years and older: A retrospective comparative cohort study. BMC Anesthesiol. 2014 Dec 20;14:126,2253-14-126. eCollection 2014.

50 Andersen $\mathrm{FH}$, Flaatten $\mathrm{H}$, Klepstad P, Romild U, Kvale R. Long-term survival and quality of life after intensive care for patients 80 years of age or older. Ann Intensive Care. 2015 Dec;5(1):53,015-0053-0. Epub 2015 Jun 3.

[51 Tabah A, Philippart F, Timsit JF, Willems V, Francais A, Leplege A, et al. Quality of life in patients aged 80 or over after ICU discharge. Crit Care. 2010;14(1):R2.

52 Zampieri FG, Colombari F. The impact of performance status and comorbidities on the short-term eCollection 2014.

53 Docherty AB, Anderson NH, Walsh TS, Lone NI. Equity of access to critical care among elderly patients in scotland: A national cohort study. Crit Care Med. 2016 Jan;44(1):3-13.

54 Gavazzi G, Krause KH. Ageing and infection. Lancet Infect Dis. 2002 Nov;2(11):659-66.

55 Pawelec G, Solana R, Remarque E, Mariani E. Impact of aging on innate immunity. J Leukoc Biol. 1998 Dec;64(6):703-12.

56 Angus DC, Linde-Zwirble WT, Lidicker J, Clermont G, Carcillo J, Pinsky MR. Epidemiology of severe sepsis in the united states: Analysis of incidence, outcome, and associated costs of care. Crit Care Med. 2001 Jul;29(7):1303-10
57 Martin GS, Mannino DM, Eaton S, Moss M. The epidemiology of sepsis in the united states from 1979 through 2000. N Engl J Med. 2003 Apr 17;348(16):1546-54.

58 Mokdad AH, Marks JS, Stroup DF, Gerberding JL. Correction: Actual causes of death in the united states, 2000. JAMA. 2005 Jan 19;293(3):293-4.

59 Niederman MS, Ahmed QA. Community-acquired pneumonia in elderly patients. Clin Geriatr Med. 2003 Feb; 19(1):101-20.

60 Loeb M. Pneumonia in older persons. Clin Infect Dis. 2003 Nov 15;37(10):1335-9.

61 Ball IM, Bagshaw SM, Burns KE, Cook DJ, Day AG, Dodek PM, et al. A clinical prediction tool for hospita mortality in critically ill elderly patients. J Crit Care. 2016 Oct; 35:206-12.

62 Nielsson MS, Christiansen CF, Johansen MB, Rasmussen BS, Tonnesen E, Norgaard M. Mortality in elderly ICU patients: A cohort study. Acta Anaesthesiol Scand. 2014 Jan;58(1):19-26.

63 Bagshaw SM, Webb SA, Delaney A, George C, Pilcher D, Hart GK, et al. Very old patients admitted to intensive care in australia and new zealand: A multi-centre cohort analysis. Crit Care. 2009;13(2):R45.

64 de Rooij SE, Govers A, Korevaar JC, Abu-Hanna A, Levi M, de Jonge E. Short-term and long-term mortality in very elderly patients admitted to an intensive care unit. Intensive Care Med. 2006 Jul;32(7):1039-44.

65 Williams TA, Dobb GJ, Finn JC, Webb SA. Long-term survival from intensive care: A review. Intensive Care Med. 2005 Oct;31(10):1306-15.

66 Azoulay E, Kentish-Barnes N, Pochard F. Health-related quality of life: An outcome variable in critical care survivors. Chest. 2008 Feb;133(2):339-41.

67 The world health organization quality of life assessment (WHOQOL): Position paper from the world health organization. Soc Sci Med. 1995 Nov;41(10):1403-9.

68 Sinuff T, Kahnamoui K, Cook DJ, Luce JM, Levy MM, Values Ethics and Rationing in Critical Care Task Force. Rationing critical care beds: A systematic review. Crit Care Med. 2004 Jul;32(7):1588-97.

69 Sprung CL, Geber D, Eidelman LA, Baras M, Pizov R, Nimrod A, et al. Evaluation of triage decisions for intensive care admission. Crit Care Med. 1999 Jun;27(6):1073-9.

70 Garrouste-Orgeas M, Boumendil A, Pateron D, Aergerter P, Somme D, Simon T, et al. Selection of intensive care unit admission criteria for patients aged 80 years and over and compliance of emergency and intensive care unit physicians with the selected criteria: An observational, multicenter, prospective study. Crit Care Med. 2009 Nov;37(11):2919-28.

71 Joynt GM, Gomersall CD, Tan P, Lee A, Cheng CA, Wong EL. Prospective evaluation of patients refused admission to an intensive care unit: Triage, futility and outcome. Intensive Care Med. 2001 Sep;27(9):1459-65.

72 Boumendil A, Maury E, Reinhard I, Luquel L, Offenstadt G, Guidet B. Prognosis of patients aged 80 years and over admitted in medical intensive care unit. Intensive Care Med. 2004 Apr:30(4):647-54.

73 de Rooij SE, Abu-Hanna A, Levi M, de Jonge E. Factors that predict outcome of intensive care treatment in very elderly patients: A review. Crit Care. 2005 Aug;9(4):R307-14.

74 de Rooij SE, Abu-Hanna A, Levi M, de Jonge E. Identification of high-risk subgroups in very elderly intensive care unit patients. Crit Care. 2007;11(2):R33.

75 Somme D, Maillet JM, Gisselbrecht M, Novara A, Ract C, Fagon JY. Critically ill old and the oldest-old patients in intensive care: Short- and long-term outcomes. Intensive Care Med. 2003 Dec;29(12):2137-43.

76 Ryan D, Conlon N, Phelan D, Marsh B. The very elderly in intensive care: Admission characteristics and mortality. Crit Care Resusc. 2008 Jun;10(2):106-10. 
77 Christiansen CF, Christensen S, Johansen MB, Larsen KM, Tonnesen E, Sorensen HT. The impact of pre-admission morbidity level on 3-year mortality after intensive care: A danish cohort study. Acto pre-admission morbidity level on 3-year mos
Anaesthesiol Scand. 2011 Sep;55(8):962-70.

78 Boumendil A, Aegerter P, Guidet B, CUB-Rea Network. Treatment intensity and outcome of patients aged 80 and older in intensive care units: A multicenter matched-cohort study. J Am Geriatr Soc. 2005 Jan;53(1):88-93.

79 Boumendil A, Somme D, Garrouste-Orgeas M, Guidet B. Should elderly patients be admitted to the intensive care unit? Intensive Care Med. 2007 Jul;33(7):1252-62.

80 Brandberg $\mathrm{C}$, Blomqvist $\mathrm{H}$, Jirwe $\mathrm{M}$. What is the importance of age on treatment of the elderly in the intensive care unit? Acta Anaesthesiol Scand. 2013 Jul;57(6):698-703.

81 Hamel MB, Davis RB, Teno JM, Knaus WA, Lynn J, Harrell F.Jr, et al. Older age, aggressiveness of care, and
survival for seriously ill, hospitalized adults. SUPPORT investigators. study to understand prognoses and preferences for outcomes and risks of treatments. Ann Intern Med. 1999 Nov 16;131(10):721-8.

\section{Appendices}

\section{A. Medline and Embase search}

(((("Infection"[Mesh]) OR "Sepsis"[Mesh]) OR ((infection[tiab] OR infectious[tiab] OR sepsis[tiab] OR septic[tiab]) AND ("2005/03/19"[PDAT] : “2017/04/10"[PDAT]) AND Humans[Mesh] AND (Dutch[lang] OR French[lang] OR English[lang] OR German[lang]))), AND ("last 10 years"[PDat] AND Humans[Mesh] AND (Dutch[lang] OR French[lang] OR English[lang] OR German[lang]))) AND ((((((“Intensive Care”[Mesh]) OR “Critica Care"[Mesh]) OR ((critical[tiab] OR intensive[tiab]) AND care[tiab]))) AND ((“Aged, 80 and over"[Mesh]) OR (senior*[tiab]) OR (elderly[tiab] OR geriatric[tiab] OR octogenarian*[tiab] OR nonagenarian*[tiab] OR centenarian*[tiab])))

\section{B. New Castle - Ottawa Quality Assessment Scale}

\begin{tabular}{|c|c|c|}
\hline \multirow{3}{*}{ 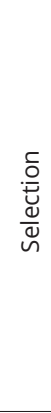 } & Representativeness of the exposed cohort & $\begin{array}{l}+ \text { Truly representative of the average VOP with } \\
\text { sepsis } \\
+/ \text { Somewhat representative of the average } \\
\text { VOP with sepsis } \\
\text { ? No description of the derivation of the cohort } \\
\text { Not representative of the average VOP with } \\
\text { sepsis }\end{array}$ \\
\hline & Ascertainment of exposure & $\begin{array}{l}+ \text { Clearly described that patient was admitted } \\
\text { to an ICU } \\
\text { ? No description }\end{array}$ \\
\hline & Outcome not present at start of study & $\begin{array}{l}+ \text { Yes } \\
- \text { No }\end{array}$ \\
\hline \multirow{3}{*}{ 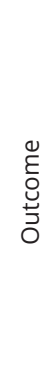 } & Assessment of outcome & $\begin{array}{l}+ \text { Record linkage } \\
? \text { No description }\end{array}$ \\
\hline & Sufficient duration of follow-up & $\begin{array}{l}+\quad \text { Yes (Survived to hospital discharge) } \\
\text { - No (only ICU mortality) } \\
\text { ? unclear }\end{array}$ \\
\hline & Adequacy of follow-up & $\begin{array}{l}+ \text { Complete follow-up } \\
+ \text { Subjects lost to follow up, unlikely to } \\
\text { introduce bias } \\
\text { - Follow-up rate }<10 \% \text { and no description of } \\
\text { those lost } \\
\text { ? No statement }\end{array}$ \\
\hline
\end{tabular}




\section{Comparison of outcomes of VOPs admitted for sepsis with other patient} subgroups admitted to the ICU

C1. Comparison with younger patients admitted to the ICU for sepsis.

\begin{tabular}{|c|c|c|c|c|c|}
\hline Mortality & VOP & \multicolumn{4}{|c|}{ Younger patients (age, yrs) } \\
\hline Dimopoulos & & $18-44$ & $45-64$ & $65-74$ & $75-84$ \\
\hline $\begin{array}{l}\text { ICU } \\
\text { Hospital }\end{array}$ & $\begin{array}{l}32 \% * \\
45 \% *\end{array}$ & $\begin{array}{l}17 \% \\
21 \%\end{array}$ & $\begin{array}{l}25 \% \\
31 \%\end{array}$ & $\begin{array}{l}29 \% \\
38 \%\end{array}$ & $\begin{array}{l}31 \% \\
42 \%\end{array}$ \\
\hline Docherty & & \multicolumn{2}{|c|}{$<65$} & \multicolumn{2}{|c|}{$31 \%$} \\
\hline $\begin{array}{l}\text { ICU } \\
\text { 1-year }\end{array}$ & $\begin{array}{l}57 \% \\
75 \%\end{array}$ & \multicolumn{2}{|c|}{$\begin{array}{l}30 \% \\
41 \%\end{array}$} & \multicolumn{2}{|c|}{$\begin{array}{l}55 \% \\
61 \%\end{array}$} \\
\hline Hifumi & & \multicolumn{2}{|c|}{$65-74$} & \multicolumn{2}{|c|}{$75-84$} \\
\hline Hospital & $43 \% *$ & \multicolumn{2}{|c|}{$48 \%$} & \multicolumn{2}{|c|}{$41 \%$} \\
\hline Izhakian & & \multicolumn{4}{|c|}{$<80$} \\
\hline $\mathrm{ICU}$ & $75 \%$ & \multicolumn{4}{|c|}{$65 \%$} \\
\hline Nasa & & \multicolumn{2}{|c|}{$<60$} & \multicolumn{2}{|c|}{$60-80$} \\
\hline ICU & $79 \%$ & \multicolumn{2}{|c|}{$46 \%$} & \multicolumn{2}{|c|}{$61 \%$} \\
\hline Skull & & \multicolumn{4}{|c|}{$65-79$} \\
\hline $\begin{array}{l}\text { Hospital } \\
\text { 30-day }\end{array}$ & $\begin{array}{l}31 \% \\
41 \%\end{array}$ & \multicolumn{4}{|c|}{$\begin{array}{l}25 \% \\
29 \%\end{array}$} \\
\hline \multirow{2}{*}{$\begin{array}{l}\text { Sligl } \\
\text { 30-day } \\
1 \text {-year }\end{array}$} & & $<60$ & \multicolumn{2}{|c|}{$60-90$} & $70-79$ \\
\hline & $\begin{array}{l}30 \% \\
57 \%\end{array}$ & $\begin{array}{l}10 \% \\
19 \%\end{array}$ & $\begin{array}{l}9 \% \\
22 \%\end{array}$ & \multicolumn{2}{|c|}{$24 \%$} \\
\hline \multirow{2}{*}{$\begin{array}{l}\text { Voga } \\
\text { ICU }\end{array}$} & \multirow[b]{2}{*}{$73 \%$} & \multicolumn{4}{|c|}{$<80$} \\
\hline & & \multicolumn{4}{|c|}{$36 \%$} \\
\hline
\end{tabular}

$* \geq 85$ years
C2. Comparison with VOPs not admitted to the ICU for sepsis.

\begin{tabular}{|c|c|c|}
\hline Mortality & With infection & Total cohort \\
\hline \multicolumn{3}{|l|}{ Andersen } \\
\hline & $43 \%$ & $24 \%$ \\
\hline Hospital & $51 \%$ & $41 \%$ \\
\hline 30-days & $51 \%$ & $44 \%$ \\
\hline 90-days & $60 \%$ & $49 \%$ \\
\hline 180-days & $60 \%$ & $53 \%$ \\
\hline 1-year & $69 \%$ & $58 \%$ \\
\hline 2-years & $79 \%$ & $63 \%$ \\
\hline 5-years & $79 \%$ & $78 \%$ \\
\hline \multicolumn{3}{|l|}{ Becker* } \\
\hline & $37 \%$ & $18 \%$ \\
\hline \multicolumn{3}{|l|}{ Heyland } \\
\hline & $33 \%$ & $22 \%$ \\
\hline Hospital & $47 \%$ & $35 \%$ \\
\hline \multicolumn{3}{|l|}{ Rellos* } \\
\hline Hospital & $40 \%$ & $40 \%$ \\
\hline \multicolumn{3}{|l|}{ Roch } \\
\hline Hospital & $59 \%$ & $56 \%$ \\
\hline \multicolumn{3}{|l|}{$\operatorname{sim}^{*}$} \\
\hline ICU & $56 \%$ & $32 \%$ \\
\hline \multicolumn{3}{|l|}{ Tabah } \\
\hline $1-y r$ & $67 \%$ & $69 \%$ \\
\hline \multicolumn{3}{|l|}{ Voga } \\
\hline ICU & $73 \%$ & $33.1 \%$ \\
\hline \multicolumn{3}{|l|}{ Zampieri } \\
\hline Hospital & $33 \%$ & $19 \%$ \\
\hline
\end{tabular}

$* \geq 90$ years 


\section{CHAPTER 8}

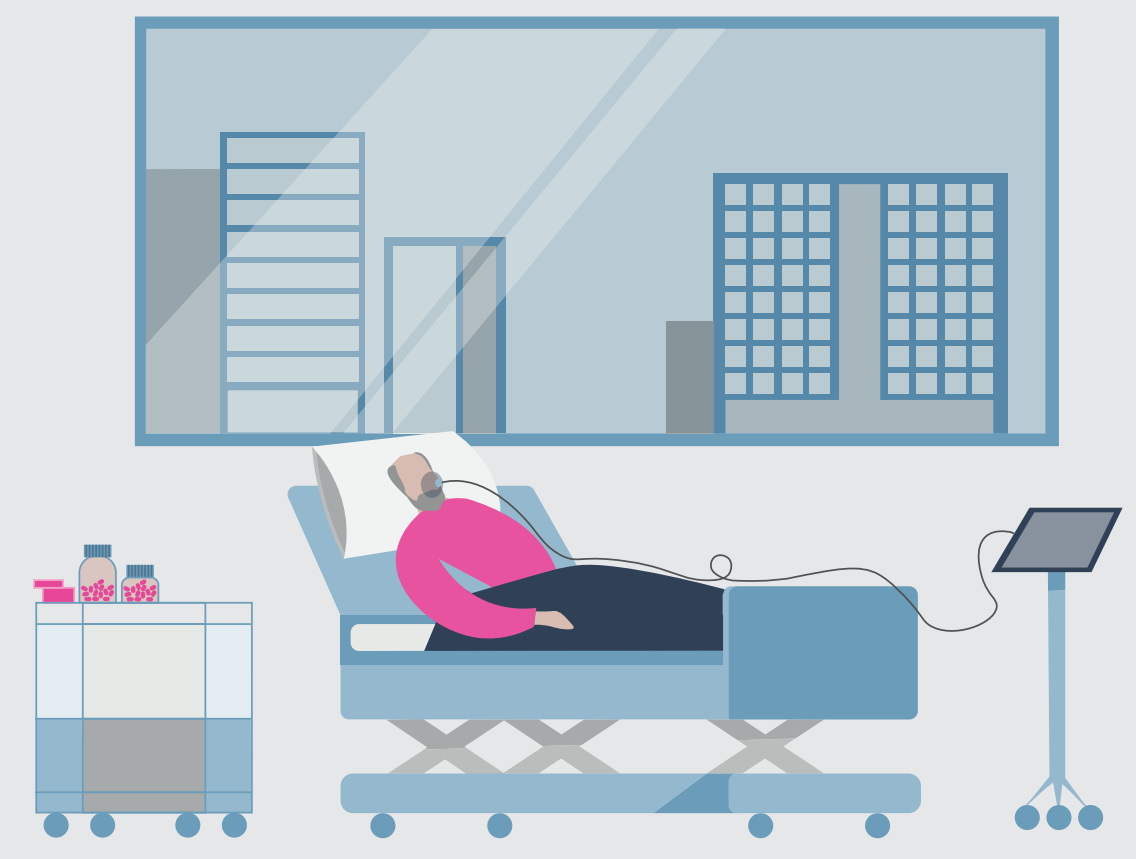

Frailty is associated with long-term outcome in patients with sepsis who are over 80 years old: results from an observational study in 241 European ICUs

Published in: Age and Ageing 2021

LEM Haas, A Boumendil, H Flaatten, B Guidet, M Ibarz, C Jung, R Moreno, A Morandi, FH Andersen, T Zafeiridis, S Walther, S Oeyen, S Leaver, X Watson, C Boulanger, W Szczeklik, JC Schefold, M Cecconi, B Marsh, M Joannidis, Y Nalapko, M Elhadi, J Fjølner, A Artigas, DW de Lange, VIP2 Study Group. 


\section{Abstract}

\section{Background}

Sepsis is one of the most frequent reasons for acute intensive care unit (ICU) admission of very old patients and mortality rates are high. However, the impact of pre-existing physical and cognitive function on long-term outcome of ICU patients $\geq 80$ years old (Very old Intensive Care Patients, (VIPs)) with sepsis is unclear.

\section{Objective}

To investigate both the short- and long-term mortality of VIPs admitted with sepsis and assess the relation of mortality with pre-existing physical and cognitive function.

\section{Design}

Prospective cohort study.

\section{Setting}

241 ICUs from 22 European countries in a six-month period between May 2018 and May 2019.

\section{Subjects}

Acutely admitted ICU patients aged $\geq 80$ years with sequential organ failure assesment (SOFA) score $\geq 2$.

\section{Methods}

Sepsis was defined according to the sepsis 3.0 criteria. Patients with sepsis as an admission diagnosis were compared with other acutely admitted patients. In addition to patients' characteristics, disease severity, information about comorbidity and polypharmacy and pre-existing physical and cognitive function were collected.

\section{Results}

Out of 3596 acutely admitted VIPs with SOFA score $\geq 2$, a group of 532 patients with sepsis were compared to other admissions. Predictors for 6 -month mortality were age (per 5 years): Hazard ratio (HR) 1.16 (95\% confidence interval (CI) 1.09-1.25, $\mathrm{p}<0.0001$ ), SOFA (per one-point): HR 1.16 (95\% Cl 1.14-1.17, p<0.0001) and frailty (CFS >4): HR 1.34 $(95 \% \mathrm{Cl} 1.18-1.51, \mathrm{p}<0.0001)$

\section{Conclusions}

There is substantial long-term mortality in VIPs admitted with sepsis. Frailty, age and disease severity were identified as predictors of long-term mortality in VIPs admitted with sepsis.

\section{Introduction}

In very old patients (age $\geq 80$ years) sepsis is a frequent reason for acute intensive care unit (ICU) admission. $[1,2,3]$ Moreover, among the patients admitted with sepsis the proportion of very old patients is increasing substantially.[4] This is due to the combination of an ageing population and a sharp rise in the incidence of sepsis in patients over 80 years. $[5,6,7]$ Therefore, sepsis in patients over 80 years will remain an important medical problem for future decades.

The mortality of these "Very old Intensive care Patients" (VIP) with sepsis remains high and more than half of the surviving VIPs experience major deterioration of their functional ability and cognitive function. [1,3,8] Such outcomes are often unacceptable for many patients as they give higher priority to preserving quality of life (QoL) above prolonged survival.[9] For these reasons, when confronted with a vulnerable severely ill very old patient with sepsis, thoughtful shared-decision making is important. However, at present, it is still difficult to predict which patients will benefit from ICU admission and for whom it will be futile.

To aid treatment decisions and to guide prognostic discussion concerning admission of VIPs with sepsis, more information about prognostic factors is needed. The previous VIP studies demonstrated that frailty is an important prognostic factor for short-term mortality in VIPs.[1] Sepsis as admission diagnosis appeared, after adjustment for organ dysfunction, not to be independently associated with short-term outcome.[2] However, the relation of pre-existing physical and cognitive function with the long-term outcome of VIPs admitted with sepsis has not yet been examined. The aims of the present study are to estimate both the short- and long-term (i.e. ICU- and 6-months) mortality in VIPs admitted with sepsis and to investigate the relationship of pre-existing physical and cognitive function with mortality.

\section{Methods}

\section{Study design and setting}

This study is a post-hoc analysis of the VIP-2 (POETICS2) study; a large, prospective, multinational, multicentre cohort study in 241 ICUs (from 20 European countries, plus Turkey and Libya).[10] The VIP-2 study is registered on ClinicalTrials.gov (ID: NCT03370692) (https://clinicaltrials.gov/show/NCT03370692)

Patient recruitment started between May 2018 and October 2018 and ended on Apri 30th 2019. Individual ICUs were asked to include consecutive patients for a 6-month period in the 1-year study period and were allowed to stop after 20 included patients. 
Patient specific identifying data were not registered, only gender and age (in rounded years). Appropriate ethical approval was sought by national (or local) ethical committees and institutional research ethic board approval was obtained from each study site.

\section{Participants}

All very old patients ( $\geq 80$ years) acutely admitted to an ICU with a SOFA score $\geq 2$ on admission were included in this sub-study.

\section{Variables}

For each eligible patient, demographic data were collected: age, sex, place of living before admission to the hospital, and reason for admission.

Patients were included with sepsis as admission diagnosis according to the Sepsis 3.0 criteria, as defined in 2016: "Sepsis is a life-threatening organ dysfunction caused by a dysregulated host response to infection".[11] For clinical operationalisation, organ dysfunction can be represented by an increase in the sequential organ failure assessment (SOFA) score of 2 points or more (see Appendix Table A1).[12] Based upon this definition, it was ultimately the admitting intensivist who categorised the patient into "sepsis" and clinically assessed neurologic dysfunction, respiratory, renal and circulatory failure. However, according to the Sepsis 3.0 criteria, we exclusively included patients with (SOFA) $\geq 2$ with suspected or demonstrated infection.

In addition to patients' characteristics and disease severity, comorbidity and polypharmacy (Comorbidity and Polypharmacy score (CPS) [13]), information about pre-existing frailty (with the Clinical Frailty scale (CFS) [14]), cognitive impairment (with the informant questionnaire on cognitive decline in the elderly (IQCODE) [15]) and disability (measured as the activity of daily life with the Katz index [16]) was collected. All recorded study variables are listed in the electronic supplementary material (ESM4) of the original VIP2 study.[10]

\section{Data measurement and collection}

Severity of organ dysfunction was determined with the SOFA score, with a score from $0-24$, giving individual values (0-4) for each of the 6 vital organ systems (circulation, respiration, central nervous system (CNS), renal, coagulation and liver function).[12]

CPS was defined as the simple sum of the number of known comorbidities and the different medications taken daily before admission (1 point for each chronic comorbid condition, and 1 point for each drug). Cardiovascular dysfunction was counted per morbidity (e.g. a patient with hypertension, atrial fibrillation and congestive heart failure would be given 3 points, even if all are cardiovascular comorbidities). The number can vary from 0 (no co-morbid condition, no medication) to infinity, although in most patients the number was $<20$. Severity of CPS has been traditionally stratified as minor/ mild (CPS 0-7), moderate (8-14) and severe ( $\geq 15)$.[13]

Frailty is defined as a clinical state of increased vulnerability from age-associated decline in physiological reserves and function in many physiological systems and was assessed according to the CFS.[14,17] This scale is composed of nine classes from very fit (1) to terminally ill (9) (see Appendix Figure A2). The frailty level present before hospital admission and not affected by the acute illness was used. Patients were classified according to the CFS as "fit" (CFS <4), "vulnerable" (CFS =4), or "frail" (CFS >4). In addition, it was registered who (ICU physician, dedicated research staff or other) and from whom (patient, family/caregivers, hospital record or other) this information was obtained.

Cognitive impairment was assessed with the IQCODE, a tool that assesses cognitive decline over the last 10 years.[15] This information was collected from caregivers. The revised IQCODE consists of 16 questions, (see Appendix Figure A4).[18,19] Each question is assigned from 1 to 5 points. The cut-off scores are based on the total score divided by the number of questions, with higher scores indicating greater impairment. We defined cognitive decline as an IQCODE $\geq 3.5$.[15]

Pre-existing physical function was assessed by the Katz $A D L$, assessing the following daily activities: bathing, dressing, toileting, transfer, continence and feeding. Each item is scored 0 (dependent) or 1 point (independent), recording a total score from 0 (totally dependent) to 6 (independent), with an $A D L \leq 4$ defining disability (see Appendix Figure A3). $[16,20]$

A dedicated website (www.VIP2 study.com) was set up to facilitate information about the study and study progress and to allow for data entry using an electronic case record form. The database ran on a secure server at Aarhus University, Denmark.

\section{Study size}

Since our study is a pure observational study, no formal sample-size calculation was performed. The numbers included are determined by the number of patients aged $\geq 80$ years with SOFA scores $\geq 2$ included by the participating ICUs in the study period (6 months).

\section{Statistical methods}

Baseline characteristics, treatment, and outcomes were compared between VIPs admitted with sepsis and other acutely admitted VIPs with a SOFA score $\geq 2$. Categorical variables are expressed as frequencies and percentages, and continuous variables as medians and interquartile ranges (IQR). Groups are compared using Chi-square tests for categorical variables and the Mann-Whitney $U$ test for continuous variables. 
In order to study the 6-month mortality, all patients were censored at six months. Unadjusted survival curves of patients admitted with and without sepsis were estimated using the standard Kaplan-Meier estimator and compared between groups by means of a log-rank test.

A Cox proportional hazard regression model was used to adjust comparison of sixmonths survival of septic and non-septic patients for potential confounders. All known predictors of outcome available in our database were entered in our model, namely: sepsis, age (five years increase), SOFA (one-point increase), frailty (fit, vulnerable, frail), place of living (own home/other), gender (female/male), CPS (CPS >15, CPS 10-15, CPS $0-9)$. Since we previously demonstrated that the geriatric parameters have a strong collinearity; including only CFS and CPS in our model was considered sufficient.

A p-value of $<0.05$ was used to indicate a statistically significant difference. All statistical analyses were performed using R 3.2.3 software packages (R Development Core Team, Vienna, Austria).

\section{Results}

\section{Participants}

We included 3596 acutely admitted VIPs with SOFA scores $\geq 2$ from 241 ICU in 22 countries, of which 532 VIPs (14.8\%) were admitted with sepsis as admission diagnosis. The flowchart of inclusions is shown in Figure 1 . The numbers of patients included by the participating countries and the characteristics of the participating ICUs can be found in the supplement (Table A1-2). Patients' characteristics are shown in Table 1.

\section{Outcome}

ICU mortality of the VIPs admitted with sepsis was $31.4 \%$ compared to $28.9 \%$ for the other acutely admitted VIPs with SOFA score $\geq 2(p=0.26), 6$-month mortality was $53.8 \%$ vs. $49.0 \%(p=0.04)$. Multivariate analysis of six months survival was performed and both the unadjusted and adjusted Kaplan Meier survival curves for six months survival are shown in Figure 2. Significant differences in 6-month mortality were observed between VIPs admitted with sepsis and the other acutely admitted VIPs ( $p=0.01$, Figure 2a), but not after adjustment for age, gender, SOFA score, CPS, habitat before admission and frailty ( $(\mathrm{m}=0.51$, Figure $2 \mathrm{~b}$ ). ICU- and 6 -month mortality of the VIPs with CFS 4 or less compared with those with CFS $>4$, and in the different frailty groups are shown in Table A5 and Figure A5, respectively. Long-term (6-month) mortality of VIPs according to SOFA-points within the various frailty groups is shown in Figure 3.

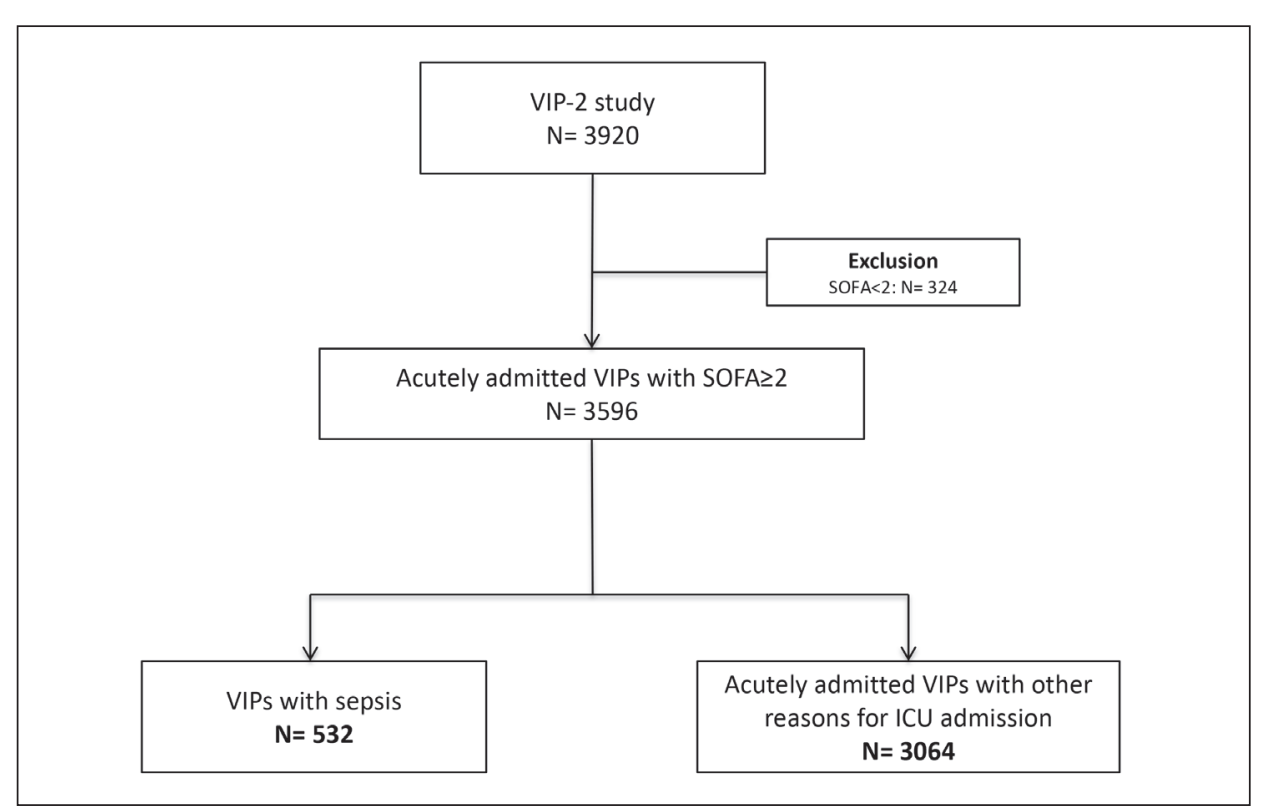

Figure 1. Flowchart of inclusion

\section{Predictive factors for 6-month mortality}

In a Cox model adjusting for known predictors of outcome in ICU patients, sepsis as ICU admission diagnosis was not independently associated with 6-month mortality (HR $0.89(95 \% \mathrm{Cl} 0.77-1.02, \mathrm{p}=0.09)$ ) (Table 2). Neither was gender (female vs. male: HR $0.96(95 \% \mathrm{Cl} 0.87-1.07, \mathrm{p}=0.49)$ ), habitat before admission (own home vs, other HR: 0.90 (95\% Cl 0.80-1.01, p=0.06)) or CPS (CPS 10-15 vs. CPS 0-9 HR: 0.94 (95\% Cl 0.83$1.05, \mathrm{p}=0.27)$ and $\mathrm{CPS}>15$ vs. CPS $0-9$ HR: $1.02(95 \% \mathrm{Cl} 0.89-1.18, \mathrm{p}=0.75)$ ).

Predictors for 6-month mortality were age (increase in risk of death per 5 years increase): HR 1.16 (95\% Cl 1.09-1.25, p <0.0001), SOFA (increase in risk of death per one-point increase): HR 1.16 (95\% Cl 1.14-1.17, p <0.0001) and frailty (CFS>4): HR 1.34 $(95 \% \mathrm{Cl} 1.18-1.51, \mathrm{p}<0.0001)$ 
Table 1. Baseline characteristics of VIPs admitted with sepsis compared to other acutely admitted VIPs with

\begin{tabular}{|c|c|c|c|}
\hline & Sepsis & $\begin{array}{l}\text { Non-sepsis } \\
\text { acutely admitted } \\
\text { VIPs with SOFA } \geq 2\end{array}$ & p-value \\
\hline Numbers & 532 & 3064 & \\
\hline Age (median; IQR) & $84(81-86)$ & $84(81-87)$ & 0.63 \\
\hline Gender (male N/\%) & $298(56 \%)$ & $1656(54 \%)$ & 0.43 \\
\hline Habitat before admission (N/\%) & & & 0.44 \\
\hline Own home (including if with spouse) & $363(68.2 \%)$ & $2223(72.6 \%)$ & \\
\hline Other home with family or caregivers & $68(12.8 \%)$ & $345(11.3 \%)$ & \\
\hline Nursing home & $33(6.2 \%)$ & $160(5.2 \%)$ & \\
\hline Hospital ward & $58(10.9 \%)$ & $288(9.4 \%)$ & \\
\hline Other & $6(1.1 \%)$ & $28(0.9 \%)$ & \\
\hline Unknown & $4(0.8 \%)$ & $20(0.7 \%)$ & \\
\hline \multicolumn{4}{|l|}{ Scores on admission } \\
\hline - SOFA score (median; IQR) & $9(6-11)$ & $6(4-9)$ & $<0.0001$ \\
\hline - CFS score (median; IQR) & $4(3-6)$ & $4(3-6)$ & 0.005 \\
\hline Fit $($ CFS $<4)$ & 195 (36.7\%) & $1174(38.5 \%)$ & 0.02 \\
\hline Vulnerable (CFS 4) & $89(16.7 \%)$ & $638(20.9 \%)$ & \\
\hline Frail $(C F S>4)$ & $248(46.6 \%)$ & $1238(40.6 \%)$ & \\
\hline - ADL (Katz) score (median, IQR) & $6(4-6)$ & $6(4-6)$ & 0.03 \\
\hline 0 & $37(7.9 \%)$ & $123(4.5 \%)$ & 0.002 \\
\hline 1 & $33(7.1 \%)$ & $104(3.8 \%)$ & \\
\hline 2 & $18(3.9 \%)$ & $137(5.1 \%)$ & \\
\hline 3 & $23(4.9 \%)$ & $155(5.7 \%)$ & \\
\hline 4 & $38(8.1 \%)$ & $237(8.8 \%)$ & \\
\hline 5 & $59(12.6 \%)$ & 354 (13.1\%) & \\
\hline 6 & $259(55.5 \%)$ & $1569(59 \%)$ & \\
\hline - IQCODE score (median, IQR) & $3.31(3.06-3.94)$ & $3.19(3.00-3.69)$ & 0.001 \\
\hline - CPS (median, IQR) & $11(8-14)$ & $10(7-14)$ & 0.09 \\
\hline Number of comorbidities (median, IQR) & $4(3-6)$ & $4(3-6)$ & 0.06 \\
\hline Number of drugs taken daily (median, IQR) & $6(4-8)$ & $6(4-9)$ & 0.22 \\
\hline \multicolumn{4}{|l|}{ ICU procedures } \\
\hline \multicolumn{4}{|l|}{ (N, \% and if yes mean duration and SD (hrs)) } \\
\hline Invasive mechanical ventilation & $260(49.1 \%)$ & 1646 (53.8\%) & 0.05 \\
\hline \& duration & $75(24-231)$ & $60(19-168)$ & 0.004 \\
\hline NIV & $86(16.2 \%)$ & $785(25.7 \%)$ & $<0.0001$ \\
\hline \& duration & $16(4-56)$ & $20(6-48)$ & 0.64 \\
\hline Vaso-active drugs & $456(85.9 \%)$ & $1823(59.5 \%)$ & $<0.0001$ \\
\hline \& duration & $48(22.25-108.75)$ & $43(16.25-97.00)$ & 0.02 \\
\hline RRT & $109(20.6 \%)$ & $317(10.4 \%)$ & $<0.0001$ \\
\hline \& duration & $95(31-179)$ & $61(23-124)$ & 0.005 \\
\hline Tracheostomy & $35(6.6 \%)$ & $225(7.4 \%)$ & 0.61 \\
\hline
\end{tabular}

\begin{tabular}{|c|c|c|c|}
\hline & Sepsis & $\begin{array}{l}\text { Non-sepsis } \\
\text { acutely admitted } \\
\text { VIPs with SOFA } \geq 2\end{array}$ & p-value \\
\hline \multicolumn{4}{|l|}{ Limitation of care $(\mathrm{N}, \%)$} \\
\hline Withhold & $186(35.6 \%)$ & 908 (29.9\%) & 0.01 \\
\hline Withdraw & $79(15.1 \%)$ & 452 (14.9\%) & 0.94 \\
\hline \multicolumn{4}{|l|}{ LOS ICU (days, median; IQR) } \\
\hline All patients & $4.77(2.00-9.00)$ & $4.00(1.92-8.12)$ & 0.03 \\
\hline Alive patients exclusively & $5.00(2.62-9.21)$ & $3.88(2.00-7.92)$ & $<0.0001$ \\
\hline \multicolumn{4}{|l|}{ Mortality } \\
\hline ICU & $166(31.4 \%)$ & $881(28.9 \%)$ & 0.26 \\
\hline 6-month & $286(53.8 \%)$ & $1500(49.0 \%)$ & 0.04 \\
\hline
\end{tabular}

A.

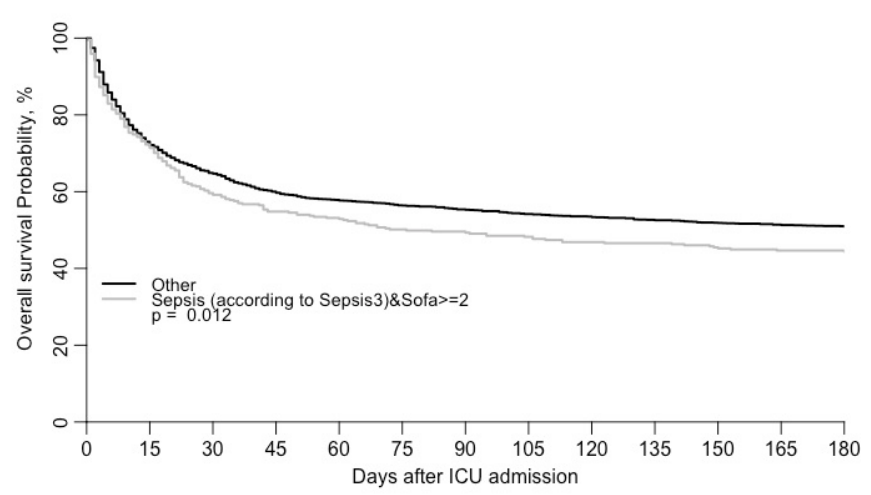

B.

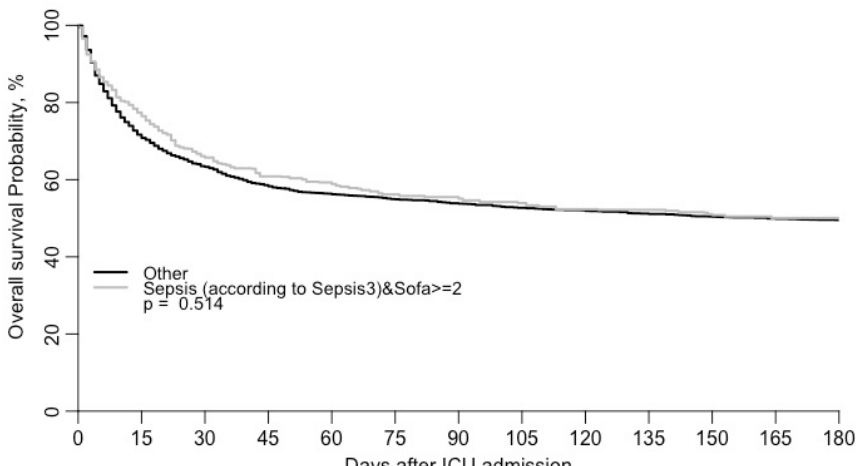

Figure 2. Kaplan Meier curves of VIPs admitted with sepsis, in comparison to other acutely admitted VIPs with SOFA $\geq 2$; (a) unadjusted and (b) and adjusted curves for six months survival. 


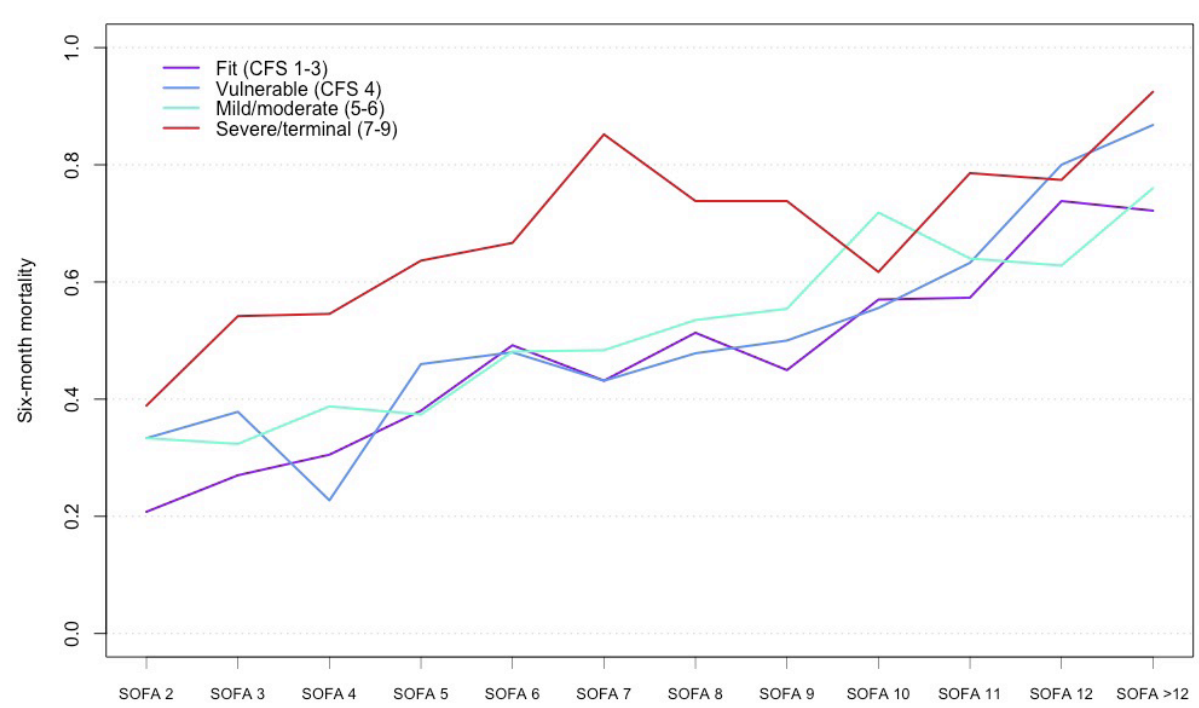

Figure 3. Long-term (6-month) mortality of VIPs according to SOFA-points within the various frailty groups.

Table 2. Multivariate analysis, factors affecting 6-month mortality of very old critically ill patients with SOFA $\geq 2$ acutely admitted to the ICU.

\begin{tabular}{lll}
\hline Variables & HR $(95 \%$ Cl) & p-value \\
\hline Sepsis vs. other acutely admitted \& SOFA $\geq 2$ & $0.89(95 \% \mathrm{Cl} 0.77-1.02)$ & 0.09 \\
Age (five years increase) & $1.16(95 \% \mathrm{Cl} 1.09-1.25)$ & $<0.0001$ \\
SOFA (one point increase) & $1.16(95 \% \mathrm{Cl} 1.14-1.17)$ & $<0.0001$ \\
Frailty: vulnerable (CFS 4) vs. fit (CFS <4) & $1.15(95 \% \mathrm{Cl} 0.99-1.33)$ & 0.07 \\
Frailty: frail (CFS >4) & $1.34(95 \% \mathrm{Cl} 1.18-1.51)$ & $<0.0001$ \\
Own home vs. other & $0.90(95 \% \mathrm{Cl} 0.80-1.01)$ & 0.06 \\
Female vs. male & $0.96(95 \% \mathrm{Cl} 0.87-1.07)$ & 0.49 \\
CPS 10-15 vs. CPS 0-9 & $0.94(95 \% \mathrm{Cl} 0.83-1.05)$ & 0.27 \\
CPS >15 vs. CPS 0-9 & $1.02(95 \% \mathrm{Cl} 0.89-1.18)$ & 0.75 \\
\hline
\end{tabular}

\section{Discussion}

In this large, prospective, multinational study, we demonstrated that long-term mortality rates of VIPs admitted with sepsis are high (53.8\%) and higher than that of other old patients who were acutely admitted to the ICU for reasons other than sepsis. However, after correction for severity of illness at admission, sepsis as ICU admission diagnosis is not independently associated with 6-months survival, nor is CPS, gender, or habitat before admission. Age, SOFA and frailty remain significantly associated with long-term mortality. Being frail was associated with the highest hazard ratio for mortality at 6 months (HR 1.38). Frailty is quite simple to assess and has proven to be a very useful tool for assessment of the pre-existing condition of VIPs in general and in patients admitted with sepsis.

SOFA influenced mortality in the different frailty groups. We demonstrated that the non-frail patients in the lower SOFA groups do considerably better in the ICU compared to the frail patients in the higher SOFA groups. For example, VIPs with both CFS and SOFA $<4$, have an ICU-mortality around $10 \%$ and a long-term mortality less than $30 \%$, but the VIPS with a CFS $>6$ and SOFA $>10$, have ICU-mortality rates of around $60 \%$ and higher, and a long-term mortality of more than $75 \%$. Frailty should be used in clinical practice as a continuum in combination with age and SOFA. Ageism should not rule selection, but neither should 'frailism'.

Proportions and ICU-mortality rates of VIPs admitted with sepsis found in our study were comparable with those found in the previous VIP-1 study.[2] A systematic review, including 18 studies and 4256 patients aged $\geq 80$ years admitted to the ICU with sepsis, reported ICU-, hospital and 1 -year mortality rates of $43 \%, 47 \%$ and $68 \%$ respectively. [3] Nevertheless, the literature regarding variables associated with the outcome of VIPs admitted with sepsis is quite scarce.

The strength of this study is its prospective, multi-centre observational design, the large number of very old patients admitted with sepsis to ICUs throughout Europe and the information about the long-term outcome. To the best of our knowledge, this is the first large cohort of VIPs admitted with sepsis with registration of pre-existing physical and cognitive function. In addition, we included information about life sustaining treatment (LST) limitations. We collected data from a large cohort from 242 ICUs in 22 European countries. The relatively short study period minimises trends in time. Almost 99.9\% (3591/3596) completed the 6-month follow-up. Previously, it was demonstrated that frailty, and not sepsis, was a determinant factor for 30-day mortality $[1,2,10]$, but the relation of other pre-existing physical and cognitive function with 6-month mortality of VIPs admitted with sepsis has not been examined. Our results are important findings to include in shared decision making.

However, our study also has limitations. First, we included patients with an admission diagnosis of sepsis as categorised by the local investigator. Acute organ failure in combination with infection should be diagnosed as sepsis according to the sepsis 3.0 definition and we must assume that the individual ICUs appropriately used this definition. However, we cannot exclude that some of the sepsis patients were misclassified by the local investigators to one of the other admission categories, such as acute respiratory or circulatory (or combined respiratory and circulatory) failure, or 
incorrectly classified as sepsis. Second, we have no information about the very old patients who were not admitted to the ICU. Hence, we cannot exclude some selection bias. It is likely that ICU admission was declined for the very old patients assumed to have a poor prognosis in the triage process. This suggests that mortality for the entire group of very old patients with sepsis probably is higher than the $53.8 \%$ found in our study. Additionally, we have no information about details of LST limitations and the differences in mechanical ventilation might also be partly determined by differences in withholding of mechanical ventilation. Third, we have no information about outcomes other than mortality; independence, returning home and HRQOL are also of great importance for these very old patients. Fourth, we have no information about patients that developed sepsis as a complication of their ICU stay. Fifth, the IQCODE proved to be the most complicated measure to obtain at admission and a high number of missing values (24\%) were seen (Table A4), suggesting that it is not ideal to use in an intensive care setting. Nevertheless, this parameter, and also the Katz index, was not included in our regression analysis anyway, because of strong collinearity with CFS as previously described [10] and hence is not justified in regression analysis, where the hypothesis assumes that covariates are independent. Sixth, we used the CPS and not one of the more traditional comorbidity scores like the Charlson comorbidity index. However, the CPS was, after all, conceived as an attempt to better quantify the magnitude of comorbid conditions using the number of co-administered medications as a measure of the 'intensity' of therapy required for associated comorbidities. Finally, results may be influenced by variations seen among different cultures within Europe.[21,22] Differences in reporting sepsis might also exist among the different countries, illustrated by the very wide range of sepsis event distribution (Table A1). In spite of these shortcomings, we believe our data provide new and valuable insights into predictive factors for outcome of VIPs admitted with sepsis.

We believe that triage of critically ill very old patients with sepsis should be performed based on frailty and disease severity, but only after careful consideration and honest discussion of treatment expectations, and wishes with the patients or their legal representatives when possible.[23] Future research on the long-term outcomes of VIPs admitted with sepsis is required, including more detailed assessments of functional outcome and QoL.

In conclusion, although we have documented a high long-term mortality in VIPs admitted with sepsis, a considerable number of very elderly patients also survive this condition, even when they become critical ill. Importantly, it is not sepsis as the ICU admission diagnosis per se, but frailty, age and severity of organ dysfunctions, which are independently associated with 6-month mortality.

\section{References}

1. Flaatten $\mathrm{H}$, De Lange DW, Morandi A et al. The impact of frailty on ICU and 30-day mortality and the leve of care in very elderly patients (>/= 80 years). Intensive Care Med 2017; 43: 1820-1828.

2. Ibarz M, Boumendil A, Haas LEM et al. Sepsis at ICU admission does not decrease 30-day survival in very old patients: a post-hoc analysis of the VIP1 multinational cohort study. Ann Intensive Care 2020; 10.

3. Haas LEM, van Dillen LS, de Lange DW, van Dijk D, Hamaker ME. Outcome of very old patients admitted to the ICU for sepsis: A systematic review. Eur Geriatr Med 2017: 8: 446-453.

4. Martin GS, Mannino DM, Moss M. The effect of age on the development and outcome of adult sepsis. Crit Care Med 2006; 34: 15-21.

5. population un esa. population.un.org; esa.un.org (9 October 2020, date last accessed).

6. Flaatten $\mathrm{H}$, de Lange DW, Artigas A et al. The status of intensive care medicine research and a future agenda for very old patients in the ICU. Intensive Care Med 2017; 43: 1319-1328.

7. Nasa P, Juneja D, Singh O. Severe sepsis and septic shock in the elderly: An overview. World J Crit care Med 2012; 1: 23-30.

8. Iwashyna TJ, Ely EW, Smith DM, Langa KM. Long-term Cognitive Impairment and Functional Disability Among Survivors of Severe Sepsis. JAMA 2010; 304: 1787 .

9. Philippart F, Vesin A, Bruel C et al. The ETHICA study (part I): elderly's thoughts about intensive care unit admission for life-sustaining treatments. Intensive Care Med 2013; 39: 1565-1573.

10. Guidet B, de Lange DW, Boumendil A et al. The contribution of frailty, cognition, activity of daily life and comorbidities on outcome in acutely admitted patients over 80 years in European ICUs: the VIP2 study. Intensive Care Med 2020; 46: 57-69.

11. Singer M, Deutschman CS, Seymour CW et al. The Third International Consensus Definitions for Sepsis and Septic Shock (Sepsis-3). JAMA 2016; 315: 801-10.

12. Vincent JL, Moreno R, Takala J et al. The SOFA (Sepsis-related Organ Failure Assessment) score to describe organ dysfunction/failure. On behalf of the Working Group on Sepsis-Related Problems of the European Society of Intensive Care Medicine. Intensive Care Med 1996; 22: 707-10.

13. Evans DC, Cook CH, Christy JM et al. Comorbidity-polypharmacy scoring facilitates outcome prediction in older trauma patients. J Am Geriatr Soc 2012; 60: 1465-1470.

14. Rockwood K, Song X, Macknight C et al. A global clinical measure of fitness and frailty in elderly people. C Can Med Assoc J = I'Association medicale Can 2005; 173: 489-495.

15. Quinn TJ, Fearon P, Noel-Storr AH, Young C, McShane R, Stott DJ. Informant Questionnaire on Cognitive Decline in the Elderly (IQCODE) for the diagnosis of dementia within community dwelling populations. Decline in the Elderly (QCODE) for the diagn
Cochrane database Syst Rev 2014; CD010079.

16. Katz S. Assessing self-maintenance: activities of daily living, mobility, and instrumental activities of daily living. J Am Geriatr Soc 1983; 31: 721-727.

17. Clegg A, Young J, lliffe S, Rikkert MO, Rockwood K. Frailty in elderly people. Lancet (London, England) 2013; 381: 752-762.

18. Jorm AF, Jacomb PA. The Informant Questionnaire on Cognitive Decline in the Elderly (IQCODE): sociodemographic correlates, reliability, validity and some norms. Psychol Med 1989; 19: 1015-1022.

19. Jorm AF. The Informant Questionnaire on cognitive decline in the elderly (IQCODE): a review. Int psychogeriatrics 2004; 16: 275-293. 
20. Katz S, Downs TD, Cash HR, Grotz RC. Progress in development of the index of ADL. Gerontologist 1970; 10: 20-30.

21. Sprung $\mathrm{CL}$, Cohen $\mathrm{SL}$, Sjokvist $\mathrm{P}$ et al. End-of-life practices in European intensive care units: the Ethicus Study. JAMA 2003; 290: 790-797.

22. Sprung CL, Ricou B, Hartog CS et al. Changes in End-of-Life Practices in European Intensive Care Units From 1999 to 2016. JAMA 2019; 322: 1-12.

23. Guidet $B$, Vallet $H$, Boddaert J et al. Caring for the critically ill patients over 80 : a narrative review. Ann

\section{Appendices}

\begin{tabular}{|c|c|c|}
\hline Organ system & Grading & $\begin{array}{l}\text { Score } \\
(0-4)\end{array}$ \\
\hline $\begin{array}{l}\text { Respiratory system: } \\
\mathrm{PaO}_{2} / \mathrm{FiO}_{2}\end{array}$ & $\begin{array}{l}0 \text { pts: } 2400 \mathrm{mmHg}(\geq 53 \mathrm{kPa}) \\
1 \mathrm{pt}:<400 \mathrm{mmHg}(<53 \mathrm{kPa}) \\
2 \mathrm{pts}:<300 \mathrm{mmHg}(<40 \mathrm{KPa}) \\
3 \mathrm{pts}:<20 \mathrm{mmHg}(<2 \mathrm{kPa}) \text { AND mechanically ventilated } \\
\mathbf{4} \text { pts: }<100 \mathrm{mmHg}(<13 \mathrm{kPa}) \text { AND mechanically ventilated }\end{array}$ & \\
\hline $\begin{array}{l}\text { Nervous system: } \\
\text { Glasgow coma scale score }\end{array}$ & $\begin{array}{l}\mathbf{0} \text { pts: GCS } 15 \\
\mathbf{1} \text { pt: GCS } 13-14 \\
\mathbf{2} \text { pts: GCS } 10-12 \\
\mathbf{3} \text { pts: GCS 6-9 } \\
\mathbf{4} \text { pts: GCS }<6\end{array}$ & \\
\hline $\begin{array}{l}\text { Cardiovascular system: } \\
\text { Mean arterial pressure } \\
\text { OR administration of } \\
\text { vasopressors required }\end{array}$ & $\begin{array}{l}0 \text { pts: MAP } \geq 70 \mathrm{mmHg} \\
1 \mathrm{pt} \text { MAP }<70 \mathrm{mmHg} \\
2 \text { pts: Dopamine } \leq 5 \mu \mathrm{\mu g} / \mathrm{kg} / \mathrm{min} \text { or dobutamine (any dose) } \\
3 \text { pts: Dopamine }>5 \mu \mathrm{\mu g} / \mathrm{kg} / \mathrm{min} \text { OR epinephrine } \leq 0.1 \mu \mathrm{g} / \mathrm{kg} / \mathrm{min} \text { OR } \\
\text { norepinephrine } \leq 0.1 \mu \mathrm{g} / \mathrm{kg} / \mathrm{min} \\
4 \mathrm{pts}: \text { Dopamine }>15 \mu \mathrm{g} / \mathrm{kg} / \mathrm{min} \text { OR epinephrine }>0.1 \mu \mathrm{gg} / \mathrm{kg} / \mathrm{min} \text { OR } \\
\text { norepinephrine }>0.1 \mu \mathrm{g} / \mathrm{kg} / \mathrm{min}\end{array}$ & \\
\hline $\begin{array}{l}\text { Liver: } \\
\text { Bilirubin }\end{array}$ & $\begin{array}{l}0 \text { pts: }<20 \mu \mathrm{mol} / \mathrm{L}(<1.2 \mathrm{mg} / \mathrm{dL}) \\
1 \mathrm{pt:} 20-32 \mu \mathrm{mol} / \mathrm{L}(1.2-1.9 \mathrm{mg} / \mathrm{dL}) \\
2 \mathrm{pts}: 33-101 \mu \mathrm{mol} / \mathrm{L}(2.0-5.9 \mathrm{mg} / \mathrm{dL}) \\
3 \text { pts: } 102-204 \mu \mathrm{mol} / \mathrm{L}(6.0-11.9 \mathrm{mg} / \mathrm{dL}) \\
\mathbf{4} \text { pts: > } 204 \mu \mathrm{mol} / \mathrm{L}(>12.0 \mathrm{mg} / \mathrm{dL})\end{array}$ & \\
\hline $\begin{array}{l}\text { Coagulation: } \\
\text { Platelets }\left(10^{3} / \mu 1 \text { or } 10^{9} / \mathrm{L}\right)\end{array}$ & $\begin{array}{l}\mathbf{0} \text { pts: } \geq 150 * 10^{3} / \mu \mathrm{l} \\
\mathbf{1} \mathrm{pt}:<150 * 10^{3} / \mu \mathrm{l} \\
\mathbf{2 p t s :}<100 * 10^{3} / \mu \mathrm{\mu l} \\
\mathbf{3} \mathrm{pts}:<50 * 10^{3} / \mu \mathrm{l} \\
\mathbf{4} \mathrm{pts}:<20 * 10^{3} / \mu \mathrm{l}\end{array}$ & \\
\hline $\begin{array}{l}\text { Kidneys: } \\
\text { Creatinine ( } \mu \mathrm{mol} / \mathrm{L})\end{array}$ & $\begin{array}{l}0 \text { pts: }<110(<1.2 \mathrm{mg} / \mathrm{dL}) \\
1 \text { pt: } 110-170(1.2-1.9 \mathrm{mg} / \mathrm{dL}) \\
2 \text { pts: } 171-299(2.0-3.4 \mathrm{mg} / \mathrm{dL}) \\
3 \text { pts: } 300-440(3.5-4.9 \mathrm{mg} / \mathrm{dL})(\text { or }<500 \mathrm{ml} / \mathrm{day}) \\
\mathbf{4} \text { pts: }>440(>5.0 \mathrm{mg} / \mathrm{dL})(\text { or }<200 \mathrm{ml} / \mathrm{day})\end{array}$ & \\
\hline & $\begin{array}{r}\text { SOFA score total } \\
\text { (sum of organ system scores) }\end{array}$ & \\
\hline
\end{tabular}

Figure A1. Sequential Organ Failure Assessment (SOFA) score (at or close to time of admission)

Assessment of renal failure was based exclusively on creatinine values, due to impossibility of using urinary output in the first 24 hours of ICU admission 


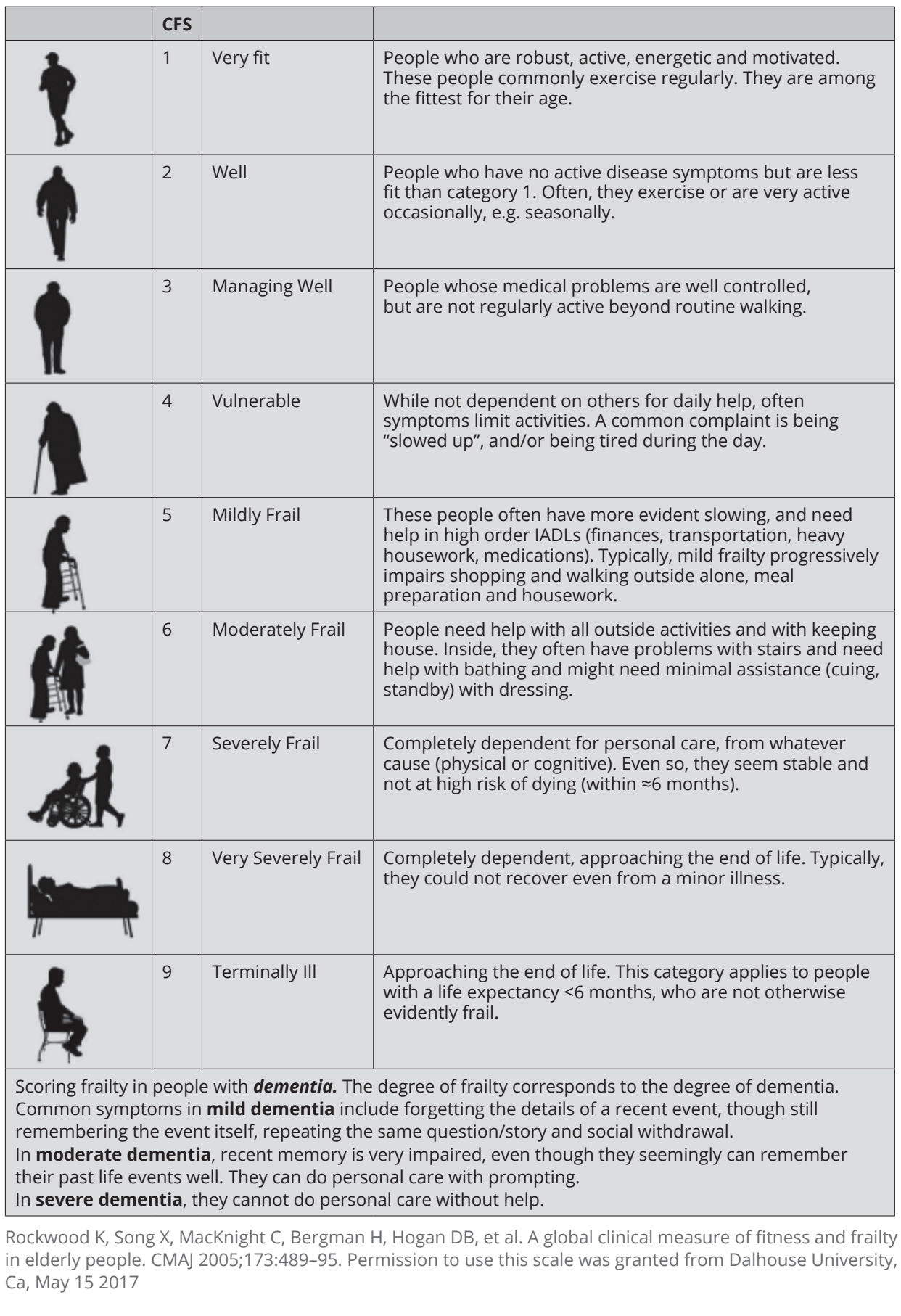

Figure A2. Clinical Frailty Scale (CFS).

\begin{tabular}{|l|c|c|}
\hline & $\begin{array}{c}\text { Independent } \\
\text { NO supervision, direction, or personal } \\
\text { assistance }\end{array}$ & $\begin{array}{c}\text { Dependent } \\
\text { WITH supervision, direction, personal } \\
\text { assistance, or total care }\end{array}$ \\
\hline Bathing & 1 point & 0 point \\
\hline Dressing & 1 point & 0 point \\
\hline Toileting & 1 point & 0 point \\
\hline Transfer & 1 point & 0 point \\
\hline Continence & 1 point & 0 point \\
\hline Feeding & 1 point & 0 point \\
\hline Total $=\quad \ldots . .$. & (scale from 0 (totally dependent) to 6 (independent) \\
\hline
\end{tabular}

Slightly adapted with permission from Gerontological Society of America. Katz S, Down TD, Cash HR et al (1970). Progress in the development of the index of ADL. The Gerontologist, 10, 20-30.

Figure A3. Katz Index of Independence in Activities of Daily Living. 


\begin{tabular}{|c|c|c|c|c|c|c|}
\hline & & $\begin{array}{l}\text { Much } \\
\text { improved }\end{array}$ & $\begin{array}{c}\text { A bit } \\
\text { improved }\end{array}$ & $\begin{array}{l}\text { Not much } \\
\text { change }\end{array}$ & $\begin{array}{l}\text { A bit } \\
\text { worse }\end{array}$ & $\begin{array}{l}\text { Much } \\
\text { worse }\end{array}$ \\
\hline 1. & $\begin{array}{l}\text { Remembering things about family } \\
\text { and friends - eg, occupations, } \\
\text { birthdays, addresses? }\end{array}$ & & & & & \\
\hline 2. & $\begin{array}{l}\text { Remembering things that have } \\
\text { happened recently? }\end{array}$ & & & & & \\
\hline 3. & $\begin{array}{l}\text { Recalling conversations a few days } \\
\text { later? }\end{array}$ & & & & & \\
\hline 4. & $\begin{array}{l}\text { Remembering his/her address and } \\
\text { telephone number? }\end{array}$ & & & & & \\
\hline 5. & $\begin{array}{l}\text { Remembering what day and month } \\
\text { it is? }\end{array}$ & & & & & \\
\hline 6. & $\begin{array}{l}\text { Remembering where things are } \\
\text { usually kept? }\end{array}$ & & & & & \\
\hline 7. & $\begin{array}{l}\text { Remembering where to find things } \\
\text { which have been put in a different } \\
\text { place from usual? }\end{array}$ & & & & & \\
\hline & $\begin{array}{l}\text { Knowing how to work familiar } \\
\text { machines around the house? }\end{array}$ & & & & & \\
\hline & $\begin{array}{l}\text { Learning to use a new gadget or } \\
\text { machine around the house? }\end{array}$ & & & & & \\
\hline 10. & Learning new things in general? & & & & & \\
\hline 11. & Following a story in a book or on TV? & & & & & \\
\hline & $\begin{array}{l}\text { Making decisions on everyday } \\
\text { matters? }\end{array}$ & & & & & \\
\hline 13. & Handling money for shopping? & & & & & \\
\hline & $\begin{array}{l}\text { Handling financial matters - eg, } \\
\text { the pension, dealing with the bank? }\end{array}$ & & & & & \\
\hline & $\begin{array}{l}\text { Handling other everyday arithmetic } \\
\text { problems - eg, knowing how much } \\
\text { food to buy, knowing how long } \\
\text { between visits from family or } \\
\text { friends? }\end{array}$ & & & & & \\
\hline & $\begin{array}{l}\text { Using his/her intelligence to } \\
\text { understand what's going on and } \\
\text { to reason things through? }\end{array}$ & & & & & \\
\hline
\end{tabular}

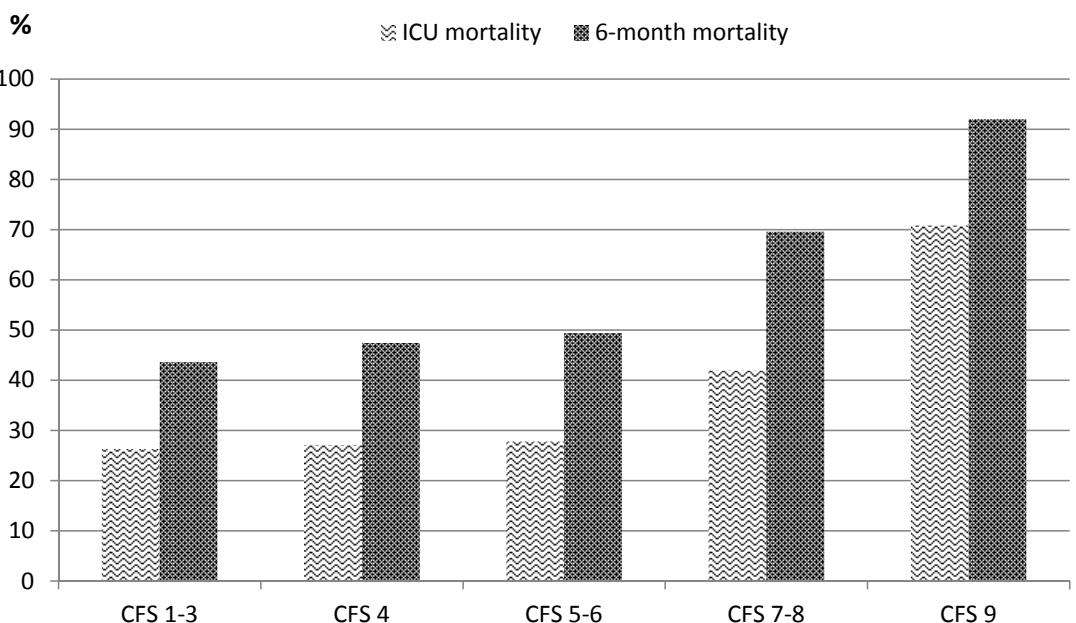

Figure A5. Mortality (ICU- and 6-month) of VIPs within the different frailty groups.

https://patient.info/doctor/informant-questionnaire-on-cognitive-decline-in-the-elderly-iqcode

The IQCODE assesses cognitive decline over the last 10 years. The information is collected from caregivers. Each question is assigned from 1 to 5 points. An average of 3 points/question is normal = no change from 10 years ago.

Jorm AF. A short form of the Informant Questionnaire on Cognitive Decline in the Elderly (IQCODE): development and cross-validation. Psycholog Med 1994;24:145-153

Figure A4. Cognitive decline questionnaire (IQCODE) 
Table A1. Countries of inclusion

\begin{tabular}{lllll}
\hline Country & $\begin{array}{l}\text { Number of } \\
\text { participating ICUs }\end{array}$ & $\begin{array}{l}\text { VIPs admitted } \\
\text { with sepsis }\end{array}$ & $\begin{array}{l}\text { Proportion with } \\
\text { sepsis }\end{array}$ & $\begin{array}{l}\text { Acutely admitted } \\
\text { VIPs for other } \\
\text { reason }\end{array}$ \\
\hline Austria & 4 & $4(0.8 \%)$ & $9.5 \%$ & $38(1.2 \%)$ \\
Belgium & 5 & $9(1.7 \%)$ & $13.8 \%$ & $56(1.8 \%)$ \\
Croatia & 1 & $5(0.9 \%)$ & $71.4 \%$ & $2(0.1 \%)$ \\
Denmark & 10 & $26(4.9 \%)$ & $16.5 \%$ & $132(4.3 \%)$ \\
England (GB) & 49 & $78(14.7 \%)$ & $10.8 \%$ & $647(21.1 \%)$ \\
France & 26 & $76(14.3 \%)$ & $13.0 \%$ & $509(16.6 \%)$ \\
Germany & 17 & $26(4.9 \%)$ & $14.2 \%$ & $157(5.1 \%)$ \\
Greece & 16 & $32(6 \%)$ & $15.0 \%$ & $181(5.9 \%)$ \\
Ireland & 4 & $10(1.9 \%)$ & $15.9 \%$ & $53(1.7 \%)$ \\
Italy & 4 & $8(1.5 \%)$ & $13.6 \%$ & $51(1.7 \%)$ \\
Libya & 5 & $1(0.2 \%)$ & $2.4 \%$ & $40(1.3 \%)$ \\
Netherlands & 12 & $42(7.9 \%)$ & $19.4 \%$ & $175(5.7 \%)$ \\
Norway & 14 & $31(5.8 \%)$ & $13.5 \%$ & $198(6.5 \%)$ \\
Poland & 27 & $68(12.8 \%)$ & $18.3 \%$ & $303(9.9 \%)$ \\
Portugal & 11 & $27(5.1 \%)$ & $17.4 \%$ & $128(4.2 \%)$ \\
Russian Federation $)$ & 1 & $0(0 \%)$ & $0.0 \%$ & $5(0.2 \%)$ \\
Spain & 17 & $54(10.2 \%)$ & $23.4 \%$ & $177(5.8 \%)$ \\
Sweden & 10 & $25(4.7 \%)$ & $18.9 \%$ & $107(3.5 \%)$ \\
Switzerland & 4 & $4(0.8 \%)$ & $6.7 \%$ & $56(1.8 \%)$ \\
Turkey & 1 & $1(0.2 \%)$ & $4.0 \%$ & $24(0.8 \%)$ \\
Ukraine & 3 & $1(0.2 \%)$ & $5.3 \%$ & $18(0.6 \%)$ \\
Wales (GB) & 1 & $4(0.8 \%)$ & 36.4 & $7(0.2 \%)$ \\
\hline & & & & \\
\hline & & &
\end{tabular}

Table A2. Characteristics of participating ICUs

\begin{tabular}{lll}
\hline Characteristic & Mean & Range \\
\hline Number of beds & 15 & $3-60$ \\
Number of admissions in year 2017 & 945 & $100-6,500$ \\
Proportion of admissions aged $\geq 80$ years (in 2017)** & $16.4 \%$ & $2 \%-50 \%$ \\
\hline
\end{tabular}

*See also the supplemental material of the original VIP2 study (ESM1).

**32 missing values

Table A3. Reason of ICU admission for the acutely admitted VIPs.

\begin{tabular}{lll}
\hline Reason of ICU admission & Number & $\%$ \\
\hline Respiratory failure & 907 & 25.2 \\
Circulatory failure & 495 & 13.8 \\
Combined respiratory/circulatory failure & 437 & 12.2 \\
Sepsis (according to Sepsis3) & 532 & 14.8 \\
Multitrauma without head injury & 70 & 1.9 \\
Multitrauma with head injury & 70 & 1.9 \\
Isolated head injury & 63 & 1.8 \\
Intoxication & 20 & 0.6 \\
Non-traumatic cerebral pathology & 177 & 4.9 \\
Emergency surgery & 475 & 13.2 \\
Other causes & 350 & 9.7 \\
\hline
\end{tabular}


Table A4. Missing values

\begin{tabular}{lll}
\hline & $\begin{array}{l}\text { Other VIPs } \\
\text { (N=3064) }\end{array}$ & $\begin{array}{l}\text { Sepsis } \\
\text { (N=532) }\end{array}$ \\
\hline Age & 1 & 0 \\
Gender & 0 & 0 \\
SOFA score & 0 & 0 \\
Clinical frailty scale & 14 & 0 \\
IQ Code & 750 & 135 \\
Katz & 358 & 65 \\
Number of comorbidities & 4 & 1 \\
Number of drugs taken daily & 5 & 1 \\
Co-morbidity and Polypharmacy score (CPS) & 5 & 1 \\
Intubation mechanical ventilation & 4 & 2 \\
Intubation mechanical ventilation duration (hours) & 1422 & 274 \\
Tracheostomy & 4 & 3 \\
Vasoactive drugs used & 1 & 1 \\
Vasoactive drugs duration (hours) & 1246 & 78 \\
Renal Replacement Therapy & 8 & 2 \\
Renal Replacement Therapy (hours) & 2747 & 423 \\
NIV & 7 & 1 \\
NIV duration & 2294 & 447 \\
Decision to withhold treatment & 27 & 10 \\
Decision to withdraw treatment & 24 & 9 \\
ICU mortality & 11 & 3 \\
ICU LOS in days & 4 & 4 \\
ICU LOS in alive patients & 885 & 169 \\
Overall mortality & 3 & 2 \\
\hline & &
\end{tabular}

Table A5. Mortality (ICU- and 6-month) of the VIPs with CFS 4 or less compared with VIPs with CFS $>4$.

\begin{tabular}{llll}
\hline & CFS $\leq 4$ & CFS $>4$ & p \\
\hline $\mathrm{N}$ & 2096 & 1486 & \\
ICU mortality & $555(26.6 \%)$ & $483(32.7 \%)$ & $<0.0001$ \\
6-month mortality & $941(44.9 \%)$ & $832(56.1 \%)$ & $<0.0001$ \\
\hline
\end{tabular}

Table A6. Mortality (ICU- and 6-month) of the VIPs according to SOFA-points within the various frailty groups,

\begin{tabular}{lccccccccc}
\hline & \multicolumn{2}{c}{$\begin{array}{c}\text { Fit } \\
\text { (CFS 1-3) }\end{array}$} & \multicolumn{2}{c}{$\begin{array}{c}\text { Vulnerable } \\
\text { (CFS 4) }\end{array}$} & \multicolumn{2}{c}{$\begin{array}{c}\text { Mild/moderate } \\
\text { (CFS 5-6) }\end{array}$} & \multicolumn{2}{c}{$\begin{array}{c}\text { Severe/terminal } \\
\text { (CFS 7-9) }\end{array}$} \\
\hline & $\begin{array}{c}\text { ICU } \\
\text { mortality }\end{array}$ & $\begin{array}{c}\text { 6-month } \\
\text { mortality }\end{array}$ & $\begin{array}{c}\text { ICU } \\
\text { mortality }\end{array}$ & $\begin{array}{c}\text { 6-month } \\
\text { mortality }\end{array}$ & $\begin{array}{c}\text { ICU } \\
\text { mortality }\end{array}$ & $\begin{array}{c}\text { 6-month } \\
\text { mortality }\end{array}$ & $\begin{array}{c}\text { ICU } \\
\text { mortality }\end{array}$ & $\begin{array}{c}\text { 6-month } \\
\text { mortality }\end{array}$ \\
\hline SOFA 2 & 10 & 21 & 9 & 33 & 11 & 33 & 17 & 39 \\
SOFA 3 & 12 & 27 & 14 & 38 & 12 & 32 & 8 & 54 \\
SOFA 4 & 12 & 31 & 9 & 23 & 19 & 39 & 18 & 55 \\
SOFA 5 & 17 & 38 & 15 & 46 & 15 & 37 & 34 & 64 \\
SOFA 6 & 23 & 49 & 24 & 48 & 28 & 48 & 21 & 67 \\
SOFA 7 & 26 & 43 & 22 & 43 & 21 & 48 & 46 & 85 \\
SOFA 8 & 36 & 51 & 23 & 48 & 27 & 53 & 43 & 74 \\
SOFA 9 & 28 & 45 & 26 & 50 & 29 & 55 & 55 & 74 \\
SOFA 10 & 38 & 57 & 49 & 56 & 39 & 72 & 45 & 62 \\
SOFA 11 & 43 & 57 & 51 & 63 & 50 & 64 & 61 & 79 \\
SOFA 12 & 57 & 74 & 60 & 80 & 51 & 63 & 58 & 77 \\
SOFA >12 & 56 & 72 & 79 & 87 & 68 & 76 & 81 & 92 \\
\hline
\end{tabular}




\section{CHAPTER 9}

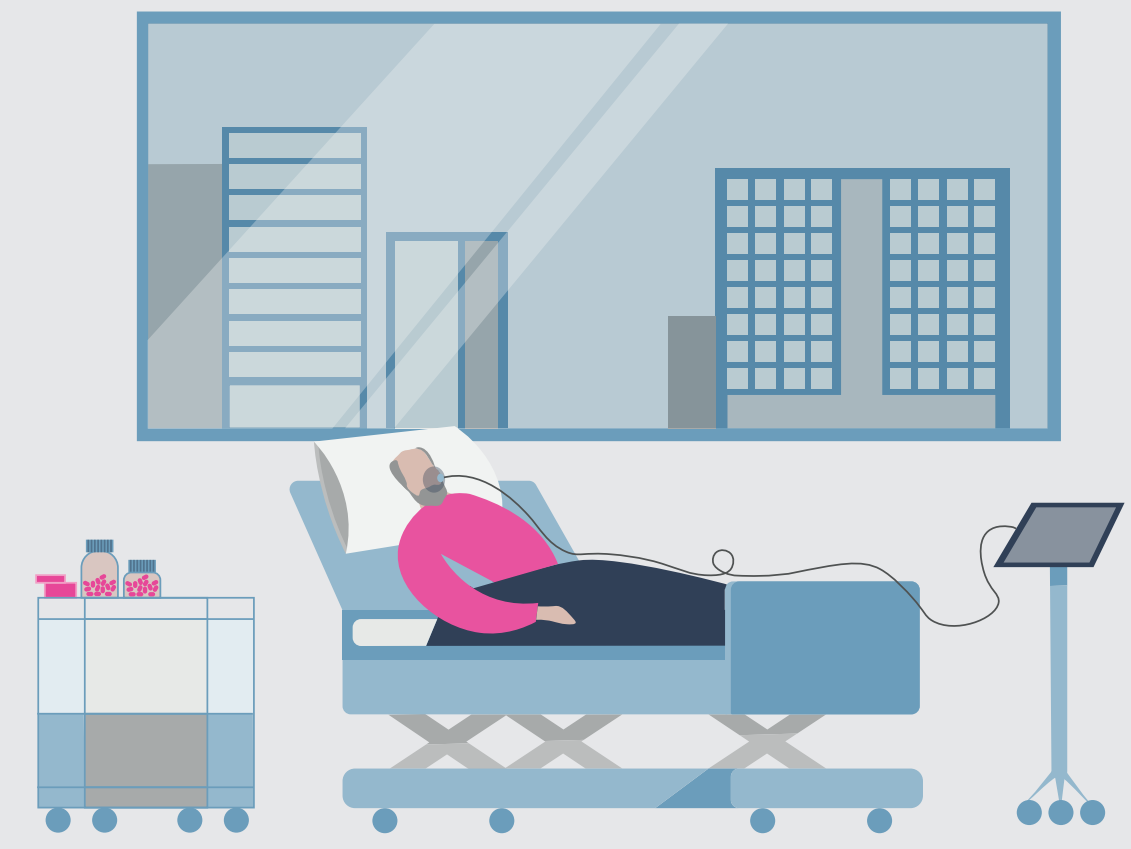

Performance of the quick SOFA in very old ICU patients admitted with sepsis

Published in: Acta Anaesthesiologica Scandinavica 2020. 


\section{Abstract}

\section{Background}

The number of very elderly ICU patients (abbreviated to VOPs; $\geq 80$ years) with sepsis increases. Sepsis was redefined in 2016 (sepsis 3.0) using the quick SOFA (qSOFA) score. Since then, multiple studies have validated qSOFA for prognostication in different patient categories, but the prognostic value in VOPs with sepsis is still unknown.

\section{Methods}

Retrospective cohort study including patients admitted to Dutch ICUs with sepsis, in the period 2012 to 2016, evaluating the outcome and the performance of qSOFA, an extended qSOFA model, SOFA, SAPS II and APACHE IV for hospital mortality.

\section{Results}

5969 patients were included, of which 935 VOPs. Crude hospital mortality rates were $19 \%, 28 \%$ and $39 \%$ for patients aged $18-65,65-80$ and $\geq 80$ years respectively. Discriminative performance of qSOFA for in-hospital mortality in VOPs was poor (AUC 0.596) and lower than that of SOFA, APACHE IV and SAPS II $(0.704,0.722$ and 0.780 respectively). A qSOFA model extended with several other characteristics (AUC 0.643) was non-inferior to the full SOFA, but still inferior to APACHE IV and SAPS II, for all age groups. The Hosmer-Lemeshow goodness-of-fit test showed non-significant p-values for all models. Accuracy for both qSOFA and the extended qSOFA was lower compared to APACHE IV and SAPS II (Brier scores $0.227,0.223,0.184$ and 0.183 respectively).

\section{Conclusion}

The qSOFA showed worse discriminative performance to predict mortality than SOFA, APACHE IV and SAPS II in both VOPs and younger patients admitted with sepsis.

\section{Introduction}

Sepsis is a worldwide major healthcare problem, responsible for significant morbidity, mortality and resource utilization, including a substantial number of intensive care unit (ICU) admissions.[1-5] In the Western population, older patients are responsible for the majority of all episodes of sepsis.[6]

As a consequence of the ageing of the Western population, it is expected that in the upcoming decades more very elderly patients ( $\geq 80$ years old) will be admitted to the ICU (very old intensive care patients, abbreviated to VOPs), because of sepsis.[7] Although a decrease in ICU and hospital mortality of VOPs has been demonstrated in recent years, ICU- and hospital mortality rates of VOPs admitted because of sepsis remain high.[8-10]

Because of this relatively high risk of hospital mortality in combination with a shorter life expectancy beyond hospital discharge, it is frequently questioned whether admission of VOPs with sepsis is appropriate. However, it is often difficult to determine for which individuals an ICU treatment is disproportional or futile. Although prognostication for VOPs with sepsis is difficult, it is of paramount importance, because knowledge of high mortality risk could aid treatment decisions and guide prognostic discussions. A quick and reliable prognostic tool for VOPs with sepsis is desired. Sepsis was redefined in 2016, sepsis 3.0 (SEP-3), because the earlier definitions from 1992 and 2001 with the systemic inflammatory response (SIRS) as basis for sepsis, turned out to be quite nonspecific.[11-16].Sepsis is now defined as a life-threatening organ dysfunction, caused by a dysregulated host response to infection, identified by an increase of at least 2 points in the Sequential [Sepsis-related] Organ Failure Assessment (SOFA) score in patients with a suspicion of infection.[11,17] The quick SOFA (qSOFA) score was introduced to easily identify patients with suspected infection with high risk for in-hospital mortality and uses three simple clinical criteria readily available at the bedside, each allocated one point (respiratory rate $\geq 22 /$ minute, altered mentation (Glasgow coma score $(\mathrm{GCS})<15$ ) and systolic blood pressure $\leq 100$ $\mathrm{mmHg}) \cdot[11,18,19]$

Since the original sepsis consensus definition study, a large number of studies from different regions of the world have validated qSOFA for prognostication in different categories of patients with suspected infection, both outside and inside the ICU.[20-22] Although qSOFA underperforms SOFA for ICU patients, there was a significant, moderate, relation with hospital mortality. Due to its predictive value and its attractive simple design several other studies have examined the predictive validity of qSOFA in ICU patients.[19, 23-33] The prognostic value of qSOFA in VOPs with sepsis, a population more likely to have poor prognosis compared to the populations in previous studies, 
is still unknown. It would be of great help when qSOFA, an easy and readily available bedside tool, turns out to be accurate enough for prognostication in these patients, since a quick and reliable prognostic tool is desired for them.

The aim of this study is to describe the outcome of VOPs with sepsis, and to evaluate the performance of qSOFA to predict in-hospital mortality in these patients in comparison to the prognostic performance among younger adults admitted to the ICU with sepsis and compared to other severity scores (an extended qSOFA model, original SOFA, SAPS II and APACHE IV).

\section{Methods}

This is a retrospective cohort study (prospectively collected data were retrospectively analysed), using clinical data of the Dutch National Intensive Care Evaluation (NICE) registry, a national quality registry in which currently all Dutch ICUs participate.[34,35] These ICUs collect demographic, physiologic, and clinical data of all admitted patients, including variables required to quantify the severity of illness (acute physiology scores (APS)) and to calculate case-mix adjusted mortality risks according to the SAPS II and APACHE IV model.[36,37] On a voluntary basis ICUs may also collect the physiological and treatment variables to calculate daily SOFA score for all their patients.

\section{Patient selection}

For this study, all patients from the NICE registry with available SOFA data, aged $\geq 18$ years during the year of ICU admission and admitted to an ICU with reason of admission sepsis between 1 January 2012 and 31 December 2016 were included. Sepsis was defined according to the APACHE IV admission diagnosis definitions (see Supplement Table S1). Patients who developed sepsis during their ICU stay were not included in our analysis. Standard care of patients admitted to the ICU with sepsis in the Netherlands is according to the Surviving Sepsis Campaign Guidelines.[38]

Patients were subsequently divided in three age categories: aged between 18 and 65 years old (ICU 18-65), between 65 and 80 years old (ICU 65-80) and aged 80 years and older (VOPs).

\section{Prediction variables and outcome}

The qSOFA was calculated using the three clinical criteria (respiratory rate $\geq 22$ /minute, altered mentation $(\mathrm{GCS}<15)$ and systolic blood pressure $\leq 100 \mathrm{mmHg})$, each allocated one point. We calculated the qSOFA based on the worst values of these three clinical variables from the first 24 hours of ICU admission.
SOFA, SAPS II (Simplified Acute Physiology Score) and APACHE IV scores were calculated according their original publications.[17,36,37]

The primary outcome measure was the performance of qSOFA in terms of discrimination (area under the receiver operating characteristic curve (AUC)) for hospital mortality. Secondary outcome measures are in-hospital mortality of VOPs, performance of qSOFA in terms of calibration (Hosmer-Lemeshow goodness of fit (HL)) and accuracy (Brier) for hospital mortality and the performance of the other ICU severity of illness scoring models.[39,40]

\section{Statistical analyses}

To assess the discriminative performance of the qSOFA to distinguish survivors from non-survivors at hospital discharge, we constructed a ROC curve and calculated the corresponding AUC. To fill the gap between the very simple qSOFA model and the complex SAPS II and APACHE IV models, we developed four extended qSOFA models. We used adjacently (1) a qSOFA combined with age and gender; (2) qSOFA combined with age, gender and comorbidity; (3) qSOFA combined with age, gender, comorbidity and admission type and (4) qSOFA combined with age, gender, comorbidity, admission type and specific sepsis diagnosis. We compared the discriminative performances (AUC) of the simple qSOFA, these extended qSOFA scores, the SOFA, APACHE IV and SAPS II among the three different age groups. For this specific reason, the dataset was split at random (1:1) in a training set and test set and performance measures are determined on the test data set (for the extended qSOFA and also, to enable comparison, for qSOFA). If confidence intervals for two AUC's were non-overlapping, we considered these AUC's as significantly different from each other.

Then we focused on the performance of the scores specifically for VOPs admitted to the ICU with sepsis and compared the performance measures sensitivity, specificity, negative and positive predictive values, AUC, brier and HL of the different scores. For calculation of the performances of the extended qSOFA scores, we again used the test set, other data originate from the total dataset.

The calibration of the model (evaluation of the extent to which the estimated probabilities of mortality from the model correspond to observed mortality rates for deciles of predicted mortality), was assessed by the HL goodness-of-fit test (chi-square statistic) and a calibration plot, with a P-value less than 0.05 suggestive of imperfect fit.[39] To assess the accuracy of the qSOFA and other prognostic scores, we used the Brier score.[40] This overall performance index reflects both the discrimination and calibration of a prediction model.

Preparation of the analysis files was done in SPSS, version 24.0. The statistical analyses were performed using statistical environment R, version 3.4.3. 


\section{Results}

\section{Participants}

We included 5969 admissions with sepsis as reason of ICU admission, including 935 (15.7\%) VOPs. The flow chart of all cases in the database, the in- and exclusions and numbers studied, is shown in Figure S1 (and see Table S2).

The patient characteristics are shown in Table 1. The mean age of all included patients was $65.4( \pm 14.4)$ years and $83.6( \pm 3.1)$ years for the VOPs. Of the VOPs, $55.8 \%$ was male, $76.7 \%$ was admitted for a non-surgical reason, mean APACHE IV score was $91.0( \pm 28.1)$, mean SAPS II score was $54.2( \pm 16.3)$ and $86.9 \%$ of the VOPs had a qSOFA score of 2 or more.

\section{Main results}

\section{Outcome}

Crude hospital mortality rates for the ICU $18-65$ population, the ICU $65-80$ population and the VOPs were $18.6 \%, 27.7 \%$ and $38.9 \%$ respectively. Hospital mortality by age is shown in Figure 1 and the differences between age groups were statistically significant (log rank, $p<0.001$ )

\section{Performance}

Discrimination

The discriminative performance of the qSOFA, the extended qSOFA, SOFA, APACHE IV and SAPS II among VOPS compared to younger age groups for hospital mortality are presented in Table 2 .

Based on area under the ROC analysis, qSOFA discriminate poorly between survivors and non-survivors among VOPs admitted with sepsis (AUC 0.596), and worse than SOFA, APACHE IV and SAPS II (0.704, 0.722 and 0.780 respectively), but comparable with the discrimination of qSOFA among the younger ICU patients admitted with sepsis (AUC 0.620 in ICU 18-65 and 0.609 in ICU 65-80 respectively). The AUC of the SOFA, APACHE IV and SAPS II demonstrated significantly better discrimination for hospital mortality than qSOFA in all age categories (Table 2).

Combining qSOFA with the factors, age, gender, comorbidity, admission type and sepsis diagnosis did result in a slight but non-significant improvement of the discriminative power of the model among VOPs (Table 2). In both groups of younger ICU patients, combining qSOFA with these factors, resulted in a more substantial and significant improvement of the model's discrimination, as evidenced by non-overlapping $95 \%$. AUC values of the extended qSOFA were similar to those of the full SOFA, in both groups of younger patients. However, even with this significant improvement, discriminative performance of the extended qSOFA in the younger patients was still inferior to that of APACHE IV and SAPS II.

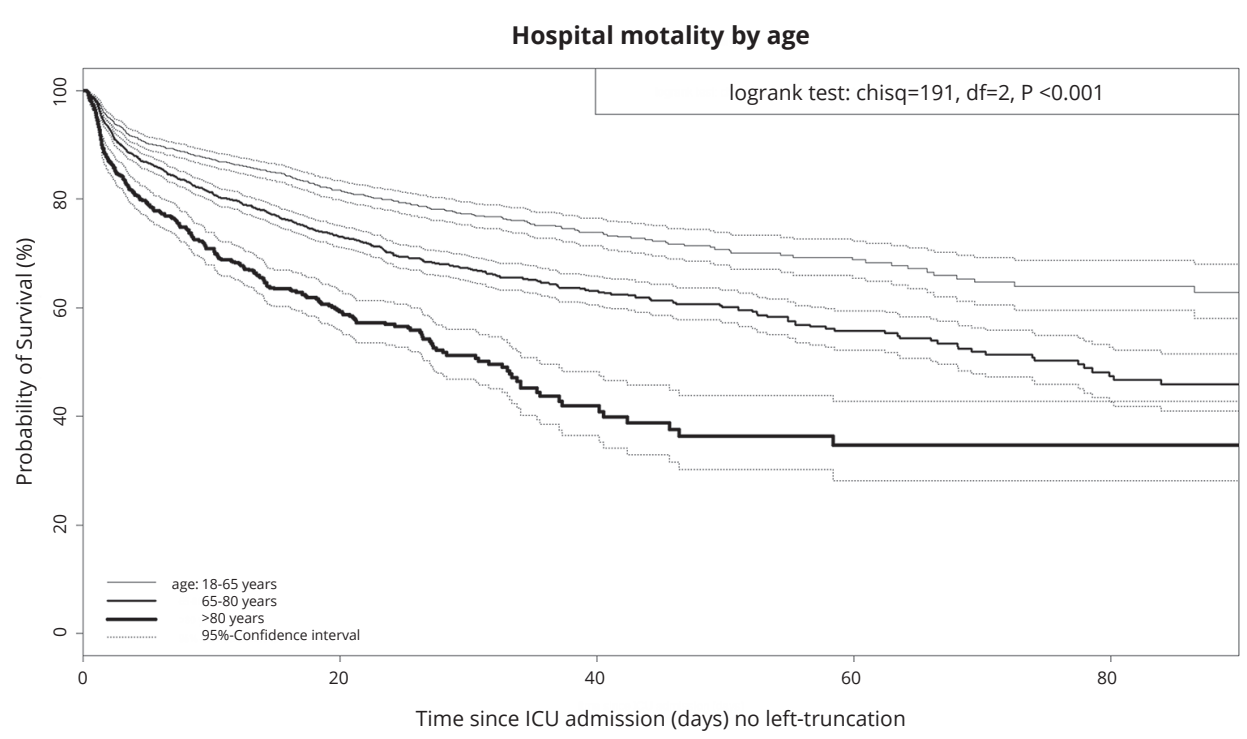

Figure 1. Kaplan Meier curve for hospital mortality per age group.

Sensitivity, specificity, positive (PPV) and negative predictive value (NPV) for hospital mortality of different models among VOPs are shown in Table 3. We calculated the discriminative performance of qSOFA both for the standard cut-off value of 2 , as for the most optimal cut-off value (3) (Table 3). The sensitivity of qSOFA with the cut-off value 2 was the highest of all scores (0.909), but at the expense of the lowest specificity (0.155) of all. The ROC curves of the different scoring systems for hospital mortality among VOPs are shown in Figure 2.

Calibration

Calibration of the different models among VOPs, measured by the HL goodness-of-fit test, showed non-significant p-values for all scores (Table 3) indicating non-statistical significance between the observed and predicted mortality and thus a good fit.

\section{Accuracy}

The overall predictive performance among VOPs, as measured by the Brier scores, was higher for qSOFA (Brier score 0.227) and the extended qSOFA (Brier score 0.223) than APACHE IV and SAPS II (Brier scores 0.184 and 0.183 respectively), indicating larger deviance between estimated and true mortality risk, which is in line with the findings for the discriminative performances (Table 3). 
Table 1. Baseline characteristics.

\begin{tabular}{|c|c|c|c|c|}
\hline Variables & $\begin{array}{r}\text { All sepsis } \\
\text { patients }\end{array}$ & $18-65$ years & $65-80$ years & VOPs \\
\hline Number of patients (N/\%) & 5969 & $2431(40.7)$ & $2603(43.6)$ & 935 (15.7) \\
\hline Age (mean; SD) & $65.4(14.4)$ & $51.6(11.0)$ & $71.7(4.2)$ & $83.6(3.1)$ \\
\hline Gender Male (N/\%) & $3490(58.5)$ & $1340(55.1)$ & $1628(62.5)$ & $522(55.8$ \\
\hline \multicolumn{5}{|l|}{ Reason of admission (N/\%) } \\
\hline Medical & 4651 (77.9) & $1875(77.1)$ & 2059 (79.1) & $717(76.7)$ \\
\hline Emergency surgery & $1118(18.7)$ & $488(20.1)$ & $449(17.2)$ & $181(19.4$ \\
\hline Planned surgery & $198(3.3)$ & $67(2.8)$ & $94(3.6)$ & $37(4.0)$ \\
\hline \multicolumn{5}{|l|}{ Admission sepsis diagnosis } \\
\hline \multicolumn{5}{|l|}{$(\mathrm{N} / \%)$} \\
\hline Cutan/soft tissue (34) & $\begin{array}{r}492(0.2) \\
2106(268)\end{array}$ & $\begin{array}{l}253(10.4) \\
873(259)\end{array}$ & $064(1.1)$ & $\begin{aligned} 55(5.9) \\
356(18)\end{aligned}$ \\
\hline GI (35) & $\begin{array}{r}2196(36.8) \\
018(15.4)\end{array}$ & $8 / 3(35.9)$ & (1) & $356(38.1)$ \\
\hline Pulmonary (38) & $\begin{array}{l}918(15.4) \\
690(116)\end{array}$ & $\begin{aligned} 333(13.7) \\
323(93)\end{aligned}$ & $\begin{array}{l}432(16.6) \\
319(123)\end{array}$ & $153(16.4$ \\
\hline Renal/UTI (39) & (1) & $\begin{array}{r}223(9.2) \\
363(149)\end{array}$ & $350(134)$ & $\begin{array}{l}148(15.8 \\
116(124\end{array}$ \\
\hline Unknown (40) & $844(141)$ & $386(15.9)$ & $\begin{array}{r}350(13.4) \\
351.135)\end{array}$ & $116(12.4)$ \\
\hline Other (36/37/57/112) & & $386(15.9)$ & & \\
\hline \multicolumn{5}{|l|}{ Comorbidity (N/\%) } \\
\hline \multicolumn{5}{|l|}{ Renal insufficiency } \\
\hline \multirow{2}{*}{$\begin{array}{l}\text { COPD/respiratory } \\
\text { insufficiency }\end{array}$} & $847(14.2)$ & 255 (10.5) & $448(17.2)$ & $144(15.4)$ \\
\hline & $161(2.7)$ & $104(4.3)$ & $49(1.9)$ & $8(0.9$ \\
\hline Cirrhosis & $244(4.1)$ & $57(2.3)$ & $126(4.8)$ & $61(6.5$ \\
\hline \multirow{2}{*}{$\begin{array}{l}\text { Cardiovascular insufficiency } \\
\text { Malignancy }\end{array}$} & $640(10.7)$ & $268(11.0)$ & $307(11.8)$ & $65(7.0)$ \\
\hline & $1035(17.3)$ & $489(20.1)$ & $461(17.7)$ & $85(9.1)$ \\
\hline AIDS/immune insufficiency & $1402(23.5)$ & $447(18.4)$ & $736(28.3)$ & $219(23.4)$ \\
\hline $\begin{array}{l}\text { Diabetes } \\
\text { qSoFA score (N/\%) }\end{array}$ & & & & \\
\hline 0 & $55(0.9)$ & $27(1.1)$ & $22(0.8)$ & $6(0.6$ \\
\hline 1 & $780(13.1)$ & 337 (13.9) & $327(12.6)$ & $116(12.4$ \\
\hline 2 & $3378(56.6)$ & $1414(58.2)$ & $1469(56.4)$ & $495(52.9$ \\
\hline 3 & $1756(29.4)$ & $653(26.9)$ & $785(30.2)$ & $318(34.0)$ \\
\hline \multicolumn{5}{|l|}{ SOFA (N/\%) } \\
\hline Score 0-1 & $158(2.6)$ & $63(2.6)$ & $70(2.7)$ & $25(2.7)$ \\
\hline Score 2-5 & $890(14.9)$ & $368(15.1)$ & $392(15.1)$ & $130(13.9$ \\
\hline Score 5-10 & $2879(48.2)$ & $1138(46.8)$ & $1255(48.2)$ & $486(52.0)$ \\
\hline Score $\geq 10$ & $2042(34.2)$ & $862(35.5)$ & $886(34.0)$ & $294(31.4$ \\
\hline APACHE IV (mean; SD) & $82.8(30.1)$ & $75.6(30.6)$ & $86.7(28.8)$ & $91.0(28.1)$ \\
\hline SAPS II (mean: SD) & $48.1(17.4)$ & $43.2(17.5)$ & $50.5(16.5)$ & $54.2(16.3)$ \\
\hline \multirow{2}{*}{ LOS ICU (mean; IQR, hours) } & 174.7 & 186.9 & 179.9 & 128.4 \\
\hline & $(34.2-187.6)$ & $(35.8-207.1)$ & $(35.0-190.3)$ & $(28.3-140.7)$ \\
\hline LOS ICU $\geq 24 \mathrm{hr}(\mathrm{N} / \%)$ & $4881(81.8)$ & $2013(82.8)$ & $2134(82.0)$ & $734(78.5)$ \\
\hline LOS Hospital (mean; IQR, days) & $19.8(6.3-25.1)$ & $21.3(6.7-27.1)$ & $20.2(6.4-25.3)$ & $14.7(4.9-18.9)$ \\
\hline ICU mortality (N/\%) & $1111(18.6)$ & $340(14.0)$ & $516(19.8)$ & $255(27.3$ \\
\hline Hospital mortality (N/\%) & $1538(25.8)$ & $453(18.6)$ & $721(27.7)$ & $364(38.9$ \\
\hline
\end{tabular}

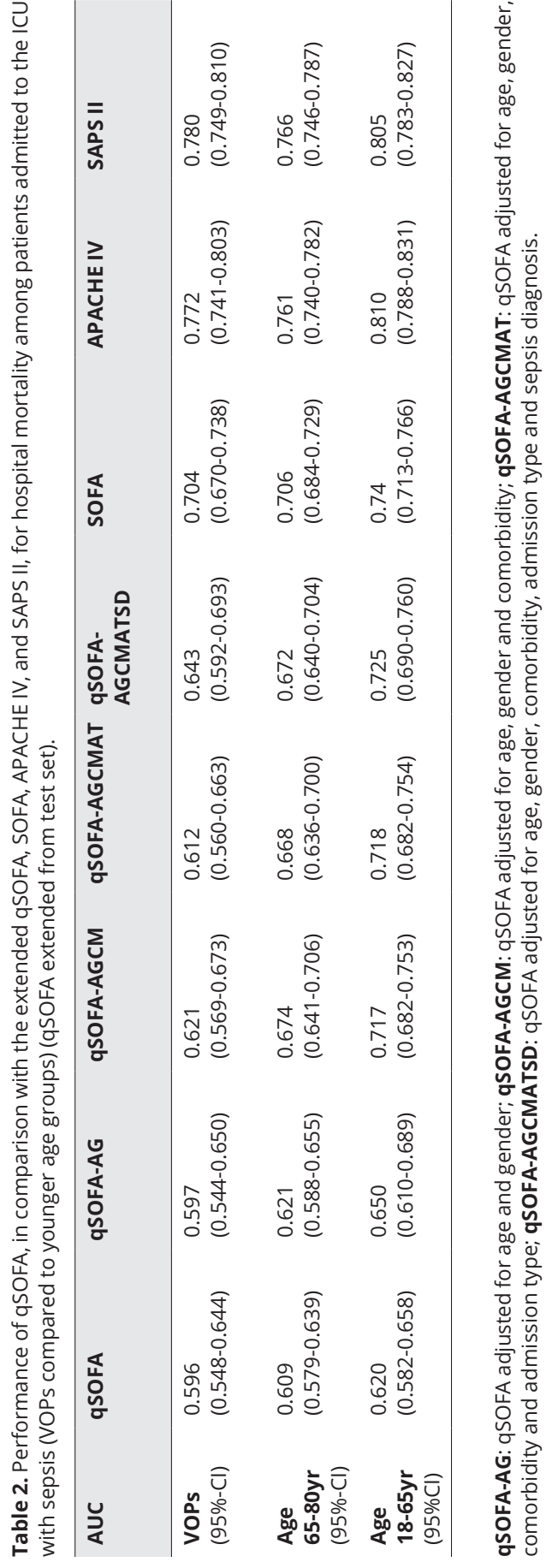




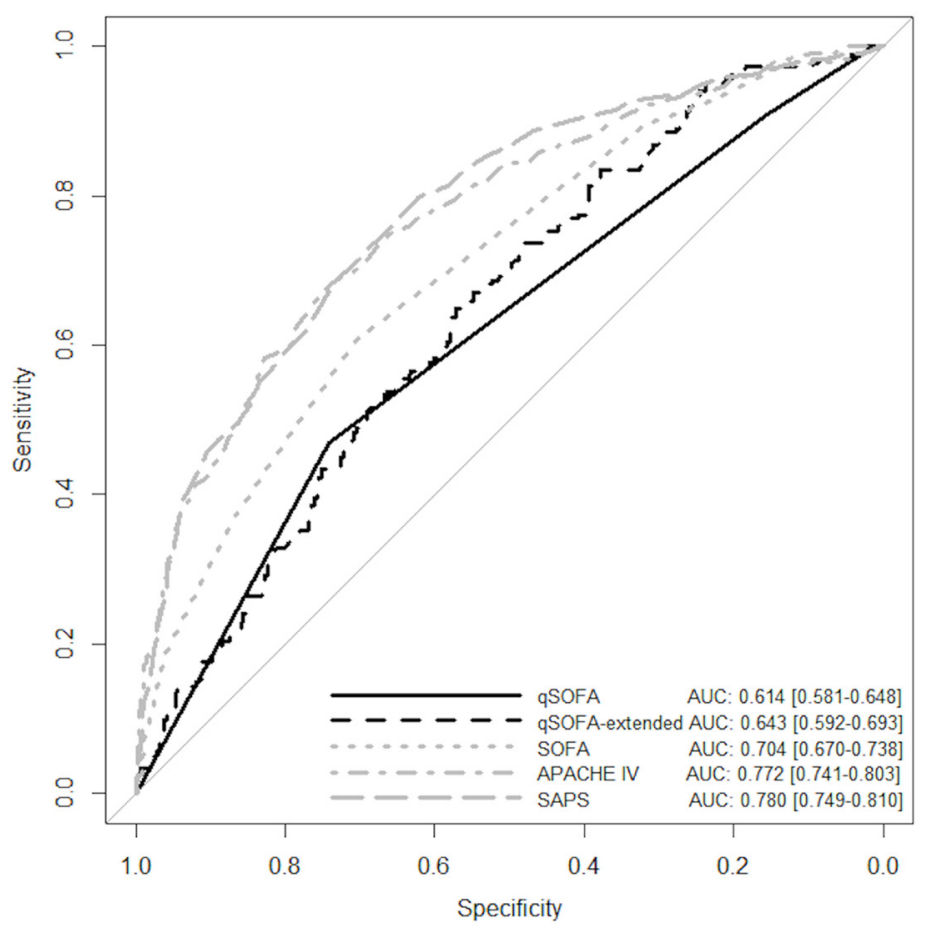

Figure 2. ROC curves of different scoring systems, hospital mortality among VOPs. (qSOFA_extended: qSOFA adjusted for age, gender, comorbidity, admission type and sepsis diagnosis. qSOFA
with optimal cut-off 3 ).

\section{Discussion}

In this study we reported the in-hospital mortality of VOPs admitted with sepsis and we analysed the performance of the SEP-3.0 qSOFA score in terms of discrimination, accuracy and calibration in these patients. We compared the predictive performance among VOPs of qSOFA to other well-known prognostic models (SOFA, APACHE IV and SAPS II) as well as to the performance of these models in younger ICU patients admitted with sepsis.

Mortality of VOPs admitted with sepsis was twice as high compared to the younger patients and qSOFA has poor predictive performance compared to other well-known prognostic models, SOFA, APACHE IV and SAPS II in our cohort. Even with a qSOFA cut-off raised to 3 , the discriminative performance was insufficient. Other factors, such as age, gender, comorbidity, type of admission and specific type of sepsis diagnosis, are known to be associated with outcome, and including these factors in addition to
Table 3. Performance of QSOFA for hospital mortality among VOPs, compared to the performance of the extended qSOFA, SOFA, APACHE IV, and SAPS II (qSOFA extended from test set).

\begin{tabular}{lcccccc}
\hline Variables & qSOFA & qSOFA & qSOFA-ext. & SOFA & APACHE IV & SAPS II \\
\hline Cut-off $(\geq)$ & 3 & 2 & -0.577 & 9 & 93 & 54 \\
Sensitivity & 0.47 & 0.909 & 0.648 & 0.610 & 0.684 & 0.706 \\
Specificity & 0.743 & 0.155 & 0.572 & 0.702 & 0.736 & 0.711 \\
PPV & 0.538 & 0.407 & 0.492 & 0.566 & 0.622 & 0.609 \\
NPV & 0.687 & 0.729 & 0.718 & 0.738 & 0.785 & 0.791 \\
AUC & 0.614 & 0.643 & 0.704 & 0.772 & 0.780 \\
(95\%-Cl) & $(0.581-0.648)$ & $(0.592-0.693)$ & $(0.670-0.738)$ & $(0.741-0.803)$ & $(0.749-0.810)$ \\
Hosmer-Lemeshow & $4.903 ; 8$ & $5.236 ; 8$ & $5.250 ; 8$ & $4.763 ; 8$ & $11.008 ; 8$ \\
X2; df (P-value) & $(0.768)$ & $(0.732)$ & $(0.731)$ & $(0.783)$ & $(0.201)$ \\
Brier, mean & 0.227 & 0.223 & 0.209 & 0.184 & 0.183 \\
(95\%-Cl) & $(0.218-0.236)$ & $(0.210-0.236)$ & $(0.198-0.220)$ & $(0.171-0.196)$ & $(0.170-0.195)$ \\
\hline
\end{tabular}

PPV= Positive Predictive Value, $\mathrm{NPV}=$ Negative Predicted Value, AUC = Area Under the Curve

qSOFA improved the predictive power only slightly, but not significantly among VOPs. The discriminative performance was still lower than these of the APACHE IV and SAPS II. However, these general severity scores also have only a moderate discriminative power with an AUC $<0.80$. Although recalibration of the APACHE IV and SAP II for VOPS admitted with sepsis would increase the model fit, we used in our study the original models, in concordance with daily practice, where these models are used in different ICU populations. Our conclusion would not have changed either, since the performance difference between the qSOFA and the other severity scores would have increased further with calibration.

To predict outcome in VOPs with sepsis, it would be necessary to develop a new model or to customize the existing severity scores to obtain better discrimination and calibration. Since the premorbid status is an important prognostic factor in VOPs, including pre-existing cognitive and functional functioning and frailty scores in such a prognostic model seems necessary. In younger patients, the extended qSOFA demonstrated a significantly increased discriminative performance, comparable with the full SOFA score, but still inferior to that of APACHE IV and SAPS II. Accuracy and calibration were additionally tested and demonstrated the best overall performance for APACHE IV and SAPS II.

It is not surprising that qSOFA, a simple three (clinical) item score, is inferior to far more extensive scores, which also include laboratory results and other factors like type of admission and chronic diseases. In an extended qSOFA model, several important factors, including comorbidity, were added to the scoring, but this was not enough to 
equalize the performance of the more comprehensive models SOFA, APACHE IV and SAPS II. Better correction for the severity of illness is needed to further improve the predictive performance, requiring a more complex model including more data, like the other extensive scores. Unfortunately, we were not able to include cognitive and functional status or frailty scores in our model. Elderly specific factors, like frailty, are far more predictive of mortality than age per se.[41-43] Frailty is one of the most important prognostic factors in VOPs and should be taken into account when evaluating outcomes in this population. This might also be an explanation for the fact that the extended qSOFA performed significantly better than the qSOFA in the younger patients, but not in the elderly group. Combining frailty with qSOFA to predict outcome would probably have given better results in these elderly patients.

The discriminative performance of qSOFA for in-hospital mortality that we found, is comparable with the values found in other studies, although these earlier studies reported a wide range of AUC values (of 0.55 to 0.82 ) and included different patient populations both outside and in the ICU.[20-22,44] One of the explanations of the differences between the performance of qSOFA outside and in the ICU is that the qSOFA scores assessed after ICU admission may have been affected by therapeutic interventions, such as vasopressors and/or mechanical respiratory support. The metaanalysis of Fernando and colleagues demonstrated that the performance of qSOFA varied with the population in which it was applied.[22] In the ICU patients (8 study cohorts, 203229 ICU patients) qSOFA was far more sensitive (pooled sensitivity 87.2 (95\% Cl 75.8-93.7), but far less specific (pooled specificity 33.3 (95\% Cl $23.8 \%$ to $44.4 \%$ ) than in non-ICU patients (pooled sensitivity and specificity resp. $51.2(95 \% \mathrm{Cl} 43.6-58.7)$ and 79.6 (95\% Cl 73.3-84.7)). In our cohort the sensitivity of qSOFA for mortality was even better, but the specificity of qSOFA for mortality is worse. This could be explained by differences in populations (exclusively patients with sepsis vs. ICU patients with infection) and the use of in-hospital mortality vs. 28- or 30-day mortality. Studies using these latter two endpoints showed substantially lower sensitivity and decreased overall pooled sensitivity.

We exclusively included patients admitted to the ICU with sepsis, since qSOFA was originally developed for patients with sepsis, but results could have been comparable for other ICU patients. Singer and colleagues showed that qSOFA could predict mortality in all patients in the emergency department (ED), both in patients with and patients without an infection (AUC $0.75(95 \% \mathrm{Cl} 0.71-0.78)$ and $0.70(95 \% \mathrm{Cl} 0.65-0.74)$ respectively).[45] Anand and colleagues, who examined the prognostic value of qSOFA in undifferentiated patients admitted to US hospitals, demonstrated that the AUROC for mortality was even lower for qSOFA in patients with suspected infection vs. those without $(0.814$ vs $0.875 ; \mathrm{P}<0.001)$.[46]
Although many severity models for ICU patients have been developed and tested last decades, no model was demonstrated to be accurate enough to be helpful for prognostication of VOPs.[47]

The strength of our study is that it is the first study that evaluated the qSOFA in VOPS admitted with sepsis. Moreover, the performances of qSOFA in these VOPs were compared to the performance of qSOFA in two younger age groups and compared to three commonly used, but more complicated, severity scores. We included a large number of patients from a large number of Dutch ICUs during a 5-years period and evaluated multiple performance measures. We not exclusively analysed discriminative performance of qSOFA as many other studies did, but we also evaluated the performance in terms of accuracy and calibration. A reliable prognostic score with overall good performance is most wanted in clinical practice.

Our study has also limitations. First, VOPs are known to have a substantial post-hospital mortality and as thus hospital mortality may give an unrealistically good impression of the outcomes. In addition, ICU-and hospital mortality rates may be influenced by discharge policies. This limitation concerns the outcome, but could also influence the predictive performance of qSOFA. However, the same is true for the performance of the other scores. To enable comparison with existing studies, including the one in which the tool was derived, we have chosen to use the in-hospital mortality rates as outcome parameter (see Supplement Table S3 and Figure S2 for ICU-mortality data). [19] Secondly, it is imaginable that ICU treatment is withheld or withdrawn earlier for VOPs which could have contributed to higher mortality rates in the VOP subgroup. Unfortunately, data about treatment limitations are not available in the NICE registry. Life sustaining treatment (LST) limitations occurs frequently in the older ICU population and are associated with increased 30-day mortality.[48] In this study of Guidet and colleagues, including 5132 patients aged $\geq 80$ years from 309 ICUs in 21 European countries, $72.8 \%$ of the patients had no LST, $15.0 \%$ had a withholding decision, and $12.2 \%$ withdrawal (including withholding). For the patients in Central Europe (including the Netherlands) and the patients admitted with sepsis, percentages of no LST were respectively $64.4 \%$ and $62.7 \%$. Although this concerns another cohort in another time period, percentages may be comparable with our cohort. Thirdly, our study is a retrospective cohort study with its shortcomings. Certain information is unfortunately not available, like the previously mentioned frailty and LST limitations, but also respiratory rate on admission. Frailty is one of the key drivers of poor outcome for elderly patients admitted to the ICU. Therefore, including frailty is important in outcome studies, and combining qSOFA with frailty data to predict mortality would probably have given better results, but as discussed previously, frailty scores are unfortunately not registered in the NICE database. Since the respiratory rate on admission is not 
available in the registry, we used the worst value from the first 24 hours instead (like in many other qSOFA studies). This could have biased the results to a higher qSOFA score, but we think that this has not have influenced our results, since a sensitivity analyses in which we used the systolic blood pressure and GCS on admission in combination with the highest respiratory rate of the first 24 hours showed similar performance (see Supplement Tables S4-6). Since we used a value for respiratory rate from the first 24 hours after ICU admission, we additionally performed a separate analysis for the population with a minimum ICU duration of 24 hours. However, when restricting the analyses to the population with a minimum ICU duration of 24 hours, similar results were found (results not shown). Lastly, since our cohort consists of patients already admitted to the ICU with sepsis, results cannot be used yet for prognostication and selection before ICU admission, which requires validation in patients on general wards and the ED.

In conclusion, in our cohort of patients admitted to the ICU with sepsis, mortality of VOPs admitted with sepsis was twice as high compared to the younger patients. qSOFA is a simple, but poorly sensitive predictive marker for in-hospital mortality and less accurate than SOFA, APACHE IV and SAPS II in both younger patients and VOPs admitted to the ICU with sepsis. Including other factors in the qSOFA model, like age, gender, comorbidity, admission type and sepsis diagnosis, did not result in an improvement of the model performance in VOPs. Hence, qSOFA cannot be recommended for mortality prediction in VOPs admitted to the ICU with sepsis. Future research should focus on the development of enhanced or modified prognostic tools with good performance in VOPs, in order to better select these VOPs who might benefit from ICU treatment and to limit suffering, both in human and monetary terms. It might be useful to take the premorbid function status into consideration and include these factors in such a prognostic model. And lastly, it is important to realize that for many very elderly, preserving quality of life (QoL) is more important than prolonging their life and thus that hospital mortality may not be the most important outcome to be analysed.[49]

\section{References}

1. Angus DC, van der Poll T. Severe sepsis and septic shock.N EngIJ Med 2013; 369: 840-51.

2. Gaieski DF, Edwards JM, Kallan MJ, Carr BG. Benchmarking the incidence and mortality of severe sepsis in the United States. Crit Care Med 2013; 41: 1167-74.

3. Kaukonen K-M, Bailey M, Suzuki S, Pilcher D, Bellomo R. Mortality related to severe sepsis and septic shock among critically ill patients in Australia and New Zealand, 2000-2012 JAMA 2014: 311: 1308-16.

4. Fleischmann C, Scherag A, Adhikari NKJ, Hartog CS, Tsaganos T, Schlattmann P, Angus DC, Reinhart K. Assessment of Global Incidence and Mortality of Hospital-treated Sepsis. Current Estimates and Limitations.Am J Respir Crit Care Med 2016; 193: 259-72.

5. Iwashyna TJ, Ely EW, Smith DM, Langa KM. Long-term Cognitive Impairment and Functional Disability Among Survivors of Severe Sepsis.JAMA 2010; 304: 1787.

6. Nasa P, Juneja D, Singh O. Severe sepsis and septic shock in the elderly: An overview. World J Crit care Med 2012; 1:23-30

7. Flaatten H, de Lange DW, Artigas A, Bin D, Moreno R, Christensen S, Joynt GM, Bagshaw SM, Sprung CL, .

8. Karakus A, Haas LEM, Brinkman S, de Lange DW, de Keizer NF. Trends in short-term and 1-year mortality in very elderly intensive care patients in the Netherlands: a retrospective study from 2008 to 2014 Intensive Care Med 2017; 43: 1476-84.

9. Haas LEM, van Dillen LS, de Lange DW, van Dijk D, Hamaker ME. Outcome of very old patients admitted to the ICU for sepsis: A systematic review.Eur Geriatr Med 2017; 8: 446-53.

10. Martin-Loeches I, Guia MC, Vallecoccia MS, Suarez D, Ibarz M, Irazabal M, Ferrer R, Artigas A. Risk factors for mortality in elderly and very elderly critically ill patients with sepsis: a prospective, observation multicenter cohort study Ann Intensive Care 2019; 9:26.

11. Singer $M$, Deutschman $C S$, Seymour CW, Shankar-Hari M, Annane D, Bauer M, Bellomo R, Bernard GR, Chiche J-D, Coopersmith CM, Hotchkiss RS, Levy MM, Marshall JC, Martin GS, Opal SM, Rubenfeld GD, van der Poll T, Vincent J-L, Angus DC. The
Shock (Sepsis-3).JAMA 2016; 315: 801-10.

12. Bone RC, Balk RA, Cerra FB, Dellinger RP, Fein AM, Knaus WA, Schein RM, Sibbald WJ. Definitions for sepsis and organ failure and guidelines for the use of innovative therapies in sepsis. The ACCP/SCCM Consensus Medicine.Chest 1992; 101: 1644-55.

13. Levy MM, Fink MP, Marshall JC, Abraham E, Angus D, Cook D, Cohen J, Opal SM, Vincent J-L, Ramsay G, SCCM/ESICM/ACCP/ATS/SIS, 2001 SCCM/ESICM/ACCP/ATS/SIS International Sepsis Definitions Conference. Crit Care Med 2003; 31: 1250-6.

14. Sprung CL, Sakr Y, Vincent J-L, Le Gall J-R, Reinhart K, Ranieri VM, Gerlach H, Fielden J, Groba CB, Payen D. An evaluation of systemic inflammatory response syndrome signs in the Sepsis Occurrence in Acutely il Patients (SOAP) study.Intensive Care Med 2006; 32: 421-7.

15. Churpek MM, Zadravecz FJ, Winslow C, Howell MD, Edelson DP. Incidence and Prognostic Value of the Systemic Inflammatory Response Syndrome and Organ Dysfunctions in Ward Patients.Am J Respir Cr
Care Med 2015; 192: 958-64.

16. Kaukonen K-M, Bailey M, Pilcher D, Cooper DJ, Bellomo R. Systemic inflammatory response syndrome criteria in defining severe sepsis.N EngIJ Med 2015; 372: 1629-38, 
17. Vincent JL, Moreno R, Takala J, Willatts S, De Mendonça A, Bruining H, Reinhart CK, Suter PM, Thijs LG. The SOFA (Sepsis-related Organ Failure Assessment) score to describe organ dysfunction/failure. On behalf of the Working Group on Sepsis-Related Problems of the European Society of Intensive Care Medicine. Intensive Care Med 1996; 22: 707-10.

18. Shankar-Hari M, Phillips GS, Levy ML, Seymour CW, Liu VX, Deutschman CS, Angus DC, Rubenfeld GD, Singer M, Sepsis Definitions Task Force. Developing a New Definition and Assessing New Clinical Criteria for Septic Shock: For the Third International Consensus Definitions for Sepsis and Septic Shock (Sepsis-3).

19. Seymour CW, Liu VX, Iwashyna TJ, Brunkhorst FM, Rea TD, Scherag A, Rubenfeld G, Kahn JM, Shankar-Har M, Singer M, Deutschman CS, Escobar GJ, Angus DC. Assessment of Clinical Criteria for Sepsis: For the
Third International Consensus Definitions for Sepsis and Septic Shock (Sepsis-3).JAMA 2016; 315: 762-74.

20. Maitra S, Som A, Bhattacharjee S. Accuracy of quick Sequential Organ Failure Assessment (qSOFA) score and systemic inflammatory response syndrome (SIRS) criteria for predicting mortality in hospitalized patients with suspected infection: a meta-analysis of observational studies. Clin Microbiol Infect 2018; 24

21. Song J-U, Sin CK, Park HK, Shim SR, Lee J. Performance of the quick Sequential (sepsis-related) Organ Failure Assessment score as a prognostic tool in infected patients outside the intensive care unit: a systematic review and meta-analysis.Crit Care 2018; 22: 28 .

22. Fernando SM, Tran A, Taljaard M, Cheng W, Rochwerg B, Seely AJE, Perry JJ. Prognostic Accuracy of the Quick Sequential Organ Failure Assessment for Mortality in Patients With Suspected Infection: A Systematic Review and Meta-analysis.Ann Intern Med 2018; 168: 266-75.

23. Raith EP, Udy AA, Bailey M, McGloughlin S, Maclsaac C, Bellomo R, Pilcher D V, Australian and New Zealand Intensive Care Society (ANZICS) Centre for Outcomes and Resource Evaluation (CORE). Prognostic
Accuracy of the SOFA Score, SIRS Criteria, and gSOFA Score for In-Hospital Mortality Among Adults With Suspected Infection Admitted to the Intensive Care Unit.JAMA 2017; 317: 290-300.

24. Costa RT, Nassar APJ, Caruso P. Accuracy of SOFA, qSOFA, and SIRS scores for mortality in cancer patients admitted to an intensive care unit with suspected infection.J Crit Care 2018; 45: 52-7.

25. Kovach CP, Fletcher GS, Rudd KE, Grant RM, Carlbom DJ. Comparative prognostic accuracy of sepsis cores for hospital mortality in adults with suspected infection in non-ICU and ICU at an academic public hospital.PLoS One 2019; 14: e0222563.

26. Finkelsztein E, Jones DS, Ma KC, Pabon MA, Delgado T, Nakahira K, Arbo JE, Berlin DA, Schenck EJ, Cho AMK, Siempos II. Comparison of qSOFA and SIRS for predicting adverse outcomes of patients with suspicion of sepsis outside the intensive care unit.Crit Care 2017; 21: 73.

27. April MD, Aguirre J, Tannenbaum LI, Moore T, Pingree A, Thaxton RE, Sessions DJ, LantryJH. Sepsis Clinical Criteria in Emergency Department Patients Admitted to an Intensive Care Unit: An External Validation
Study of Quick Sequential Organ Failure Assessment.J Emerg Med 2017; 52: 622-31.

28. Johnson A. External validation of the Sepsis-3 guidelines.Crit Care Med 2016; 44: 91 .

29. Khwannimit B, Bhurayanontachai R, Vattanavanit V. Comparison of the performance of SOFA, qSOFA and SIRS for predicting mortality and organ failure among sepsis patients admitted to the intensive care unit in a middle-income country.J Crit Care 2018; 44: 156-60.

30. Siddiqui S, Chua M, Kumaresh V, Choo R. A comparison of pre ICU admission SIRS, EWS and q SOFA scores for predicting mortality and length of stay in ICU.J Crit Care 2017; 41: 191-3.

31. Umemura $Y$, Ogura $H$, Gando $S$, Kushimoto $S$, Saitoh D, Mayumi T, Fujishima $S$, Abe T, Ikeda H, Kotani J, Miki Y, Shiraishi S-I, Shiraishi A, Suzuki K, Suzuki Y, Takeyama N, Takuma K, Tsuruta R, Yamaguchi Y subgroup analysis by the Japanese Association for Acute Medicine Sepsis Registry Study Group.J Infect Chemother Off J Japan Soc Chemother 2017; 23: 757-62.
32. Ho KM, Lan NSH. Combining quick Sequential Organ Failure Assessment with plasma lactate concentration is comparable to standard Sequential Organ Failure Assessment score in predicting mortality of patients with and without suspected infection.J Crit Care 2017: 38: 1-5.

33. Giamarellos-Bourboulis E,, Tsaganos T, Tsangaris I, Lada M, Routsi C, Sinapidis D, Koupetori M, Bristianou M, Adamis G, Mandragos K, Dalekos GN, Kritselis I, Glannikopoulos G, Koutelidakis I, Pavlaki M, Antoniadou E, Vlachogiannis G, Koulouras V, Prekates A, Dimopoulos G, Koutsoukou A, Pnevmatikos I, loakelmidou , Kotanidou A, Or for improvement in early risk identification.Clin Microbiol Infect 2017; 23: 104-9.

34. Dutch National Intensive Care Evaluation (NICE) registry. [Internet]. Available from: http://www.stichting nice.n

35. van de Klundert N, Holman R, Dongelmans DA, de Keizer NF. Data Resource Profile: the Dutch Nationa Evaluation (NICE) Registry of Admissions to Adult Intensive Care Units. Int J Epidemiol 2015; 44: $1850-1850 h$

36. Le Gall J-R, Lemeshow S, Saulnier F. A New Simplified Acute Physiology Score (SAPS II) Based on a European/North American Multicenter Study.JAMA J Am Med Assoc 1993; 270: 2957.

37. Zimmerman JE, Kramer AA, MCNair DS, Malila FM. Acute Physiology and Chronic Health Evaluation (APACHE) IV: hospital mortality assessment for today's critically ill patients. Crit Care Med 2006: 34: 1297-

38. Rhodes A, Evans LE, Alhazzani W, Levy MM, Antonelli M, Ferrer R, Kumar A, Sevransky JE, Sprung CL, Nunnally ME, Rochwerg B, Rubenfeld GD, Angus DC, Annane D, Beale RJ, Bellinghan GJ, Bernard GR, Chiche J-D, Coopersmith C, De Backer DP, French CJ, Fujishima S, Gerlach H, Hidalgo JL, Hollenberg SM, Jones AE, Karnad DR, Kleinpell RM, Koh Y, Lisboa TC, Machado FR, Marini JJ, Marshall JC, Mazuski JE, McIntyre LA, McLean AS, Mehta S, Moreno RP, Myburgh J, Navalesi P, Nishida O, Osborn TM, Perne A, Plunkett CM, Ranieri M, Schorr CA, Seckel MA, seymour CW, Shieh L, Shukri KA, Simpson SQ, singer M, Thompson BT, Townsend SR, Van der Poll T, Vincent J-L, Wiersinga WJ, Zimmerman JL, Dellinger RP.
Surviving Sepsis Campaign: International Guidelines for Management of Sepsis and Septic Shock: 2016. Surviving Sepsis Campaign: Internation
Intensive Care Med 2017; 43: 304-77.

39. Lemeshow S, Hosmer DW. A review of goodness of fit statistics for use in the development of logistic regression models. Am J Epidemiol 1982; 115: 92-106.

40. Arkes HR, Dawson N V, Speroff T, Harrell FE, Alzola C, Phillips R, Desbiens N, Oye RK, Knaus W, Connors AF. The Covariance Decomposition of the Probability Score and Its Use in Evaluating Prognostic Estimates. Med Decis Mak 1995; 15: 120-31.

41. Flaatten H, De Lange DW, Morandi A, Andersen FH, Artigas A, Bertolini G, Boumendil A, Cecconi M, Christensen S, Farald L, florer, Jung C, Marsh B, Moreno R, Oeyen S, Öhman CA, Pinto BB, Soliman IV, SzczeklkW, Valentin A, Watson $x$, Zaferidis T, Guidet B, VPP study group. The impact of fraily on ICU and (30-day mortality and the level of care in very elderly patients ( $\geq 80$ years).Intensive Care Med 2017; 43:

42. Pietiläinen L, Hästbacka J, Bäcklund M, Parviainen I, Pettilä V, Reinikainen M. Premorbid functional status as a predictor of 1-year mortality and functional status in intensive care patients aged 80 years or older. Intensive Care Med 2018; 44: 1221-9.

43. Krinsley JS, Wasser T, Kang G, Bagshaw SM. Pre-admission functional status impacts the performance of the APACHE IV model of mortality prediction in critically ill patients.Crit Care 2017; 21: 110,

44. Lo RSL, Leung LY, Brabrand M, Yeung CY, Chan SY, Lam CCY, Hung KKC, Graham CA. GSOFA is a Poor Predictor of Short-Term Mortality in All Patients: A Systematic Review of 410,000 Patients. Clin Med 2019; 8: 61.

45. Singer AJ, Ng J, Thode HC, Spiegel R, Weingart S. Quick SOFA Scores Predict Mortality in Adult Emergency Department Patients With and Without Suspected Infection.Ann Emerg Med 2017; 69: 475-9. 
46. Anand V, Zhang Z, Kadri SS, Klompas M, Rhee C. Epidemiology of Quick Sequential Organ Failure Assessment Criteria in Undifferentiated Patients and Association With Suspected Infection and Sepsis. Chest 2019; 156: 289-97.

47. Minne L, Ludikhuize J, de Jonge E, de Rooij S, Abu-Hanna A. Prognostic models for predicting mortality in elderly ICU patients: a systematic review.Intensive Care Med 2011; 37: 1258-68.

48. Guidet B, Flaatten H, Boumendil A, Morandi A, Andersen FH, Artigas A, Bertolini G, Cecconi M, Christensen S, Faraldi L, Fjølner J, Jung C, Marsh B, Moreno R, Oeyen S, Öhman CA, Pinto BB, Soliman IW, Szczeklik W, Valentin A, Watson X, Zafeiridis T, De Lange DW, VIP1 study group. Withholding or withdrawing of (280 yers) admitted to the

Philippart F, Vesin A, Bruel C, Kpodji A, Durand-Gasselin B, Garçon P, Levy-Soussan M, Jagot JL, CalvoVerjat N, Timsit JF, Misset B, Garrouste-Orgeas M. The ETHICA study (part I): elderly's thoughts about intensive care unit admission for life-sustaining treatments. Intensive Care Med 2013; 39: 1565-73.

\section{Supplement}

Table S1. APACHE IV sepsis diagnoses codes

\begin{tabular}{ll}
\hline 34 & Sepsis, cutaneous/soft tissue \\
\hline 35 & Sepsis, Gl \\
36 & Sepsis, gynecologic \\
37 & Sepsis, other \\
38 & Sepsis, pulmonary \\
39 & Sepsis, renal/UTI (including bladder) \\
40 & Sepsis, unknown \\
57 & Cholangitis \\
112 & Arthritis, septic \\
\hline
\end{tabular}

Table S2. Differences (in age, gender, APACHE IV and mortality) between in- and excluded patients (because of missing scores), per age category.

\begin{tabular}{|c|c|c|c|c|c|c|}
\hline & \multicolumn{2}{|c|}{$18-65$ years } & \multicolumn{2}{|c|}{$65-80$ years } & \multicolumn{2}{|c|}{ VOPS } \\
\hline & Incl $(2,413)$ & Excl (149) & Incl $(2,603)$ & Excl (147) & Incl (935) & Excl (42) \\
\hline $\begin{array}{l}\text { Age } \\
\text { (mean, SD, range) }\end{array}$ & $\begin{array}{c}51.6 \\
11.0,18-64\end{array}$ & $\begin{array}{c}50.3 ; \\
12.2,18-64\end{array}$ & $\begin{array}{c}71.7 ; \\
4.2,65-79\end{array}$ & $\begin{array}{c}72.1 ; \\
4.2,65-79\end{array}$ & $\begin{array}{c}83.6 ; \\
3.1,80-95\end{array}$ & $\begin{array}{c}\text { 83.5; } \\
3.6,80-95\end{array}$ \\
\hline $\begin{array}{l}\text { Gender } \\
(\% \text { male })\end{array}$ & 55.1 & 56.4 & 62.5 & 60.5 & 55.8 & 57.1 \\
\hline $\begin{array}{l}\text { APACHE IV } \\
\text { (mean; SD, range) }\end{array}$ & $\begin{array}{c}75.6 ; \\
30.6,9-214\end{array}$ & $\begin{array}{c}72.1 ; \\
38.6,0-206\end{array}$ & $\begin{array}{c}86.7 ; \\
28.8,22-221\end{array}$ & $\begin{array}{c}86.3 ; \\
37.5,13-217\end{array}$ & $\begin{array}{c}91.0 \\
28.1,33-206\end{array}$ & $\begin{array}{c}86.2 \\
32.8,24-174\end{array}$ \\
\hline $\begin{array}{l}\text { Hospital } \\
\text { mortality (\%) }\end{array}$ & 18.6 & 31.5 & 27.7 & 36.1 & 38.9 & 40.5 \\
\hline
\end{tabular}

Table S3. Performances of qSOFA for ICU mortality

a. Performance of qSOFA among VOPs compared to younger age groups for ICU mortality.

\begin{tabular}{llllll}
\hline AUC & qSOFA & qSOFA-AG & qSOFA-AGCM & $\begin{array}{l}\text { qSOFA- } \\
\text { AGCMAT }\end{array}$ & $\begin{array}{l}\text { qSOFA- } \\
\text { AGCMATSD }\end{array}$ \\
\hline VOPs & 0.619 & 0.646 & 0.638 & 0.637 & 0.656 \\
$(95 \%-\mathrm{Cl})$ & $(0.567-0.671)$ & $(0.589-0.703)$ & $(0.581-0.695)$ & $(0.582-0.692)$ & $(0.602-0.710)$ \\
Age 65-80yr & 0.617 & 0.625 & 0.663 & 0.659 & 0.663 \\
$(95 \%-\mathrm{Cl})$ & $(0.584-0.651)$ & $(0.588-0.662)$ & $(0.626-0.700)$ & $(0.622-0.695)$ & $(0.627-0.700)$ \\
Age 18-65yr & 0.632 & 0.653 & 0.697 & 0.702 & 0.708 \\
$(95 \% \mathrm{Cl})$ & $(0.591-0.674)$ & $(0.608-0.697)$ & $(0.656-0.739)$ & $(0.660-0.743)$ & $(0.668-0.748)$ \\
\hline
\end{tabular}

qSOFA-AG: qSOFA adjusted for age and gender; qSOFA-AGCM: qSOFA adjusted for age, gender and comorbidity; qSOFA-AGCMAT: qSOFA adjusted for age, gender, comorbidity and admission type; qSOFA-AGCMATSD: qSOFA adjusted for age, gender, comorbidity, admission type and sepsis diagnosis. 


\section{Table S3.}

b. Performance of qSOFA among VOPs compared to SOFA, APACHE IV, and SAPS II, for ICU mortality.

\begin{tabular}{lllll}
\hline Variables & qSOFA & SOFA & APACHE IV & SAPS II \\
\hline Cut-off $(\geq)$ & 3 & 9 & 96 & 56 \\
Sensitivity & 0.510 & 0.690 & 0.745 & 0.761 \\
Specificity & 0.724 & 0.682 & 0.763 & 0.722 \\
PPV & 0.409 & 0.449 & 0.541 & 0.507 \\
NPV & 0.797 & 0.855 & 0.889 & 0.889 \\
AUC & 0.625 & 0.743 & 0.818 & 0.822 \\
(95\%-Cl) & $(0.589-0.662)$ & $(0.708-0.778)$ & $(0.787-0.849)$ & $(0.792-0.852)$ \\
\hline
\end{tabular}

PPV= Positive Predictive Value, NPV= Negative Predicted Value, AUC = Area Under the Curve

Table S4. Data about the additionally calculated qSOFA-2 (using the systolic blood pressure and GCS on admission and the highest breathing frequency of the first 24 hours, instead of the worst values of the three parameters from the first 24 hours).

\begin{tabular}{lllll}
\hline qSOFA-2 score (N/\%) & $\begin{array}{l}\text { All sepsis } \\
\text { patients }\end{array}$ & $\mathbf{1 8 - 6 5}$ years & $\mathbf{6 5 - 8 0}$ years & VOPs \\
\hline 0 & $269(4.2)$ & $120(4.6)$ & $108(3.9)$ & $41(4.2)$ \\
1 & $2242(35.4)$ & $945(36.4)$ & $963(34.9)$ & $334(34.1)$ \\
2 & $2750(43.4)$ & $1093(42.1)$ & $1208(43.7)$ & $449(45.8)$ \\
3 & $749(11.8)$ & $288(11.1)$ & $343(12.4)$ & $118(12.0)$ \\
Missing & $326(5.1)$ & $148(5.7)$ & $140(5.1)$ & $38(3.9)$ \\
\hline
\end{tabular}

Table 55. Performance of qSOFA-2 among VOPs compared to younger age groups for ICU- (a) and hospital (b) mortality.

a. Performance of qSOFA-2 among VOPs compared to younger age groups for ICU-mortality

\begin{tabular}{llllll}
\hline AUC & $\begin{array}{l}\text { qSOFA- } \\
\mathbf{2}\end{array}$ & $\begin{array}{l}\text { qSOFA- } \\
\text { AG }\end{array}$ & $\begin{array}{l}\text { qSOFA- } \\
\text { AGCM }\end{array}$ & $\begin{array}{l}\text { qSOFA- } \\
\text { AGCMAT }\end{array}$ & $\begin{array}{l}\text { qSOFA- } \\
\text { AGCMATSD }\end{array}$ \\
\hline VOPs & 0.591 & 0.602 & 0.588 & 0.597 & 0.619 \\
$(95 \%-C l)$ & $(0.537-0.645)$ & $(0.544-0.661)$ & $(0.529-0.647)$ & $(0.540-0.655)$ & $(0.563-0.674)$ \\
Age 65-80yr & 0.583 & 0.583 & 0.635 & 0.631 & 0.643 \\
$(95 \%-C l)$ & $(0.546-0.619)$ & $(0.544-0.622)$ & $(0.596-0.673)$ & $(0.593-0.669)$ & $(0.605-0.681)$ \\
Age $<65 y r$ & 0.614 & 0.644 & 0.687 & 0.692 & 0.701 \\
$(95 \%$ CI) & $(0.571-0.657)$ & $(0.601-0.687)$ & $(0.645-0.729)$ & $(0.651-0.734)$ & $(0.660-0.742)$ \\
\hline
\end{tabular}

qSOFA-AG: qSOFA adjusted for age and gender; qSOFA-AGCM: qSOFA adjusted for age, gender and comorbidity FA adjusted for age, gender, comorbidity, admission type and sepsis diagnosis.
Table S5.

b. Performance of gSOFA-2 among VOPs compared to younger age groups for hospital mortality.

\begin{tabular}{llllll} 
AUC & qSOFA- & $\begin{array}{l}\text { qSOFA- } \\
\mathbf{2}\end{array}$ & $\begin{array}{l}\text { qSOFA- } \\
\text { AGCM }\end{array}$ & $\begin{array}{l}\text { qSOFA- } \\
\text { AGCMAT }\end{array}$ & $\begin{array}{l}\text { qSOFA- } \\
\text { AGCMATSD }\end{array}$ \\
\hline vOPs & 0.568 & 0.572 & 0.591 & 0.589 & 0.629 \\
$(95 \%-C l)$ & $(0.518-0.618)$ & $(0.518-0.626)$ & $(0.537-0.644)$ & $(0.536-0.643)$ & $(0.579-0.680)$ \\
Age 65-80yr & 0.595 & 0.598 & 0.660 & 0.656 & 0.664 \\
$(95 \%-C l)$ & $(0.563-0.627)$ & $(0.564-0.632)$ & $(0.628-0.639)$ & $(0.623-0.689)$ & $(0.632-0.697)$ \\
Age <65yr & 0.600 & 0.641 & 0.708 & 0.709 & 0.715 \\
$(95 \% C l)$ & $(0.561-0.639)$ & $(0.602-0.679)$ & $(0.672-0.744)$ & $(0.673-0.745)$ & $(0.679-0.751)$ \\
\hline
\end{tabular}

qSOFA-AG: SOFA adjusted for age and gender: qSOFA-AGCM: qSOFA adjusted for age gender and comorbidity qSOFA-AGCMAT: GSOFA adjusted for age, gender, comorbidity and admission type; qSOFA-AGCMATSD: qSOFA adjusted for age, gender, comorbidity, admission type and sepsis diagnosis.

Table 56. Performance of qSOFA-2 among VOPs for hospital mortality.

\begin{tabular}{lll}
\hline & qSOFA-2 & qSOFA-2 extended \\
\hline Cut-off $(\geq)$ & 2 & -0.353 \\
Sensitivity & 0.668 & 0.566 \\
Specificity & 0.438 & 0.642 \\
PPV & 0.431 & 0.502 \\
NPV & 0.674 & 0.698 \\
AUC & 0.574 & 0.629 \\
$(95 \%-C l)$ & $0.539-0.609)$ & $(0.579-0.680)$ \\
Hosmer-Lemeshow X2/df (P-value) & $4.496 ; 8(0.81)$ & $7.3 ; 8(0.505)$ \\
Brier, mean (95\%-CI) & $0.233(0.225-0.241)$ & $0.227(0.214-0.239)$ \\
\hline
\end{tabular}

PPV= Positive Predictive Value, NPV= Negative Predicted Value, AUC = Area Under the Curve 


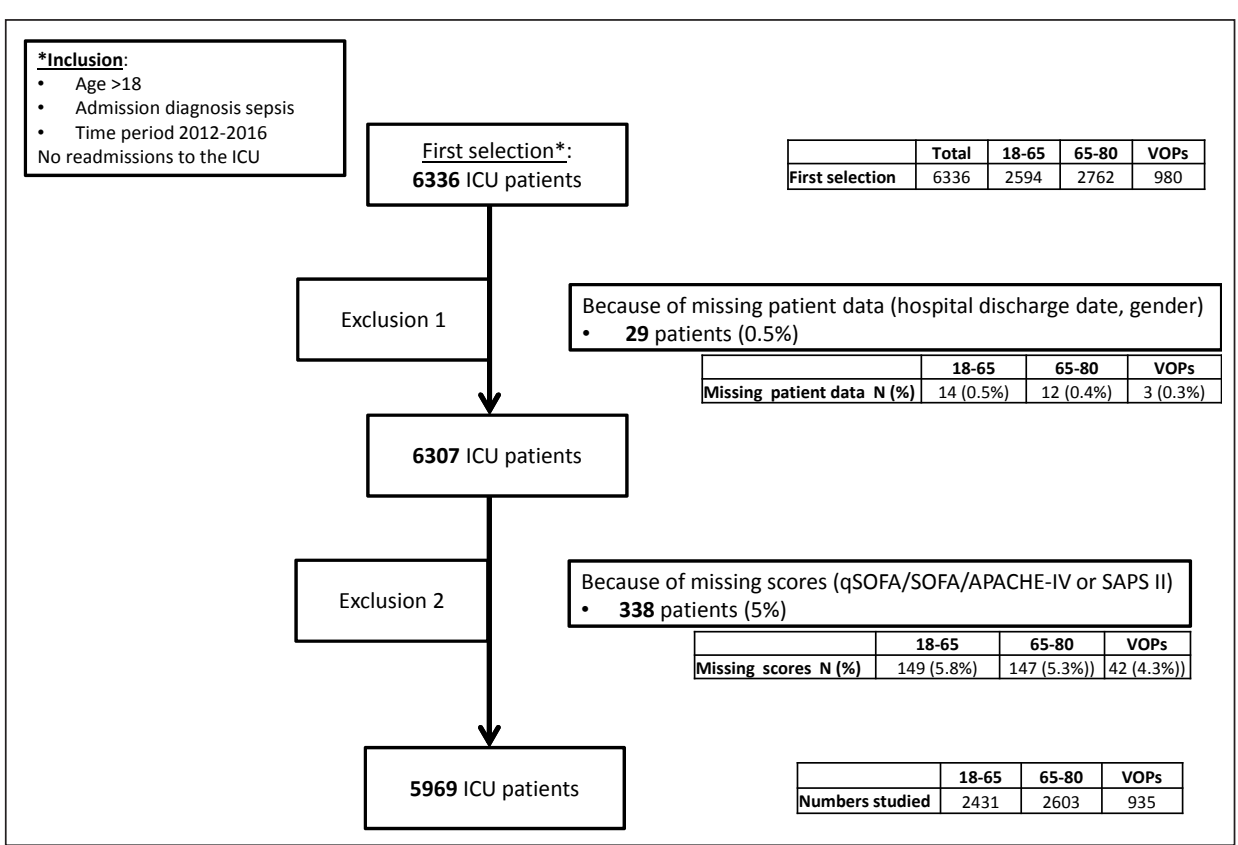

Figure S1. Flow chart of the study.

There was no difference in the proportion of missing samples among the age groups $(P=0.218)$.

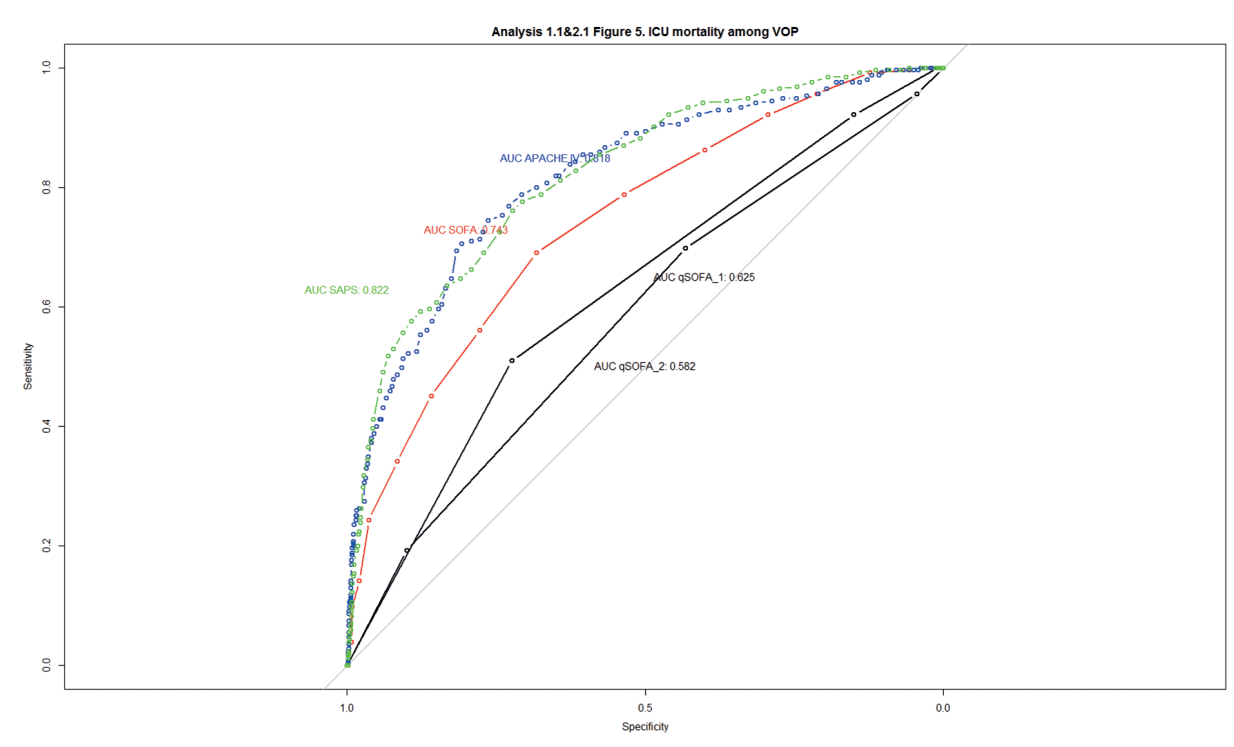

Figure S2. ROC curves of different scoring systems, ICU mortality among VOPs. 
PART III

\author{
General \\ discussion \\ and summary
}




\section{CHAPTER 10}

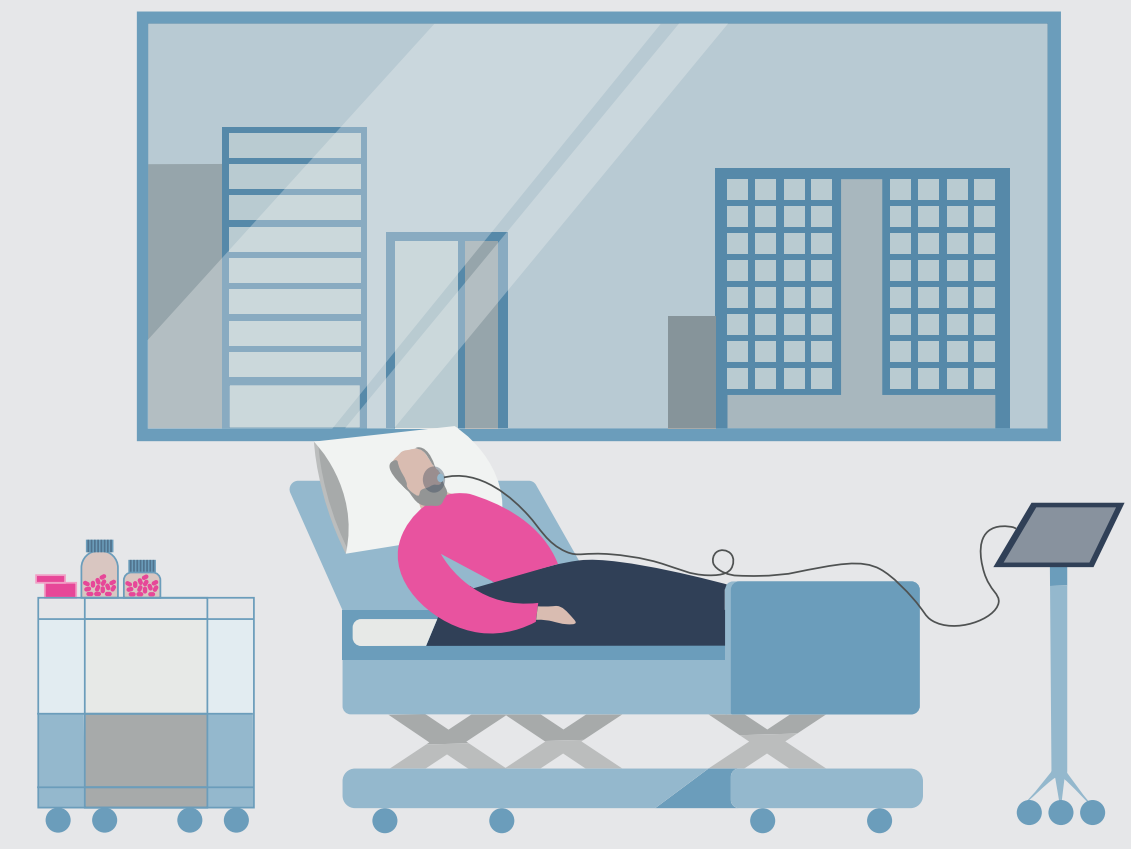

General discussion 


\section{Introduction}

This thesis is about very old intensive care unit (ICU) patients. Many intensivists struggle with the question which patients will benefit from ICU treatment, and for whom it will be inappropriate or even harmful. Therefore, the aim of this thesis is to provide information about appropriateness of ICU care in very old patients to guide triage decisions and to inform patients or their surrogate decision-makers and enable them to participate in shared decision-making concerning goals of care.

In this chapter, the main results of our studies and the implications are discussed and future perspectives of treatment of very old critically ill patients will be addressed.

\section{Intensive care medicine in our ageing population}

Our population is ageing as a consequence of high birth rates in the period 1945 to 1955 (the 'Baby Boom generation'), increased life expectancy and decreased birth rates in recent decades.[1-3] While at this moment, less than 5\% of our Dutch population consists of very old people (80 years or over), they are responsible for more than $10 \%$ of hospital admissions and around 15\% of the ICU admissions. These numbers are expected to increase upcoming decades. However, in the 10-year period that we studied, the percentage of general ICU admissions attributable to the very old patients remained stable in the Netherlands, although the percentage of adults aged 80 years and older in the population and the percentage of hospital admissions attributable to these very elderly increased [chapter two]. This finding is in contrast to previous studies in other countries and could be explained by more strict ICU admission policies or more proactive treatment restrictions set on the wards in the Netherlands, possibly resulting from advanced directives. It might illustrate the changing opinions about the balance between harm and benefits of ICU treatment of the very old patients. The severity of illness of the very old patients (expressed by APACHE II and SAPS II predicted probability of mortality) remained stable in this studied period. Unfortunately, our research cannot answer the question whether this triage is too strict and whether we are depriving the very old patients of opportunities. Noteworthy, however, is that the percentage of very old patients admitted to the ICU following cardiac surgery did increase. This finding may be due to improvements in techniques in cardiac surgery and changed ethical reasoning around cardiac surgery in old patients and is consistent with other Dutch reports in recent years, describing increases in the mean age of patients undergoing cardiothoracic surgery.[4]

\section{Outcomes of the older ICU patients}

In our Dutch setting, very old intensive care unit patients (abbreviated to VIPs or VOPs) seem to have benefitted almost equally from improvement in quality of care over time as the younger patients admitted to the ICU. In the period 2008 to 2014, the crude and risk-adjusted short-term and long-term mortality decreased for patients admitted to Dutch ICUs, both in very old patients and in patients aged less than 80 years. For the very old patients, ICU mortality decreased from $18 \%$ to $13 \%$, in-hospital mortality from $31 \%$ to $21 \%$, 3-month mortality from $37 \%$ to $30 \%, 6$-month mortality from $42 \%$ to $34 \%$ and the 12 -month mortality decreased from $46 \%$ to $40 \%$. The significant annual decrease in risk-adjusted mortality was also shown in different groups of patients (medical, emergency surgery, planned surgery, and cardiac surgery) in both very elderly and younger age groups. Changes in discharge policies seem not to be an explanation for decreased mortality rates at ICU- and hospital discharge, because mortality rates after discharge also decreased. The mortality reduction in VIPs could neither be explained by stricter triage, since APACHE IV/SAPS II predicted mortality did not change and the comorbidity scores even increased from 2005 to 2014 [chapter three].

The mortality rates of the patients aged 90 years and older admitted to Dutch ICUs in the last decade were not as disappointing as assumed. They had a lower ICU mortality and a similar hospital mortality compared with octogenarians admitted to the ICU. Nevertheless, their long-term mortality was higher compared with octogenarians Obviously, their resting life expectancy seems to be lower. However, almost 3 of 4 of the patients aged 90 years and older admitted to Dutch ICUs survived the hospital, and almost one-half of the patients were still alive 1 year after ICU admission [chapter four]. These unexpected good outcomes might be the results of triage and a possible 'survival of the fittest phenomenon'.

\section{Healthcare costs of very old ICU patients}

The very old patients are known to be responsible for a substantial part of healthcare costs. Since outcome of very old ICU survivors is worse than for younger patients and their resting life expectancy is lower, cost-effectiveness of ICU admission of the very elderly is frequently questioned. We demonstrated that Dutch VIPs were more expensive in the year before, the year of and the year after ICU admission, compared to younger ICU patients and compared to the very old control population not admitted to the ICU [chapter five]. However, our study was unfortunately not able to provide an answer to the difficult question whether the costs of very old ICU patients is justifiable or not. Obviously, in times of increasing pressure on the healthcare budget, discussion about what society should accept to pay for a gained life year (value of the statistical life year, VOSL) and for a quality adjusted life year (QALY) is important. And because ICU resources are often limited, as are the number of life years that can be gained in good health in VIPS, studies that evaluate cost per QALY in VIPs admitted to the ICU would be valuable. However, QALYs are often based on surveys that incorporate 
physical functioning, which is often lower in the very elderly, carrying the risk of unjustly suggesting futile care. Several health-related quality of life (HRQoL) studies suggest that very old ICU survivors may accommodate to a degree of physical disability and report good emotional and social well-being.[5]

\section{The old ICU patients admitted with sepsis, outcomes and predictors for survival}

Sepsis disproportionally affects older adults and as a consequence, older patients are responsible for the majority of all episodes of sepsis, with incidences that are still increasing.[6, 7] Mortality rates of the very old patients admitted with sepsis are quite high. Almost half of these patients died in the hospital and after one year more than two thirds of the patients had died. The mortality rates of the very old patients admitted with sepsis were higher compared to the very old patients admitted to the ICU for another reason than sepsis [chapter seven]

The mortality rates of the VIPs admitted with sepsis that we found in our systematic review are comparable with the outcome data that we found for VIPs admitted with sepsis in our Dutch cohort study (the hospital, 3-month and 1-year mortality of very old patients admitted to Dutch ICUs in 2018 were 36\%, 45\% and 53\% respectively).[8] The high long-term mortality in the VIPs admitted for sepsis was also found in our recent large multinational (241 ICUs in 22 countries) prospective cohort study. The 6 -month mortality in VIPs admitted with sepsis was higher than in the very old patients acutely admitted for other, non-sepsis (but also with SOFA score $\geq 2$ ) reasons ( $54 \%$ vs. $49 \%, p=0.04$ ). However, this increased mortality in the VIPs admitted with sepsis was due to severity of illness and frailty, as sepsis was not independently associated with 6-month mortality, nor was the Comorbidity and Polypharmacy score (CPS), gender or habitat before admission. Frailty, age and disease severity (SOFA) were identified as predictor for long-term mortality of VIPs admitted with sepsis. Being frail was associated with the highest hazard ratio for mortality at 6 months (HR 1.38) [chapter eight]

In our national cohort of patients with sepsis admitted to the ICU, mortality rates of VIPs admitted with sepsis was twice as high compared to the younger patients. Adequate triage of the very old critically ill patients with sepsis requires tools that can properly discriminate who will and who won't survive. We demonstrated that qSOFA is a simple, but poorly sensitive marker for in-hospital mortality and thus is not suitable for this. Although the other severity scores (SOFA, APACHE IV and SAPS II) have higher discriminate performance than qSOFA, both in younger patients and very old patients admitted to the ICU with sepsis, these scoring systems are still not good enough either to be used on an individual level in daily practice. Including other factors in the qSOFA model, like age, gender, comorbidity, admission type, and sepsis diagnosis, did not result in sufficient improvement of the model performance in VIPs. Hence, qSOFA cannot be recommended for mortality prediction in very old patients admitted to the ICU with sepsis [chapter nine].

\section{Triage, including decision-making during a pandemic}

The survival chances of the very old and extremely old patients indicate that for the group that receives ICU treatment, this treatment can be valuable, even if aged older than 90. From this, we could conclude that if unlimited IC capacity were available, perhaps more elderly people would still have to be offered ICU care. However, there is no unlimited IC capacity and it also entails high costs for the entire society. Due to the increasing numbers of very old critically ill patients, clinicians will be forced to offer ICU treatment only to those patients that are most likely to benefit. Moreover, many older patients prefer preserving QoL and autonomy above a prolonged survival. Reliable models to use in prognostication for individual patients are still lacking Therefore, the estimated risks and benefits should be carefully weighed for each particular very old critically ill patient. Although this holds true for all patients, in the very old population mortality and morbidity risks are higher and benefits might be limited. This stresses the need to carefully address prognosis and risk factors and to align treatment goals in line with the preferences, expectations and personal values of the very old patients.

The decision-making processes around the ICU admission of very old patients have been put into sharp focus in 2020 during the COVID-19 pandemic. The urgent need to meet the high demands associated with the large numbers of acutely ill patients during this pandemic has quickened discussions about prioritisation of resources with a focus on objective benefits. Under normal circumstances, age should, together with other risk factors, be weighed as a risk factor for poor outcome. However, in times of scarcity, it is justified to prioritize the younger patients, in order to maximize the benefits for the largest number of people, according to the utilitarian approach.[9] After all, chances of survival rates after ICU admission decrease with increasing age. The use of age as a selection criterion in case of scarcity can also be justified by pointing at the "fair innings" that a patient has had (fair equality of opportunity). This strategy does not amount to age discrimination as all people are treated alike: everyone will become older and thereby their claim on life-sustaining treatment decreases. Most proposed 'COVID-19 code black scenarios' indeed included denial of the very elderly to the ICUs [chapter six] 


\section{Future perspectives for intensive care medicine in an ageing world}

Although the research questions defined at the start of this thesis have been answered, it is still hard to provide an answer to the question which very old patients should be admitted to the ICU in case of severe acute illness. There is still a great demand for further research. It would be most helpful if we could identify those very elderly who will really benefit from ICU treatment in terms of gained life years in good quality, not only because of the increasing number of very elderly in our population and the increasing pressure on our health care budget, but above all to minimize suffering of the very old patients and their loved ones. Future research should focus on developing a reliable prognostic tool, with good performance in very old patients, in order to be able to select those critically ill very old patients for whom ICU treatment is beneficial. Since preserving quality of life (QoL) seems more important than prolonging life for many very elderly, (hospital) mortality should not be the only outcome of this tool. However, acceptable QoL and an acceptable functional and cognitive performance are highly different per individual, partly depending on individual experiences, values and norms, making development of such a tool very complicated.

Nevertheless, in order to be able to make the right decisions and provide beneficial and high-quality care to the very old critically ill patients, we need more robust evidence and research on mortality and morbidity of subgroups, post-discharge survival, functional and cognitive outcomes, and HRQoL. In addition, it would be interesting to learn more about the experiences, expectations and goals of care of the very old patients. Despite the increasing number of studies on very old ICU patients, major challenges lie ahead in improving their care. The current evidence about very old ICU patients is mostly observational and hampered by selection bias and confounding by indication. The paucity of high-quality evidence leaves many questions regarding the optimal management of very old critically ill patients unanswered. Although randomized trials remain the 'holy grail of research', several other methods could improve the current evidence, like subgroup analysis of already performed studies and pooling of raw data of subgroups of very old ICU patients from previous randomized studies.

More research about the following items could support physicians in triage and treatment of very old patients to be admitted to the ICU:

1. Information on the experience and opinion of very elderly on ICU treatment, but also important are the experiences and opinions of the patients to whom ICU treatment was declined.

2. The type of information older patients and their informal care givers need to decide on ICU treatment.

3. A comparison of outcome of the critically ill very old patients treated at the general ward with outcome of the very old patients that received ICU care. (Unfortunately, in current studies, the data about the very old patients to whom ICU admission was declined are lacking).

4. Insight into the predictors of good outcome (as defined by elderly themselves).

5. A prognostic tool with excellent predictive performance in terms of discrimination and precision to predict outcome as defined based on the preferences of acute severely ill very old patients.

6. Evaluation of the additive value of geriatric consultation to assess patients' expectations and priorities in ICU treatment.

7. Functional outcome and the additive value of an age specific (dedicated for the very old patients) ICU treatment (including for example more attention to sedation, medication (delirium), non-pharmacological interventions and an adapted revalidation program). 


\section{References}

1. Centraal Bureau voor de Statistiek (CBS). Statline. http://statline.cbs.nl/Statweb/dome/default.aspx

2. Nationaal kompas: vergrijzing. https://www.volksgezondheidenzorg.info/onderwerp/bevolking/cijferscontext/vergrijzing. Accessed 2 Oct 2020

3. population un esa. population.un.org; esa.un.org. Accessed 2 Oct 2020

4. van Herwerden, L.; Noyez, L; Takkenberg, H.; Versteegh, M.; Wijgergangs L (2012) The Dutch Data Registry Cardiac Surgery, Results of collaboration between 16 Dutch cardiac surgery centers. De Nederlandse centra. [Article in Dutch]. 2:22-23

5. Andersen $\mathrm{FH}$, Flaatten $\mathrm{H}$, Klepstad $\mathrm{P}$, et al (2015) Long-term survival and quality of life after intensive care for patients 80 years of age or older. Ann Intensive Care 5:53-015-0053-0. Epub 2015 Jun 3. https://doi. org/10.1186/s13613-015-0053-0 [doi]

6. Angus DC, Linde-Zwirble WT, Lidicker J, et al (2001) Epidemiology of severe sepsis in the United States: analysis of incidence, outcome, and associated costs of care. Crit Care Med 29:1303-10

7. Martin GS, Mannino DM, Moss M (2006) The effect of age on the development and outcome of adult sepsis. Crit Care Med 34:15-21

8. Haas, L.E.M.; Kerckhoffs, M.C.; Bakhshi-Raiez, F.;Emmelot-Vonk, M.H.; de Lange DW (2020) The admission of very old patients to our intensive care units: a review. Netherlands J Crit Care 28:6-12

9. Emanuel E], Persad G, Upshur R, et al (2020) Fair Allocation of Scarce Medical Resources in the Time of Covid-19. N Engl J Med. https://doi.org/10.1056/NEJMsb2005114 


\section{CHAPTER 11}

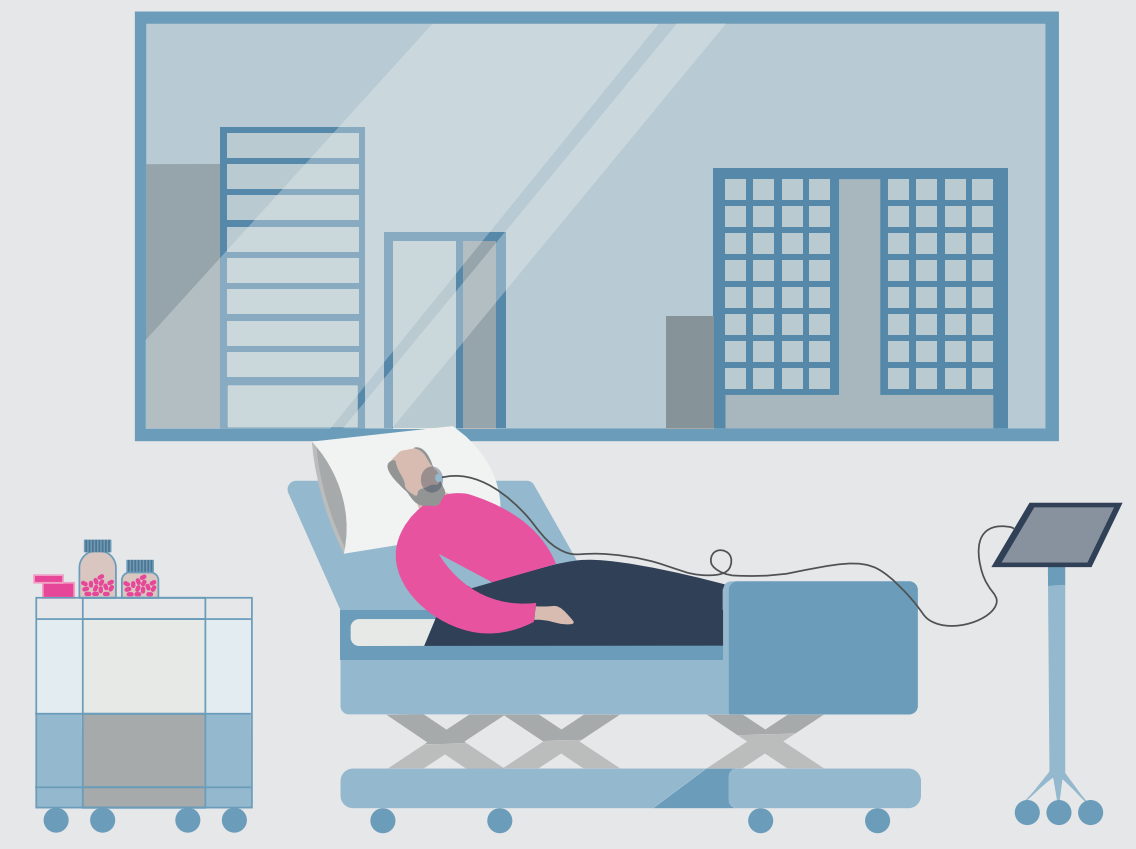

summary 
The Dutch population is ageing, corresponding to demographic changes observed in many other countries in the Western world. This has an impact on our healthcare. Although the elderly comprise a minority of the population, they are responsible for a substantial proportion of healthcare use, including ICU treatment. The very old patient requiring ICU treatment is an emerging phenomenon. The 'Very old Intensive Care Patients' (defined as aged 80 years and older and often abbreviated as VIPs or VOPs) have a higher mortality risk. Despite advanced treatment modalities, a substantial proportion of VIPs will not survive hospitalisation. Moreover, the majority of the patients who do survive will suffer from a persisting or severe functional and/or cognitive decline after hospital discharge, and many will not be discharged home. In addition, their remaining life expectancy is lower because they are older. The balance between potential benefits and burden of ICU treatment may, therefore be more negative than in younger patients. This stresses the need to weigh the proportionality of ICU treatment carefully. Therefore, the principal aim of this thesis was to evaluate what defines appropriateness of ICU care in very old patients.

\section{Part I: Very old patients admitted to the ICU; trends, outcomes, costs and triage} In the first part of this thesis we describe the very old patients admitted to the ICU in general. We investigated the trends in proportions of VIPs on Dutch ICUs in the last decade, their outcomes, their healthcare costs and the use of age in the ICU admission decision.

In chapter two, we show that the demographic changes occurring in Europe and other high-income countries are mirrored in the Netherlands and that this resulted in significant increases in the numbers and percentages of hospital admissions attributable to the very elderly. The ageing of the Dutch population is a consequence of high birth rates in the period after the Second World War (the 'Baby Boom generation'), increased life expectancy and decreased birth rates in recent decades. Life expectancy in the Netherlands is expected to increase to 87 years for males and 90 years for females in the year 2060. The proportion of persons in the Netherlands aged 80 years and older was $1 \%$ in 1950 and is expected to increase to $9 \%$ in 2040 and $11 \%$ in 2055 . In the period 2005 to 2014 , the percentage of adults aged 80 years and older in the population increased from $4.5 \%$ to $5.4 \%$ and the percentage of hospital admissions attributable to these very elderly increased from $9.0 \%$ to $10.6 \%$. However, in contrast to previous studies in other countries, the percentage of general ICU admissions attributable to the very elderly remained stable in the Netherlands at $13.8 \%$. This finding could be explained by more strict ICU admission policies or more proactive treatment restrictions set on the wards in the Netherlands, resulting from advanced directives and it might illustrate the changing opinions about the balance between harm and benefits of ICU treatment of the very elderly. The severity of illness of very elderly patients (expressed by the Acute Physiology and Chronic Health Evaluation (APACHE) IV and the Simplified Acute Physiology Score (SAPS) II - predicted probability of mortality) remained stable in this studied period. In contrast, the percentage of ICU admissions following cardiac surgery attributable to the very elderly did indeed increase significantly in this period from $6.7 \%$ to $11.0 \%$. This latter finding may be due to improvements in cardiac surgery techniques and changed ethical reasoning around cardiac surgery in elderly patients and is consistent with other Dutch reports in recent years, describing increases in the mean age of patients undergoing cardiothoracic surgery.

In chapter three, we describe the trends in short- and long-term mortality, both in very old patients and in patients aged less than 80 years admitted to Dutch ICUs. For both groups, the crude and risk-adjusted short- and long-term mortality significantly decreased in this period. For the very elderly, ICU mortality decreased from $18 \%$ to $13 \%$, in-hospital mortality from $31 \%$ to $21 \%$, 3-month mortality from $37 \%$ to $30 \%$, 6 month mortality from $42 \%$ to $34 \%$ and the 12 -month mortality decreased from $46 \%$ to $40 \%$. The decrease in mortality was also shown in the different subgroups of patients (medical, emergency surgery, planned surgery, and cardiac surgery), in both the very elderly and younger ICU patients. Since mortality rates after discharge also decreased, changes in discharge policies seem not to explain the decreased mortality rates at ICU- and hospital discharge. The mortality reduction in VIPs could neither be explained by stricter triage since APACHE IV/SAPS II predicted mortality did not change, and the comorbidity scores even increased in time.

We, therefore, concluded that, in our Dutch setting, VIPs seem to have benefitted almost equally from improvement in the quality of ICU-care over time as the younger ICU patients.

In chapter four, we separately describe the outcomes of the even older ICU-patients (defined as aged 90 years and older) admitted to Dutch ICUs in the last decade, because many intensivists seem reluctant to admit patients aged 90 years and older to the ICU. We show that, in the Netherlands, their mortality rates are not as disappointing as often assumed. They had a lower ICU mortality $(13.8 \%$ vs. $16.1 \%$; $p<0.001)$ and a simila hospital mortality ( $26.1 \%$ vs. $25.7 \%$; $p=0.41$ ) compared with octogenarians. Nevertheless, their long-term mortality was higher compared with octogenarians ( 3 months mortality $43.1 \%$ vs. $33.7 \% ; p<0.001$ and 1 -year mortality $55.0 \%$ vs. $42.7 \% ; p<0.001)$. Obviously, their resting life expectancy seems to be lower. However, almost 3 of 4 of the patients aged 90 years and older admitted to Dutch ICUs survived the hospital, and almost one-half of the patients are still alive one year after ICU admission. 
The very elderly patients are known to be responsible for a substantial part of healthcare costs. In chapter five, we demonstrate that Dutch VIPs are more expensive in the year before, the year of, and the year after ICU admission, compared to younger ICU patients and a very elderly control population not admitted to the ICU. Of course, our study is not able to provide an answer to the difficult question whether the costs of VIPs could always be justified. Since the outcome of very old ICU survivors is worse than for younger patients and their resting life expectancy is lower, the costeffectiveness of ICU admission of the very elderly is frequently questioned.

Obviously, in times of increasing pressure on the healthcare budget, discussion about what society should accept to pay for a gained life year (value of the statistical life year, VOSL) and for a quality-adjusted life-year (QALY) is important. Moreover, because ICU resources are often limited, as is the number of life-years that can be gained in good health in VIPs, studies that evaluate cost per QALY in VIPs admitted to the ICU would be valuable. However, QALYs are often based on surveys that incorporate physical functioning, which is often lower in the very elderly, carrying the risk of unjustly suggesting futile care. Several health-related quality of life (HRQoL) studies suggest that very old ICU survivors may accommodate to a degree of physical disability and report good emotional and social well-being.

In chapter six, we discuss the use of age in ICU triage. Under normal circumstances, age is, together with other risk factors, weighed as a risk factor for poor outcome. This may lead to the shared decision to forego ICU treatment, but it cannot be justified to withhold ICU admission for all patients above a certain age. However, in times of scarcity, not only the proportionality of treatment and autonomy of the patient but also the shortage of resources may play a role in ICU admission decisions. Therefore, we discussed that in circumstances of a pandemic, it is justified to prioritise the younger patients to maximise the benefits for the largest number of people. This is according to the utilitarian approach, which aims to maximise the benefits for the largest number of people and prioritise care based on the (estimated) greatest advantage of ICU treatment, the so-called incremental probability of survival. After all, chances of survival rates after ICU admission decrease with increasing age. The use of age as a selection criterion in case of scarcity can also be justified by pointing at the "fair innings" that a patient has had, meaning that older patients have already had their opportunity to reach a certain "mature" age, which has given them a fair equality of opportunity. The idea is that everyone should have an equal opportunity to lead a life of a certain duration. Although there is no hard rule for what is a fulfilled life age for a person, most policies state that those in their $80 \mathrm{~s}$ and beyond, who have had a chance to experience life and flourish as a human being, should receive lower priority. This strategy does not amount to age discrimination as all people are treated alike: everyone will become older, and thereby their claim on life-sustaining treatment decreases.

\section{Part II: Very old patients admitted to the ICU for sepsis}

The second part of this thesis is dedicated to VIPs admitted with sepsis. Very elderly are, compared with younger patients, more susceptible to sepsis. They have less physiologic reserve to tolerate the insult from infection and are more likely to have underlying diseases. As a consequence, they are responsible for the majority of al episodes of sepsis. Incidences of sepsis increased last decades, and these increases are particularly seen in elderly patients. At present, most sepsis episodes are observed in patients older than 60 years, with a sharp increase in the incidence in people older than 80 years. Sepsis is one of the leading causes of morbidity and mortality in very old patients and appears to be a common reason for very old patients to be admitted to the ICU and due to the ageing of the population, sepsis in patients over 80 years will remain an important medical problem for future decades.

In chapter seven, we present a comprehensive systematic review of the literature on outcomes of VIPs admitted with sepsis. A systematic search was performed in Medline and Embase to identify studies that described the outcome of these patients. In the end, 18 studies, including 4562 very old patients could be incorporated in our systematic review. We found a median ICU-mortality of $43 \%$ [range 30-79\%], a median hospitalmortality of $47 \%$ [31-84\%] and a median 1-year mortality of 68\% [53-83\%]. Mortality rates of the VIPs admitted with sepsis were higher compared to the VIPs admitted for another reason than sepsis. The patients who survived seem to experience significant disability without diminished HRQoL, although data about the functional outcome and QoL of very elderly admitted with sepsis, unfortunately, were scarce. We concluded that mortality rates of VIPs admitted with sepsis are quite high. Almost half of the very old patients admitted to the ICU with sepsis died in the hospital, and after one year, more than two-thirds of the patients had died.

We were very interested in predictors for survival for these VIPs admitted with sepsis. Therefore, in chapter eight, we analysed the results of a large, prospective European multicentre study on VIPs admitted with sepsis to $241 \mathrm{ICUS}$ in 22 countries. This study included 3596 acutely admitted VIPs, of which 532 admitted with sepsis. Sepsis was defined according to the sepsis 3.0 criteria. Patients with sepsis as admission diagnosis were compared with the other acutely admitted patients with SOFA score $\geq 2$. In addition to patients' characteristics, disease severity, information about comorbidity and polypharmacy and pre-existing physical and cognitive function was collected. We 
demonstrated a substantial long-term mortality in the VIPs admitted for sepsis (6-month mortality 54\%). Although ICU mortality was comparable (31\% vs $29 \%$, p $=0.26$ ), mortality after six months was higher in VIPs admitted with sepsis than for those acutely admitted (with SOFA score $\geq 2$ ) for other, non-sepsis reasons ( $54 \%$ vs $49 \%, p=0.04)$. This increased mortality in the VIPs admitted with sepsis was due to severity of illness and frailty, as sepsis was not independently associated with 6-month mortality, nor was CPS, gender or habitat before admission. Frailty, age and disease severity (SOFA) were identified as predictor for long-term mortality of VIPs admitted with sepsis. Being frail was associated with the highest hazard ratio for mortality at six months (HR 1.38)

In chapter nine, we describe the discriminative performance of the qSOFA and other severity scores for mortality in very old patients admitted to the ICU with sepsis. In our cohort of patients admitted to the ICU with sepsis, the mortality of VIPs admitted with sepsis was twice as high compared to the younger patients. qSOFA showed to be a simple, but poorly sensitive predictive marker for in-hospital mortality and less accurate than SOFA, APACHE IV, and SAPS II in both younger patients and very old patients admitted to the ICU with sepsis. Including other factors in the qSOFA model, like age, gender, comorbidity, admission type, and sepsis diagnosis, did not result in sufficient improvement of the model performance in VIPs. Hence, qSOFA cannot be recommended for mortality prediction in very old patients admitted to the ICU with sepsis.

In chapter ten, we discuss the main findings of the performed research and address future perspectives for intensive care medicine in an ageing world.

In conclusion, this thesis illustrates that decision making in very old patients requiring ICU treatment remains complex and challenging. Although older patients often have less to gain from an ICU admission than younger patients, ICU treatment certainly can be beneficial. However, since ICU treatment often is burdensome and expensive and the majority of patients will suffer from a persisting or severe functional and/or cognitive decline after hospital discharge, it is important to carefully consider the desirability and proportionality of possible ICU admission. Physicians should address the prognosis and risk factors of ICU treatment (including assessment of frailty) and explore the preferences, the treatment goals, expectations and personal values of the very old patients. The ongoing increase of very elderly patients asks for more research about intensive care medicine in this older population. 


\section{CHAPTER 12}

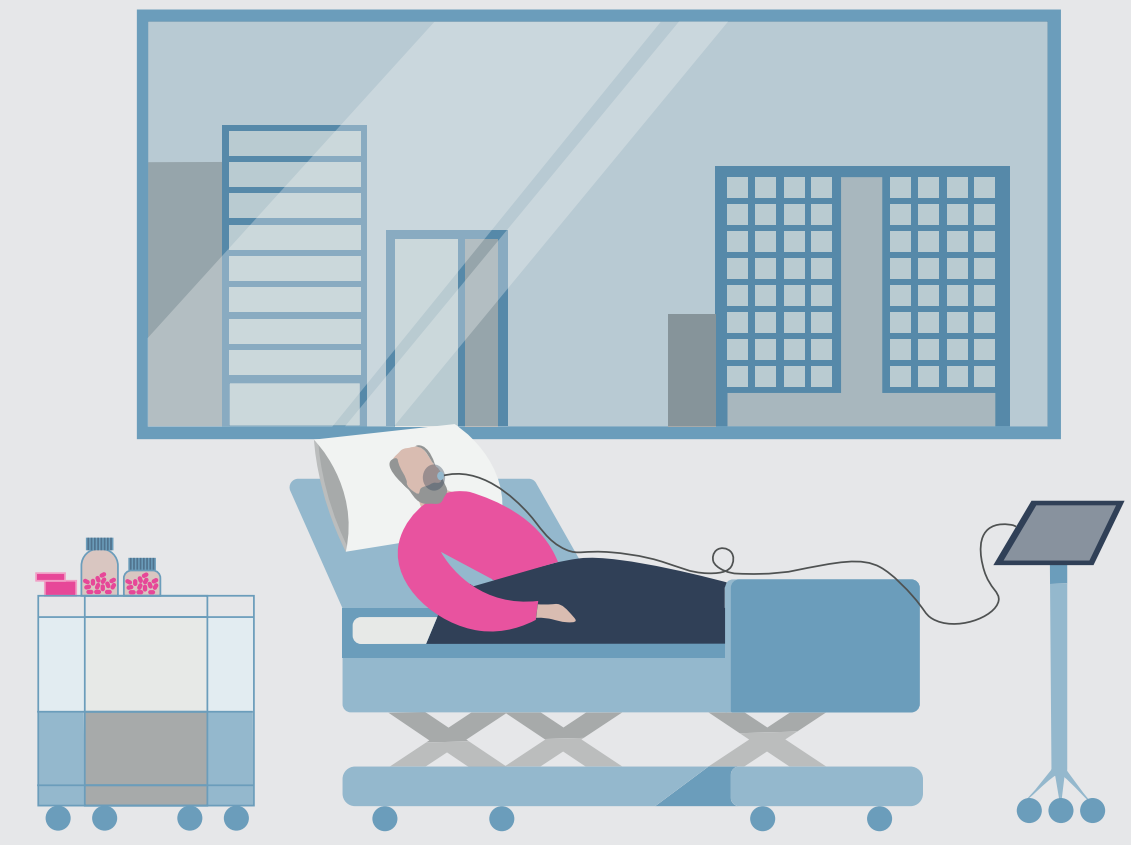

Nederlandse samenvatting 


\section{Inleiding}

Onze populatie vergrijst en in Nederland is er zelfs sprake van een dubbele vergrijzing. Enerzijds neemt het percentage ouderen toe ten gevolge van de babyboom na de Tweede Wereldoorlog en anderzijds groeit de levensverwachting. Dit heeft zijn weerslag op onze gezondheidszorg. Hoewel ouderen een minderheid van de bevolking vormen, zijn zij verantwoordelijk voor een aanzienlijk deel van het zorggebruik, inclusief intensive care (IC)-opnames. Zowel Nederlandse als internationale studies laten een sterke toename zien van deze oudere patiënten in ziekenhuizen en op IC-afdelingen.

Oudere IC-patiënten (gedefinieerd als $\geq 80$ jaar, in het Engels 'Very Old Intensive Care Patients', afgekort als VIPs of VOPs) hebben een grotere kans op overlijden gedurende hun opname en, als ze het verblijf op de IC overleven, een grotere kans op fysieke en cognitieve achteruitgang. Daarnaast is hun resterende levensverwachting meestal lager dan die van jongere IC-patiënten.

Oudere patiënten hebben dus minder te winnen met een IC-behandeling dan jongere patiënten. Bovendien is een behandeling op de IC voor patiënten vaak belastend. Het is daarom van belang de voors en tegens van een IC-behandeling zorgvuldig te wegen. Dit proefschrift beoogt een antwoord te geven op de vraag: "Wanneer is IC-behandeling voor een oudere patiënt zinvol en proportioneel".

\section{Deel I: Oudere patiënten opgenomen op de IC; trends, resultaten, kosten en triage}

Het eerste deel van dit proefschrift gaat over VIPs in het algemeen. Dit deel beschrijft de aantallen en percentages van VIPs op Nederlandse IC-afdelingen de afgelopen jaren, hun uitkomsten, de zorgkosten en het gebruik van leeftijd in de beslissing tot wel of geen IC-opname.

In hoofdstuk twee laten we zien dat de demografische veranderingen die worden gezien in Europa en in andere Westerse landen ook terug te vinden zijn in Nederland. Dit resulteerde in een significante toename van de absolute en relatieve aantallen ziekenhuisopnames van oudere patiënten. De vergrijzing van de Nederlandse bevolking is een gevolg van hoge geboortecijfers in de periode 1945 tot 1955 (de 'Babyboomgeneratie'), een gestegen levensverwachting en dalende geboortecijfers in de afgelopen decennia. De levensverwachting zal naar verwachting toenemen tot 87 jaar voor mannen en 90 jaar voor vrouwen in het jaar 2060. Het percentage Nederlanders van 80 jaar en ouder was $1 \%$ in 1950 en zal naar verwachting toenemen tot $9 \%$ in 2040 en $11 \%$ in 2055 . Hoewel op dit moment minder dan $5 \%$ van de Nederlanders 80 jaar of ouder is, zijn zij verantwoordelijk voor meer dan $10 \%$ van de ziekenhuisopnames en bijna 15\% van de IC-opnames. Naar verwachting zal er een verdere toename worden gezien in de komende decennia. Opvallend was dat wij in onze studieperiode (van 2005 tot 2014) een stabiel percentage IC-opnames van patiënten van 80 jaar en ouder vonden, terwijl het percentage volwassenen van 80 jaar en ouder in de Nederlandse bevolking steeg van 4,4\% naar 5,3\% en het percentage ziekenhuisopnames van deze oudere patiënten ook toenam (van 8,7\% naar 10,7\%). Dit is in tegenstelling tot resultaten van studies in andere landen, die een stijging van het aantal IC-opnames van patiënten van 80 jaar en ouder laten zien. Deze bevinding zou kunnen worden verklaard door een strenger IC-opnamebeleid of het vake afspreken van behandelbeperkingen in Nederland (bijvoorbeeld bij opname via de Eerste Hulp, op de verpleegafdeling of al eerder bij een bezoek aan de polikliniek of bij de huisarts in het kader van zogenaamde 'Advance Care Planning'). Mogelijk wordt in Nederland anders gedacht over de balans tussen voor- en nadelen van een ICbehandeling van oudere patiënten. De ernst van de ziekte van de oudere IC-patiënten (uitgedrukt middels de Acute Physiology and Chronic Health Evaluation (APACHE) IV en de Simplified Acute Physiology Score (SAPS) II - voorspelde sterftekans) bleef overigens stabiel in onze studieperiode. Het percentage IC-opnames van oudere patiënten na een hartoperatie steeg in deze periode wel (van 7\% naar 11\%), hetgeen mogelijk samenhangt met vooruitgang in de hartchirurgie. Deze laatste bevinding komt overeen met eerdere Nederlandse rapportages, die een stijging van de gemiddelde leeftijd laten zien van hartchirurgiepatiënten.

In hoofdstuk drie beschrijven we de veranderingen in de mortaliteit op korte en lange termijn, zowel voor de oudere patiënten als patiënten jonger dan 80 jaar, die zijn opgenomen op Nederlandse IC's. Hoewel de sterfte van een oudere IC-patiënt ongeveer 2 maal zo hoog was als die van jongere IC-patiënten, daalde voor beide groepen zowel de totale als de gecorrigeerde sterfte (zowel op korte en lange termijn) in deze periode aanzienlijk. Voor de ouderen IC-patiënten daalde de IC-mortaliteit van 18\% naar 13\%, de mortaliteit in het ziekenhuis van $31 \%$ naar $21 \%$, de mortaliteit na 3 maanden van $37 \%$ naar 30\%, de sterfte na 6 maanden van 42\% naar 34\% en de sterfte na 12 maanden daalde van $46 \%$ naar $40 \%$. De daling van de sterfte werd ook aangetoond voor de afzonderlijke opname categorieën van patiënten (medisch, spoedoperaties, geplande operaties en hartoperaties), ook hier weer voor zowel de oudere als de jongere ICpatiënten. Aangezien de sterftecijfers na ontslag ook afgenomen zijn, is een vervroegd ontslag geen verklaring voor de afgenomen sterftecijfers bij ontslag van de ICU en/of ontslag uit het ziekenhuis. De afname van de sterfte van VIPs lijkt ook niet verklaard te kunnen worden door strengere selectie bij opname, aangezien de ernst van ziekte (APACHE IV en SAPS II-voorspelde sterftecijfers) stabiel waren en het aantal chronische aandoeningen van de patiënten zelfs toenam in de tijd. Wij concludeerden dan ook 
dat de oudere IC-patiënten in Nederland ongeveer evenveel geprofiteerd hebben van verbeteringen van de kwaliteit van de IC-zorg in de afgelopen jaren als de jongere patiënten

In hoofdstuk vier beschrijven we de uitkomsten van nog oudere IC-patiënten (gedefinieerd als $\geq 90$ jaar), die in het afgelopen decennium op de Nederlandse IC's zijn opgenomen afzonderlijk, omdat veel intensivisten terughoudend lijken te zijn om deze zeer oude patiënten op de IC op te nemen. Wij laten zien dat de sterftecijfers van deze IC-patiënten in Nederland helemaal niet zo teleurstellend zijn als misschien vaak wordt gedacht. Hun sterfte op de IC was zelfs lager, en de ziekenhuissterfte vergelijkbaar, met de tachtigjarigen die werden opgenomen op de IC. Desalniettemin was hun mortaliteit op lange termijn wel hoger dan die van de tachtigjarigen, maar hun resterende levensverwachting is natuurlijk ook lager. Bijna 3 van de 4 patiënten van 90 jaar en ouder die werden opgenomen op de Nederlandse IC's werden levend uit het ziekenhuis ontslagen en bijna de helft van de zeer oude patiënten was 1 jaar na opname op de IC nog in leven.

Het is bekend dat de oudere patiënten verantwoordelijk zijn voor een aanzienlijk dee van de zorgkosten. In hoofdstuk vijf tonen we aan dat de kosten van Nederlandse VIPs hoger zijn in het jaar voor, het jaar van, en het jaar na opname op de IC, in vergelijking met jongere IC-patiënten en een oudere controlepopulatie (patiënten die niet op de IC zijn opgenomen). Uiteraard kan ons onderzoek geen antwoord geven op de lastige vraag of de kosten van oudere IC-patiënten altijd te rechtvaardigen zijn. Aangezien de prognose van een oudere IC-patiënten vaak somberder is en de resterende levensverwachting lager, is er regelmatig discussie over de kosteneffectiviteit van een IC-opname van oudere patiënten. Natuurlijk is het belangrijk om in tijden van stijgende zorgkosten en toenemende druk op ons zorgbudget de discussie te voeren over wat de samenleving zou moeten accepteren om te betalen voor een gewonnen levensjaar (waarde van het statistische levensjaar, VOSL) en voor een voor kwaliteit gecorrigeerd levensjaar (QALY). Omdat IC-bedden in Nederland duur en schaars zijn, evenals het aantal levensjaren in goede gezondheid die gewonnen kunnen worden bij VIPs, zouden studies die de kosten per QALY van op de IC opgenomen VIPs evalueren waardevol zijn. Echter, omdat bij het meten van QALY's vaak het lichamelijk functioneren wordt meegenomen (en dit vaak lager is bij oudere patiënten), bestaat het risico dat hiermee ten onrechte zinloze zorg wordt gesuggereerd. Verschillende studies die hebben gekeken naar kwaliteit van leven in relatie met gezondheid (HRQoL), suggereren dat oudere patiënten na een IC opname, ondanks fysieke beperkingen, een goede kwaliteit van leven ervaren.
In hoofdstuk zes bespreken we het gebruik van leeftijd bij de beslissing over een ICopname (triage). Onder normale omstandigheden wordt leeftijd, samen met andere risicofactoren, afgewogen als een risicofactor voor een slechtere uitkomst. Dit kan leiden tot de beslissing om af te zien van IC-behandeling, maar het is niet gerechtvaardigd om alle patiënten boven een bepaalde leeftijd te weigeren op de IC. Echter, in tijden van schaarste, zijn het niet alleen de proportionaliteit van de behandeling en autonomie van de patiënt die moeten worden meegenomen in de beslissing over opname op de IC, maar ook het tekort aan middelen. Ten tijde van een pandemie kan het daarom gerechtvaardigd zijn om jongere patiënten prioriteit te geven ten koste van ouderen, als hiermee zoveel mogelijk mensen een gunstige uitkomst kan worden geboden. Dit is in overeenstemming met de utilitaire benadering (het utilitarisme), dat tot doel heeft om goed te doen voor zoveel mogelijk patiënten (zoveel mogelijk levens redden) en zorg te prioriteren op basis van het (geschatte) grootste voordeel van IC-behandeling, de zogenaamde 'incrementele overlevingskans'. De overlevingskansen na opname op de IC nemen immers af met het stijgen van de leeftijd. Het gebruik van leeftijd als selectiecriterium in geval van schaarste kan daarnaast ook worden gerechtvaardigd op basis van de 'fair innings' die een patiënt heeft gehad, wat betekent dat oudere patiënten al de kans hebben gehad om een bepaalde 'rijpe' leeftijd te bereiken ('fair equality of opportunity'). ledere persoon zou gelijke kansen moeten krijgen om de verschillende levensfases te kunnen leven. Hoewel er geen harde definitie is van een voltooid leven, wordt vaak gesteld dat zij van tachtig jaar en ouder, die de kans hebben gehad om het leven te ervaren en als mens te floreren, een lagere prioriteit zouden moeten krijgen. Dit is geen leeftijdsdiscriminatie, aangezien alle mensen gelijk worden behandeld; iedereen wordt ouder en daardoor neemt hun aanspraak op IC-behandeling af.

\section{Deel II: Oudere patiënten opgenomen op de IC vanwege sepsis}

Het tweede deel van dit proefschrift richt zich op de oudere patiënten die met sepsis op de IC zijn opgenomen. Ouderen zijn kwetsbaarder en hebben door de afgenomen fysiologische reservecapaciteit, verschillende fysieke veranderingen en hun verhoogde gevoeligheid voor infecties, een hoger risico op het krijgen van sepsis. De incidentie van sepsis is de laatste decennia toegenomen, en deze toename wordt vooral gezien bij oudere patiënten. Sepsis is nu al een belangrijke oorzaak van ziekte en sterfte van oudere patiënten en vaak een reden voor IC-opname, maar gezien de toenemende incidentie van sepsis (die vooral bij ouderen wordt gezien), in combinatie met de vergrijzing, zal de oudere IC-patiënt met sepsis de komende jaren een belangrijke patiëntenpopulatie vormen. 
In hoofdstuk zeven presenteren we een uitgebreide systematische review van de literatuur omtrent de uitkomsten van oudere patiënten die met sepsis op de IC zijn opgenomen. In Medline en Embase werd systematisch gezocht naar studies die de uitkomst beschreven van oudere patiënten die vanwege sepsis op de IC waren opgenomen. Uiteindelijk konden 18 onderzoeken, met 4562 oudere IC-patiënten, in onze systematische review worden opgenomen. We vonden een mediane IC-sterfte van 43\% [range 30-79\%], een mediane ziekenhuissterfte van 47\% [31-84\%] en een mediane sterfte na 1 jaar van 68\% [53-83\%]. Het sterftecijfer van de oudere patiënten die werden opgenomen vanwege sepsis was hoger dan de sterfte van de oudere patiënten die vanwege een andere reden op de IC werden opgenomen. De oudere patiënten die overleefden, lijken ondanks fysieke beperkingen geen verminderde kwaliteit van leven te ervaren, hoewel gegevens over de functionele uitkomst en kwaliteit van leven van oudere patiënten die met sepsis op de IC zijn opgenomen helaas schaars bleken. Wij concludeerden dat de sterftecijfers van VIPs die met sepsis op de IC werden opgenomen vrij hoog zijn. Bijna de helft van deze patiënten stierf tijdens opname in het ziekenhuis en na een jaar was meer dan tweederde van de patiënten overleden.

Aangezien we benieuwd waren naar de voorspellers voor overleving van VIPs opgenomen vanwege sepsis, hebben we in hoofdstuk acht de resultaten geanalyseerd van een grote, prospectieve Europese multicenter studie van VIPs die met sepsis zijn opgenomen op 241 IC's in 22 landen. Deze studie includeerde 3596 acuut opgenomen oudere IC-patiënten, waarvan 532 VIPs opgenomen met sepsis. Sepsis werd gedefinieerd volgens de Sepsis 3.0 criteria. De oudere IC-patiënten opgenomen vanwege sepsis werden vergeleken met de oudere acuut opgenomen IC-patiënten met een SOFA-score $\geq 2$ met een niet-sepsis opnamediagnose. Naast de patiëntkarakteristieken en de ernst van de ziekte, werd informatie verzameld over comorbiditeit, medicatiegebruik en de pre-existente fysieke en cognitieve conditie van de oudere patiënten. De lange termijn sterfte van de VIPs opgenomen met sepsis was aanzienlijk (sterfte na 6 maanden 54\%). Hoewel de IC-sterfte van de VIPs opgenomen met sepsis vergelijkbaar was (31\% vs. 29\%, $\mathrm{p}=0,26)$, was hun mortaliteit na 6 maanden hoger ( $54 \%$ vs. 49\%, $\mathrm{p}=0,04)$ in vergelijking met de VIPs acuut opgenomen omwille van andere, niet-sepsis-redenen. Deze verhoogde mortaliteit was echter te wijten aan de ernst van de ziekte en kwetsbaarheid, want sepsis als opnamediagnose bleek niet onafhankelijk geassocieerd te zijn met de 6-maanden sterfte, noch was de 'comorbiditeit-polyfarmacie' score, het geslacht of de woonsituatie vóór opname. Kwetsbaarheid, leeftijd en de ernst van de ziekte (SOFA score) werden geïdentificeerd als voorspellers voor de lange termijn sterfte van VIPs opgenomen met sepsis. Kwetsbaarheid ('frailty') was het sterkst geassocieerd met de sterfte na 6 maanden (HR 1,38).
In hoofdstuk negen beschrijven we het voorspellend vermogen van de qSOFA en andere 'ernst van ziekte'-scores voor sterfte van oudere patiënten die met sepsis op de IC zijn opgenomen. In ons cohort van patiënten die met sepsis op de IC waren opgenomen, was sterfte van de oudere patiënten twee keer zo hoog als die van de jongere patiënten. De qSOFA bleek een eenvoudige, maar slecht gevoelige voorspellende score te zijn voor ziekenhuissterfte en minder nauwkeurig dan SOFA, APACHE IV en SAPS II, zowel bij de jongere als oudere patiënten die met sepsis op de IC werden opgenomen. Het opnemen van andere factoren in het qSOFA-model, zoals leeftijd, geslacht, comorbiditeit, opnametype en sepsisdiagnose, resulteerde niet in voldoende verbetering van de prestaties van de score bij VIPs. Daarom kan qSOFA niet worden aanbevolen voor het voorspellen van de sterfte van oudere patiënten die met sepsis op de IC zijn opgenomen.

Hoofdstuk tien bevat de algemene discussie van dit proefschrift. In dit hoofdstuk bespreken we onze belangrijkste resultaten en worden aanbevelingen gedaan voor verder onderzoek omtrent IC-geneeskunde in de oudere patiëntenpopulatie.

\section{Conclusie}

Dit proefschrift illustreert dat de besluitvorming omtrent IC-behandeling van oudere patiënten complex is. Oudere patiënten hebben vaak minder te winnen met een ICopname dan jongere patiënten, maar bij goede selectie kan IC-behandeling zeker zinvo zijn. Aangezien een IC-behandeling belastend en kostbaar is en veel patiënten restklachten hebben na een IC-opname, is het belangrijk de wenselijkheid en proportionaliteit van een eventuele IC-opname zorgvuldig af te wegen, om ongewenste zorg in de laatste levensfase te voorkomen. Een goede inventarisatie van de prognose en uitgangsconditie (inclusief beoordeling van de kwetsbaarheid), maar ook van de persoonlijke waarden, behandeldoelen, verwachtingen en voorkeuren van de oudere patiënten, is hierbij van groot belang. Het toenemende aantal ouderen vraagt om meer onderzoek naar IC-geneeskunde in de oudere patiëntenpopulatie. 


\title{
Appendices
}

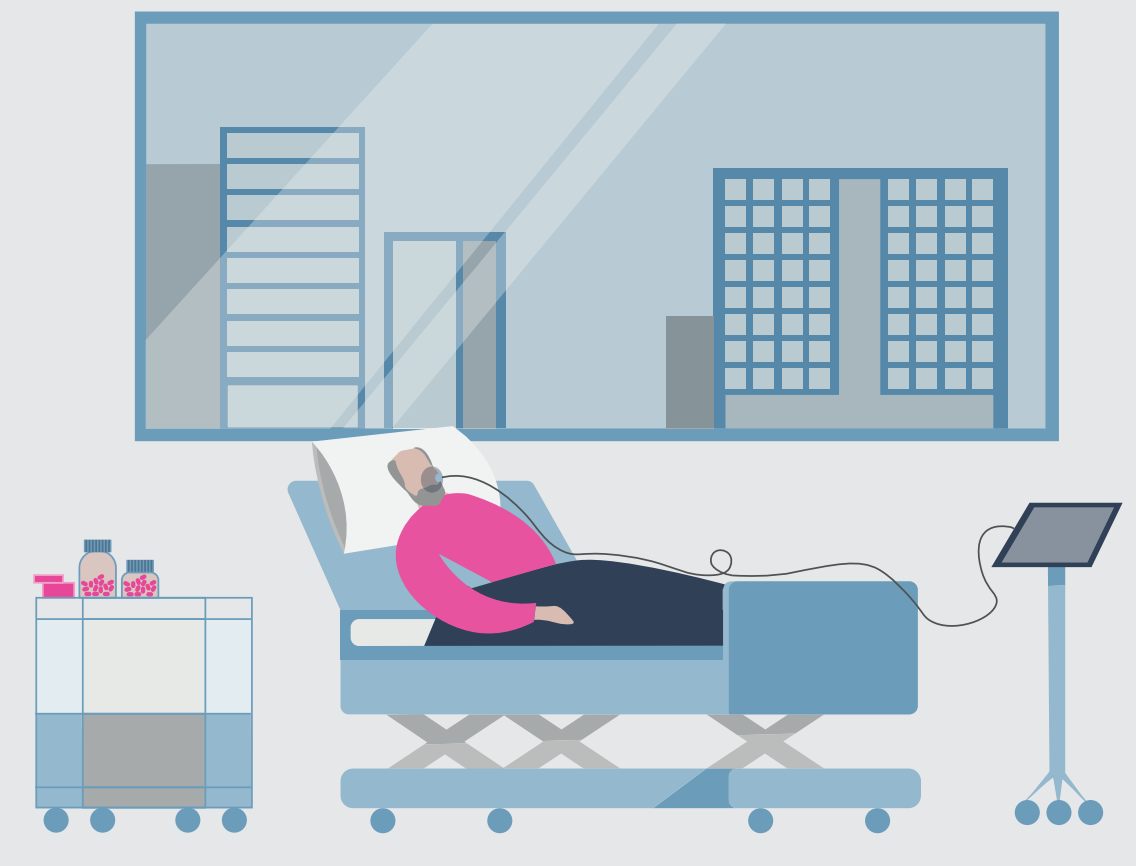

\author{
List of abbreviations \\ List of publications \\ Acknowledgements in Dutch - Dankwoord \\ Curriculum vitae auctoris
}




\section{List of abbreviations}

ADL

Activity of Daily Life

ANZICS Adult Patient Database of admissions to adult general ICUs of the

Australian and New Zealand Intensive Care Society

APACHE Acute Physiology and Chronic Health Evaluation

APS Acute Physiology Score

AUC Area Under the Curve

CAP Community Acquired Pneumonia

CFS Clinical Frailty Scale

$\mathrm{Cl} \quad$ Confidence Interval

COPD Chronic Obstructive Pulmonary Disease

CPR Cardio Pulmonary Resuscitation

CPS Comorbidity Polypharmacy Score

CVA CerebroVascular Accident

DNR Do-Not-Resuscitate

eCRF electronic Case Record Form

ED Emergency Department

GI Gastro Intestinal

GDPR General Data Protection Regulation

HL Hosmer-Lemeshow

HR Hazard Ratio

HRQoL Health-Related Quality of Life

ICU Intensive Care Unit

IMV Invasive Mechanical Ventilation

IQCODE Informant Questionnaire on COgnitive Decline in the Elderly

IQR InterQuartile Range

LOS Length Of Stay

LST Life Sustaining Treatment

NICE National Intensive Care Evaluation

NIV Non-Invasive Ventilation

NPV Negative Predictive Value

OHCA Out of Hospital Cardiac Arrest

PCG Pharmaceutical Cost Group

PFS Premorbid Functional Status

PICS Post-Intensive Care Syndrome

PPV Positive Predictive Value

QoL Quality of Life
Renal Replacement Therapy

Subarachnoid Hemorrhage

Simplified Acute Physiology Score

Standard Deviation

SocioEconomic Status

Standardized Mortality Ratio

Sequential Organ Failure Assessment

United States

Value of the Statistical Life Year

Very Old Intensive Care Patient 


\section{List of Publications}

This Thesis

1. Haas LE, Karakus A, Holman R, Cihangir S, Reidinga AC, de Keizer NF. Trends in hospital and intensive care admissions in the Netherlands attributable to the very elderly in an ageing population. Crit Care 2015;19:353.

2. Karakus A, Haas LEM, Brinkman S, de Lange DW, de Keizer NF. Trends in short-term and 1-year mortality in very elderly intensive care patients in the Netherlands: a retrospective study from 2008 to 2014. Intensive Care Med 2017;43:1476-1484.

3. Haas LEM, LS van Dillen, DW de Lange, D van Dijk, ME Hamaker. Outcome of very old patients admitted to the ICU for sepsis: a systematic review. Eur Ger Med 2017;8(5-6):446-453.

4. Haas LEM, van Beusekom I, van Dijk D, Hamaker ME, Bakhshi-Raiez F, de Lange $D W$, de Keizer NF. Healthcare-related costs in very elderly intensive care patients. Intensive Care Medicine 2018;44(1):1896-1903.

5. Haas LEM, Termorshuizen F, de Lange DW, van Dijk D, de Keizer NF. Very old patients admitted to the ICU with sepsis; outcome and discriminative performance of the quick SOFA (qSOFA) and other severity scores for mortality. Acta Anaesth Scand 2020;64(4):508-516.

6. Haas LEM, Bakhshi-Raiez F, van Dijk D, de Lange DW, de Keizer NF. Outcomes of intensive care patients over 90 years old, a 11-year national observational study. J Am Geriatr Soc. 2020;68(8):1842-1846.

7. Haas LEM, de Lange DW, van Dijk D, van Delden JJM. Should we deny ICU admission to the elderly? Ethical considerations in times of COVID-19. Crit Care. 2020;24(1):321.

8. Haas LEM, Boumendil A, Flaatten H, Guidet B, Ibarz M, Jung C, et al. Frailty is associated with long-term outcome in patients with sepsis who are over 80 years old: results from an observational study in 241 European ICUs. Age and Ageing 2021.

\section{Related publications}

1. Haas LEM, Karakus A, de Keizer NF. The Art of intensive care medicine in the ageing population. Crit Care Med 2016;44:e776-7.

2. Haas LEM, Karakus A, Fijen JW, de Lange DW. True changes in patient characteristics and outcomes or partially a reflection of different study populations? : Discussion on "Comparison of European ICU patients in 2012 (ICON) versus 2002 (SOAP)". Intensive Care Medicine 2018:44:1195-1196.
3. Haas LEM, Kerckhoffs MC, Emmelot-Vonk MH, de Lange DW, van Dijk D. [Too old for the intensive care unit? Backgrounds and challenges]. Ned Tijdschr Geneeskd 2019;163.

4. Haas LEM, Kerckhoffs MC, Bakhshi-Raiez F, Emmelot-Vonk MH, de Lange DW. The admission of very old patients to our intensive care units; a review. Neth J Crit Care 2020; 28(1):6-12.

5. Ibarz M, Boumendil A, Haas LEM, Irazabal M, Flaatten H, de Lange DW, et al. Sepsis at ICU admission does not decrease 30-day survival in very old patients: a post-hoc analysis of the VIP1 multinational cohort study. Annals of Intensive Care 2020;10(1):56.

\section{Other publications}

1. Haas LEM, Tjan DHT, Schouten MA, van Zanten ARH. [Severe pneumonia from psittacosis in a bird-keeper]. Ned Tijdschr Geneeskd 2006;150:117-21.

2. Haas LEM, Tjan DHT, van Zanten ARH. Fatal Clostridium septicum infection in a young pregnant woman. Neth J Med 2006;64:254-5.

3. Haas LEM, Tjan DHT, van Zanten ARH. "Nutrothorax" due to misplacement of a nasogastric feeding tube. Neth J Med 2006;64:385-6.

4. Haas LEM, Tjan DHT, Die A, van Zanten ARH. Coma in an alcoholic: MarchiafacaBignami disease. N Z Med J 2006;119:U2280.

5. Haas LEM, Tjan DHT, Van Zanten ARH. Tension pneumothorax with a patent thoracostomy tube. Neth J Med 2006;64:351-2.

6. Haas LEM, van Lelyveld SFL, Nohlmans M, Tjan DHT. Haemorrhagic lesions in a critically ill patient. N Z Med J 2006;119:U2317.

7. Haas LEM, van Zanten ARH. Clinical image: How hot is a nasogastric tube? Neth J Crit Care, November 2005.

8. Haas LEM, Tjan DHT, van Zanten ARH. An Introduction to sepsis. GSK Lifelines Newsletter, Issue 10, 2006

9. Haas LEM, Tjan DHT, van Zanten ARH. Moving a hospital: Consequences for critical care services, Neth J Crit Care 2008

10. Van der Steen MS, van Lelyveld-Haas LEM, Tjan DHT. Inventarisatie Medium Care in Nederland. Neth J Crit Care 2008. 
11. Haas LEM, Dekkers AJE, Postma B, Tjan DHT. A unusual cause of a spontaneous bacterial peritonitis in a young healthy woman. N Z Med J 2008;121:82-5.

12. Van Lelyveld-Haas LEM Tjan DHT, Borm GF, van Zanten ARH. Clinical validation of the non-invasive cardiac output monitor USCOM-1A in critically ill patients. Eur J Anesthesiol 2008;25: 917-24.

13. Van Putte-Katier N, Rooman RP, Haas L, Verhulst SL, Desager KN, Ramet J, Suys BE. Early cardiac abnormalities in obese children: importance of obesity per se versus associated cardiovascular risk factors. Pediatr Res 2008;64:205-9.

14. Bergman R, Tjan DHT, Schouten MA, Haas LEM, van Zanten ARH. Pleural Enterococcus faecalis empyema: an unusual case. Infection 2009;37:56-9.

15. Haas LEM, Tjan DHT, van Zanten ARH. Milde therapeutisch hypothermie; Ervaringen en resultaten van de eerste twee jaar na implementatie. Ned Tijdschr Geneeskd 2009;153: 1308-13.

16. Haas LE, Schultz MJ. Selective decontamination of the digestive tract reduces pneumonia and mortality. Crit Care Res Pract 2010;2010:501031.

17. Schultz MJ, Haas LE. Antibiotics or probiotics as preventive measures against ventilator-associated pneumonia: a literature review. Crit Care 2011;15(1):R18.

18. Haas LEM, Oedit Doebe S, Diepersloot R, Fijen JW. Clostridium op de IC (Reactie). Ned Tijdschr Geneesk 5 januari 2012.

19. Haas LEM, Kortlandt BC, Thijsen SFT, Fijen JW, Sankatsing S. A fatal complication of a simple peripheral venous catheter. International Journal of Clinical Medicine 2012.

20. Haas LE, de Rijk NX, Thijsen SF. Human metapneumovirus infections on the ICU: a report of three cases. Annals of Intensive Care 2012;2:30.

21. Van der Wekken RJ, Ros FE, Torn E, Haas LEM. A red eye on the ICU. Neth J Medicine 2013

22. Haas LEM, Thijsen SFT, Heemstra KM. Human Metapneumovirus in Adults, review. Viruses, 2013.

23. Hamers PAH, Oedit Doebé S, van der Griend R, Thijsen SFT, Haas LEM. Atypical presentation of Varicella zoster pneumonia in an immunocompromised adult. BMJ Case Reports 2013.
24. Hoekstra RJ, Smakman N, Sanders FBM, Haas LEM. Leave no stone unturned in case of groans. BMJ Case Reports 2013.

25. Otten M, Sepehrkhouy S, van Everdingen KJ, Haas LEM. Primary small cell carcinoma of the liver, a rare entity. BMJ Case Reports 2013.

26. Rijk NX, Sanders FB, Boereboom F, Haas LE, Is there free air in the abdomen? A false impression of a pneumoperitoneum. Neth J M 2014;72:228-232.

27. Haas LEM, Stam AJ, Taris M, Bossink AWJ, Fijen JW, de Lange WCM. Op het verkeerd been door een tuberculosekweek: een leerzame casus uit de praktijk. Ned Tijdschr Med Microbiol 2014;22:nr 4

28. Matthes A, Breumelhof R, van Beeck Calkoen E, van Everdingen KJ, Haas LEM. An elderly lady with an inspiratory stridor. CRIM 2014, October 14.

29. Jonkman E, van Tuyl B, Sanders F, Haas LEM. Severe acute pancreatitis after EUSguided FNA of a pancreatic cyst: a rare, but serious complication. BMJ Case reports 2015, May 12.

30. Haas LEM, van der Ploeg RS, Quak JJ, Burgmans JPJ, Otten M. A young man with severe and disabling complications of septic shock. Am J Crit Care September 2015 24: 450-452.

31. Schulkes KJ, Tervaert JW, Rijken F, Haas LE. Dapsone hypersensitivity syndrome not related to G6PD deficiency. BMJ Case Rep. 2015 Dec 18;2015.

32. Arslan F, Mair J, Franz WM, Otten M, van Lelyveld L. Acute pontine infarction after percutaneous coronary intervention: a very rare but devastating complication. Neth Heart J. 2015 Jul;23(7-8):366-7.

33. van der Meer MG, van Boekel GA, Haas LE. Young man with diabetic lipaemia. BM Case Rep. 2016.

34. de Jong E, van Oers JA, Beishuizen A, Vos P, Vermeijden WJ, Haas LE, et al. Efficacy and safety of procalcitonin guidance in reducing the duration of antibiotic treatment in critically ill patients: a randomised, controlled, open-label trial. Lancet Infect Dis 2016;16(7):819-27.

35. van Gorp F, Wejden LC, Stienstra NA, Kuck EM, Haas LEM. Severe neurologica symptoms following synthetic cannabinoid intoxication. Neth J Med 2017;75(4):158160. 
36. Petri AJ, Limper M, Milne M, Haas LEM. Gamna-Gandy nodules of the spleen and asplenism in SLE: a novel association? BMJ Case Rep 2017.

37. Haas LEM, Sonnen MPAM, Hugenholtz GWK. Methylfenidaat en apathie op de IC (ingezonden reactie). Ned Tijdschr Geneesk 22 sept 2017.

38. den Os MM, Vermeulen M, Naafs D, Haas LEM. Tension pneumothorax and pneumoperitoneum after double-lumen endotracheal intubation. BMJ Case Report 2017.

39. De Bruijn A, de Rijk NX, Haas LEM. Traumatic occlusion of the renal artery. Neth J Med 2018;76(5):257-258

40. Rijsman LH, Kwakernaak AJ, Huisman S, Dutilh J, Haas LEM, Thijsen SFT. Fata staphylococcus toxic shock syndrome following influenza B virus infection. Tijdschr Infect 2019;14(4):147-51.

\section{Curriculum vitae auctoris}

Lenneke Haas was born on the 25th of July 1978 in Borne, the Netherlands. She is the daughter of Fred Haas and Henny HaasPulles and has one sister Boukje (1977).

In 1996 she graduated from the "Oosterlicht College" in Nieuwegein and moved to Antwerp to start her medical studies at the University of Antwerp. She studied from 2000 to 2001 at the University in Bonn (Rheinische Friedrich-WilhelmsUniversität).

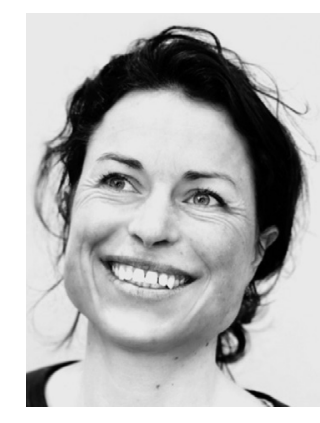

After obtaining her Medical Doctor degree (cum laude) in 2003, she entered the residency program of Internal Medicine at the University Medical Centre Utrecht (prof. D.W. Erkelens and prof. E. van der Wall). From 2003 to 2007 she was subsequently resident in Hospital Gelderse Vallei in Ede (dr. R Heijligenberg) and the University Medical Centre Utrecht. During her ICU internship in Ede (dr. A.R.H van Zanten and D.H.T. Tjan), her love for intensive care medicine arose and she decided to become an intensivist.

In 2008, she started her fellowship at the Department of Intensive Care Medicine of the Academic Medical Centre Amsterdam (prof. dr. M.B. Vroom). After she completed her training as internist-intensivist in 2010 (and obtained the European Diploma in Intensive Care (EDIC I \& II)), she started as an internist-intensivist at the Diakonessenhuis Utrecht

Besides her work she enjoys spending time with her family and friends, practicing sports, making a walk with their dog Klaas, reading a book and to drink coffee. Her favourite spots are in the mountains and near the water. She lives in IJsselstein with her husband Steven and their two sons Kas (2007) and Jorre (2010). 


\section{Dankwoord}

Het schrijven van een proefschrift doe je zeker niet alleen. Ik wil graag iedereen bedanken die mij, op wat voor manier dan ook, geholpen heeft bij de totstandkoming van dit proefschrift. Zonder al jullie hulp was dit boekje er niet gekomen. Ontzettend bedankt daarvoor!

Als eerste wil ik mijn promotoren heel erg bedanken. Ik kon me geen fijner team wensen!

Prof. dr. D. van Dijk, beste Diederik, dankjewel dat jij direct enthousiast reageerde toen ik een paar jaar geleden contact met jou zocht en dat jij mijn promotor wilde zijn. Heel veel dank voor jouw vertrouwen, fijne begeleiding, geduld, jouw altijd laagdrempelige beschikbaarheid en de hele fijne samenwerking.

Prof. dr. N.F. de Keizer, beste Nicolet, ook zonder jouw steun was dit proefschrift er niet geweest. Ons eerste artikel samen was het begin van deze promotie. Ik wil je heel erg bedanken voor jouw hulp, jouw enthousiasme, en jouw altijd snelle, positieve en lieve reacties met goede adviezen, zodat ik weer verder kon. Hoewel we elkaar maar twee keer 'live' gezien hebben, voelt het toch alsof ik je al een hele tijd ken, maar er zijn in de afgelopen jaren ook heel wat mailtjes heen en weer gegaan. Ik ben blij en dankbaar dat jij mijn andere promotor wilde zijn!

Daarnaast ook heel veel dank aan het derde lid van mijn promotieteam, prof. dr. D.W. de Lange. Beste Dylan, ik wil je heel erg bedanken voor de intensieve en prettige begeleiding tijdens mijn promotietraject. Fijn dat ik je altijd mocht stalken, en dat je me dan steeds snel weer verder hielp. Ik hoop dat we ook na dit project nog zullen samenwerken.

Geachte prof. dr. M.H. Emmelot-Vonk, prof. dr. E. de Jonge, prof. dr. E.J.O. Kompanje, prof. dr. A.J.C. Slooter en prof. dr. A.M.G.A. de Smet, graag wil ik u hartelijk danken voor de beoordeling van mijn manuscript en uw bereidheid zitting te nemen in mijn promotiecommissie.

Prof. dr. A.R.H. van Zanten, beste Arthur, dankjewel dat jij een van de andere opponenten wil zijn. Ontzettend leuk, vooral omdat mijn liefde voor de IC-geneeskunde is ontstaan tijdens mijn IC stage bij jou en Dave in Ede en omdat ik mijn allereerste artikel destijds samen met jou heb geschreven.
Beste Dave, jouw enthousiasme voor het vak is erg aanstekelijk. Ik wil je heel erg bedanken voor de leuke tijd en fijne begeleiding in mijn 'Ede-periode', ik kijk er met heel veel plezier op terug

Graag wil ik ook de Stichting NICE en de deelnemende ziekenhuizen hartelijk danken voor de waardevolle data die de basis hebben gevormd voor een groot deel van mijn proefschrift. Ook wil ik hierbij de patiënten bedanken die hebben deelgenomen aan de VIP-2 studie. Hopelijk draagt dit proefschrift bij aan verbetering van de zorg van ouderen op de IC.

Dank ook aan alle co-auteurs, die een belangrijke en waardevolle bijdrage hebben geleverd aan de hoofdstukken van dit proefschrift. Attila, onze twee artikelen samen was een mooie start van mijn proefschrift. Ik hoop dat we in de toekomst nog vaker samen projecten zullen doen. Marije, veel dank voor jouw onmisbare hulp in de beginfase en bij het schrijven van het systematic review. Ik zou het heel leuk vinden om opnieuw samen onderzoek te doen en met jou en jouw collega's verder samen te werken in de zorg voor de oudere IC-patiënt in het Diak. Prof. J.J.M. van Delden, beste Hans, dankjewel voor jouw geduld en de fijne begeleiding bij het schrijven van hoofdstuk 6 . Ik heb veel van je geleerd en ik bewonder jouw kennis en enthousiasme. Ik vond de discussies over de ethische aspecten van IC zorg van oudere patiënten hee waardevol. Monika, hoewel het geen hoofdstukken van mijn proefschrift zijn, wil ik je hierbij toch bedanken voor jouw hulp en de fijne samenwerking bij het schrijven van onze twee overzichtsartikelen. Leuk dat na onze fellowtijd samen in het AMC, onze boekjes nu zoveel raakvlakken hebben.

I would also like to thank the members of the VIP-study group for the collaboration. I feel really honored that I could join this outstanding group and that this collaboration has led to one of the chapters of my thesis.

Mijn collega's van het Diak, veel dank voor de hele fijne samenwerking. Dankzij jullie is het Diak voor mij een fijne werkplek. Lieve collega's van de IC: mijn collega intensivisten Jan Willem, Sarita, Attila, Natasja, Martine, Marnix en Marthe, maar natuurlijk ook alle IC-verpleegkundigen, arts-assistenten, Marianne, Gerda, de afdelingsassistenten, en de anderen van ons fijne IC team; ik vind het fijn en leuk om met jullie samen te werken en ik ben trots en dankbaar om deel uit te maken van dit team! 
Martine, ontzettend leuk dat jij, als mijn Diak-maatje, mijn paranimf wilt zijn. Dankjewel voor jouw gezelligheid en steun, en dat ik altijd met jou kan sparren. Ik hoop nog vele jaren met jou samen te werken!

Daarnaast zijn er vele lieve vrienden en familie die ik hier niet allemaal apart kan noemen. Dank voor jullie interesse in mijn onderzoek, maar vooral ook dank voor alle leuke en belangrijke momenten buiten het werk.

Dank voor de kopjes koffie, de borreltjes, de gezellige etentjes, het samen lunchen, gezellig bijkletsen aan de telefoon, de lieve appjes, de heerlijke weekendjes en weekjes weg, de wandelingen met de honden en alle andere fijne momenten samen! Ik hoop daar nog heel vaak samen met jullie van te kunnen gaan genieten!

Lieve schoonfamilie, dank dat ik deel uit mag maken van jullie familie, van Tolbert en Rotterdam tot in Mali.

Lieve Jos en Ferdinand, ik ben blij met jullie als schoonouders! Dank voor de steun en warme belangstelling die jullie altijd hebben getoond voor mijn onderzoek en ik kijk uit naar weer een weekendje samen. Lieve Willemijn en Koen en natuurlijk kleine Luuk, helaas ver weg, maar het is altijd heel fijn om elkaar weer te zien. Ik denk nog vaak terug aan de erg leuke week bij jullie in Jeruzalem. Hopelijk zien we elkaar snel weer! En lieve Merel en Ray, het is altijd ontzettend gezellig om jullie weer te zien. Jullie zijn altijd zo gastvrij, warm en belangstellend en de jongens vinden het ook geweldig bij jullie. Merel, ik ben erg blij met jou als andere lieve schoonzusje!

Lieve Boukje, lief zusje, wat ben ik gelukkig en trots dat jij mijn zus bent. Dankjewel dat jij mijn paranimf wilt zijn, wie anders dan jij kan dit het beste doen. Hoewel we elkaar de laatste tijd misschien wat minder hebben gezien, voel je toch altijd dichtbij. Dankjewel dat jij er altijd voor mij bent. Lieve Hajo, ik ben erg blij met jou als zwager. Dank voor jouw warme belangstelling, de fijne gesprekken en ik heb genoten van de fietstochtjes samen in de bergen! En lieve Silke en Jip, wat ben ik trots om jullie tante te mogen zijn. Het is altijd erg fijn en gezellig met jullie; ik hoop dat we nog van heel veel leuke dagjes, weekendjes en vakanties samen mogen gaan genieten!

Mijn lieve ouders die er altijd voor mij zijn en voor wie deze paar zinnen van dankbaarheid veel te weinig zijn. Lieve papa en mama, ik ben jullie ontzettend dankbaar voor de fijne en liefdevolle opvoeding die jullie mij gegeven hebben en de liefde, de hulp en de gastvrijheid die jullie nog steeds aan mij (en de mannen) geven. Jullie zijn altijd enorm betrokken bij alles wat ik doe en staan altijd voor mij (ons) klaar. Ik kan me geen betere ouders wensen!
En tot slot, mijn liefste mannen Steven, Kas en Jorre. Liefste, dit boekje is er door èn voor jou! Dankjewel voor jouw onvoorwaardelijke liefde, jouw belangstelling, hulp steun en nog zoveel meer!! Samen zijn we een goed team. En mijn allerliefste jongens, ik ben zo ontzettend dankbaar en gelukkig met jullie, ik ben enorm trots en geniet elke dag van jullie! Mama's ...boekje is nu eindelijk af (-). Lieve Kas, super bedankt voor jouw gave tekening voor de cover, ik vind hem supermooi! Mijn liefste mannen, ik hou intens veel van jullie!! 